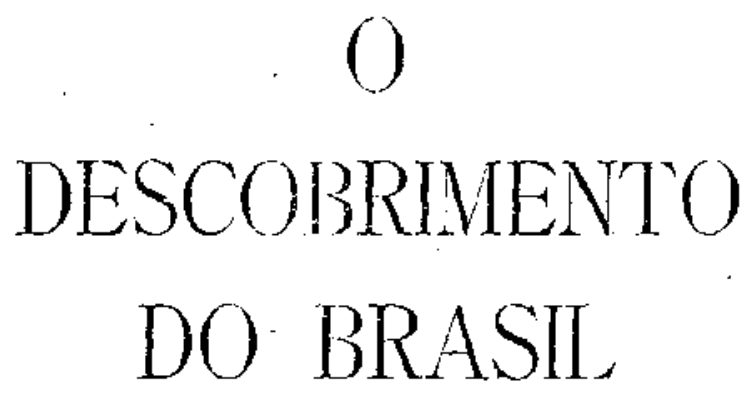

Emplicto

DA

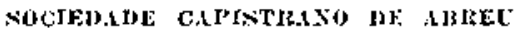

t925 
PUBLICACOES

DA

SOCIEDADE CAPISTRANO DE ABREU

Recife, 12-6-19tu.

Sadeu Rocka

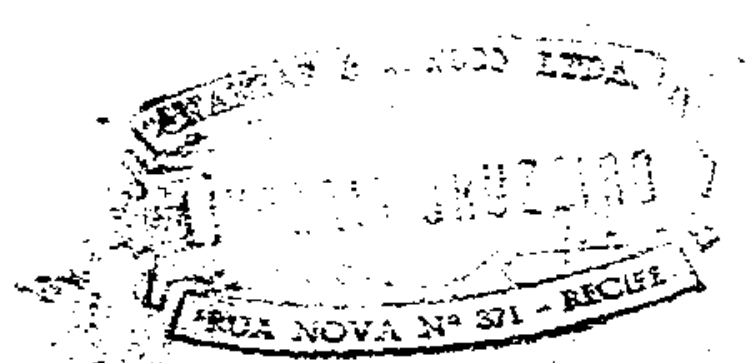




\section{O DESCOBRIMENTO DO BRASIL}


J. CAPISTRAND DE AGEEU

J'ĹBLICACGES DA

SOCIEDADC CAPISTRANO DE MBTEL

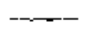

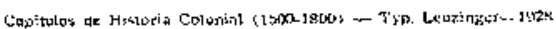

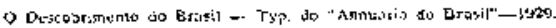

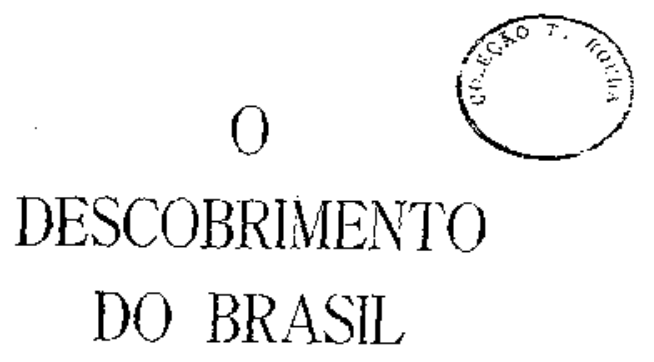

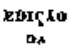

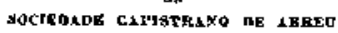
ANNUARIO DO RRASIL

1929 


\section{INDICE}

DESCOBRLMENTO DO BRASIL - SEU DESENYOLYTMENTO NO SECLILO XVI

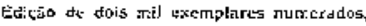

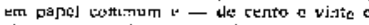

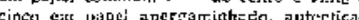

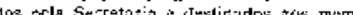

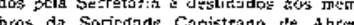

1-Pretençĩus irsucezas.

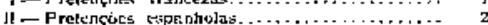

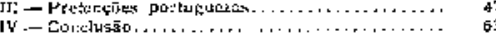

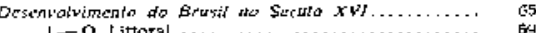

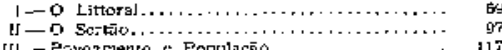

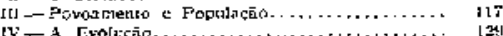

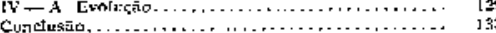

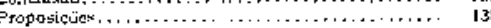

O LESTCOBRIMIENTO DO ERASLL PELOS PORTUGLEZES

$1 \rightarrow$ A viogem.

11. Qucstūes cornexas.

- DESCOBRIMENTO DO ERASLL - POVOADESCOBRIMENTO DO ERASLL GO POAL

1-A India 5 os descobrimentos tos Purtugtezes:

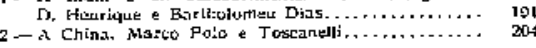

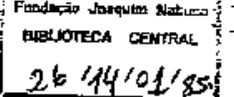

为, 


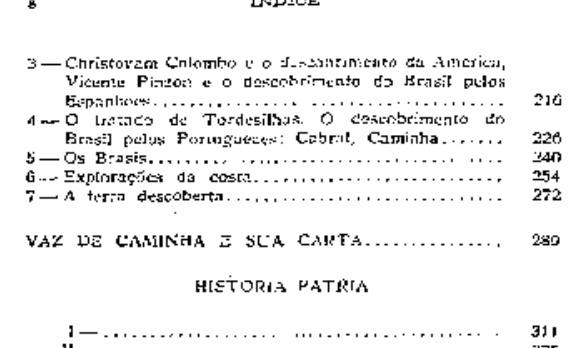

DESCOBRIMENTO DO ERASIL 


\section{DESCOBRIMENTO DO BRASIL}

Tres naçōes da Europa uisputare-st: a roris de ter descoberto o Brasil: a Franç, a Fispanha o Porugal.

Vujamos an qus assentam estas juetancōex.

I

PREIENCOES FRANCEZAS

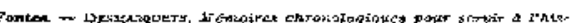

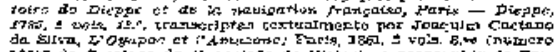

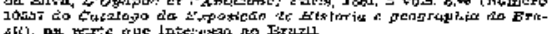

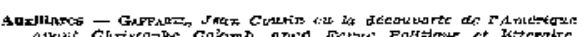

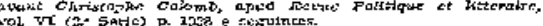

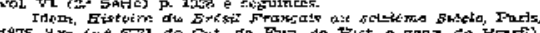

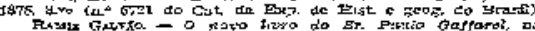

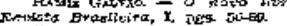

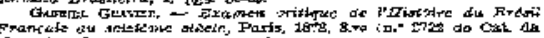

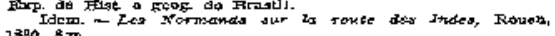

1. Segurdo Desmarquets nas Mímoires chronologiques pout servir à lhistoje de Dieppe, neercadores de grosso trato desta cidade fizeram em 4488 


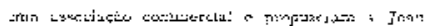

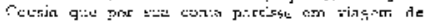
:

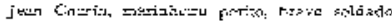

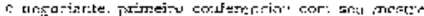

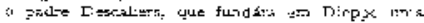

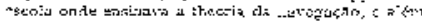

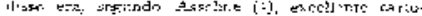
«rupl:o.

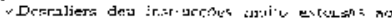

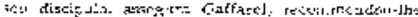

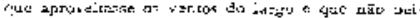

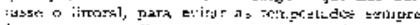

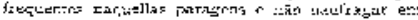

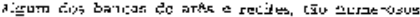
ก. $c x-5$

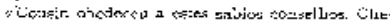

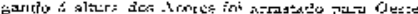

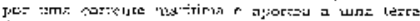

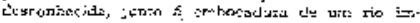

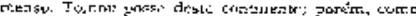

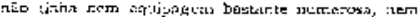

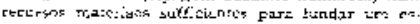

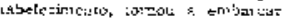

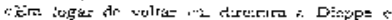

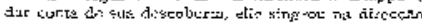

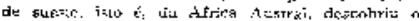

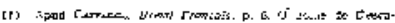

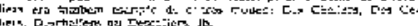

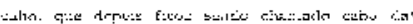
A Alnas, ต:

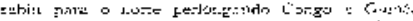

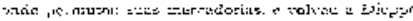

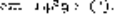

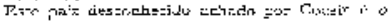

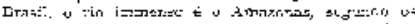

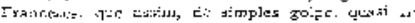

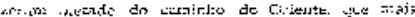

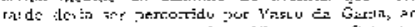

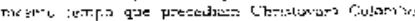

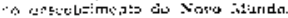

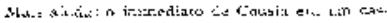

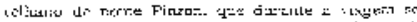

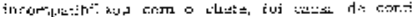

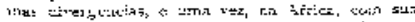

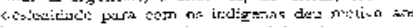

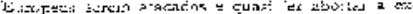

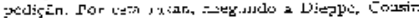

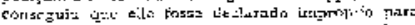

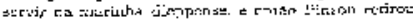

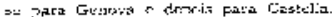

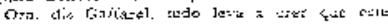

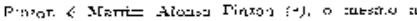

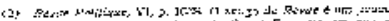

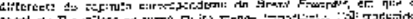

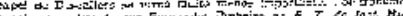

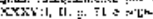

(1) 8. ate 


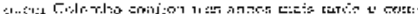
:

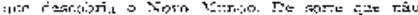

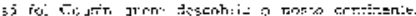

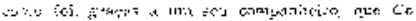

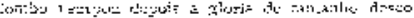

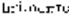

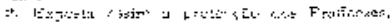

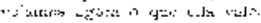

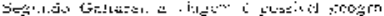

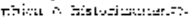

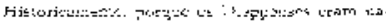

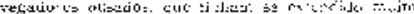

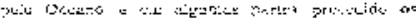

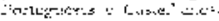

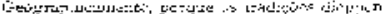

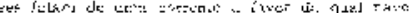

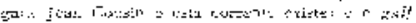
sireturs it:

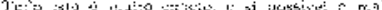

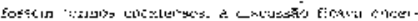

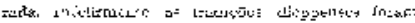

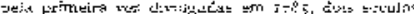

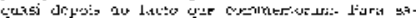

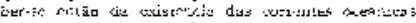

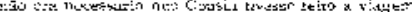

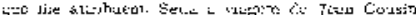

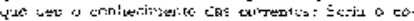

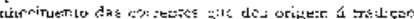

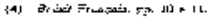

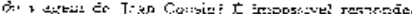

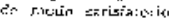

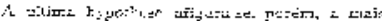

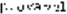

F

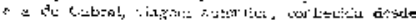

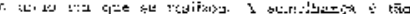

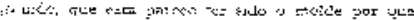
A.: cm:vะ

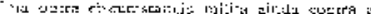

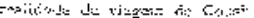

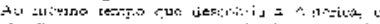

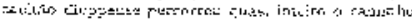

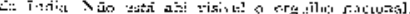

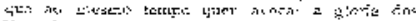

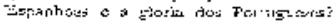

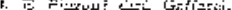

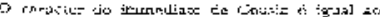

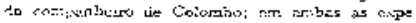

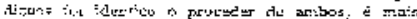

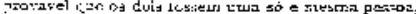
iם

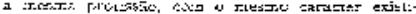

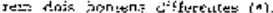

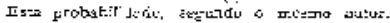

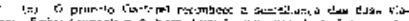

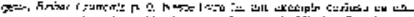

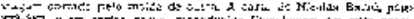

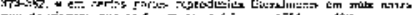

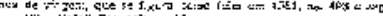


morritse quasi cerlexa si consultaxtmos a Diario de

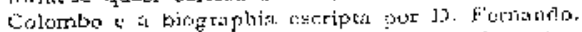
dhi vé-ze que mutes vazen Colomlo corfersutio:t

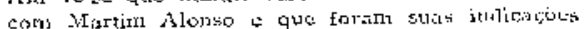

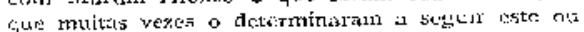
aquelle rumo. Jir-sesa pue Colombo so dirigia me-

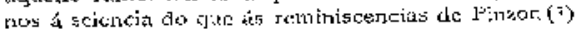

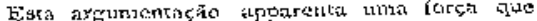

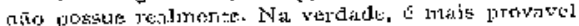

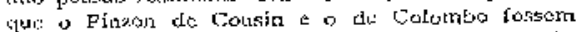
a mosme hament, do que rossim dois loomens diftsrentes. Nis houve Cousin o Pinzon

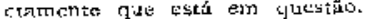

Quarto as reliteroes elutre Colonibo a Cirtuot,

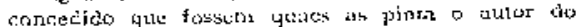

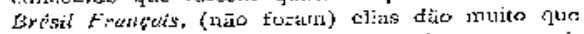

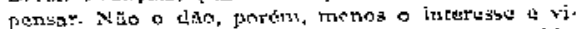
leca is Colombo, trijo cartacter ate hoje tom sidu acatirlo, o yuc ate se ton querido canolixar; a ge morosiclude inverosinill, a discreçio Reruica, a mo.

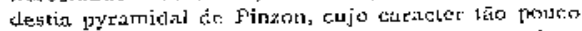
se coadunava com est:1s qualidideles (*) o, sobre. זuth, a ingenvidacle refractutia da companha, you nunce sispeitiou ou surprtinundeu coisa algura, or, si a suspeitou ou surprehordeu, rintea a arriculou de modo a cahir zo domituio putbisico.

(A) Brestr Fronsats. p. 14 .

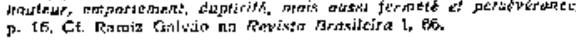

A piocha yuc resiltaria deste conjunto de cir.

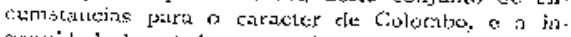

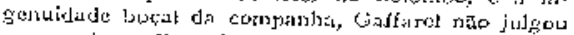

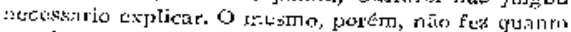
go dicsinletesse de Pilzzon.

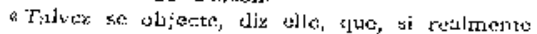
frimot tivesse descobortes a America ante-5 de Cr.

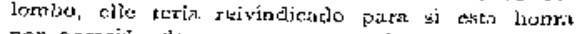
por accasido do processo que ste inscrutrou quindo mortel o Almirante. sins Pi:szon torte despecdido

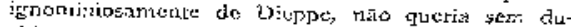
vidil uvivar uri nezocio de que se saljita male

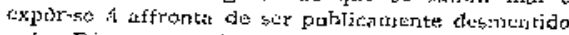
pelos Dieppensa.5. si reclarshase pirra si a ghoria do tert primeixo avistado a terra novalo (i)

Estes xejaros teriam forca inconcestavel, si of

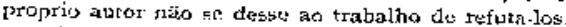

i: Fxistion entzo, diz elle, relaçion frequentes

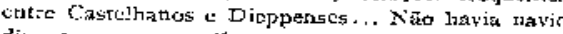

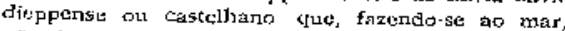

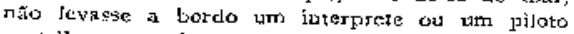
castejhano un dicpperise $x$ (10)

Si joto $d$ exacto, turna-se evidente que nio so o silcircía de pinzon nâo era bestante paral cue nan tosse devasfiato o seu passado, como era inceirameute inutil e inefficnz. De que servia o sitencio, si a sada instantes chegavarn a Castella pilotos interpretes de Dicppe; de que servia, si a cach ins-

(9) Frust Francais. p. 16uit. 
to in a Dieppe interprctes e pilutos de Castella"

Gaffarel comprehindeu que este moljun rāo :ra sufficiente \& apresentis outro. Pinzon remia qut os Dieppenses o desmentissem publimanenti, si stilla misse para si a gloria de primeiro ter descuberto it terja nova (12)

I) ardo dis barato que tal rereio pudiesse acruar tobre hosivo e tlaneiro que o aptor descruve, vejamoss si existia tal peigo.

Ainda uma vis. \& Gaffarel quem responde át Garlarel.

Desde y 500 , Cabral decharou que havia chegado o Brasil, e a mesmo fizeram Vicentc Yañez Pinzon Diego de Lepe. Por que nāo protestarala en

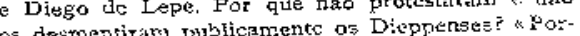
os desmentiram publicamentc os Dieppenses? k Poque, tomo os Phenicios na antiguidate, respotidc o nosso autor, glardavam cluidadosámente o segredo le seus descaberros

Si assim era, que perígo havia para pitzon cle ser publicarncnte desmentido? fazian os Dieppenses, por causa delle, hma excepcãu io systena adoptaclo?

4. Ainda outro argumento

farel e que se prende a Pinzon.

Em 3499 urn l'inzon, Virknte Yañcz, salviu e

(11) Brérid Francais. p. 16. tho de Desmarguets: Les armerteurs de telle ville ctolent corvereus

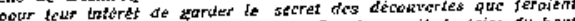
tears naviresi its tacherent cette gate Cotrsint yenoit de faire du boin

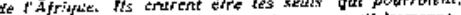
pintirer jusqu'aux Indes, of en tirss ust parti tmmense. descobrir terra e foi dar exactamente ho Amazonas, isto E, no pontu do Brasil visitato por Cousin spid irmediato Pinzon, serrundo Desmaroums.

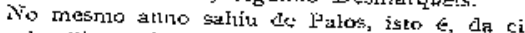
clacle rlos I'irzon, Diego de Lepe, cuja viagern: $t$ quasi identica a de vicente Yañez.

Logo, concilut o autor da Histoire du Brisit Franfais, havia em Palos, na familia o ua raita

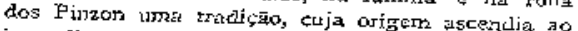
immeliato de Jear Cousin (19).

E bem possivel, mas ondre está a prova?

O simplns facto das duas viagens năn a fornece. Deste que erre sla texceira expediçño Colomio cluegou a terra firme, a tendencia dos navegantes foi procurareen a Anscrice do $5 u l$.

Colombo descobrí de Paria para diante. Hojuda, que se lige seguix, descobriu do Oyapoik ate Paria. Vicente Yañez descobriu do cabo de Sanco Agostinho do Oyapok. Diego de Lepc descobrim do crbo de Sajto Agostinko para o Sial.

Vì-se, portaxito, que a simples ambiçắo de en. contrar logares ainda néo percorridos basta para expìcar a contiguidade e a coínciclencia dos desco. brimentos.

5. Passemos a outros pontos.

Segundo Desmarquets, Jean Cousin, o prede. cessor de Colombo e precursor de Vasco da Gama,

(13) 8

(13) Ertsit Francais, 11. 17. Pedro Martyr da unta explicag5o

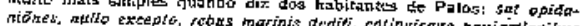

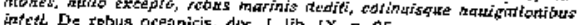


era distiputo do padre Descaliers, nocavel castographo miscido th 140. Deste Descaliters exisrem cartas e porturlaros datados de I 550 a 1553, 1sto é, de quando elle ja devía ter de 1 ro a 113 arenos.

t pláusivel que em tal idade um homem possa entregar-se a trabelhos deste orclom?

Para sahir-se da difficuldade, Gä́farel imaginou diversos expodientes.

Frimcijo: que havia dois Descaliers, -nuggestāo que Major refuton de modo täo cabal (1.4) que elle a abandonou.

Segundo: que os portulanos de 1550 e 1553 eram copia de portularos mzis antigos, suggest夜 que tambem abandonou $\mathbf{A}$ vista das observaçōes de Malte-Brun (15).

Iercciro e tultimo: que Descaliers erz, thầo thestre de Jean Cousin, como o affirma Desmarquets, nas simplesmente seu contemporanco e da mesma idadr que cllc, como $\$$ st leduz de Asseline.

Esta ultima opinitio $\epsilon$ a quc sustenta na Histoire du Brésit Franfais.

Vejamos o seu valor.

Si Descáliers :inha approximadamente a mesma idade quat Cousin, 4 preciso começar por inquerir qual a idace de Jean Cousin.

A estc respeito quanto dis Gattarel है exlremamente vago: Cousin estava na flor dos annos tho ardor das esperançss (t6) - cis tudo.

(14) Mas Э月, Vida do Infante D. Menrique p. 455

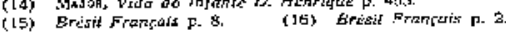

litiamente, ahi mesmo clle afrizra que deste sua mocidade o tauta dieppense se entregara il na vegaçäo; que ora föra soldado, orn negociantc, que se distinguira crn um corrbate contra os knglencs dera prova de si nas costras da Africa e cri diffe rentes viagens de longo eurso, - ludo isto antes de 1488 (17).

Para um homem les feito differentes viagens de longo cursu, ter-se distinguido em urn combate corno commandantc de navio, possuir so mesmo tempo bastante prosticio pars que negociantes de Grosso crato the confiassem ung empress tīo im portante como uma viagern de exploraçäo por mares e triras desconbecidas, trirrta annos sâo antes te meros que de mais.

Supponkamos, portm, qua Cousin tivesse nascido etn r 4 Go e contasse entāo só vitue ${ }^{2}$ cito annos. Si o padre Descalfers era epproxinadamerte da mesma jdade que elle, deveria ter nascjdo neste anno, pouco mais ou menas.

Sendo assim, o padre Descaliers teria desenhado o5 portulámos de $155^{\circ}$ e 1553 com perto de cern annos, - noventa em um caso, noventit e tres emp outro, ${ }^{\circ}$ que diruinue, mas nüo faz desapparecer a fifficuldade apontado por Major.

6. Resta exáminar o ultimo argumerto de Craffart.

E ccrto, reconhece clle, que nem un dochmento coevo attesta a viagem de Cousin; que Drsnjarquets

(17) Erisit Frongait p. 2 
กaั่ \& digno de grande confianca; mas Desinarquets escreveu $\alpha$ vistá de docimeritos officiats, rotritos, etc. Si taes documcratos näo existem, \& porquc em 1694, ctúndo Dieppe foi hombardeacla petos Inglezes, queimaram-se com todos os outros que estavam no archivo do a.mirantado (15).

$A$ bstraindo do juizo sobre Desmarquets, ora peio autor consjiterado uma autoridade dL peso, que pecca antes pelos pormenores que pelo fundo (13), ura como escriptor que mistura a verdade com a menliri, contunde as epocis e os homens ( $\left.{ }^{\circ}\right)$, é impossivel najo reparar na exquisitice de documititos consumidos em 1694 serem consultedos por um holnem que escrevia em 1785 . F un caso de longevidade quasi täo notavel como o de Descaliers, na hypothese dos dorumentos serem os xnesmos.

Si, porém, nāo foram os mesmos, ainda $\leqslant$ nais digno de reparo que, hayendo crtre a expediçăo de Cousin (1488) e o incendio dos archivos cie Dieppe ( 696 ) mais de dois seculos de permeio, ninguem se lembrasse de consulta-Ios. On a tradiçăo já exístia e, si ninguem consultou os documentos, \& porquc ella nāo inspirava coufianga nem merecia credito; ou nāo existia, e díse aqui o mesmo que jía se suggeriu a respeito das correntes uccanicas: foi de. pois do incendio, que impossibilitava refutaç̄o demonstraçắ; foí por causa do incendio que a tra

(18) Gresil Fronsais p. 4

(I9) Artsit Francais p. 4

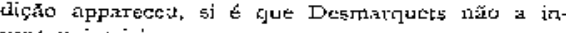
ventou inteiriça.

7. Dois arros unpois do livro de Caffarel appareceu em Rouen um opusculo de Gabriel Gra vier defendendu idéas scrmelhances $\left({ }^{* 1}\right)$.

Gravier năo pugna por esta ou aquella exptdiçăa. Emborz a viagen de Cousin afirure-se-lihe possivel, elle nato se alista entre os campeoes. Suas proposiçỏes säo gencricas e poden reduzir-se a esta: antes dos Portuguczes e Espanbors terem vindo ao Brasil já ste paiz fora visitado pelos Francezes.

Os argmentos que aprestrta sāo dois: um tre tho da Copia der Newen $Z_{\text {eytung auss Presittig }}$ Landt: e um crecho de Gonneville, francez que em 1504 estreve em differcntes logares do nosso terrirorio.

O trccho da Zeylung dix pouco mais on menos. que os naturaes do Frasil disseram a naverantes portuguezes que de tcmpos em tempos inm áquelias paragens etr navios homens brancos, vestidos, de barba geralmante ruiva, que us portuguezes julgavara franceczes $(\mathrm{gz})$.

(21) Les Narmends sur ta route des Itudes.

(22) Eis O teecho corun o traduz Humbotdr: "Les habitans de cette colte ont suconte que de tertips en temps its 5 voient arriver d'autres vaiseaux dont lequipape porte deg habiti gemblables aux notres et qui ont jrexque togk la barbe rouge (blortdo). Les Portayjis

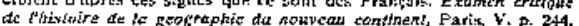
Ct. Les Normands str ia routc des Jndes. p. 40.

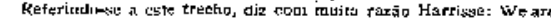
inclivee to think that the early date of the visity of the French navi- 


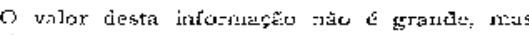
Gravicr procura e, d:é icto ponto, conseguc dar the forche. Eis corme:

A Leytung ᄀăis trax cla:a

Humboldr, give primeiro a conheceu, sracas a ridktnstein, fixou a viagem nella descript: entre 1531 e $\mathbf{1} 540$ ( luçāo que aprescintava offerecia graves difficuidades. Varnltusers fixou-a primeiro em 1508 (viagem de Solis \& Pinzon), ciepois, talvez por sufrestcoss do Jozquim Caenano de Silva, en r viagem de Gon(zalo Coelho).

Gravier is de opiniāo que a viagem retle reteribia ź a de $150 \mathrm{~s}$, em que veio Vespucti como piInto, e serviu de clefe D. Nuno Manuel, segurdo Vianhagen: ou Airdré Coagalves, segundo Candido Mendes.

Iara prova-lo, Gravier procura estabt!ecer ur parallelo estre a expediçăo ta: qual a ratram रi: cortas de Vespucci e a exipedicho narrada pela Zeyiung (").

Esta comparaça \& fejea com muito cuidado,

gators to Bracil rralx in better anthoritics." Bibijothere Amerlearo

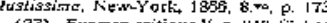

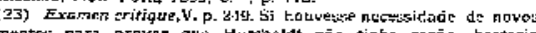
in: Americena Vetustissinta, str posterier a tsth, anno

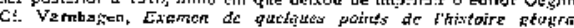
prique ofu Brêsilis D. 51.

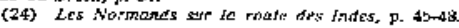

e. dix $n$ autor, mereceu a approvara de tutosidikde täo cmincré como D'Avezac (

Tolizvia rāo convence, puis, âpesa: de taterm rivicos e grandes os pontos de contacco entre aì duas viagens, as divergencias aindel s서 mojoresBasta cine nos lembrencos:

1. que os navegantes da Zeviung, depois de lerem chegado aus quarcista greus sul, tomatam outrà vei para o Brasil ( $\left.{ }^{\prime} i\right)$, ao passo que vicspuce sefuin directamente para a Europa;

2.0 que ла Ztyturg se aftirma que já cstavam conliecidas too a too leguas de terra, ao passo que Vespucci veio na primeira expodiçāe txploradom, cilando o territorio era de todo desconhecido;

3. qux tha Zeytung se fala err 7aturaes que vestiam pelles, circumstancia que com certcza väo teria escapado a Vospucci, si della tivesse tido conhecimento;

4. que, emïm, da 7eytung se decluz quc of fim principal da expediçüo era a viagem para a Ma lacea, ( $\left.{ }^{2}\right)$ ao passo que das cartas de Vespucci csti: objecto nāo transparece na primcixa viagem.

Parece, portanto, que näo podem identificar-so

(25) Les Narmands sut: to roule des incics. p. 49

(26) Torack coxpto 2

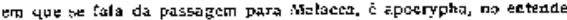

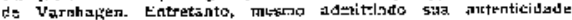

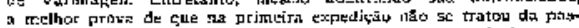

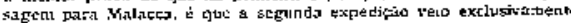
fratar deatc abjescte. 
as duals viuesens, e portanto o testumutio dos ir digenas so púde zefotir-ste a urne época postcrior i2 $150 \mathrm{r}$

Supponliamos ura instimte sue Gravier tenba raziw, que a Zeytung seja effectivamerte a narrativi da expeclisto di 1501 . O que so póde dahi concluir i vovieumente que on Portuguezes suspeitavatti que Ds Fratuceses tinham chegado an sul clo Brasil. Uma suspeita titio 4 prova.

$O$ trecho de Gonteville no parece maits con. Sludente:

De alguns annos a esta parce, diz elle, os tran cezes tênt icto a Brasil (ab). Estes alguns unnos de: guando se deve corttar? De 1503, ert que a 24 de Junho partitam de ITonfleur? De 19 de Junio de: $1505 \mathrm{em}$ que Gonneville $\mathrm{foz}$ csta declaraçäs?

$\mathrm{Na} u$ ulinia lyppothesc, incontestivelnientc a wais provavel, c preciso estar muito preventito para enscrgar nas patavras do marinheiro de I-Ionflcur a affirmaça do descobrimento do Brasil pelos Franceecey.

Na segunda, a que Gravicr (t9) admitte, ha mais verosencihanca incontestave'mente; mas quis valor tem esta affirmaçào vaga, en clue nä $5 c$

(28) Eis textualmunie a qut diz Gansevills: "empuis aucunts annies en tá les Di

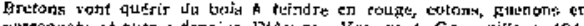

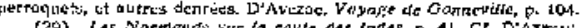

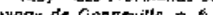

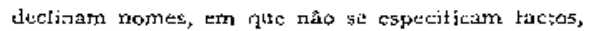
em que se nồ determinam logares?

$$
\text { 8. En resuno: }
$$

A vingem de Jean Cousin e possivel geographica a historicntnente; mas. $4 \mathrm{~J}$ laz dos doctimentos conlueciüos e dos argumentos dos que a dúfendem, näo titi provada-

A intervença de Descaliers é difficuldade insoluvel; porque, ou fosse mais velho que Coustis ou da mesmí idede que elle, näo podia normutmente traçar cartas geographicas em I5j3 \& chtrttanto elfe traçou-ב. e taes cartas existem.

A irstervengazo de Pinzon dá logas a depla difficuldade: ou ge tern de admittir dois homeny con a mesmo nore, com o mesmo caracter, con a mesma profissta, no mestran tenpo; ou se tem de adinittir indos os seus precedertes, dos precedentes do Colombo, de toclas as regras de verosemellhança.

A identidade enrre parte da viagem de Caboal e parto da de Cousin; a quasi identirlacle entre parte die viagem deste e parte da viagem de Vasco da Gama, săo novas difficuldades; patenteiam o orgu tho nacional a esforgar-se: por entobtir as mesmo гетро a gloria de duas nacö̌c rivales.

A falta de documentos cocros, as contradicsües dos que defentem a radiça dieppense, que fura adnitir a viagem tem que soccorrer-se a Desmats quets, unico quc a attosiz, $\varepsilon$ para defende-la tôm

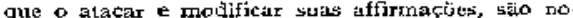
vas difficuldades. 
F rijda ha oucras e outras.

Portanto, por ora, 6 irppossivel reconhecer qut. o descobrimento un Brasil \& devide a Francezes.

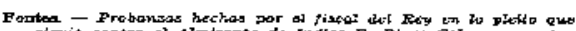

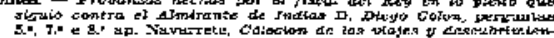

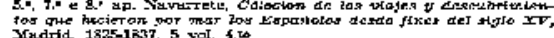
JesN Se Len Coen, Jlappe mundi, ap. Jomard, Las manumarts de $3 x$ gevgraphie, Pats, $\delta$, al, fol.

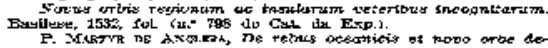

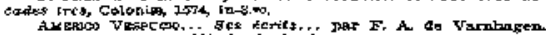

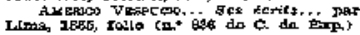

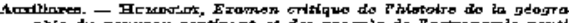

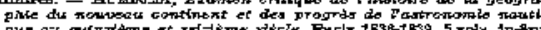

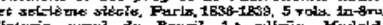

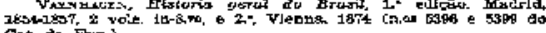
Cat do Bris.)

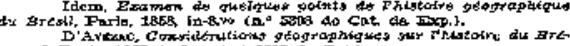

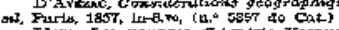

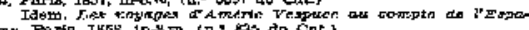

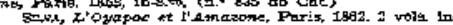

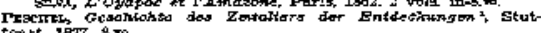

9. Lqui pisa-se terreno mais solido $\_$passa-se do doninio de tradiçñes vagas, incoherentes, quicas inventadas, nara factos precisos $\mathrm{c}$ textos autenticos. 
Deste o seciso XVI os Espanhoes reclaniaram conno sel o discobrimento do Brasil, e ringuem ainda lho contestou con vantagem. Dutidas e pontos obscuros existem, - niso ba nciga-lo, ... mas varsan intes sobre minucias do que sobre o facto fijnclamental.

Entreburto, \& preciso desde o principio iazer

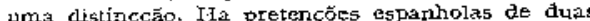
orders: umas que forary manifestatias desde o seculo XVI e têrk sido defendidas sem soluçāo de continuidade; outras nque appareceram pola prineira vez em nosso ternpo, ha menos de trinta annos. As primeiras trupam.se á roda de Victnte Yañez linzon - Diego de Lepe; as sefrundas gruparo-se í roda de Alonso de ILojeda e de Amerigo Vespucci. Estas

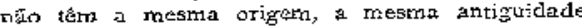
gice aquellas, merr o mestno valor.

Vejamo:

10. Vicerste Yariez Finzon, segundo Fedro Mar tyr, partita de Palos coun quatro caravellas nos pritzcipjos de Dezenbro de 1499 (1) \& pelas Canariars foi ao Cabo Verde, á ilha de Santiago. Dahi seguí a 13 de Janeiro (z) com vento do sudpeste pela pròa e, ravegadas rrezentis letouas, passon a Jinha. Com - niesma ruTno seruin mais duzentas c quarenta Je guas e por fim, dejpois de I4 dias de viagen desde

(1) Circiter calendas Deecmbris, dis Pedro Martyr p. 95; a XVH Nayembris, dix Gristarus

p. 1 II
Santiage (3), no dia 26 de Janeiro thegou a um cabo, a que der o norne de Sonta theria de Consolacion. Daģai foram beirando a costa e, de pois th diversios inciclences, claegarain ao Hairy.

A viagem de Pirzon of de autinticidade incor cussa; en 1500, Juan the la Cosa e o governo es parshol; em I 501 Pefro M.artyr; ern 1504 Aryelo Trcvizano, e cleste entako muitos outros, todos os historiadores, tem dido testemunho della

As duvidas versam apenas sobre 1rtes incicentcs: - posto de partida entre: Palos e Santá Varia de la Consolarion; o ponto de cherrada; 2 o ponto ats onde beirot o littoral americano.

11. Sobre o primeiro incidcate ralou-se rinzon no denoimento quis fez a zi de Warro rte 1543 e discorctam dois $d c$ seus companheiros. Un, Pedro Rannirez, diz que o ponto de partida foi das ilhis de Anton, que svavarrete conjoctura serem umas sitiadiss quarenta Jeguas no norte do Cabo Verce; outro. Diego Fernaniez Colmarrera, diz que toi da ilha do Fota

Qual dos dois tcon razäo? D'Avezac pensa que Colmencro, porque o sen testemunho é apenas ex. plicitamert to contestafo por Pedro Ramirez, zo passo que o deste, explicitamente condemnado por Diego Herrances Colrienero, \& condemnado inpiticamente por Antorio Hernandez Colmanero e Manuci

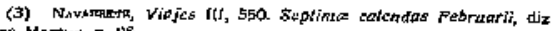

Pedró Mativir, D. Ge. 
de Valdovinos, que däo recorelue como porto de peistida as ithas de Cabo Vorche:-

Nio parece entretanto que qualtuer das duas opiniües possn prevalecter; primeiro, porque a dis. cordancia oue patentciam onfmciuece a ambas; se gundo, porque furam exprimielas de 1513 is 1515 , muitos annos clepois do acontecimento a gue $5 \%$ reft:rem, quando já nāo devia estar frowoti a len?branga que delle guardavam.

A opinião que parcec misis provavel \& a de Fedro Martyr, que dá como ponto de partida a ilhi de Santiago (x). Ts certo que Pedro Martyx näis fez parte da viagem, mas, além de tor interrogado os marinkeiros (o) e o proprio Pinxon, a pitrte do suas iDecadsw que trata do assumpto foj steriptá en 1501 , e por corseguinte offerece milores garantias.

12. Qual o primeiro ponto do Brasil a que che gou vicente Xañc\% Pinzon?

Interrogado a este respeito, declarou elle emi Sevilha que föra o calio de Santo Agostinzo, e o mesmo artestaram García Henander (de Fillelva) - Manuel de Vadovinos. Entretanto, Varmagen de opiniāo que foi a porto do Mucuripe (")

Eiş as raxócs qtte apresetcula:

r. Sabindo das ilhas do Cabo Verde cm rumo de su-\$udoeste, näк se póde chegar ao cabo de Santo

4) De reous Orearticis, n. S15.

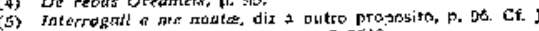

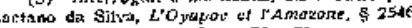

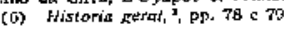

Agostinho: entrexanto, inforest tio Expoimetio tos

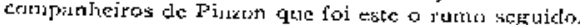
2. $A$ insti utri pocico ao norte do cabo de Santo Arostinho pende para kiste; entretanto a cusitit que: Pilizan die ter beirudo corria a loeste qullartit it rorocites.

s.o A distatusia do littonal descoberto por In:nen foi oflicialmente comjutata em seiscentes letrusti; entretarito, a distancià cumputada da costat cle Sianto dgostinlio náio confere.

Estas objecexases podern ser respondidas em pouscas jutivias.

i). Admittido que partindo de Caloo Verrtc, cm rtroe de S. S. D.. Pinzon was rhesaria as sinto Agostiplus, poderr tiratr-se duhi duas conclusōes:

Ou que Pinzon mino elsegou realmente no cabo de: Sabto Agrostixiln:

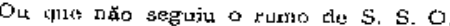

Varnhager aceita a primeira mas a 50 gundi E a ratis provarti (admitticlo que no rumo de S. S.O năo se possa vir de Suntiago a $S$. Agostirlzo) (i)

(7) Um Jusstralto ofticial de ma einhx a quenr cunsultei sobre

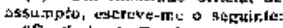

"Pnrtíndo de Sastiago emr rumo oe S. S. O. verdadeiro (22090")

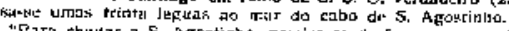
"P.,T⿰ theysar a S. Agostinho, pretish-se de razer o rumo de 250 ac $S .0$, verdadeifo.

"Para chegur so Mucelipe, épretino iazer a rumo de 40 S. O

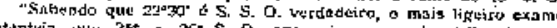

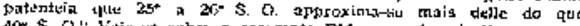

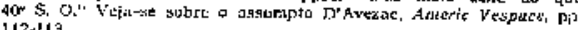


Em primciro logar Pinzon e 5eus rompanheiros declaram explicitamente cult: San:a Maria di: lia Cos. solacjor. 5 o mesmo cabo it que os Portuguczes deran o rome de Santo Agostinho.

Em segundo logar, ha desaccordo sobre o yumo: pinzon e seus cornpanheiros Joca de Limbria ou Lingria e Diego Hemandez de Colmenero năo de clararn rumo; Antonio Hernandez Colmenero diz sit dueste entre mcias do sul: Pedro Ramirez e Maruel de Valdovinos dizem 5. \$. O., tudo de 1513 a 1515 ; Pedro Martyi diz SO. pela prôa (b) em 15or; Tre visano diz que navegaram cons ventos de lesie, en 1504 (9). Quem pode decidjr no meio de tantas affirną̧⿻肀 centradictorias?

Acrresce que Pinzor em isog esteve outra vez no cabo de \$. Agostinho (10) e que pot conseguinte refrescou suas reminiscencias; que a primeira viacem que fizera, realizando-be t:un mau tempo, a agulha nāo lhe podia dar indicaçöes mujto precisas que as correntes nāo erarn rutīo conkecidas. Etc

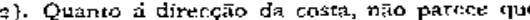
- angumento scja mair forle $\mathrm{Si}$ a costa corre di um modo e Pinzon diz que tella corte de outro,

(B) De rebus Ocearicis: stricum. quem suduestum appeltant, quit medius inter Attsrtum est ac Zephyrum, capiunt in proram, p. Ds,

veja-se a paf. seguinle. orbis, p. 139

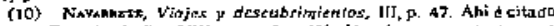

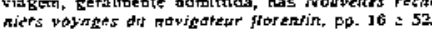

par cuc dizer que Pinzon näo correu esta costa, antes que dizer que elfe năo soube descrever ₹ costa nu torrell?

Entretanto, esta $t$ a opinizo mais provavel; porque so passo que näo ha desaccóndo quanto á 5 ynonimia entre Consolaciots e $\$$. Agostinho, ha des. accordo entre os coripanheiros de Pinzon quantr á arrumaçáso do littural. Pinzon da oesto quarta a noroeste; de seus companheiros, Juan de Umbriz dá noroeste-sueste; Antonio Fernandęz de Colme. nero, rordeste; o physico Garcia Hermandez, noroesto. Prova de quanto umaz yiagem cursiva, narradz cantos annos depois de feita, insufficiente para della tirarem-se eonclusôes rigorosas

3). E. o compluto official das legruas?

Fste computo, felizmente 'publicado por $\mathrm{N}_{\mathrm{z}}$. vitrecc (11), pode ser examinadoj mas guem quer que se di a este trabalho póde reconhecer tuda nelle, menos caracter official.

Nia provisáo real addiszida por Varrhagen, tratasc simplesmente de um requerimento de A rias Perez e Ditgo Fcrrandez, gue na parte que tern importancia para este ponto diz o segtinte:

"Sepates que Arias Aerez, 6 Diego Ferrandez, sobrinos de Vicente Yañez Pinzon, por ellos, en nambre del dicho su tio nos ficieron relacion por st pelicion, diciento: que el dicho ste tio é ellos. com thestra licencia, puede haber un año poco mas o menos, que armaros catiol carabelas para diss

(11) Viajes y destubrimiertos, $1 t$, 92. 


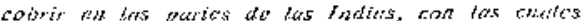

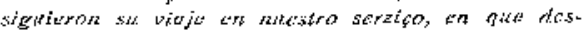
cobriron soisctontios legnas de terra firnte cor ettro matis, ete:.

Isto \& computo offirial ? E corsputo simplesmonte ce Arias Porez c Diego Ferandea: conse tal tes tarto vilor quanto o de fluan de (Tmbria, cajo calcuio \& de sno loevus; c o do physico Garcia Her

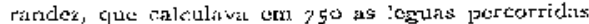
itúx Ferria.

Supponlaneros, porem, que iotik: offirial; em que

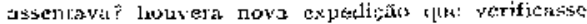
át distancin? que garrantis nos ofterece?

Vambarcen ajretsentz ainda outros argumentos at l'kvor do Mlucuripe: ramo primeiro porto a clue ehenou Vicente Yaťe J'inzon (12).

Tuna di: la Coga arn 1500 sitita o cabo rlexer. berto por Pirtzon muico a toeste da terra descolostia

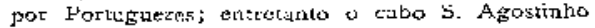
fíca. bastante a teste clestan terria.

Diego Ribero em 1529 indicou o descourimento de lirzon para leste do cabo de $S$. Roque e nído parán sal.

ì exácto.

Deve-se, porem, notar jue: o mappa de Juan

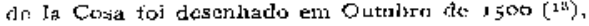
ances de haver sido cxplorido o sul do Brasis, e portatito ñ̂́ pócle neste ponto ter a importancia - - - - - - -

(12) Historia gefat", p. 79

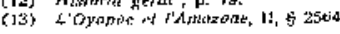

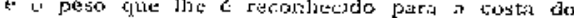
ninili:

Quausto ao mappit le Jiego Ribero, este jrovit

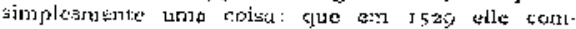

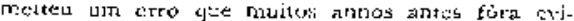
tado. Com effeito, shik Charta tacrina flortugalensitum.

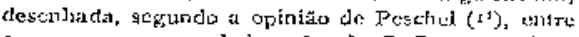
I501 O Tơ, to sul do rabo de S. Rocye estí si. thatdo o calso de Sasta Cruz. Orat, que cabo dio

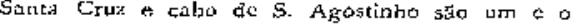
tnesrio locatr, depuzerstm Girciat Hernander o pl:y. sico, Garcia Hermandak (de J.Juclval) a Manuel de Valtovisins.

Attinente to frimciro ponte de Brasisl at qite

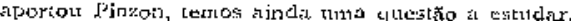

Sanla Marja de la Consolacion e Rostro J-Icitnoes

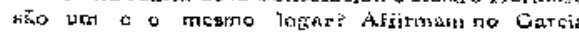
Flornandez, o physien, Perlow Ramirce, Dingo Her nindez Colnichero, s Mánuel de Vatclovinos.

Ifumboid implicitanente \& deswa opiniz̃o, e Pes. she! die mujto claramente: 0 primetiro ponto da costa que thamaran TRestre Hermoso ou cabo de Ii Consolation recebeu mais tarde dos fortuguezs - nome de cabo de serria Cruz ou da Santo Agos. tirlho $\left({ }^{16}\right)$.

Apesar de comprovadia por tantos tescenumbos coltemporsheas, reforgátos par allcoridades como Illumboldt e Peschel, esta opiniăo nzo d verdadetri

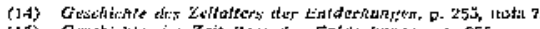

(15) Oeschichtet tiss Zeitallers der Entreckertgin, p. 355 
Prova.o a capitulaçăo que os reis de Esponha assentaram ent Granada com VicentL Yañcz, a ; de Sertersbro de isor.

Ahi se lis:

* Tenemos que en quanto nuestra rnerced e vo luntad furete. . vos el dicho vicenti Xaxkez... useacles" nuestro Capitan c Gobernador de las dichas tierras de suso nombradas desde la dicho puria de Santa Muria de Ia Consolation segulendo la costa hasta Rostro Hermaso, \& te alji toda la costa que se corre al Norueste hasta t] dicho Rio que ros po. sistes nomore Sania Maria de la Mar-dulecy (in).

Este documento serve tambern para provar que e de Kostro Hermoso a nüo de Santa Maria de la Consolacion que a costa corse para Norotste, e que por conseguinte os aggumentos tirados por Vamlia.

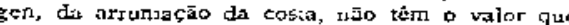
elle thes atribuilu

13. Qtral a termo dos descobrimentos de l'inzon nil viagern de I $499+1$;00?

As opiriöes vaxiam; mas, depois que Joaquim Cactano da Silva exaninesu tão magistralmente assumpto, nấ pode haver mais duvida: foi o cibo de Orange, primivivarente conhecido pelo nome de cabo de S. Vicente, e o rio de Oyapole, ha tanto tempo conhecido pelo nome de ro de Vieente Prinzon.

Para prova-lo, o illustrc brasileiro accumulon tantos documentos e tāo ligados, que se torna difficjl

(16) Rcrista do tastituto, XXi1, p. 495. C. Varmuanav. Exanten de quetgues points, \& 42 expó-lus. Basta dizer que Pinzon den rono ultino descabrimerse sel a provincia de Parirura, lome tirado de indios gise habitavam o cabo de Orango e suas immediasêti; cue os nomes antigos daquellas terras (terra de 5. Amb-osio c ramo de S. Vicente) estāo te accôrdo com o nome dos snntos comne. moraclo: pesla igreja no tempo em que deve ter sido a viagem; que o nome de Vicente Pinzon, daclo no Oyapok desde tempos immenoriaes, E uma tradicäo viva de sua passagem por lá.

1. Passemos aguris a Diego de Lepe.

Deste saberse apenas que, partindo de Cadiz ou Palos ('T) poucn depois de Pinzon, encumtnhou-se a ilha do Fogo no Cabo Vorde. Dahi seguiu em numo approxinadamente de sudoeste, cheggou ao caho de 5. Agostiriho, yue dobrou até certa dis. tancia. DAvezac 6 de opiriaso que elle chegou até o rio de Contas (18), mas en ralta de documentos, LaI opiuiäa não póde ser sustentada nem combatida.

Du ponw tixtretro a que shegou as sul de S Agostinho, - bahia de S. Jutia, segundo seu com parheiro Alonso Rodriguez de la Calva, rio de $S$. Julian, segundo Christobal Garcia-volveu para o lorte, e, depois de incidentes sabidos, encaminhou. se para as colonias espanholas.

15. Mtenos conhecida ainda que a viatreal do Dieco de Lepe é a de Velez de Mendoza, cuja li.

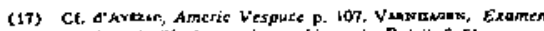

de quetgues points de litheoure blogeraphique de Bresil, 51 
conça prara kiescobrir terras $\$$ da if de Agosto de 1500 .

Segruto utis, ioi aperas wa dos compasheiros de Dicso do Lepe.

Serundo outras, eile: fex effectivaluctec a viagem e: dobson a cebes de $S$. Agostinho fara o sul.

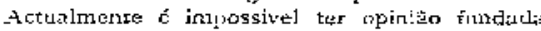
sobre o assurnpto (2\%).

1\}. Passemos agora í pretençes espantru'as, quaes as manifestou o nosso eminente coropittriota Friarucisco Adolpho de Varntuágen, Visconce de i’orte Seguro, na primeiza ediçăs de sua Historia gerut erst $185 \div 20 \%$.

Dix elfe que der mezes antes du l'inzon, t:m Junho de 1499 , Alopio IJojela; navegindo $4 \mathrm{~cm}$ com panhil de Juan de la Cosa e Amerigo Vespucci, aportod ao delta do Assú, ro Rio Grande do Sortu.

Expor os seus irgumeotos o toma-los nas con. sizcraçăo que merecem é :rabat!n şue exigiris ?arsus deservolwimencos. O proprio l'trahagen empre fou reste afan mujto5 ald os de sua vidn, argemplntando, deseniolvendo, ruitificande. Fijresanto, algu mas consideracúc:s bastarăo para mostrar qule hăo

(19) Scbre a viagom de Vcicz de Merifo2 a, v. Navannm: Viajes

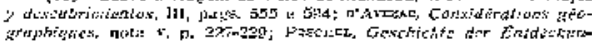
gen, pres. $258-250$

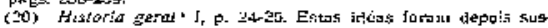

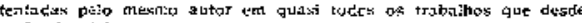
untio ds मे मे luz. se pöde incluir Vespucci e Hojeda entre os drsco. bridortes do Brasil.

Si Vespucci affirina ciee chergou dos 3 gratus cle latitude sul, Hojeda affirra que chegow epenas : 200 Iculas de Paria, isto es, aos if graus de latirude rorte, 5egrundo o calculo de Jo.nquim Cactano dic Silva (12). O5 dois iestemuiness contadizeni-se, an rularisese por conscruints, e nem se prodc combativer $\sigma$ de Hojeda ern nome dc Yesplicci, nem o de Ves pucci em none de Hojeda. O que se deve fazer o procurar testeminhos complementares, cue fítsan inclinar a balanca a favor de um oy de outro.

Felizmente abundam.

Na mesma vizcetm crm que forarn Hoicda e Vos. pucci ia Juan de Ia Cosa, clijo testemurio é portanco jgrial ao deiles em valor.

Vejamos, pois, o que diz a este respeico Juan de la Cośa.

En sua carta, diz Silva, zoo leguas di litto ral, contades da base de peniosula de Paria pa: o sueste, vern dar em una behia, err clijo liraico occidtental esté escripto mores, isto ś, môtes, e cujo limice oriental é formado por uma longat pont7, situada tra laritude septentrional de quatro prizas e neto e terdu 20 sul o nome de tierra de 5 . ambrosio.

* Esta bahia e a do Oyauwok.

c- latitude de sua ponta oritatal prova-o clara. nerre: - cularro gráos e rieio.

a $\mathbf{E}$ esta indicaçăo é confirmads pela de môtes

(21) L'Oyopor at Ismatonc, II. \& 230 ? 
no outro lado da bahia, isto 6 , cor cssas montanhas caracteristicas to Oyapok, que devian nál viatzem yee fiztrand do sul para o no-te, necessariamente tex chamado a attença de Vijcents: Pinzon t Lepe, vcios quaes regulori-şe Juan de la Cosa quarto i parte meridional de sua charta" (2a).

For conscguinte, Juan de la Cosit está de accôrdo com I-Lojeda: isto E, como fste diz que nāo navegaran até a Iimliz \& fuc nern clegaran aos linites seprentriouzes do Brasil, quarto mais aos cinco graus ce laticude sui.

Passemos agora de Hojeda e seus companhciros Juan de fa Cosa e Amerigo Vuspucci, nos comparheiros de Pinzon.

Vejamos si cstes dizem aleuma coisa a tal res. peito.

Dizem:

Juan de Eimbria declara que smanca antes gue esta tierra desfobriesen no habia iáo por ati et dicho Almirante (Colomáa) ni otra persont de estos reinos"; Gazcia Hernandez, pinytion, que ia $n z$ viagerl por escrivăo del-rei, declara gue «aries nunca habia sido descublerta aquella tierra ni hombre la habia descubierto; Diego Heraandez Colmenero detara que wa dicha tierra no extava descubierto antes:; Garcia Hcrnandez (de Iiuelva) dectara vue * aquelle costa atinea la descubrís atra persona ninguna salvo et dicho Vicenti-añess. Os ulitros com panheiros náo se explicam a tal respcito; porér

(22) l'Oyupace it tiAmatore, It 52563 e 2569 . usando da palavra fescatorir, impicitaminte estấ le accôt-do.

Quanto a Pirzon, este rárabern nāo civerge,

"Vicente Pínzon, dis Silva (:J), aualifica de descoberto seu reconkpcimento do cabo de Consolacion - desctório; cmprega a mesna cxpresiao para a costa comiprehendida entro esce cabo e O Amazonas - descrbíó; a mesma expressāo para o Amazonas - descubrio: a mesma expressāo para a piovincia dos Paricuras - descubrio. Mas quauto á costa tomprehendida enrre a provincia dos Paxicuras e a boca septentrional do golfäo de Paria, elie limita-5e a dizer que a perlongon w corrio de laengo.

«Por que esta differença?

«E que nestas ultimas paraigen, Vicente Pinzon fóra precedido por Chrisrovam Colonbo em 1498 e por Alonso de Hojeda em 1499 '.

Assim, temos, de un lado o testemunho isolado de Vespucti, diecndo que veio ao Brasil en $\$ 499$ com Hojeda $\leftarrow$ Juan de la Cosa, seguudo Varnhagrn; - terras de outro Jado o testemurzo destes, dizendo que nāo passaram de duzentas legrans ao sul de Parta zos 4 1/2 de lacitude norte; monos o testemunho de Juan de Umbia, de Garcia Hemandez, physico, de Diggs Hernandez Colmencro, de Garcia I Iernandcz (de Huelva), de Pinzon, que trolos affirman a prioxidade do descobrimento de Pinzon.

Sí passarmos dos contemporaneos immediatos de Vespucci e Hojeda, a concoriancia é a mesma:

(29) L'oyapac et rAmazonc, II 52568 


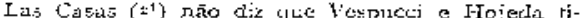
Fcrsem pussado a lintak, Hervera (25) diz posilina. mente que Firzon loi o primeiro csparleol gue a pitestal.

17. Diarte de tantos lestomunhos, rão é PLTretittcio hesitar.

For ciue, entrejunto. Vanhagen nāo só besitou cono declazoy unica vercludtira a marrativa de vespucci?

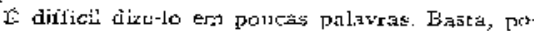
rem, saber-se que Vespacci essegura ter faito duns viagens por conta do governo espanhol antes do antro 1501, em que passol ao 5trvico de l'ortugat

Uesde aue. IIumbolds na sua obra molumeneal sobre a Geographia do Novo Mundo estridon a questōo intrincadissine to navegador floristino, fi. coy gerelwente altrittido țue a pritreira viagem teve loger om r499, sob an ordens de Hojeda.

Quarto á segunda, as opiniǒes nå testão injul: accurdes: Humbold̀t, drpois de kesitar entre i vic

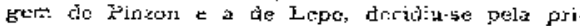

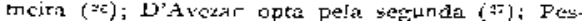
thel parece de opirizo que lespuecl näo tez tall viajgen.

Foi for esse tempo que apparecen o livro do

i29) Histarta de las Indias, cap. 14b, vol. II, p. 3n7.

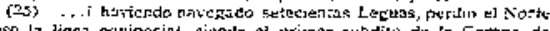

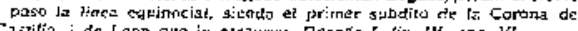

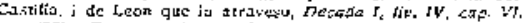

(25) Exrimen cribugue, [v, r. 200-213, 233-in)

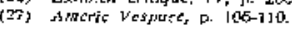

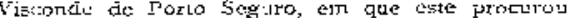
provar ụis a primeira vingern de Vtspacci nāo ti-

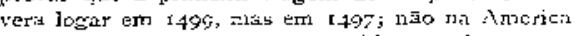
mericional, mas ne incrica do Norte, pelas costas de Yuedrett, FIorida oriente dos Estados-Unidos,

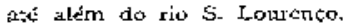

Fazendo jisto, te berr clara que na segunda vio sem, quer ella tivesse logar com f fojeda, corn sustertid Varnharen, ques fosse com Finsou, como propōe Humboldt: quer corn Diego cit J Lepe, conto opina d'Alezac; b bum charo jue Vespucci estove no Brasit.

Isto, porisu, nöo e tuma noviclade e fumbolit já tirha chegato a esia coprlitsa $\mathrm{em} i \delta 36$.

O que: por som, daki năo póde cleixar de contcluir-se e:

1.\%, qqủ̆o pouk confiança mereren:, isoliados, os cscriptos de Vespucci, pois nas minos de Eumpoldt dăn-bos una viagern á America do Sul; nas màns de Variluagen dāo-nos uma viagern â Amorica do Nores;

2.0, que sendo a prinieira viagem de Vespucc em compantia de Hojedr e Juan de la Cosa, como - deronstrou Hurnboldr e liarthaten nāo o Lestrutu; o trelhor arzumerto de que Hojeda näio veio ao Brasil, é te-le Vinihagen empurredo tanto para - Norte que quasi roçou pela terras pulares.

18. Em resumo:

Está provado que, sahindo de Palos a 18 de Novembro de I 499 com quatro caravellas, Vicente 


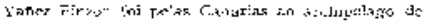

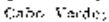

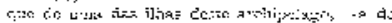
Salsigu-

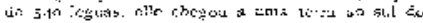

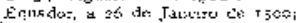

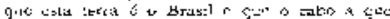

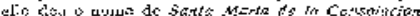

< 0 de Sacto igostíto:

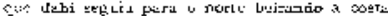

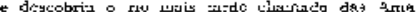

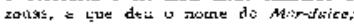

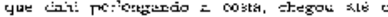

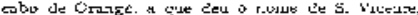

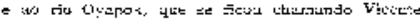
TiLบบ:

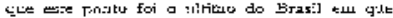
meun.

Q

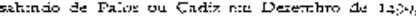
foi ter $z$ ilha rlu Fora, re, Lisbo Vecde:

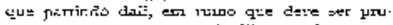

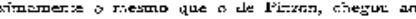
cabo de S. Rosusiniz:

que " dobrou e sepuiu pave o si: duranc: rstopn

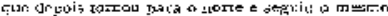

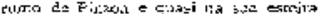




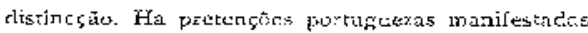
desde o seculo XVI; ha procencöes poriegutzas si

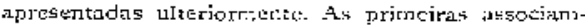
se ao nonle de Fedr'alvates Cabral e seus conpas.

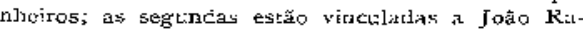
maiho.

Em ux escripto datado ¿̇e 3 de Julho de $37 E_{4}$, affirmoi o seguiztre frei Gaspar da Madre de Dews:

E $\mathrm{E}_{\text {a }}$ temio ures cópia do testaniento origmal cis Joāo Ramalho, escripto nas notas da vilia le 5 . Friulo pelo tubelitio Lutrenco Var, aos 3 de Mriso de 1580 .

$\therefore$ A factura do dito lesitaniento, além do Teferide, Tabellião, assistirāo o jLiz orclinario Fedro Jius ts ciatto testcmunhas, os quaes todos ouvirăo as disposiçōes do testador. Ellı durs veces repetio que rinha algrus rovente annos de assistencia lirsta te:Trk, serm que algum dos circumstantes Ihe advertisze que se enganava, o que certameritc foriāo si o vellir por cadico crrasse a conta...

* Si pois na era die i 580 contava Joz̀o Kamalho alsuns go anuos de residuncia no Brazil, seure-se que aqui cherou er. 1490, pouco mais ou menos; c como a Ancerica pela parte do Norte roi Lescobertid em 1492, resulta que no Brazil assist:rāo Portiguczes 8 annos (sic) pouco r.ais ou menos, antes de se saber na Evropa que existia o mundo nit)

Matatis matandis, o intuito de frei Gaspar iit $-x^{-19}$

(1) Revista do Inst. Gist. II, Fp. 420-42T.
Wadre do Detes é jencico ao ele: Desmarquets. Ha apenas uma ligeiril clifferenci. Nio holve um Es.

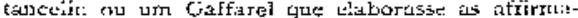
çбes broncas do escriptist paulisiano, e Jlaes désso consiätencia e áp parencia de força. Pelo corttrario, Cartidico Mendes dissccou-25, e de ral mario tnos truc a ribilidade dellas, quc nade mais deixou a riazer.se.

20. Vejarros. com um jouco de mirlado a gie FIcm a palavras de frei Gaspar, e admittamos que - testameato seja autcrtico.

A faltá ie protesto das testemunbas rada prova. Ellas vierima para altẹtar que Joūo Ramatho fixcta taus e tines declaracōes, năo que taes e caes decia. rarposes fcitas por 네]e erann virdadciras.

De mais, curio podetiam sabcr si o eram? Sí vindo com elle, s6 tendo por conseguinte uns iso annos pelo menos. Esta reuniăa de centenar:os nâo E cixcumstancia tāo communn que sirva para provar un farto duvidoso.

$\mathrm{Si}$, porenl, não tínham vindo com elle, as testemunhas nady uabiam com cerreza, e a sua alliesão, ou dntes o seu silencio, nada signtifica.

Mas que diz ern summa o testamento! Que Jaĩo Ramalho timha uns noventa annos de dsisistencia t:o Brasil. Ors atgurs noventa astnos quer dizer mencsi de noventa, - potanto cste computo nāo comprovin, ptima facie, a asserçāo de frei Gaspar.

Viem o comprova ignalmente a seguinte affir. maçä́o de Taques Paes Leme, escriptor mais antigo, mais critico "mais conscienciaso: "Antonio Rodr- 


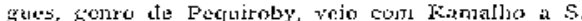

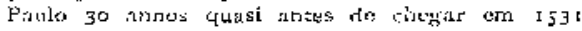

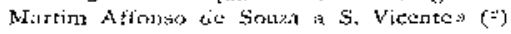

Frinta armos antes no mesrjo ternpo tue nos

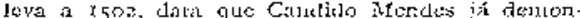
scroul ser at vecrcladeira (s), mostra que aigurts no-

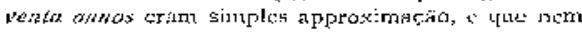
chegian'ats a oitentá.

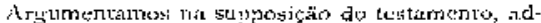

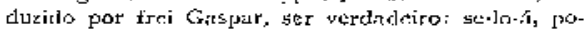
rom, refaluncentus?

Todak as probab!lidades săto que nìo of

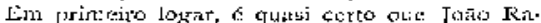

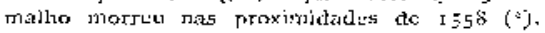

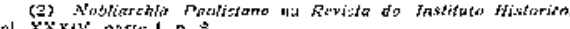
vol. XXxiv, parte I, p. S

(3) Revista dia filstituto, val. Xt, parte H. He. Ifis.2.77

(i) Revisto do tastiterta Historico. XL. parie II, P. RSE. Az:erkmo

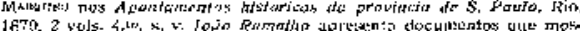

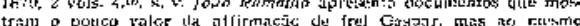

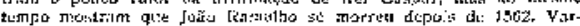

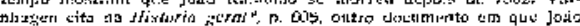

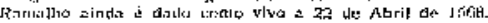

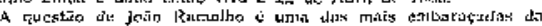
historia primitive do Bras:I,

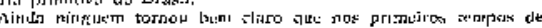

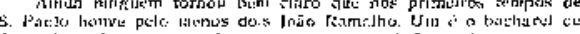

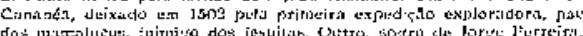

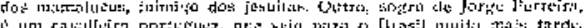
co:rl Martim Af:unato oul logir depsis.

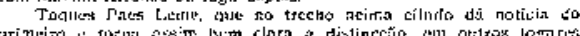

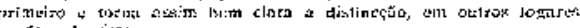
pirdated de vista
Erm scegunde togar, a assistencia rI. testenunhas provar de mais.

Lim tereeiro obar, nem fäei Gatspar vil o origgina: do tastamentor. nem o puljlicit, rom diz comn louve a copia de: cut se servit:

Fm quirto locker, nem Pedro laques, um rlos ra:2is profumclos irvescigadores fla historia patria 4 he

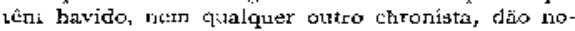
ticia de documento de tal importanciz

h'or estes motivos póte-sé euncluir:

Ou o restamento näo fe auteritico, e nüo pócle potalite sisvir de base a clualquer affimasio;

Ou i autentico c estudado conscigllciosimnente

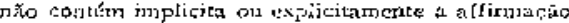
dat chegatir de Joño Ramaltio ao Brasil, antes de

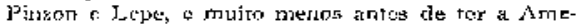
ricen siclo descoberta pror Clyriytovam Colombo (b). 2L. A viagem de Calural a muito toubecida.

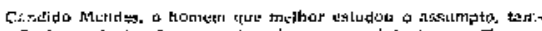

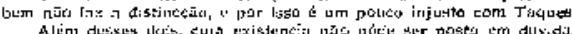

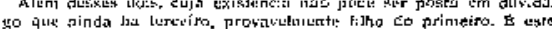

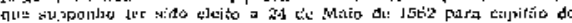

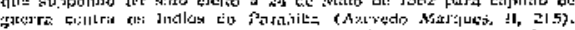

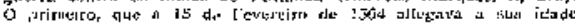

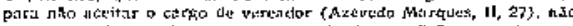

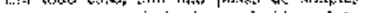

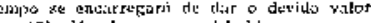

(5) Vilshis [ren, que debalde procurak a priglnal de tertamento

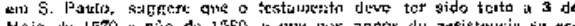

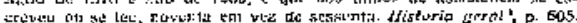


Sahindo do Tsjo, segunda-feira 9 le Ifrras cle I joo, com rreze navias, a I4 passou entre as $C$ a

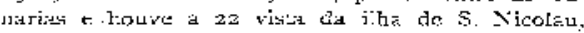
uma das do Cabo Verte. Ahi desgrarrou-se a nuw de Vasco de Athayde que, apesar das diligencias

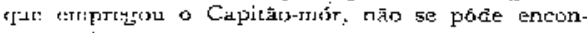
trar mais.

Do Cabo Verde, fazcrido rurzo approximada miturt e cobriu sigtaes de terra em uma grands quantidade de hervas compridas, a que os mareantes chaman bitfilho e rabo de asno.

No dia seguince, quarta.feira 22 de Abril, peln marhth acharam aves chamadas fura-buchos, $c$ á rarde um grande monte redoncio e nuuito alto, coru outras serras mis ao sul, e terra coberta cic frandi arvorcdo. O Capitāo-rśr deu ao monte o nome de Nunce Paschoal e át terra o de Vera Cruz.

Nesta noite ancoraram ojra te seis leguas de terra.

Ao ourzo dia approxinaram.se alé a distancia de meja lemwa langndo ancora em direitura 1 boca de un rio (o). Foi a exarnina-lo Nicolau Coclho, compankeiro de Vasco da Gama tha tiagem á Incia, e o primeiro portusyez conhecido que pison em territorio brasileiro.

A noite vertoc tä̊ rijo de sueste que fox gerrar as naus, pelo que sexta-feira, ás 8 horas da manhă,

(6) Este rio, segundo o Sr, general teaurepaire Rohan, $f \circ$ Cahy. O primitivo e ceturt Parto Seguro. p. 15-16. a armada fec-se de vela do Jongu ca costa, á ỉro. cura de um sirrgidouro, que fo: encontrado dahi a des leguis.

Sabbato, 75 de shril, a armada, que na $4.55-$ pitr? surgira rerca de uma legua co recile que protegia o ancoradolico, entrou no porto, que por sux axoellencia fo: clamádo Porto Segiro.

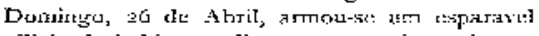
num ilheo da behiz, e rielle cantou-5e missal e houve 5етr)āo. No mesro dia foj decidido em conselbo mandar-sc a el-rei noticia da cescolver:a pelo navio de mantimentos.

Sesunela-feira, 27 de Abril, foram a tern mestre Jchanes Erenelats, o piloto do Capitāo-mór c o de Sarcho dc: Torr, e tomando a alrura do 5o' ao mcio-dia, acharam a latitude meridional de dezesete stalis.

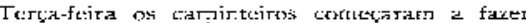

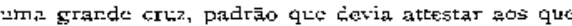
viessem postcriormente que a terra já föra descober:á por el-rei de Portugal

So die I.n de Maio desembarcou a gente da armada: a procurar o melhor logar para ser plan thcla a criz. Escolhido o local, emquanto lins pre paravam a cova, foram ouros, a maneira de prociંisto, buscar à cruz, çuc plantaram, depois de pre gaths as armas e divisn reacs.

No dia 2 sahil para a India Pedralvarcs Cabral e para o reino o enissario que devia levar a noticia

Na terta ficaram dois degredados, dos vinte que 


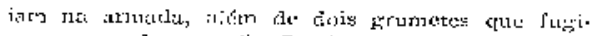
ran. bregunco nos diz Ciminizlat.

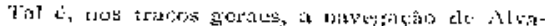

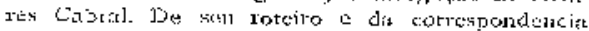

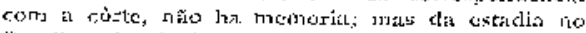

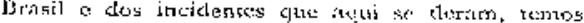
tina chronicad minuciosa $c$ encantadora de Pere Var de Cuminta, en algum poncos completicla

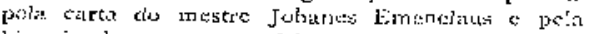

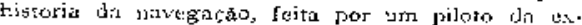
peedičra.

Sitia facil can ostes ducumentor mulejplicar

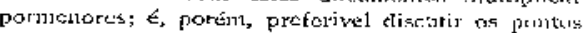
controversos

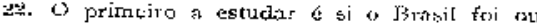
IŨ̃o iltsescobreto por azátso.

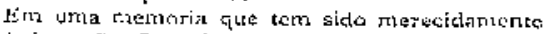

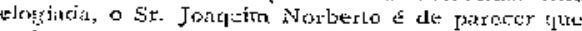

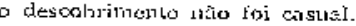

O principal funclimento de sua opiniāe trecho ela cartat escrijnta de Porto Sururo il $D$. Manuel por mesire Johanes Emenelaus. Dix o mestre

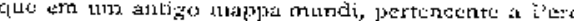

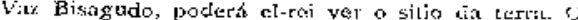
matspit-dundi, que tambern reposenta a Mim, thito cortifica si a terra ba habiada on $n$ 落.

Este trocho, que absixo risi fielnente trans criputo (i), te de umia obscuridade desesperatoril.

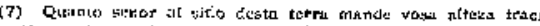

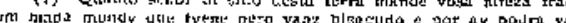

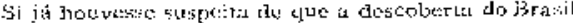

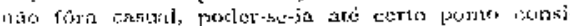
derato como um ialicio favoravel: ntlite Concalve

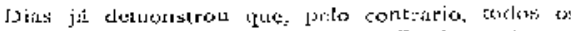

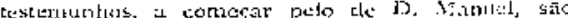

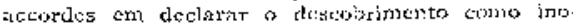
jílugdo o fentuilin.

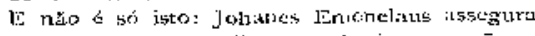

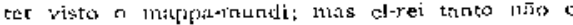

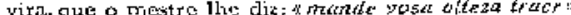

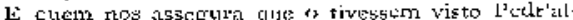
vare:s Gabrial a scals companheiros? Èntriatillto, wisa circumstancia \& indjepersavel para a proposiçăo de Sr, Norlaerto ber fotsuitudin.

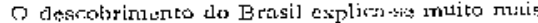

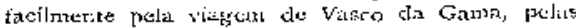

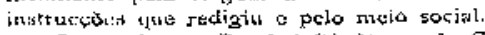

Como observa Peschel (1), Vasco da Gama, cmb sua primeira viagern para a India, pilssúta por 거sum terngo ao lorko dias costay do Erisil, sem at reconhecer, pois, sahinuo do Caion Verde a 3 de Agosio de 1497 , no dia 22 achatva-se a foo leguas da costa atricanla, isto $E$, त $\mathbf{4 5}^{n}$ at Occidente do Sul clá Atrica.

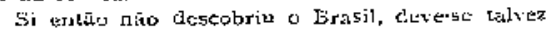
a circumstancias insigrtificances, a menos gate เziّا

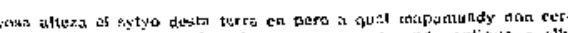

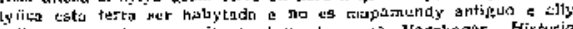

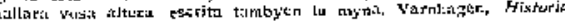

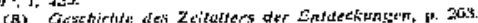




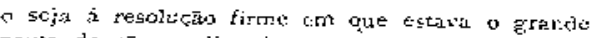
ratuta de riāo se divertir err ibutras emprisas antes

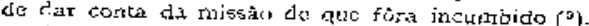

To trecino do Roteiro de vasco da Giamr está notacia urra circunzsancit, cuío alcance escarjou í Peschel, mas quẹ é precisp pồ ctr eviticncia: as wes que a roire tiravam cortia sisoeste, täo rijas como aves que iam para terra. Os forturiczes, diznos o rilho de Christervam Colombo (10), jizcram a maior parte de suas descobertas regulando-se pelo vio das ares; a descobrider da America muitas vezes tegulou por ellas o seu ramo. E, pois, forra de duvida que liasco cha Gama teve nāo suspcita como nos assegura Camós, nas certeca de uma corra ánda nio conhecid:

$\mathrm{Nas}$ longas enrrevistas que tew con: Pedr'alvarch

(1) Eis o trecho da: Rotesfo do Yasco da Guma.

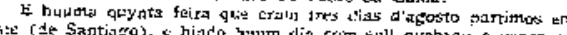

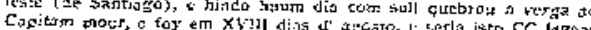

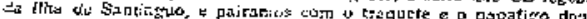

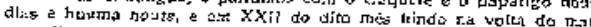

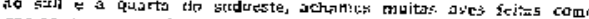
garcoeeriz. " ciando

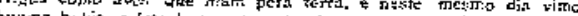

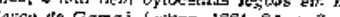
(so) Eis o trecho o in

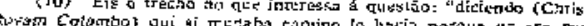

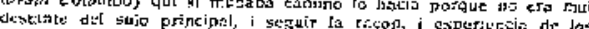

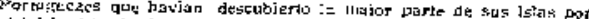

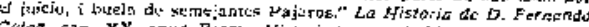

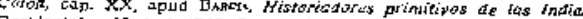

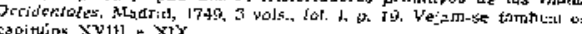

E ratural gure o eusacio marinheiro mais de timi vez lhe falasse no problena yue pescritira sen

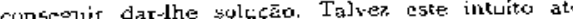
cerro ponco haja influido sobre as inst-uectós quit formulou.

<: Estas :nscruccries, interpetra tiduezac, si atter dermos a direccāo conbecida dos ventus aliseos do humisperio austal, coulvalen a una recommserithomispherio a is tomar a partir do encontro delles. câes expressia do tomar a partir do encontro delles, a bordada de sudinste para correr com amuras a

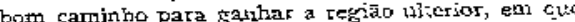
para direito a lesce para

dobrar o Cabos (w).

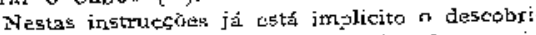
mento du Brasil e a molbor grova es a frequercia com que aqui vieram ter os que as seguiran, comierat de Cabral em 1500 e de Joăo da Nova em $x$ cos.

Além das signaçs de terra entrevieros por liasco da. Gama en suxa primeira tiagem, e das instruç̄ōes cue formulou, concorren efficamente para o des cobrimrinto do Brasil o estado extāo vigente dos espirito5: "s a irtensa curiosidade movida pelos $\mathrm{rE}$. centes destobrimentos no Nowo Mundo e a nobre cmulaçan que taes descobrimantos: fcjoos em servico de ume raça comperidora, haviañ de excitar

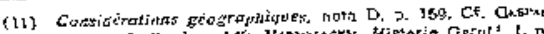

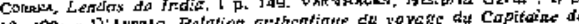
Gonrerizle, p. to 


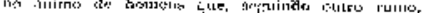

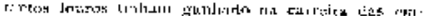

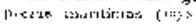

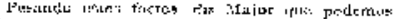

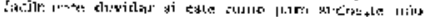

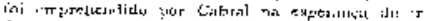

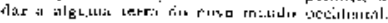

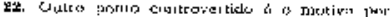

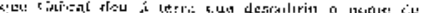
Virk cisur.

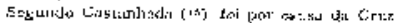

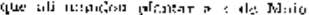

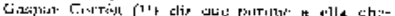
I:istuit il 3 rie Mazy.

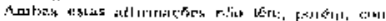

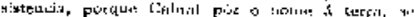

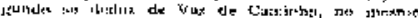

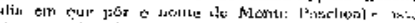
6, $x$ s2 atrarit,

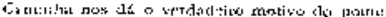

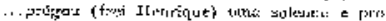

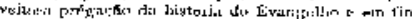

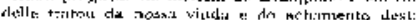

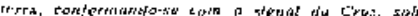

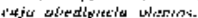

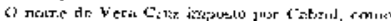

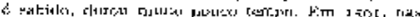

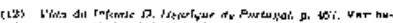

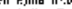

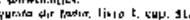

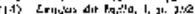

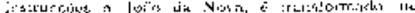

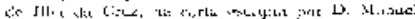

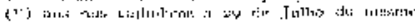

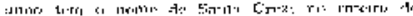

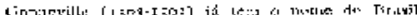

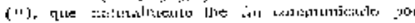

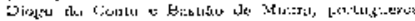

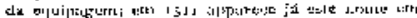
documentis offixisl. $\left(^{7}\right)$

s.2 Qulru fimnis resntrnvertito, si n aceoril

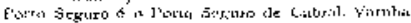

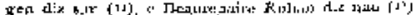

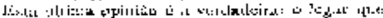

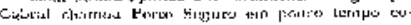

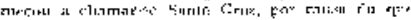

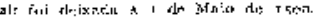

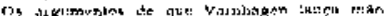

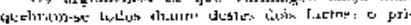

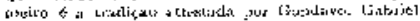
Fis

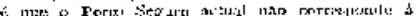

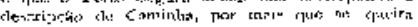
faser de :

24. Kimpt ilitudit in :

\footnotetext{
(IB) Fo, t:

1.

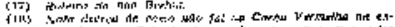

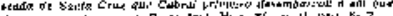

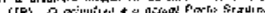




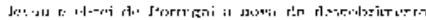
te $15: a s i t$

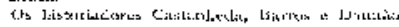

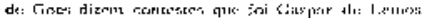

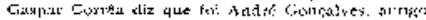

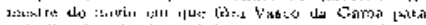

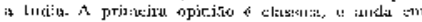

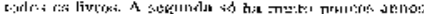

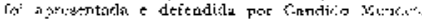

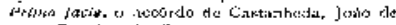

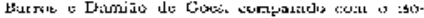

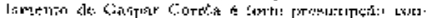

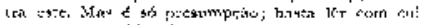

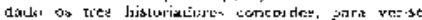

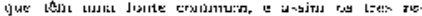
duentio a cem.

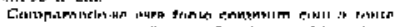

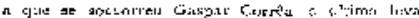

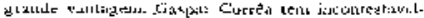

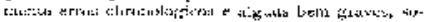

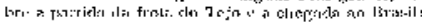

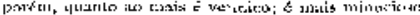

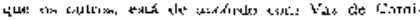

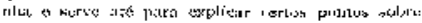

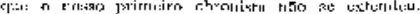

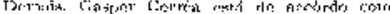

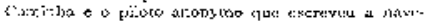

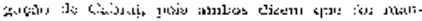

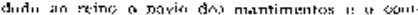

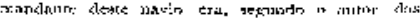

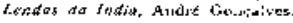

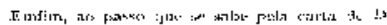

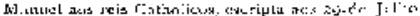

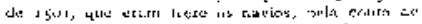

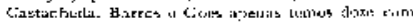

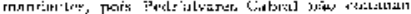

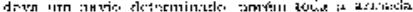

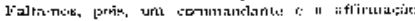

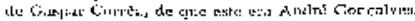

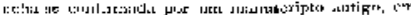

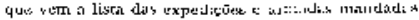

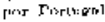

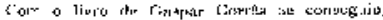

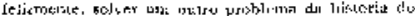
dhan

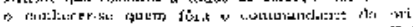

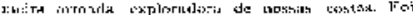

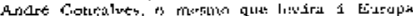

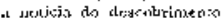


25. Todos os tesforgus atte ìoje feitos para recuar - clescobrimento do Brasil jara antes de i 500 räo tèm resistido a critica.

A tritdiçño franceza da viagem de Cousin, que fixa o descobrimento cio Brasíl no anno de 1458 , căo est insuptraveis.

A viagrem de Joâd Ranalho em 1490 ou ci uma

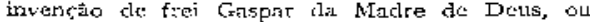
răo passa de uma mystifícars̄o em que elie căhiu.

A interpretaça da viagem de IIojeda em 1499. qut: Varnhagen clá basengdo-se nas cirtas de Ves. purci, rem contra si o testemixrlu de Hojeda, de Juan de la Cosa, dos comparheimos te Piuzom, do propíio Pinzon, e cudos os rcsultados apurizes no estudo clos tixits t: ria critica dos factos.

E. zortanto, com os cixurnentos di दut dispo. mos, incontestaval clue a descobrumento do Drisit Lri enil I 500 .

F. from os Espanhoes que o descobrimam, porcule Cabral viu terra mais de mexaclu Abril; Pinzon viu-a en Fevereiro, e I-cpc, quando Cn bral ainda 
atru percelbera signacs de terra, já dobráat a caho de 5. Agosticho pira o sul e tornasa para n norte.

Esta \& a solução chronalogicu.

A. solução sociologrica d́ difíerente; nada deve. inos aos Ispanboes, nada infleirarn sobre no:tro vida primtitiva; prendero-se muito menos á nossu historia do que os Functerts.

Sodiolog:camente falando, os descobridores do Brasil foram os Portugrezes.

Nolles inicia-te a nossa histonia; por elles continua por seculos; a clles se dever principalsrente os esforros cue produziram una naçâo moderna b civilizada em territorio antes povoado e perromido por bioncas tribus nomactas.

\section{DESENVOLVIMENTO DO BRASIL NO SECUI_O XV}

Si, por urt taso de lon revidade extraordinaria, tosse dado a Pedralvares Cabral perconer ietidamente en 1000 o paiz de que apenas avisteta costas no ultimo anno do seculo anterior, elle teria diante dos olhos um espectaculo novo e intcressante.

Veria, a conccar to norte, a furlaleza do lires Reis Magos, ütirua vedeta da civilizaçāo, imporsdo resptite a03 Potigitares. Em Natal agrglomerava-so aDs poucos a fropulaçāo, que em breve devia cxrendcr-se ao Ceará e dini por diante até D Amazonas.

Veria a Parahiba com o scu force do Cabe dcllo, com as casas que $\mathrm{j} \alpha$ se alongavam pelo morso pitoresro, com os engenhos que irradiavam pelas varzens ubertosas.

Veria Itamaracá, a ilha encartadora, pobcrta de plañtaçöes.

Vcria I garaçú, a etntiga; Olinda, a orgulhosa; Recife, simples morada de pescadores, que nzo tar daria a eclipsar a todas.

Veria Porto Calvo, tāo celcbre depois nas lutas hollandezas; S. Christovam acalentado pelos rrurmurejos to Coting-iba; a cidade do Salvador com 


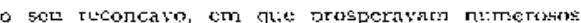
engenhos a vicejavam por leguas e leguis os ca-

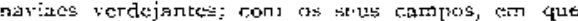
a secin pascia ćs masialas, aos milhejros.

Veria liheos, Santa Cuux, a jrimeira terra sellada com o eunio portugucz; Porto Stryuro, seminario de ousadas bandeiras; Esjsiritu Santo a pe netrar are as esirtioraldis tncantadis, verdes corno os sonhos que sorriar aos se.jo habitares.

Veria a hio de Janciro, esstratado no meio dr um amphytheatro immenso, de que $5 c$ ictroçn as gcracöes idus, á espera de feitos dignos do scenatio: con es stas fihas ftitictiras; com a sua bahia

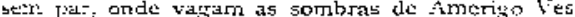
pucci, que legou o nome a ur continerits que rino descobriu; de Gongalo Coelho, o risicedate pertinaz;

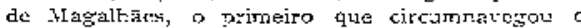
robo; de Nabroza, de Anchieta, de Xes de Sí, de Villegit:gnon, o casalleiro romancsco e datia!ji:dus.

Veria S. Vicente, a obra de Mar-irs Afformo; Santos, obra de Braz Cubas; itumaen, mais tarcle

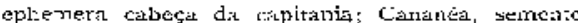

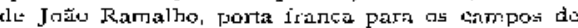
Curitiba, do Vismāo e da Vaccaria.

A dez lecruas do Occano, verid a villat de $S$. Paulo, obra dos jesuitns. Debalde ssces a haviam assentacio na aba da montanha, como que para crase-va-la atrithoada no cupo: a popklaçāis tsiz_ava, ㅁanksoo-clava, investia e conecava a innundar todk America.

E nestes povalos dispersos veria mais o des cobridor do Brasil industitias desconhecidas, racas rovas, instituiçōes que $5 e$ decomplimkarr. e instirsi. góes qui germinaram; riquexas que projectavim scu britho aos oinos dos habitantes; c5rolas; mo5teiros, conftarias, odios, affinicades, inceligencins que te abriam a luz terras que nâno resistiam atri ciforcos uos habitantes nara a.rancar-lhe o segredo: em surome, num vaso colossël uma elaboraçāo irnmensa,

Tudo isto era a obra de umi seculo. Vejamo-la por meror. 


\section{O LITTORAI}

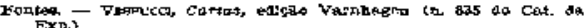

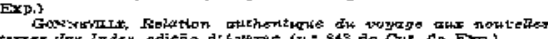

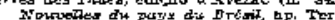

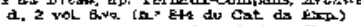

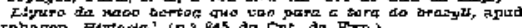

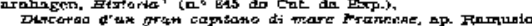

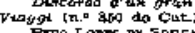

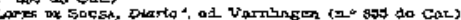

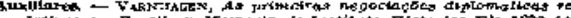

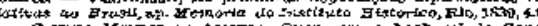

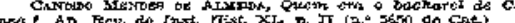
(ittor cae)

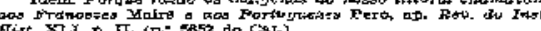

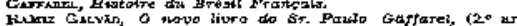

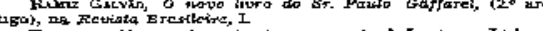

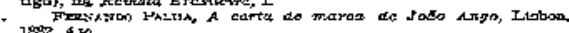

Portugal tomou desdc logo conta da terra doscoberta por Cabral. Meros de dez annos the bo.5taram para contornar a vasta extensāo das cosks: do paiz.

A. comecar do norte, encontrámos em frimcito logar a expediçáno exploradora de João Coilho, infelizmente quasi desconlecida. 
A data con que je renlizcu ainda estí por dc. terminar, $F$ bos $\mathrm{em} 1514$ ciava-jhe vinte amnos de:

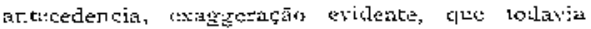
stasice parta has mostrar juirto fo! intige.

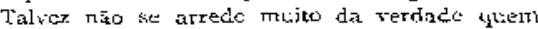
suppozer gue Toño Cocltro foi ao norte ao nicsmo tempo que Andre Gonçalves its 20 sui. E esta stpposiçco aszume visos de proviavel si reflectirnios yue Joño Coclino i nome desconlictido; cyue talver seja

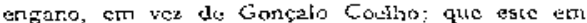
i503 ja cstava em Portugal. to masmo tumpo, tomos assin mp'icaçio do motivo por que neste anro fo: elic escoliniclo para commandar a seguncia ar. mída porturucza gue veio ao Bratil

En todo caso, mesino que fojse Joăo Coclho

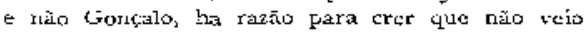
miuito postciormente a $\mathbf{5 0 2}$.

Nesce ar:m foi reconhecida a posica do das terras ao norte do cabo de $S$. Agrstinbo. Por que seria sul exclusivamentc exploxaclo, cuando esca parte do norte cstava dentro dat demarcacta de Torclesilles?

Pouco mais ol menos por csse tempo, temos noticia de outra viatrem a norte de S. Agostinho: a de Fernando de Noronha, "jue desccbrily á :1lia de seu nome provavelmente a 34 de Junko de 1703 .

Ha einda tradjęa de uma viagerm exploradora as torte emprehendida com licença reyia por Affonso Ribeiro, a quem os naturaes da terтa malaram. Froses, que della nos dá noticia $t$ que se lhe incorforou, nacla adianta sobre os descobrimentus ytu fcz. Si ć a mesma de que fala Herrera, saliu do cabo de
5. Stgosininlo. conrorion a cura firme atú Darion

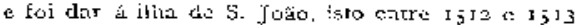

3. Iarcir clo cabo de 5 . Arestinlin para o su: as explorsçus eštå meihor comlucciclas.

Lngo, em l joo zoxis, a partir de Porto Seguis pira o norte ate frovavelnture a cabo clcscoborto por Pinzon, it exploracão de André Goncalvis arcestadì por Gaspar Corréa. Lieve eer sido riulito cursoric, porque Andre Gonçalves purtincio a I de Marc de Sarla Cruz já estava na Europa antes de Uu-

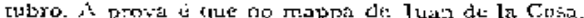
feito neste maz, já figura à terra descobertá pelos Portuglczes, de que elle räo podia ler conluccimento, silua prot André Gonsalves cu sens companhejros.

Fui em I jol que veio a p:imeirat expeciç̄o trerdadeirariente expluradora ao sul. Commanclawa ó mesmo Andze Gonçityes e vinha aella por piloto ou comographo o celebre florentino Vespucci.

If op niño geral que surgiu no cabo ic 5 . Roque. Canclido Mendes alfirma, porćm, que foi nos ifarcos, ao notte da bahia ca Traigéo:

1. porque o nome de Harcos conmemora os padrōes que Vesjucci diz tercm sido assentadtos;

2.0 porcuc, si fira o cubo de $S$. Roquc, é certo que se perderiam ros baisos que correm delle para a nores:

3. porque Vospucci se rofere a uma terra e não 11 um calvo, corno doclaria gquando tratál do de S. Agostinlio (1).

(1) Revistu fo Inst. Hist., XL, parte i1, b. 103. 
Estas räzes, por maís forkes que sejam, rãus parene que destuam a opiritio seral.

Basta lembrar que of marces plastialos entr: a bahie liormosa cixves do descobrimento it possc da terat, mas simples divisas entre a capitania de Fero Loves to d the Joañ de Barros, para tue perca todo o valor o primeiro aretumento.

Levado pelos oucros doj, algum tempo ju] yuei que fosse năo os Marcos, porém a bahia da Traiçāo, o primeíro ponto avisiacio por André liosçalves, prus alóm de cstat de accôrdo com ä duas contliçōer deduzidas por Candido Mentes das cartas 1e Yeu. puect, a nome da bahia ce Traição 6 mito tnigo c cotninemora factos serncillantes aos que se deram entre os naturaes e os Portirueas no primeiro clasembirguc destes.

Entretanto, nism essta nem a opirifä́o de Cardido ricndes resistem ao scginte tacos: que debic I jos - cabo de S. Rociue está fizuriclo llás cartas como o punto in:cial de uma cxplorarāo quic terminou en? Cananéa.

Do ponto á que primeiro cizcgou, a amáda foi seyuindo pedra o su?, beiranto a cosia, plantando padrōcs, faxendo sondagens, traçando cartas e teiros, baptisundo os lospares encontrados. $\mathrm{cm}$ geral con os liomes di santos, o yue se explica pelo cositume da epraca e pila preserca dc padies a bordo.

A.té que ponto da costa bras:leita cheraram os exploradorrs, f guestáo alindi hoje controvercida.
Segundo Varnbaben chegaram ao rio da Prata ( segundo Candido Mendes năb passaram de Cană. Tार्स: (3).

E está vltima apiniåo parcç maiis ce-ta:

I. porrue a descripcăo dada por Vesuucci se applica mal as costas aridri do sui

3.0 porque até $\times 513$, pelo menos, as cartas gerrrapizicas conhecidas só fijuram o Brasi: de $S$. Koque aré Cananéa ou Cananor, com esta escripto este nomis em algumas;

3.o porque Gonnevillc; que en I jo4 esteve t:rtrc os Carijós, fronteiros dc Cananta, thâo er.controu lá vestigios de europeus, ao passo que os encontrou e indicou ao norte, entre os Tupinambás;

4.9 porque Vuspucci pintá invariavelmęnte os na iuracs da terra corno hús, ao passo sue desde $S$. Francisco do \$ul elles já começam a vestir-se, cotrio se va em Gornevillc c ne Zeytung;

5. - porque o rio da Prata é muito notavel para quc chegando aré lá Vespucti trāo o livesse visto, $c$ terdo-a vistu nào é provavel que o rêto mencionasse (t).

(3) Historis "zerat', P. s3.

(3) Revist. do trit. Hist. XL, 2. II, Tä. 105 e scgg.

(4) Na viaguma de vespucci, ha um lato astronertico que, is pe cido mus, o Sr. Dr. M. Pertiza Reis teve a bondade de estudar. Eis a opiniäo do eminitte satror:anio:

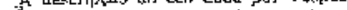
ân If mrior latitude $\mathrm{cm}$ que olle se achor.

Xá carn a Med!ci (Revist. do Inst., XLI. parte 1, 27) qpardo elle

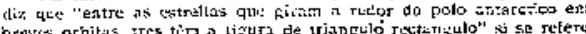




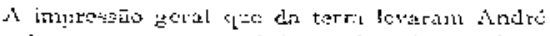

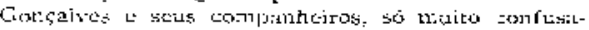

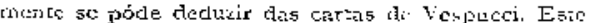

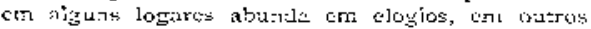

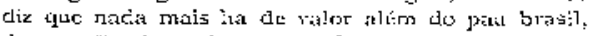
ta canalintuili e da inorit de nytrot.

Trtas contradicçues explicantsc: talvc\% peio du. plo sertimento clue o dominava: de tm lado a suis impressão real e a de seus rompanheiros; dic outro - descjo de exalçar a terra em cujo descoprimeola

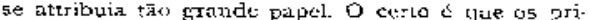
meiros nomes dados a terra - Toira dos Papaguirs, terria do Brasil - mostian bem o pouco apreço en que a tinham a a potea utilidacls que lue scconle-

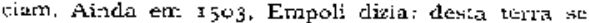

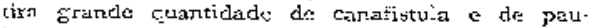
brasil c nūo cchanos más coisa de valor $(3)$.

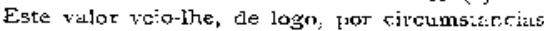
extrinsecas e fortuitas: a chegada de Joto da Nova com as noticias das rirjuezes de Malacis; o desejn

it Trizagulo Austril carro guer o Yisecnde de Porto Sezuro, poi

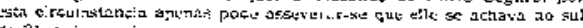
de 21 arios mais ov miros.

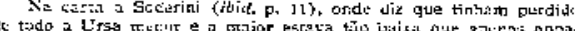

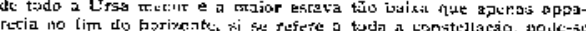

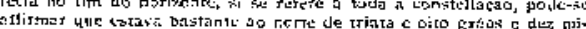
nates

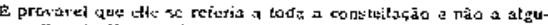

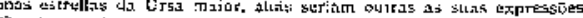

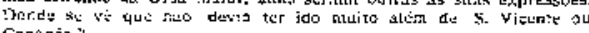

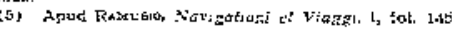

de procerar pelo sul do Tiras:L una passiegem perta logar dic tantas ríjucras.

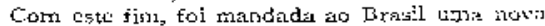
axdacta tom 1503 . Tra mais poderosa que a ireimeira, pois esta cuistava de tres ravios e agutella conscava de seis. Wân ste destinlava mais it explo raģto di terra avistada por Pedralvares. Tinha por rapitâo-mèr Goncalo Coelho, e commatidava țm dos navios Ameriso Vospirci.

Destle o principio da vingem, houve conllictos entre Gonçalo Coelho \& Vespuccix que foram mais

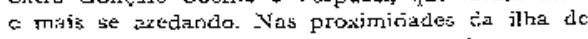
Fernando de Noronha natrayou a rapitanea, c o capitân-mbr mandol: o navegante florentino explorar urt porto en que pudezsen abrigar-se. Ameriza toi mas tanto demorou que Gonçalo Coclho seguiu iclo mist fora.

Voltando no firs cle oito dias, por vêr uma das tlaus em distancia, Vespucsi com ella sle conseria scguín para a bahia de Fodos ds Santos, yue fôra marcada para ponto de reuinäo no regimento dado ź rnמadid, Ahi se demorou mais de dois mezts, encaminhando-sc depoia paria o sut, fundou ina teitoria, a primeira que houve no Brasil. Candido MIndes perisa que o logar desta feitoria í Carn vellas, opiniăo já apresentara com certas rescras por Navirete (c); mas um documento encontrado por Varnhagen (ं) evidentia quts fó o labo lirio.

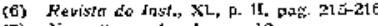

(T) Noyvelies recherches, 7,10 
Dahi depois ce feitos a lite teremos de nos re. terir depois, segunin Arectigo para Porruga!, chegando a Lisboa em is de Junko de I 504 .

Gorçalo Coelho seguira igualmente para o sul. As cartss antigas traziarn na posiçāo approximada. mente do Rio de Jancixo uma legendid jndecifravel, que, cor aquella perspicacia assombrosa e aquelle tino admiravel que o constituen talyes o primeiro incrprete dos antigos documentos geog-aphicos $\mathrm{cm}$ nosso seculo, Juaquin Caetano da Silva mostrou sibrificar C.o Coelho derentirn, o logar en que se deteve Goncalo Coelho (B).

Foi aqui que, quem sabe quarto tempo? elle esperou peilo companheiro desleal, e viu.se por firm constrangido a abrí una de uma conpresá qui al g!tujs annos mais tarce deveria cobrir de glorias o grande $\$$ lagaliñes.

Doposs éa vingern de Coclho, corrsitueraçōes desenvolvicas em ur trabalho já publicado, levam a aclrititir a armada çue, ex falta de mollus rome, póde chamar-se de D. Nuno Manuel (?).

Scgundo a relasăo confusa e obscura cue della nos restar. combinada com as corjectures iuminosas do Virnhagen, os nawegantes passaram das beisces. lis a setecentas leguas já conlecidas e foram ver â bahia cie S. Mirihias. Dahi o mat tendo obrigoti-ns

(8) Pokzo Stectero, Noutettes reshercher, p. It.

(9) D. Nuni Kandel ex 1504 estava on lorrugal, onde trat

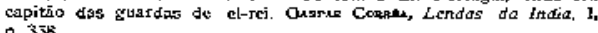

a retrocxtler. Vieram lescobindo rios, entre os quaes o da Prata, onde tivcran as prineiras noticias dis riquezas \& da civilibaçāo do Perú, presa que en breve deveria cahir nas másos d́vicias dos Esparhoes. Ha motivos para trér que nesta viajem tomazari párte Joäo de Lisbon e Vasco Galiego, de quem Lm manuscripto de Alexándre de Gusmäo noticla urna viagerm do rio da Frata om 506 (10).

Parece olre esta armadia nāo tinha por fim umi trploraçă da tcrra, mas simplesmcnte a procur: da passagern do sul, que Goncalo Coclho năo plidera achar, para Malacca Entretasto, nāo podendo realizar o scu intcrito, ella fex exploraçōes de 5 Mathios para o borte. Iigadas assim as obserracües realixadas por Andrt Gonciaties e talvez por Goncalo Coeltho, resultov una noça basiante completa do contorno oriental do Sul da nossa patria dcsde so att $40^{\circ}$, enr menos de dez annos depois do seu descobrinento.

Fara o norte este resultado ja fû̀ra obtido antes, poís mesmo deixando de parte a exploraçáo de Cocho, subre a qual tarto se ignora, cemos as exploraçōes de Vicente Yañez Pinzon e a dẹ Diegn de Lepe logo no primeiro anno do seculo, que rāo de 80 sul a $5^{\circ}$ norte, approximadamerite.

Ao mesmo tempo das prirrcinas expediçäes e logo $\mathrm{cm}$ segutda, comecaram a ser frequentadas as costas co Brasil. Viniam aqui ter as naus da carreira da

(10) viswricex. Examen de qucloues poirts, s 91. Cf. Diario dx Peto Lopes' $\mathrm{p} .87$. 


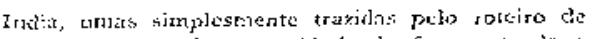
Gruma, outras yela tecessidade de face agnada e lemìis.

Contam-ne entre esten r.avegartes Jonto da Nova

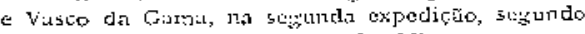
Gaspar Corréa (2x); Affonso dis Albuquereque, se

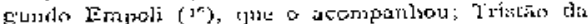
Cirilda, D. Francisco de silmetida, ete.

Pouco a prexu foran, porén, se desviando as

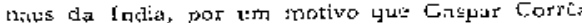

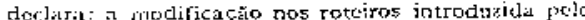
judeu Zacuzo (ib). mudisnça de quo juffilizmenic at:, chas possuimos a motrito.

Clurm motivo que iumbejn roncorse's para des

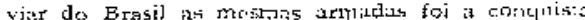
de ilalaces por Afronso de Alboçelerque, cumbuis: que rorrou citspersuvitis al procurá is o cmpentso

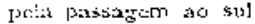

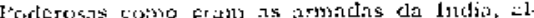

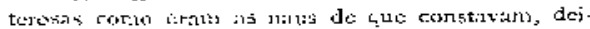
xaram tnenor sulco na historia da rossil petría do

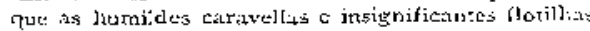
a. descle logo romeraram it vir a diasil, umas

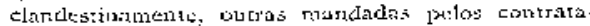
diors: cla jrociośt matlei:u

Foi por thlas tue as communicaçūes se torná ram frestien:ss e as relicones quasi regulares com a

(1) Lerdas on radia, 1, pp. 35,27

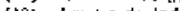

bitropa; que se deschvolveu clesele o punciajio un:

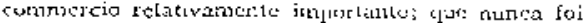

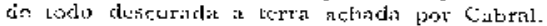

Ni⿺ possceimos muitos docunentos para deter.

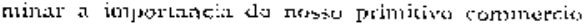

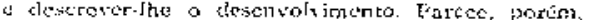

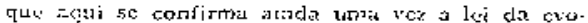
lugâo do simpies para o complexo. Prea retonlie. celo, basta cxaminat o clue poderctios chandr mi.

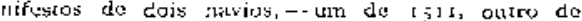

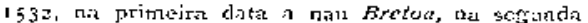
La piterine.

A rial Bretoa levou do Cibo frio en $1 j 11$, cicurn mil e nove toros de paubrasil. thiren a seis chetalus, vinte e trote toirts, dezescis yatels, clozeseis sugs:ins, quine papagaios e t'es ractacos.

O carreganiento dá prítrinte cra de cincen ril

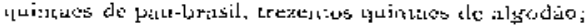

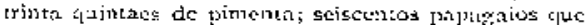
íf folavam francezi ires nil pelles de leqpardose

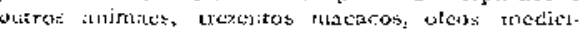
nites, etc.

0 arrizanco relativo a ta féfitine, publieado

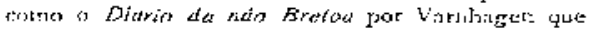
os descoistiu, dá-nos informasúces curinsas cjumto

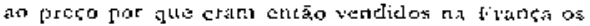

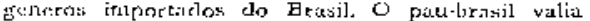
oite ducabios o quintali o altrorlïo, dez ducaclos o quientál; a jinereta trés dicados o quintal; os pa

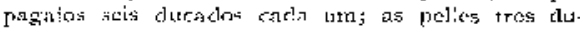
caclos cada uma; os macacos seis ducudos cada um. 
Sesundo o Barīn de Sánt-BIizncard. a carfa de La Pitirine ascendia a setisenta e duis nith e rezterios clucídos.

Sobre o commercio de escraves răo temos in. formaryes muito trínuciosas. Herrerd lata de upa cararejila aprisionida $\mathrm{cm}$ Cadiz cort 20 inclios. cm

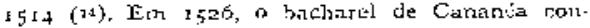
tratou con Djiogo Garcia a conducçāo a vericia de Soo escrayos. Eis tudo quanto sc sabe.

O governo, por sua parte, favoreceu bastance este commercio jrifuge, isentando de impostos os es ravos introduzidos ate certo numero.

No commercio dos escravos, sábemos que ti verarn griande parte os Portuguezes e Esparblioes:

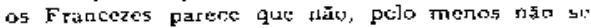
porle provid-lo com os docimentos detualumente rorhecictos.

Err roca dos objectos que obtimhan dos rata ruraes, os que tulto com elles commerciavars iffe reciam-lhes carapucas, avelorios, espelhos, machidus * coisas de pouco valor.

Provavelmente os que primeiro majs lucres ad terjram foram os degradidos, que fich vam lonsp? tegsper na terra, aprendiam a lingua, jodiam fazi:r os negocios mais pausadamente \& descobriam hivias nercadorias, cujo valor sabiam mais prexado pelos 50 us compatriotas.

Seria isto o que determinou muitos dos tripos. lantes que vieram nos primeiros navio's a destrtarem

(14) Decada 1, Liv. X, emp. Xir).

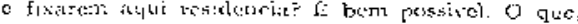

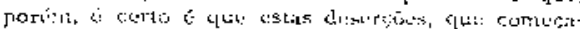
rän con a armuda dis Calaral, fóxisz carlus dia jo

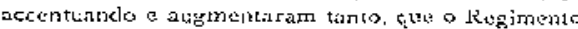
da ríu Breter cem un tirigo espectil pitra a catio.

Estu:s primeiros habitadores-desertores a de grididudos - tòm una inportaticia especial la his toria de nossa patria que ainda nấo foi bem aponzadi3. Para comprehende-?a basta lembrar қjue, quando comecarats as tertativas seguicias de colonizibino, estes homens já se tinhan adaptado a tera; que cram por conscguinte un modelo; que este no-

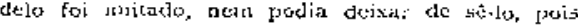

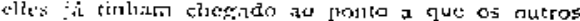
devian: tencler.

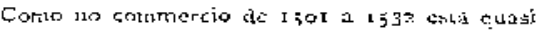

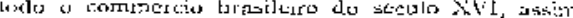

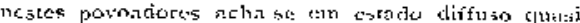
suclil a socirdide posterior.

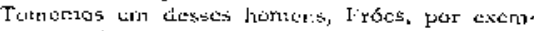

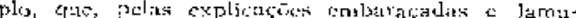
ricantá de sua carta a D. Manucl: parece ter sido radia thatis nadia reseros qui um vilgat desertor.

No rncio dos Brasis, elic náo pueliá deixar de alinkentak se conto elles, pois netri encontalva trifo

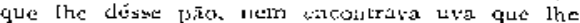
classe virho, rem creontrava ne:h unat das combmodiezeles a gue se acostutrita na veliza teurropa.

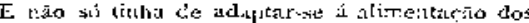
Brasis, conio tinjal de se nelaptar ans procesos ent[regacles para olde-]i; tinha de enpregias os mesmos 


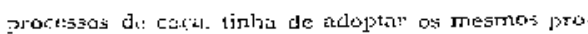

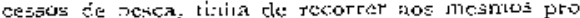
cessos de artioultua, alenas lacititados pelos conheciuinton o viso dos metacs.

- Hén listo, cille titslia de se adeptár mais ou

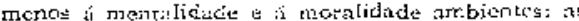

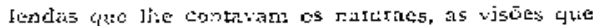
os hallecinarer. as abusôes or antes, as formulas

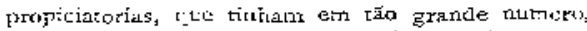

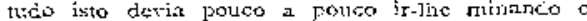
ce-t:bro a producirulo revulucōes majs ou monus profundis

Tambera por sed lado, thle devia imfluis sobie os Erasis, e easirar-lhes rnuitas coisas que ants nio sabiam.

Si roflextirnos, poiern, qui a saciedsde offerece uma forcia de xresistencia maine gue o individun, impüi:-se , conclusiáo de que Fross, Dil oulto nualquer, foi reiss innuenciado pelos Bragis do que estes o foram por elle.

Para sumuir tudo em uma palavra: dẹntro de poucos annos un bomom nestas concličes ficant moralmento urr mestico. E claro que nesti1 mesticagerr: morial devia haver differentes gradaçō.

Havin primeiro o homcm que nito xeagia absolutarecte, que tomaida todos os habitos dos Brasis: exemplo o Caste:tayo de tuie nos fala Gabricl Soarest, eimotitado por Diogo paca, de Pernambuco, cull os beiços firtulos conso as Putíguares eiltro

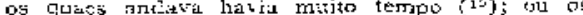
interprets notmandos que, segundo Lery, comanct

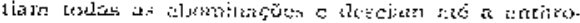
poplozxis (4).

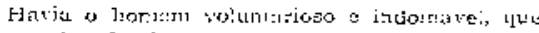

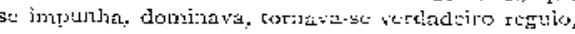

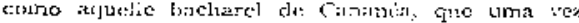

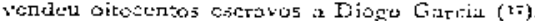

I-lavir, cmfin, o homeri mediorte, qus nu desciak to betoque nem se alcave no poderto, ha: turcza irdolente, desannuriada de presceuparóses,

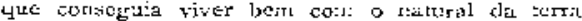
c com o curoneu; gut inflitia pouco, suc soffrin por seu liado poscia infitcticia: exemplo Diugu A vares, täo ecicbro cons o nome de Caramert: (1)

Vos primciros temposi, os tres rypos coexistiran?,

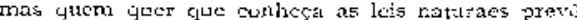
descic logo suc o prísiciro, lma anorma!idirie, tm serdadeiro monstro, reso poderia continear.

0 sebuncio, typo de tramsicaso, deveria durar misis tempo, goneralizar-sc majs, N'āo podia, enve tanto, ir muito adiante, nen foi, apesar dus esfurços que neste sentido empregaram os jesultas.

Era ao terceiro que cabia a sobrevivencia, desd. que os Partuguezes, corsiderando sua a terro des coberca, declarasam intrusos os stus povoatores.

Rateila do Brasiz. F. 26.

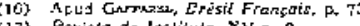

(17) Acvista do lestitufo, XV D. Q de modo almiravel for Candido Menlles, Revista to instifata, XL 


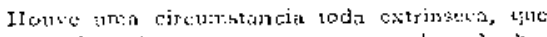
depessa den rigor so spe representado pelo bn charel de Camancu e concorreu para nue desde lugro alle predominase: a presença dos Francezers.

Jú vimos que estes protendem ler desceserto o Brasil e que as suas pretençōes, á luz dos docu. mentos que possuimos, nâe rossistliti á critica. 5. porér, eerto que a presenga delles data dos prì meiros tempos do descubrimento.

Pode-se ate dizer que um dos matiures progressos que rem feito o esludo de russa historia no seculo dczescis consistiu ern recuar a epoca de 5 tha che áda. Coin effento, os primeiros historiadlores só daram noticia della um I 555 com at expediçăo de villeraignon. O Rotciro de pero Lopes repurton-a * 1531. Os dueuncestos relativos reportaramana ia

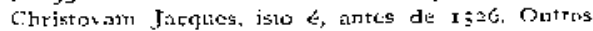
docunentos publicados postersormente denuncians. the esm 1504 .

Eviste, publicacia pelo emincre georrapho DAvrzac, a relacão de urna viagen faira ao birusil por egse tempo. Exerutou a $p$ de Gonneville, que salinindo de Honfleut toi pelo Cabo Vcrdo a alrura das lhas mais tarde chamadas de Iristio da Cunha, $c$ emfir vejo ao Brasil, onde esteve tm S. Fran cisco do Sul, e ao roorte do Cabo Frin, scrumido Varnhagen; entre os Tupinambís cta Bahia. segundo D'Avezac.

No mesmo amso, é tradiçân que vio Denis de Honfleur, e depois vieram mijtos outros, de que

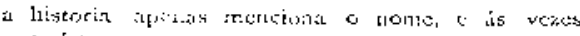
ni-jin isto

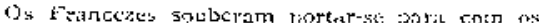

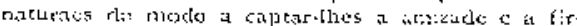
mar uma diliatle clic atravbisou mils de um seculo sem internitencia.

Ser france cra itn come bulvo-cordacto entrs cortels tribts. O allemán tlins Staden mais de uma

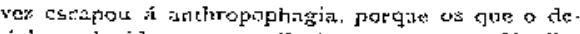
rinhar duvidavina que elle fonse portiguez. No lim do rissmp seculo, em brenhas descentlycidits de Minas Geraes, por ande se internatra o inflion Kniver declarando.se francer, sasto bó foi puspiadu cumo si tornou sma especie de chefe, a clien obesicia ums

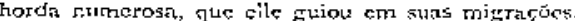

Os duis rornes que os Brasis davarto ilos Fran. cees 5 to amhos mracteristicos da improsiäo que estes lics causaran. Lim foi o de Mair, isto \&, creador, ransfornador, sugundo Tlieve:, grelos ob jecros que traziam, pelos inscrumertos que permutavent pelos officios e artes que iam ensirando. O outro foi Aytrkjubo, papagrio amatello, pela effu. siso, pela conterialidade, e fiquele habit quc sāo täo saracterízticos dos filhos di Callia.

Hala mostrar a differença que existe entre o procedier de Francezes e Portuguezes, basia com. parat dois factos. Gonneville, nāo podstido manclar a sua cerra o indio Essomeric, que daqui levara, calsov:- com umn parentr e del lhe sen nome. Jc xonymo de Albuquerque, salvo da morte por umá .mu:Iner que por sua causa tudo abandonára, depoj: 


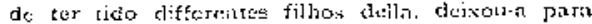
casat cory uma curopica.

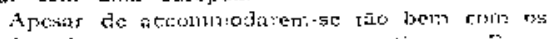
Bratsis, talvez mesaro que jor este motivo, os fira cezess rááo puderarn colrsctvar paecs em os l'or. tuguezes.

$A$ difference de nacionaladaces cavou entre as duas raçōes um abysmo; a icltuntidade de ju: lito e a ronciguicliste do campo de exploraçäo aprofinclaran-no. If́nuve lutas c udirgs lerriveis; quebra cle

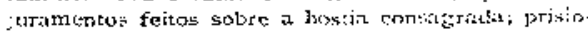

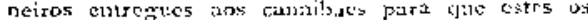

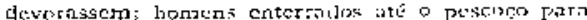

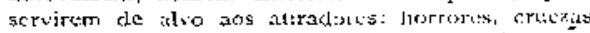

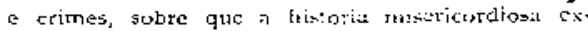
toncieu a arraistia de sua pentmoma.

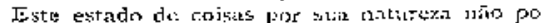

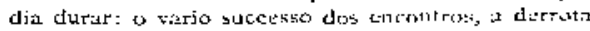

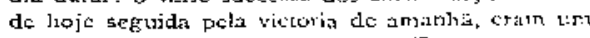
pullinmcnro, nāo eram s soluç̃os. Entretaloto, esta

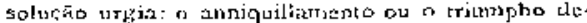
finitive nas podia mais ser acilade.

Fotam os Portiguedes que venccram, \& assin

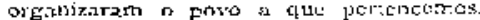

Os ineios a tuc se soccorreratil joetser resumirse it tres.

IFoi a primeiro as armadas de guarda-costa, que

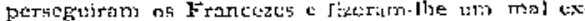
traurdinarjo. Si estes fossem mordades pelo froverno teriam provavelmente resiseado ao crmbaxe; mus representavam armatores partictilares, cquc tinlam di rluciro empregacle ra expeculario, glie pecisavam

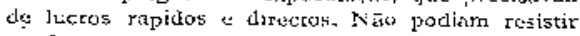

1.)rite os cliefes lins armadis de muardá-costa conbecemos o rome $c$ us icitos de alchus: Clyribto vim Jacques, que mais det untr ver foi clo cabo de S. Agostinlio do rio da Prata, a fiz irma guetra de cxterminio aos Francezes; Artorio Ribciro, seu 5uccesser, de quem mutito pouco se sabe; Martirt Aifonso de Sortsa, o juluro viee-si, gue proseguiu na sencla de Cliristovan Jucapuen e teve ele mais a gloria de Euadat $\mathrm{S}$. Vjecute e I'jratining:i.

As armactäs de :rilareln costn, \& bem facil de comprelıencles que, alïm de d:spendiosas, eran at

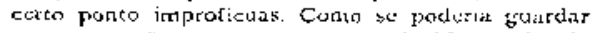

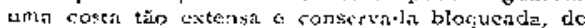
mede a t]

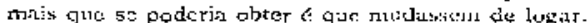

Foi entá inaginado o scigundo racio: as negociaçues diplomaticas.

I'ois que o jovo inareer, por sua miliplicidade * pelat rispidez eorn yue substituinm etiperesas novas a novas empresas, to podia ser sulujugasle. cra preciso asscgutar-se o governo francez.

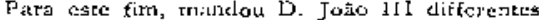
pessous que pouco coilseguiran, o por fim a corde de Casianheira. Estio hoje improssas, gracas ao

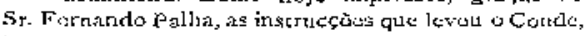
inserueçes entertillaadas, jyzantipns, matibosas. em que tudo rscé previsen, w que o procedimento do embaixadirs estí prescripto de antemino, an que o implecvisiso quasi que está aroinllado. 


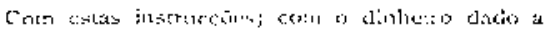

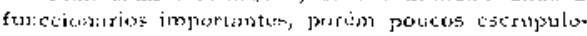
sos:

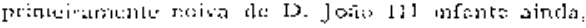
teve de rasar com D. Mariliel. porijue etse $x$ de-

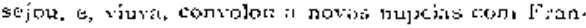

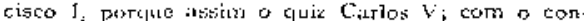
curso de didros factores, que taire\% ainda renhamos a conhecer, a conde de Casturnlucira obteve quanto ฉุuiz.

Porcm isto ara muito menos do cue se supp'1. nha. Depois do rei ter impediclo ass navogácốs para - Brasil, qui soguancis laviz cie que tal determi

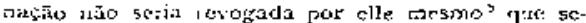
furangit de que o sẹ suctessor năo a revogarja? e rorno buma grinde extensío da custa, como e a

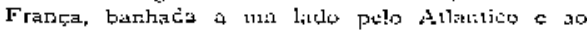
outro pelo Mecliterraneo. corsegrie que de todos os portos náo sibisse nat para o Brasil:

Era preciso deseotrir novo meio, que foi o ter. ceiro.

Nâ era necesiario graude furespicacia para atinar com elly. Empyyicamente atú já exissia em embrytio: era o povoamento.

Ameriero Vespteci. como vinzos, furrdol suma fei. torja no Cabo jrio. Parece tite Gomcalo Coelho fundou outri so Rio de Jandio. Em Pernamiuco wntes de I 526 existia outra. Secgindo todas as probabilidades Christoram Jatules funclon aindis uma cm Itamaracá

Ioda a questáo ne reduzia a fazcr conscientz-

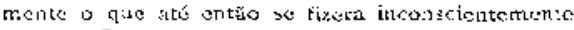

Foi Gotivea quen chergon a testia talés por una serie de tactocinios sorraclos, clite ainda hoje troz servarn o scit valor.

Quil a cithis por give os Francezes vio no Brásil inqueriu cile.

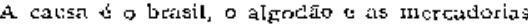
que elless văn buscar.

Ora, si tizermos desapparecer esta causa--isto 6. :i itnpossibilitarmos exte cornn.crcio-, desappis recerí o clfeito, a prosença dos Francezss naquella terra.

O meio is sirnples. Fundem-5o dez ou doze feitorlas. Estas nūo deixarāo que os intrusos comriuri-

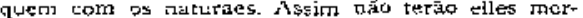
cadorias a transportar. Nino as tendo, deixaräo de ir la, porquus: niso biso de queres voitar com os navios descartigulos.

Estus ponderaçōes calaram nej espirito de $D$. Joâo I!I I, quic aliús jú as elitrevirz vagtamente quando manclol Martim Affonso ao Brasil.

Foi ertio que the reio a sdoa das donatarias que, comecando err $t \$ \$ 4$, abrem um novo periodo ers nossa hizroria.

Deale esta epoca, estuva perdidir a cansa dos Francezes.

Expulsos do Rio de Janeiro, abrigaratm-se em Serripe; expulsos de Sertipe, abrigarare-se na Parahiba; expulsos da Parahiba, abrigaram.se no lRio Grande do Norce; expulsos do Rio Grarted do Norte, abrigaram-se no Cenrá e Marăhã̃o; expulsos do 
Miararbano ef Centá, abrigaram-se na Cuyane. Si dihi näo foram cxprulsos, como planejou Filippe I I quardo concedeu a Capitajia do Cabo to Norte a Bento Maciel, deve-se s irdepender,cin de port. gid, a suerra hollandera e a factos s:letwenicmles.

Fublico o scguince documento, cm primeiro lo gar, porque rincla está inerlito, em serrundo, porque encerra curiosas noticias dus primeiras cxploraçes as norke.

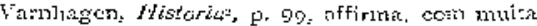

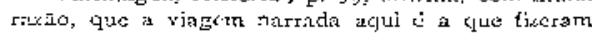
certos porcuguczes, que partindo do Brasi. Soram vor Darien a ilha de S. Joào, onte os pregderan \& nindiaran para S. Doningos. (CE. Hersela, des. J, liv. $X$, cap. $X V I$, e dec. II, liv. I, cher, Xil.)

Sto esto: provavelmette us onse portlguezes deprois trocados por scte castelintros aprisiondes na bahia clos Innocentes, e nëo ns que os compa. rheiros de Solis aprisiomaram ro calio de S. Agos-

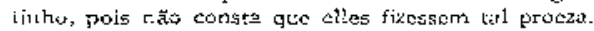
(Cf. Herrera, dec. Il, liv, I, cap. VII e liv. II, Cap. Vist).

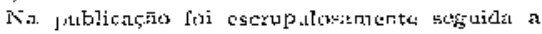
orthograploia do origin:di, de que o Institato Histotico possue unя cópia zutentica.

* Senion - cu esprevi a vosa alteu desta yлlyas mile cstou preso como vosa alccza sabe i a assy senhor tyri qua maneyra que $f_{y z}$ treladar ho procstio jue cortra hos fereram st bo matrley a vosa al teza peri. clue fose curformedo do que se dysyin conted nos; c despois clela senter ser ho preceso tho que se njays 20 dyamte fex nelle i Asy he gue sayo ho aicjurycle mayor narcos cagyinr com huurr describarg:r lie amile de rudas as corsas mandaya que mice franciseo Corso e proto Corso / ho que clui avya estaclo fosen rutydos a tormento ham prodyjucarndo ato proviclo comtra nos per ho prometor di justyc:1 / do qual mandado e desembatro ros ape. jentos per a telaçarn de sua alteza os quacs $5 \mathrm{cnhor}$ comfyrmarim a sentenca do aldpaycte mayor; to 

C) SER'AO

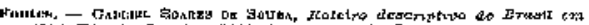

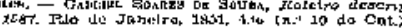

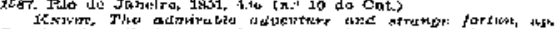

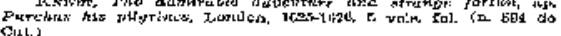

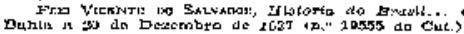

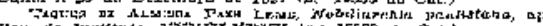

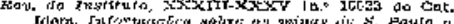

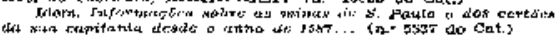

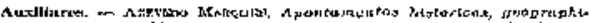

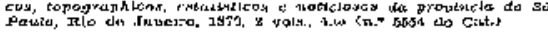

Logo que os Europeus chergraram to Brasil co. heraw de envolta com ucitas informacess verdi cleiriss os lincannentos de uma geographia phantastica.

Falavam-lhus erre momeanhas tāo altas gute as aves näs poctiam tianspo.las; on rios que, de cho fre, desispa-ceiam para surgir muitss leques alím: chl lagnas abundantes en purolas; en utr ago in: mensu de que manavam o Amazonas, o 5 . Fran cisco \& is Prata.

0 effuito destas informacöes näo se fey csperat: is internacūes comecaran descle logo, an masmo tempo quasi que as exploraçim:s cosictras, a medra- 
ram e: dcselnvolictain se ta:ato ciac, antes be trans corrido o seculo, tinhanes o phennmeno considi rave! les Biandeitantes.

A primesira entradia de quac ha noticia dlatt-se em 1504, anno em que Vespucci, acompilstindo de usis trintir homens, pencirou umas quatental logias

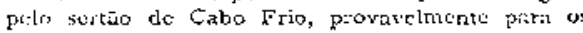
ladios do rio S. Joào ou de queleuer cios seus ifflue-jutes.

Gunçalo Coelho $t$ bem possivel ghe Iu tempo cule cicmorol no Rio cle Janciro houvesse tentado

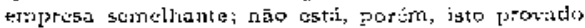

Da рсгусла colorio gue se zrupou a rotie de

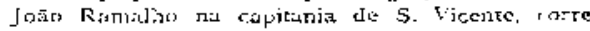
como certe que partiu uma sxpedican pirrit o in

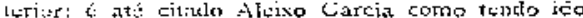

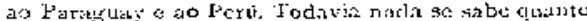
ao rutmo sigurido, Motri ilualito no inlio em que se del o facto, tuus en todo caso deve th't sido antusior a 1530 , cuirá sistcrior a 1526,

Em 1531, Martins Afíomso de So.ja ríndou do kio lle Jinejo guatio homens pria terra dentro, gue tornzratn passados dous reseses, terdo cominhado cento e quine lezbas, das quals sescenta " cince po: rramkles montanlass e rincoelta por um visto carnpo. Estai montarluas sto as serris dos Orgătos * puravclmerie as campos a clue chegararn Jorám os des Goytacaze:

A 1 de Settrnbro de $153^{r}$, de Cinnarća mandou o mestro Marriro Afionso mus treju de quisenta brisiciros a cuarersta wpingurdeiros, de feto Lobo a descobrir pela cerra dentro. Levou.0 a dar este passo Francisco de Claves, compunteiro tis Jä́o Rá maliro, que se obrigou a tornar dentro de dez mezes com juitrocentö cscravos carregados de prata e ouro. Tudo qแanto se sabe do elestino vilerior clesta bendeira \& que foi completimente destroçacla pelos Carijos. (1)

Im 1552 approximaclamente, o capicùo de Porto Suguro mardou ao sertīo doze christäos, acompi. nliados de indios, ans quaes se incorporou o paclre Joño de Aspilcueta. Da marraţăo confusa gue cstc now deixou aperas se colhe oue chegaram as serranitas dunde mircann os afl'luentes do lado dircito co S. Francisco. Puvavelmente of esta uma das entra. elas fle: Setbintitio Femandes Fourinho, de que dí

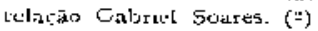

Seinstiăo Tauritho, partinda de Porto Seguro metteu-se tatto pelin terra dentro, que se dichou em dire:e do $\mathrm{R}$ :o de Janciro. Dahi retroceder a veio ter io J tquitinhonha, yue desces ern canoas, chegatuclo an mar depois de vinte $\varepsilon$ quatro dias de

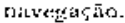

Sebastiāo Fuminho fez outra crtrada pelo rio

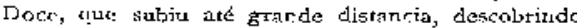
entäo as esmerraldas. (:)

Fsta viarem foi antarior an governo de Luis de Brico e A.lneida.

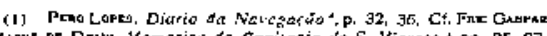

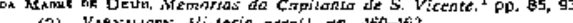

(3) Rotrira, np. Ex]-i1, $64-70$ 
Y.teis de Brito a Alrejela, á vista das infor:mit-

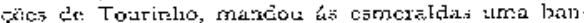
ditra commandaéa por Artonio Ibias tejorno, clue

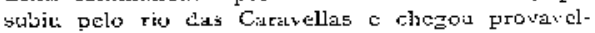
incuie is proximidades do rio Doce. Dabi dividiase: a tropa, descendo uns pelo Jequitiritzurilı, outios vindo por terra ao Jequitić. (")

Gubriel Soares da ainca notiria dr: d'eas eniradas feilas proximamente no mestmo tempo: uma ć Bastiö́o Alvares, de l'orco Seguro, que a mandacio

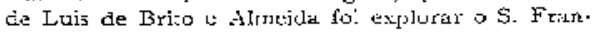
ciern, e trabalhou por descobrir quento púde no que gaston cuntris anлess e um grande pecliaco did fazer.da de el-rei; oulra de Jöa Cotho de Sousá, nute subit: mais de cem leguas alsim to tm surni.

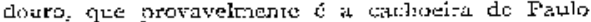
Affon=o. (5)

Ios palavras do chronisra, parece cecuzir-se que, ac contrario de Bastiaso Alvares que subiu contra a corrente, Joāo Coelho de Sousa dcsceu a favor thellit, provavelmente por ter chegado a rio $S$. Francisco pelo Paraguaçú ou Gusiape.

Galbricl Sroves que, segundo parcas, tit intria de Toāo Coclho (i), tambem passa como um tos gramdes bandei-antes do secuio.

(4) Roteiro, pp. 60, 67, 7I, Frei Viçente do Szalütdes conta n

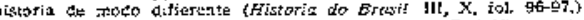
(5) Rateiro, ㄱ. to C1. ज्tire Basteso Alvares, Frei Vicente do Satvador, III, Cap. IX, j. G7.

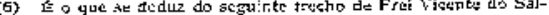
vacer: cste seve
Tm lima das cropiss manuscriptas do seu koteiro, elle diz que passol muitos dos decesele annos que revidiu no Etatsjl a percorrer o interior. Na obre

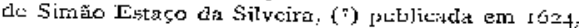
diz-so ç̣e elle foi a descobrimento do Maranlä́o pox terra, chczando ás calueceiras do S. Franciseo e. é serra Verds, perco da sovernacīo esparhoia de Charcas. Pelo livro di Frej Vicente do Sal. vacios: sabemos quc em 1591 on 559 clle cluegeru ate as cabeceiras do Paramucú onde infelizmente m.ol'reu (").

A obra ec Frej Vicurte do Saliador nos lá relaçāo de una entracla feita posco mais or menos neste terapo por Lis Aliores d'Ispinha que, par-

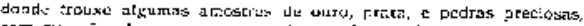
coml qut näa chezoll por morr

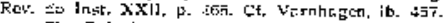

(7) Relçüo summaria das caneas do Maremhäo, cm Canticio

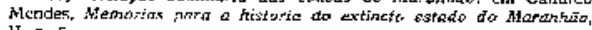
II, ?. 5

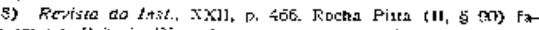

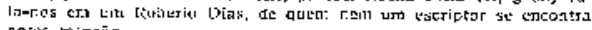
antes Menşä́.

E possivtl qui haja xisto simples iragibaja de tistur:acior

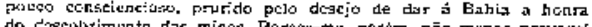

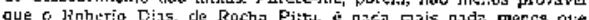
Ambes sfyeran as vis.

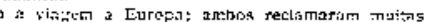

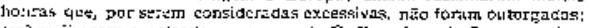

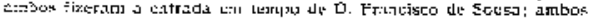
Mag antes de wer ceroudos os sells csforços.

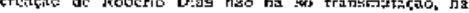

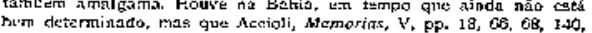


tindo dos Illikos a pretexto de vinsar-se de t:mas alciciat gut: málaram uns christāos, to que distavan trista leguas, eprisjosouras, e passou adiantc tapu rando nuts gerte.

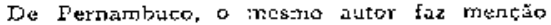
dic muilas entridas.

A primeira teve logar no grverno de Duarte de Albuquerque Coclho (I $; 60.1573$ ) contra os is. dios do cabo de $\$$. Agostinho. Serundo as palavras do chronista gue parectrm exagreracias, jarr slem de vurt: mil indios, sete compantias, em que entraram a gente de lgurdýa tornmandade por Fitr. näo Lourenço; a do Paraly ( $(2)$ por Gonculo Mendes

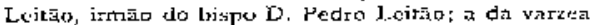
clo Capibxribe pelo fidaigo allemino Clıristovam Lins; z de Odindiz commastada por differentes cinefes,

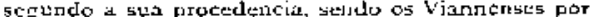
Jutio lizes; os Porturenses por Bento Dias de San. tiágro; os Lisboetas por Goncalo Mtendes d'Elvas;

- -

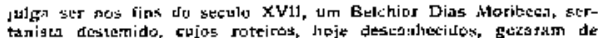
krande nameddit. Foi, portanto, cosl o arorte de Dials Moributs e enft

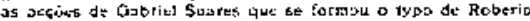

Tayuts, r:a xu: Noblfiurchro Puxulistaso, exprime uma opiniáo

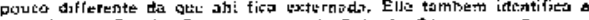

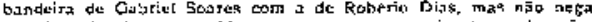
a Lxistcacia deste: consitie-rses apentas como gria da exploracáo. Nobliorctia Pautistara na Revissa do Inst. XXXIV p. II. pp. 151-152).

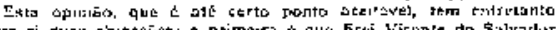

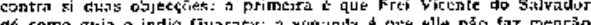
des como grija o indio Giarityi a a de Iramarací por Pcro Lobo, que desistiu cha hanra e preferiu ster simples soldado no batadräo dos aver. turetros, O successo foi completo, firindo desdc or. tāo o cabo de $s$. Agostinho en poder dut portuguexts.

A segunda bandeira foi contra os naturaes do Serunaen, scado os que iam por werre commandados por Jeronymo de Albuquetrepe c os de tris por Felipne Cavalcanti. Tambem o sitecesso destil nä́o foi merros ftiz. (10)

A rerceira que sahiu en 1578 era commundida por Francisco Barbosa da Silva coir desriro ao $S$. Francisco, indo por teria um roro die selenta homens, do mar.do de biogo de Crasto, lingua que já tomaira parte nas tistrarlas anteriomente man ciaclas da Bahia. Esta bandeira iuternou-se pelo laclo dircito do S. Frarciscn, inde cherar destrocida to Cotinguiba.

A quarta logo depois desta dirigiu-sc ao $\mathbf{S}$ Francisco, c exa mandada por Francisco Calras Gaspar de Athaide, aluxiliado por Braço de peixt, um dos chefes tobajáras. Pelin deslealdade the que usararn com este, foi inteiro o mallogro. (11)

Depois da conciuistat de Sergipe por Christovan de Barros foram ro sctra duss tropas commandadas por Christovam da Rocha c Radrigo Martins, que nate riveram melhor successo. (1")

(I0) Fart Viessite za Sist., liv. III, Lap. X'V, p. A4.

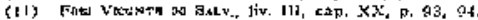

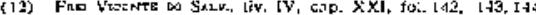


Do Espiritu Sanzo ha certeza que Doningos

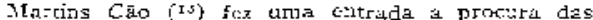
esneeraldas por orjem de D. Francisco dre Sousa, spundo este: ainda cstara na Bahia, jsto $\dot{\varepsilon}$, aries de 1598 .

Ha airrda floticiat de urra ertrada f́ejta no mesmo ou ro scguinte anno po: ordern de D. Francisco de Sousa. (11)

Provirclmcnte \& esta a de Arrvedo Coutinho. que, como se sabe, é posterior é de Domingos Milatirs Cầ.

Do Rio de Janeiro tcmos noticios preciosas transmittilias por krivet de entradas fëtà ás cabeceiras

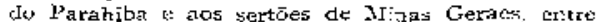
I 592 e 1600 .

De S. Paulo, 25 bandicins são numerosas.

Diz o epitaphin (tó) de Braz Cubas que esto destobriu outo no anno de 1360

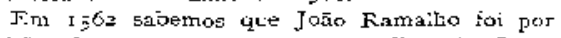
capitùo das guerras contra os Lndios do Para. hibil. (10)

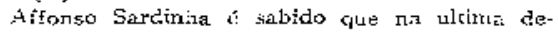
calá do secule, descobriu at miras de Sorocabe. $i: \bar{j}]$

Jorre Corrêa emi 1594 ioi para o sul fazer guerral dive Curijós. (19)

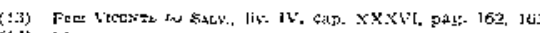
(14) Jítem.

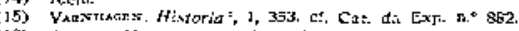

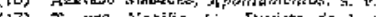

YXXLII, parte 1
Para resumir, os nomes de sermaislizs e bundeirututis pauliztas de dje ha memoria săp crn numero extraordinario. Só o parire Simāo de Vasconcellos. que apenas trata do assumpto incidentemente, nomé Joào dc Sousa Pereira, Francisco Cortti, Domingos Luis Grou, Manuel Veloso te Fipinta, Joses Adomo, Ascenso Ribciro, Join Gago, Jeronymo da Veiral, ste. $\left(1^{19}\right)$

Corn o livro de Tacucs e o de Azevedo Marques poder-5e-in eleval este numetis no dectrplo.

De todas estas entradas ben pouros são os rorciros yue se corservamt. Gabricl Soares clí-ros al guas, porém cunfusamente. Frci Vicente do Salvador clás uncros, mais circunzstanciados quario a parte anedortica, porem inteiramerte deficicrtes até quanto á geographia. Finivet dásnos algurs, porern mijio defticientcs tambern quanto ss indicacouts. Marcgrav so, dá zur que 6 o mais completo e o rtais lucido auc posstimos, tasto que por elle ste póde facilmontc reconbecer o caminlo procurado.

Felimentis, contratrando-5c os roteiros que ainda ros restam daquelle tempo com os que ha ce tenz pos posteriores pode-se fazce um roteiro theorico gue servir para encedear e syitematizar os desco. brimentos e os rumos dos bandkirantes.

Para tracar tsile rotciro theorico, é preciso attender ao seguinte:

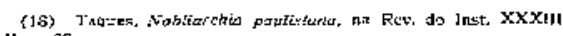
7. II. P. E2.

$\log [2007$ 
As moutanhas foram scmpre a belisa, o platol flut tiveram a vista açuolles homons miprelende. clores.

Os rios form os camirhos que seguram de pre. fercncia.

Nắlo 6 presiso explicar o motivo par que as montanhas figuraras de modo tāo imporcante nas primitivas exploraçōes do interior: 1 sus fixidezz invariavis], a sua visibilidade a grande distancina sāo

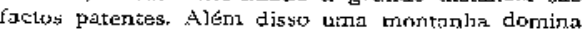
grande parte do jaiz, e della pode fazer-se um re. conhecirrento previo do espaço a percorrer, urita recapituI

Quanto aos rios, as vancagens são talve: maiores.

Mirsteando um rio nāo ha meio de ume pessoa se perder. O rio trarante a ayoa, condiç̄o indis. pensavel de vida, facilita a alimentaça, dirceta mente pelo peixe que contern, indixectamente pela caca que velst beber no scu Icito. Em paiz habitarlo pox inimigos, $\epsilon$ um fosso, "que de urm lado difficult maito os ataquas. Fimfim, si subir contra a corrente ă 6 facil e exigc granti: esforço muscular, \& certo

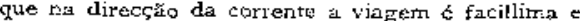
quasi dispersan esforco.

Nia realidacle tal $t a$ in portancia das rios nesta piette da rossa historiat que as barksleiras deverl cías sificar-se näo pulo pontor donde partiran, mas pelos ríos que margearam ou nuvernram

Todos os rios do Brasil represenlaram papel mís ou meros consideravel no klevassamento do interior ha, poreni, alsuns que exceder a codos: a Tietk, a
Parahiba, o S. Fratcisers e o Arrazoras, Com:o este so comeca a apparccor no scruio seguinte, deixa-jocmos de parte.

A preponderancia do Tíete ta tamanina qua gc ralmente sáo ronsiderádos synonymos paulista e bundeirntc. Isto b, porem, ume injustica. Si o raracte ristico de tass expediçose 6 a insignia sob que inar chavarn, entāo os Paulistas săo provávelmente 1? unicos bandeirantes, pois nào constà que allhures L5assem de bandeira. Si o que ha do fundartental

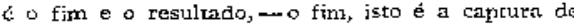
indios e a procura de abjectos de valor; o resul tado, jsto $\epsilon$, a exploraçāo inconscientc do territorio, eritẫo quași todas as provincias tem bandeirantes Brsta lembrar of nomes de Pedro Teiceira, Cosia Fa vella, Walheta, Dias d'Avila, Domingos Affonso Cer tīo, Tocirinho, etc.

lodavia mosmo extendendo o norre det har deiras as expediçōes de outrạs provinciás, o Ticte ainda fjea em posiça excepcional que apenas the póde disputar com aliflma vantagem o S. Francisco. Si o Tietê foi o camirho de Minas Geraes, do Yaraná de Santa Catharina, ro Rio Grande do Sul de Goyaz e Mato Gro55o, - o S. Francisco foi 0 caminlio pata pate ce Goyar, do Piauhy, do Ceará, de Minas Getrats a $\mathrm{R}_{\text {in }}$ de Janciro.

O Tieté possuia condiçōes naturacs que o clestinavam a este papel. Tima cra a sua proxirnidods do max, que foi motivo para of Fortuguezes virem tomo estabelecer-5e em suas margens, e toma-lo por ponto de particla. Outra era a direçüu de sua cor- 


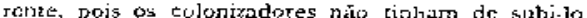
riss de descelo, o gute era muiro mais facil. Outs erat o systerua de suas rerteaies, que o purha cm cortacto com o Parahiba, o Mogygurctu, o l'arana.

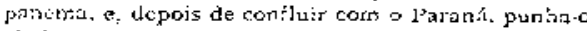
aiucia en contacto con os affluentes do latagltay.

Os Paulistas comesaram a descer o Tiete desde os primeiros tempos, provayelmeste antes do meiado do seculo XVI. Uns foram subindo pelos seus aff $]_{11}$. entes, Juquiry, Jundiats', Piracicaba, Sonocaba. Ot. tros foram ate o Forima.

Aqui encontrararn sircunstancias, ¿і primeira vistit insignificastes, clue exercerum exrande influs . cia sobre a direcrấo das birudicitas e sobre a formackio territorial do Brasil Arima da confluencia do Ticte, o Parand tem um salto gue é jnupossive] ranspir: o die Urubupungá: abaijo elle tem o

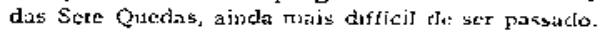
A consequencia foi que as bandciras inhax, ou de torrar, acto de que nato eram capazes acjuelies ho. mens destemidos, ou de intermar-se pelos afflucntes do lndo direito e do lade estquerclo do Paraná

Tioj o qui fizeram.

l'zercee que os affluertes do lacio direito do Pr ranti foram explorados anles dos afflitentes do bado esiplitordo, pois sabersos que etn 1531 jú houvera

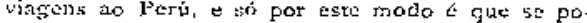
ter texplicar. Sabe-se pelos mappas anrifos que dojs destes rios forere logro praticactos: en primeiro logar o Ivinheima com o Mbotctchu que com elle contravcte; em segundo logar o Pardo com o $\mathrm{Ca}$ mapuan, Coxim e Tachary, que the correstondem.

Os afflucters do inco esquerdo do Parank, fo ram explorados, a Eartir ca for, mais tarcle, lass comeros do suculo XVI, Foi entáo que se deram as lutas terrivais com os Jesuitak nas margens co Parankpancrma.

As bandciras que jrefariram suhir pelos afliu. crtes do Tiece, seguiram rumos differentes. Lins fo rain dar an Mugvguaçú e Pardo, e pelo Faraná hiba foram a. Goyaz, exe:mplo Sctbastiz̄o Marinha, que, \& tradiçito, descobric primeiro aquella minas cm 1592; outros swbiram para Minds Geraes; ou tros passaram ato trecho rredio do Paranajanema: otrros pelo Snromaba forajn clar ao Paraní, Santíl Catharind e kio Grande do Eul.

O I'vrahiba toi aracado successiyancrite por tres poritos diversos.

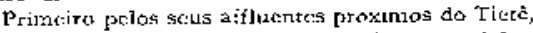
como se ví no roteiro de Ginimer. Este camirho, dures pouco cempo, o desappareceu logo que toratr fundados Tauba: povoatos.

Quasi ao mosmo tempo, sabe-se pela viagem de Kriver, foi acacado pela serra do matr, nas proximilades de Paracy, por oncle loi çuasi doís sectilos - camiriho por terra entre Kio de Janciro e S Paulo.

Iais carde foi rambern pela serra dos Orgäos, seruindo o Ifuarú e o Inhomirim.

Lim dos sets affluentes mais insignificantes, ? Embahu, foi o ponto de lisaçäo com Minas Gerices 
e com o trecho superior do Paraná e, indirecta. me:ute, com o S. Francisco.

O 5. Francisco nüio "stava err. cordiçōes tāe lia voraveís romo o Tricte, pois exa preciso stibilo con tra a correnie e logo a pequena distancia do rar cncontrava-se a cachoeira, ou sumidouro, como lirităo chamavam, de Faulo Affonso.

Mas estas deswantagens exam mais Lue ampla.

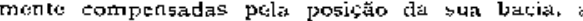
coste: ligada pelo Paracatú, Preto, Cruruja. Cari.

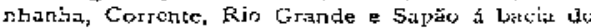
Paranahiba e Tocantins; ao norte Iigada at Iat picurú, Parnahiba e outros rips menos importalthts a léste ligado ao Real, I ta jicurú, Paraguaçú, Cúztas, c outros menos importantes historjamente.

O S. Francisco ainda teve umo circernstincia mito favoravel: a veretacto de seu sertio, em ze j] de carrasce, cutiriga, e mato ralo, que nta oppu. rha d.s intermas̄es os mesmos embaracos que a matta virgem.

Os jontos de alacjue do S. lirancisco podem reduzir-se a tres.

O primeiro foi pola foz; emborz estorvadus: logo no principie pelo immenso sumidouro que tanto preoccupou ds primeiros bandeirantes, as entradas conmettidas nesta directāo tiveram grande impor. tancia, pois pelo Moxotb, Pagejú, Terra Nova, ria cho da Brigrida, levaram ao Jagtaribe, ato Cariri, e posteriormente ao Piathy e ao Marandato; pelo porto de Folinas, Propriá, Berume, levaram ao cer. tro de Sermipe e da Bahia.
O gefrondo foi pelo Itapicurí, Paraguaçú e seus iftluentes, peio trecho medio de rio de Contas; de importancia ainda maior para a colonizaçă $e \mathrm{ex}$ pleraça da Bahia, de Minas Geraes, de Goyaz, de Piauliy, pela contiguidade en quc estavarn com os rios Salitre, Verde de Bairo, Paramirim, Santo Ono fre, Rans, e estes com os affluentes da nargem esquercla do $\mathrm{S}$. Francisco.

O kareciro foi pelns cabeceiras, principalmeute pelo rio das Velluas, thos sertöes de Sabaraboçú, Che pilva-se ahi das margens do Parahilan, transpordo a serra da Mantiquejra, e depois a bacía do Rio Grinde, ou Pazará. 
Na obra de Piso e Marrgrav, onde se acha perdido, povalas pessoas inäo procurar este rotcira. Par isso putulica-o. E o trimeiro, que re conste, ce vinger a Vimb Geraes, e presta-sc a umat cont. paraçào muiro curiosa com a que um seculo de. pois nos uta Amonil na Cuttura e opulencis do Brasil.

Varnhagen conhecia c ietere-se a elle na His. tarian, p. 460. Levado, porérn, pela identidadi do nome de Climnter, que figura no livro be Marctrav e figrara na carta de $W$ clbeeck, elle commet:ث̈t un erro inexplicartol: identificou as duas viagens.

Entretanto, a differença en:re ellas é finclamencal.

Uma teve loyar depois que D. Francisco de Sousa sahiu da Bahia para 5. Prulo, isto é entre 1508 \& 1602; outra reve logar depois da tomada ca Bahia, depois de 1634. Umat partic de S. Paulo, ourra partiu da Bahia. Uña foi a Sabará, ern Mi. nas Ceracs, otutra as minse dc Salitre, na Bahia. Numa apparecem Francisco Dias d'Avila, Calabar e Glimmer; cris ontra só apparece Gijrnmer.

Pelo roteiro junto, traca-se facilmente o terreno percorrido: de S. Pauio foram ao Paralíba, provavelmente pelo Araraquaria ou Jaguitry; dçsceram - Parahiba até inmediaçōes do Cruzeiro ou Cachoeira; beirando o Embahú transpozeratm a Mantiqueira, descendo pelo Capivary e Rio Verdc.

Este cuniniho até certo ponto corresponde com a tritrido dis ría frerted co bio verde.

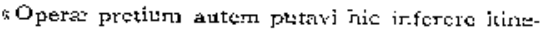
rarium cluod à Willkitro $G$ limmerio nostrate acecoi. Is rarrat eo tempore quo ipso in Preefectura $S$. Vincentii decreret, venisse ad illas purtcy 2 Præfectura Bahize Franciscum de Sowsa; acceperat cлin it quodim Brasiliano metallum quoddam, iे montibus Sabaroasort, ut Ferebat, crutpm, colotis cyanci sive caelestis, arenulis quibustar aurei coloris in. terstinctum, quod cum à mirereniis cffet probalum, in quiriali triginta marcis pari argenti continere Cepreliensuni fuit. I-Fac illeceìra provocatus Gujoernator montes; hosce \& metrilla diligentius investi. sanda putans, septurginta at7t octaginta qua Lusi[anos, q1:a Brásilienses, to mittere sit atimun indusit Cum his Glinmestius nostes pulectus, itineris ra tionern ita destribit.

\& Ab oppido S. Pauli, in persfoctura S. Vincertii, profecrì primitun ad municipium S. Nicluaticis per vetimu5, (quod distar à superiori versus ortun glin-

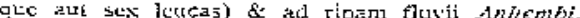
atquic ibident comtrleatus pazacos invernitnus, quos barbar: humeriš exant portaruri. Deinde fl:urium il:ud trajrcimus: \& qualuor aut yuincue dierum pedestri itinere per densas $\$$ ilvas promovimus versus Artti:m, ad flutiolum cjuj oritur ì montibus Cunrimunis atr Martmiminis, ubi zuri suit restalla. Hic cantis aliquot \& corticibus arborum corjunctis, secundo hoc anniculo desctndinus quirque aut sex djebus, inci- 


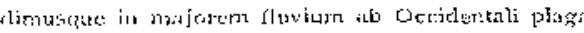

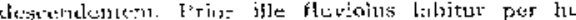

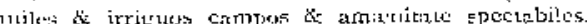

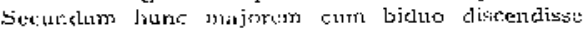
mus, moir.jinus in tluvium arlinus longe majoretn,

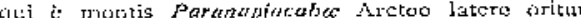

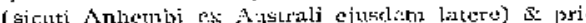

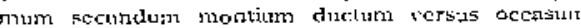
elilatrens, deis cubiro flexus, alifguanclie fertur versus Arctum, Ne tandell, ut vulgo credicur, illabitur in Oceanuru inrer Promonturjum Frio sc Prefecturam Spiritus Sancti, piscibus tam majoribus quam minatibus erresie fetus: vacunt tluvium cle Sorobis IHune quofue quindeciry sut sedecim tiebus descen clentes porvenirnus a Cataxacten, ubi fluvius als cditis muntibug comstrictus, prosecps ruir versus Ortum: quaprepter hic canoas nestras depressimus \& rursis peclestre itcr atrosessi, justa \& per alium arimem, qui ab nccasu advenic \& navigionum non est patiens; quincluc aut sex dicous perverimus ab altissimum moritem, quo superate descendimus in parcotissimos campos, lucis quoluc hac inac opecos,

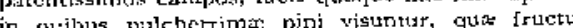
ferunt mele capitis funnani, cujus auces medium cligitum crassie, cortice testintur instar castanew $S$ optirni sunt saporis \& nutrimenti: (vix \&ubito, ittam lonui so Zaburcio arbore f ejusmodi arlores per

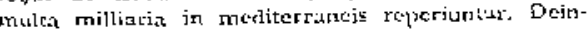
ceps tritue perventulus ad huviem qui ab ortu descendir quern transeuntes quatuo-decirn ditbals promovinias versies Cormm, per parentes campos of

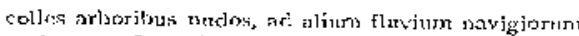

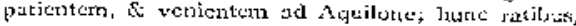

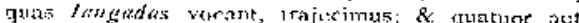
guintule: Jeucarum intervallu allum jluvium offencli mis, penis ab itrete allalstritem \& savigiorum pa

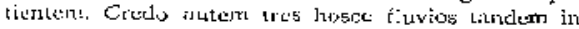

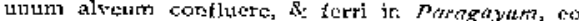

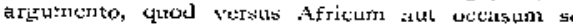
proripiant. Forro toro illo itinere quod hactenus dos. cripsimus, nihil culti vidituus, nullos morrates. 1,ic illic tánturn ruitnes togorum, nibjil vìctui opportunum procer gratmers \& a diquoe fruetus silvestres; obscrva. vinus iamen not:numeluam sumum ascendepta:n vacitutur thim jer bas solitudines barbari gujiclam cum conjugibus \& Ijberis, inctratis sedibus, qui obviis uturntur, uullat senentis turá. Ad postremum hune fluvium dernutr pagum inclipenatsm invenimus, है 1mitur copian, lempestive sdmodun, siquiden omis quan nobiscum tulerimus, jam crat consumte, \& jam iljijuandiu silvestribus fructibus aut herlsis campestribus farteris expleveramus

"Mtthitenl pene inlegrum bic morati, st annon: parata, denuo iter promorimus versus Cornm, mense umo inbsoluto, mallis fluvitis obyiis pervenimus ad viam latan \& tritam, \& duns annes diversia molis, tui ids Africo allabcotes inecr montana Sabaratsu eluctantur verstus Boream; atque hos esse fontes seur caspita fluvij S. Frajcisci oplnor. A pago supradicto ad hos amnes wull os mortales vidimus, sed accepinus ultra montes rationem barbaram ad. modum populosart agere; tui de Europacorum horum 
Gdente (roscio rlis preto) curriorits farti ur.to

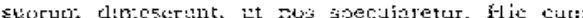

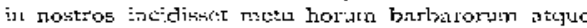
annolve inopida, nondinn cxplorato tretallo, cujis

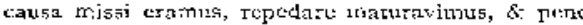
farte cnecì rediimus ad payum jilutn barbarorum. Lbi viribus recuperatis \& annona parata, Bden jtinerc quo reneraraus, ad fluvitm illum ubi canoas depresseramus, sut:ius reversi; atgue his refecti fumíni nos commisjnus, eoque adverso prorcptavimus usque ad iltius fontes; arque i:a nowem mensibts iv hane expeditionem impensis, primo Mogomimin, dein ad oppidtm 5. Pauli redjimus.

POVOAMENTO E POPLIACAO

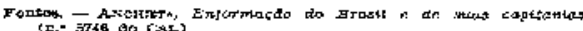

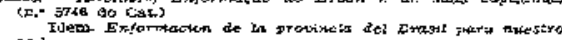
farite.

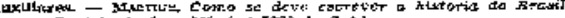

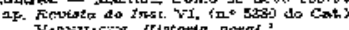

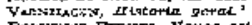

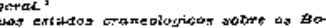

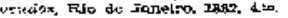

1) povodiziento do Brasil começou do modo se gijdo dit1 1534 , quanto o territorio foi reparticlo em quinze pedaços e doado a tive donztarios.

Ferrase apreciado de modos diversos este plano de D. Joāo III, e alsurns tén censurado os podercs ytuasi illimieados concedidos aos capitžn-mores e a grande extcneăo das capitarijas.

Estas censiras rāo tث̂n grande.valor. $O$ poder

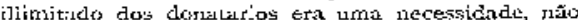
tantry paris que jodessern dompinar os colomos, como porq̨ue $\mathrm{cm}$ sociedades rudimentares como as qua entìn be funduvan a clivišio de poderes era :rr.poisiver. Ora todo o poclerin dos dotialiaries consistia cin accumulatem o poder executivo, o poder judi. ciario $c$ o poter jegislativo. 


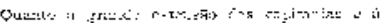
C. cros o, o a

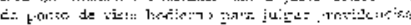
uي

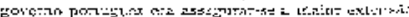

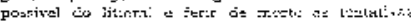

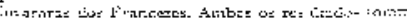

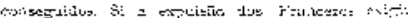

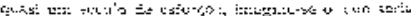

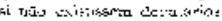

-

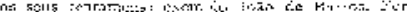

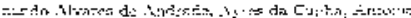

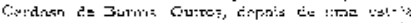

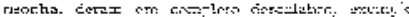

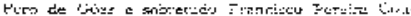

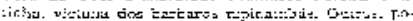

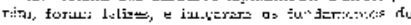

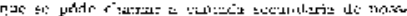

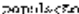

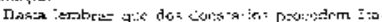

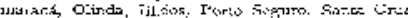

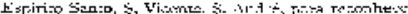

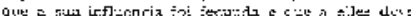
r.: t:= o povo briziitiro.

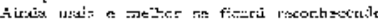

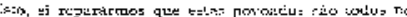

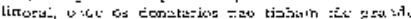
inscresso exta:a a

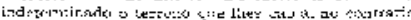

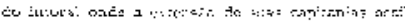

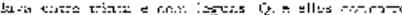

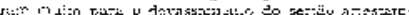

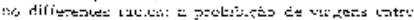

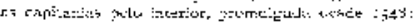

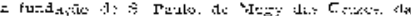

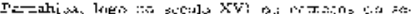

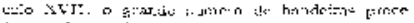

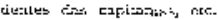

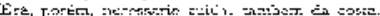

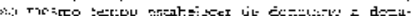

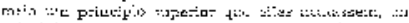

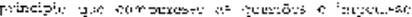
c

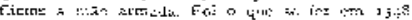

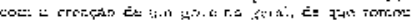

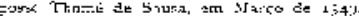

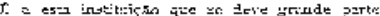

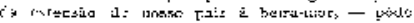

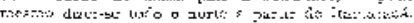

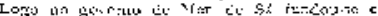

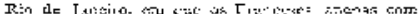

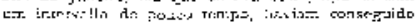

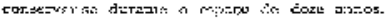

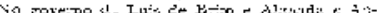
luvio es Salpo:x, :

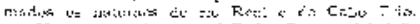
No fur o..

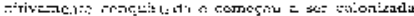

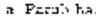

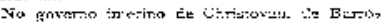




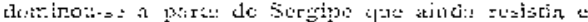
flizedor-se S. Ct:ristom.

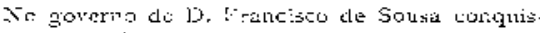

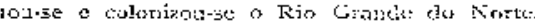

Werers de vine rimus depors deate fueto. O Basil j:i at:ingira ao Natte us limices gro deycis

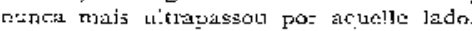

Ear restrio:

A tondercia dus doratarios deveria ser alom garem se pelo interior, onde o sew domivio era. illimilátlo.

A tertct:cia dos govemadores ropins deveria set alonfarem-5c po:o ex-evior, ondr: havia maint perigo de estrangreiros s: mais instabllidade na posse,

E elles a angaram-se principalmente petas costas do norte, portili, testrneto tesde i 580 Pottugal

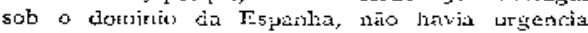

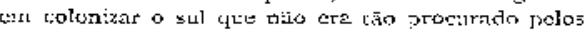
estrangciros, a to certo ronto estiva gararticlo polos c.stralselecíriencos p!:-:ti:int.

Só depois da separaçāo de l’ortungiol da Ĺspia-

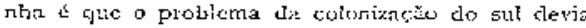

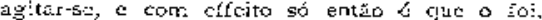

Agore que eiri imperfeitamente traçatio o rumo que tomol is pordamento, rejzтаt como se formon a Fropeiticiso.

T.ogro que os Furopeus chegaram it estas pleigas, encortrarian-nas poroadas por differteles uibus.

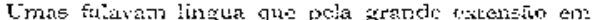

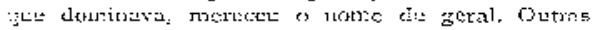
faldavarn litigua geralricase pouco confeciclas is de

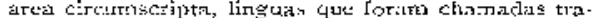
v'aldas. Os primeiros, stgundo Fei Vicerte do saivador chimavam a si Apuabeios (= Apiabeté, segurulo Eaptista Cactano); ans sezundos davall os nones de Tapuias, isto É, de inimigos.

Os modarnos estudos eraneologicos têrn distinguido enrre os Tapuias a Apuabetos pelo misos tres raçż: primeiro a dos Tupis, a mais numerosit, a rotiis importante, a menni barbare, geralmente lacalizada no litioral e nas margens dos rios, e que pirece tor vindo do norte, dos Galibis e Garaibas; segundo a dos Bococudos oil Aymorćs, terror des cispitalias çue hoje forman a provincia da Bahiin, airclit ingorn cncarronados em Espirito Santo e vi:aas, raca provenience do Ostet, segundo Bapistat Cactinno, \& lute mostra vlustigios patentes de crizamerto con o homen iossil dia Lagôn Sania, descoberto pur Ldnd; Lerceiro a dos Bugres, Jocalizados entre o Uriguay o o Paxarapanens, continuaçīo evidenterente dos homers dos sambaquis.

$\hat{A}$ sate's chlementos primitivos desde logo viaram junzar-se os Portugriezcs, que comeranco em ijoo peloz dois derindados c dois descrtores que fićrian cm Porco Segiro; continuantir com os que fijaran por stia livre vmeacle ou vieram degradados cleste

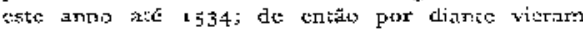
en maicre nirneto, ern mil de una vez em $\$ 349$

Nìo titrdou ritito que destes e dos raturas se 
u=i ins;

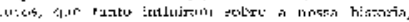

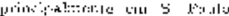

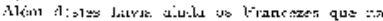

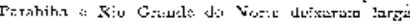

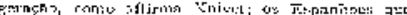

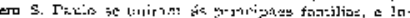

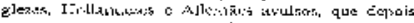

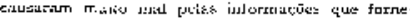

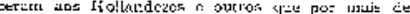

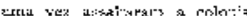

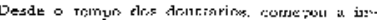

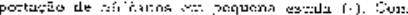

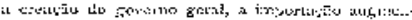
kex: $v$ tu

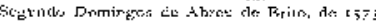
$R$ if de vions de :

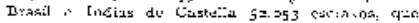

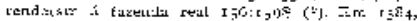

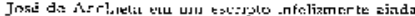

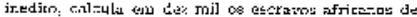

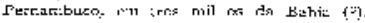

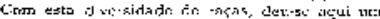

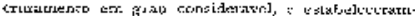

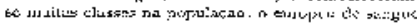

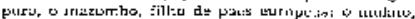

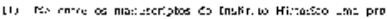

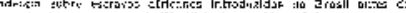

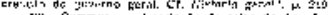

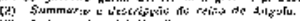

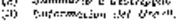

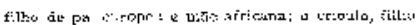

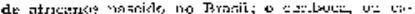

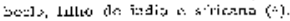

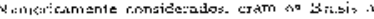

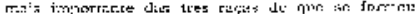

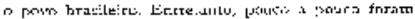

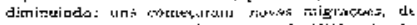

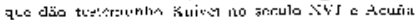

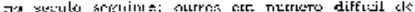

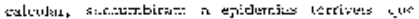

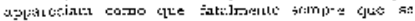
a. Nh

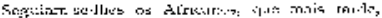

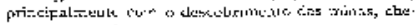

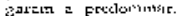

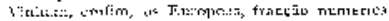
do ate

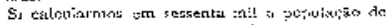

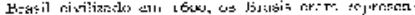

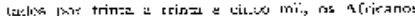

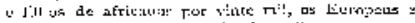

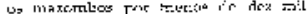

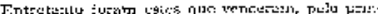

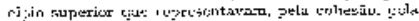

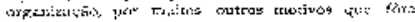

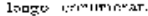

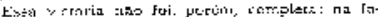

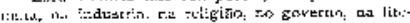

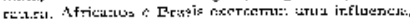

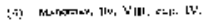




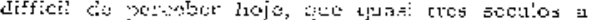

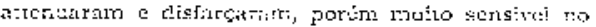
eecuio XVI.

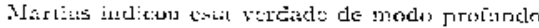
quarses dises que o somalo dis racan do Brazil t:

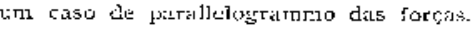

(9) stituclo actual da antirojologia brisileiris nia nos permitte dincia lirat conclusōes rígorosas sobre as cifferentess racas que acjui viviem dittes dis the-

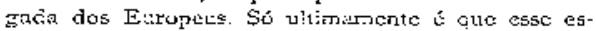

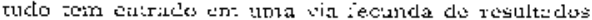
postivos; mesmo assi:m o riaterin? de que disponch

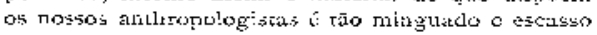

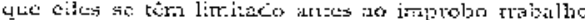

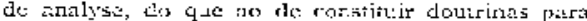

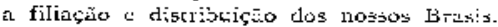

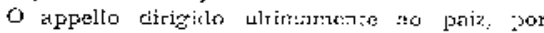

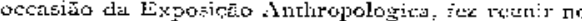

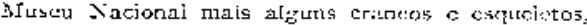

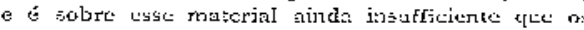

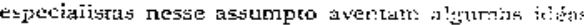
5yrtheticas, que varnos expor, sem issumit át tusponisisilidarte dellas.

$E$ assim que se seredita la existuria de jan Lypo [usij], conccmporaneo la spoca cia rerana, cujas vestigios foram coscobertos pelo siticio Lund,

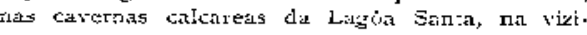

rhatega des rio $\mathrm{S}$. Wrecisco. o seu curacteristico

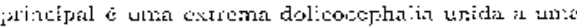

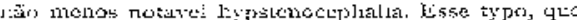
- parcere consti*uir o honen prituitiwo do besil cmח!n:o novas jesquizas paleontringiris tio demonstrárem o cortrario, atravessando os scculos proparzour-se até nós, pois cncontran-se vestigios delie no actual Botocudo.

Este, porém, já nà̃o è um zepresentantc piro: apresen:a caracleres de diffurciciação que so deve antes intribuir io cruzannterto, do gue cunsiderar como restulcado da seleç̧āo oul da acçāo do meio.

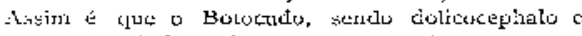
hypstenocophato, o 6 , no entanto, ravito menos que (s) Homem dá Lagoil Santid, e a diarretro vertical

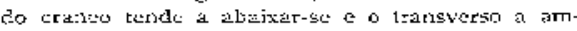
pliaj-se (i). Ouros ratacteres eraneometricos ainda

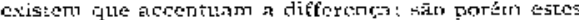

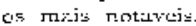

Alésn dissos, affirma o dentor Rodrigues Peixoro

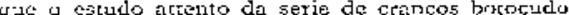
revel:; logn as observador alfei:o a estas jines:jgaçōes, que se träa ail de deis typos que tumas vezes se cruzam, outras vezes se contre!pósun \& iso latr pela lei do atavismo. Ora es o typo de Lund,

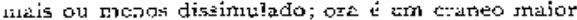
de puredes rruito espessas, de aspecto mulo rais gioseciro c caracterizado por um prognathismo aind.

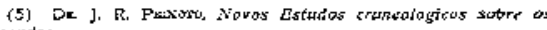
Botoctios. 


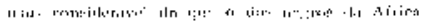

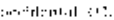

ت.4.

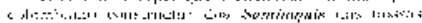

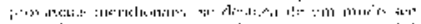

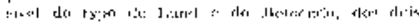

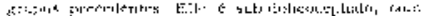

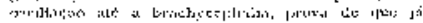

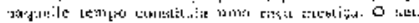
III

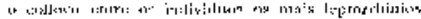

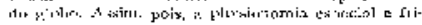

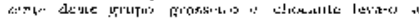

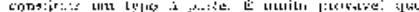

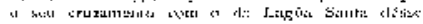

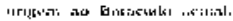

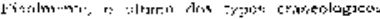

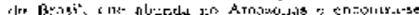

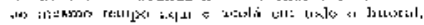

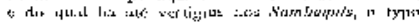

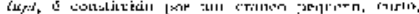

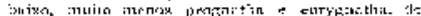
-

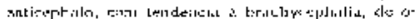

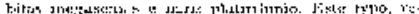
l.d:i:

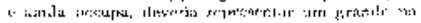

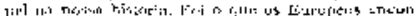

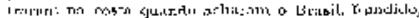
-...

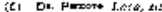

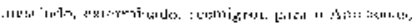

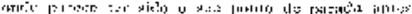

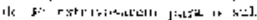

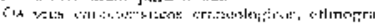

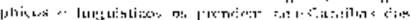

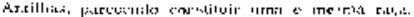

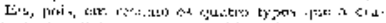

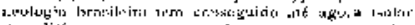

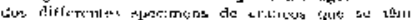

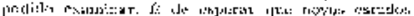

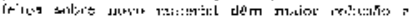

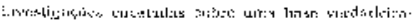
IIs

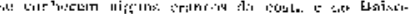

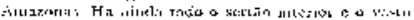

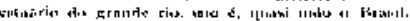




\section{A EVOLLCAO}

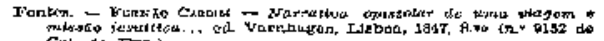
CaL dA Wixp.s.

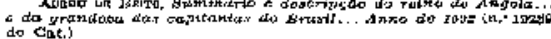

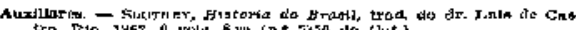

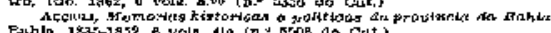

Exposto como a Brasil toi descoberto, como 50 explorou o littoral, como se devassou o sertāo, qu runo tornou o povoamento e como se consticuiu a populaç̄on, resta yer a sociedade cunal existia no firn do seculo XVI.

I'bde-se defini-la: a sociedade portuguezo mais

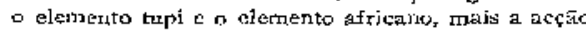
riesologica.

Qtialquer funcęào social cornparada com a fun çăo que the corrajportia na sociedisle metropoli. tana, apresentava desce logo divcrgencias que sal. tuvim á vis:a.

1. Começando pela familia, a de nozar gue os homens de orifom européa vieram primeira e an major nuzidero que as mullieres da mesna origern. 
DaJji relateres incegula:es que aindis mais fin-

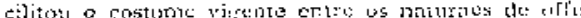
ritecereur mulineres tos Inospedes.

Mials tarde, princtialtintate desde 15,50, viliam mulheres europóts, mas dito vicum ene numero st:fficiente: a prova \& que: Sisbrega, csorcuendo pisa o Keino, asseruldida que mesmo as de vida termali encontratiant com quem casassem.

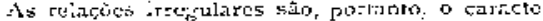

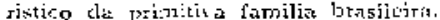

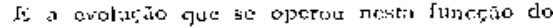

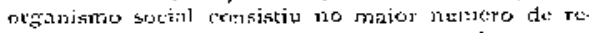

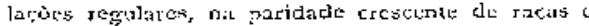
cdurate eno ente os conjuges, por constsiliste

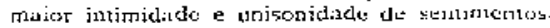

2. Na redigita temos princire pialles desinosa. lizados cytt nito se preoccupavam com, a doetrima, que cscandalizavary prelo extmplo. que vivials na SITROTizi.

A evelur,io cotisistiu na moratizaça do cicro - princ:palmemte devida nos jesuitas, 10 déscuvolvi mento do culto externo, na creactas de confrarias, an injortancia qut o clenicuto religipso comesou a excrctir sobre is vida.

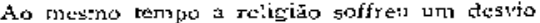
para que Aricanos e Brasis pudessem emprehendc-la e adopta.la, a parte dogmatira ficou arro pliadà. \& festas, novenas, confissöes, jejurs, discjplinamertos e penitentias eresceram de modo mormal.

a. Na industria encontramos primeiro apenas a extractiós de piub-basil, de canafistlia, a colheitir

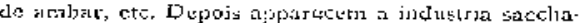
rirtit e outeas congeneres, a criajia da geteles, ecr. Na prirteiro esirgio, apenas of fornecimerbo de ab;xcriinis prinas; no segundo, o foreceimento de ma. tcrias milis ou menos claboradas.

A Noluçáo consistiu na produçáo de generos mais variados a meclida que o seculo $5 \mathrm{c}$ adiantou - foi a cvoluça cyualiantiviti na producço dos ge.

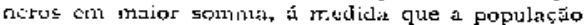
cresee, que a procura das merchlorias se tornou normal, que a ser ric:essisidate: se tornou sensivel, -. foi à seveluçito cu!tanritariva

A crolucio, alem disto, consistit: no aperfujcon. meilo dus processos empregnzos. Astim, no termpo dc Cilbricl Soares, saberse que a trandioea cra ras. pada com uma cortolit, depois feita massa numba bedra oll num talo, secedda cm tipiti, convertida cm fartirhn numa pancliz. Mais tarde apparece a faca para al raspagem, ituventa-sc a cevadeira, a prenséd \& o forto.

Fucto scmelhante se cieu no fabrico te assucar.

4. T'rimitivanente havia apenas uma profissāo - a de bristiteiro, negrociatite de: pantistasil.

Depois appareces a de pedreitos, carpinteiros, mestres de assucar.

Depois appareceram outras profissoes e outros officios.

E muitas profissôes eram ís vezes exercidas pelo mestro inclividuo. 


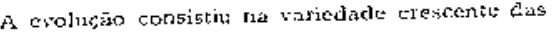
protissöes.

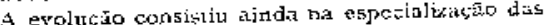
prófistótes em cacla jadividuo.

5. Os gencros primicivamente cran transportadus a hombro; os passageiros, yuando nie jam it pe. cегr tambem urarsportados a hombro, cul redes. A evoluca consistiu $\mathrm{cm}$ substituir quadrupedes aos iomens como força locomotora; em destinvol. ver o fabrico de carros, batcoj to outros meios de iransporte.

6. As vias de communicarcèo terrestre cram primejtarnente perda beiran do mar e pelas notrens dos rios.

A crolurāo consistiu tern ubrir carrinhos; cm cormos mais curtos. * mais נunncrosos.

7. No tempo dos donatarics o representante do governo era do mesmo cempo lim industrial. Nia orearizacia do governo geral airdir $5 e$ vê esta contusăo do systerna productor e reguludor, pois vie. ram como empregados publicos, pedreiros, carpin. teiros, mearcinsiros, etc.

A evolucăa consistin na esptcializıçāo progressiva do governo, ra perda de funç̧ö́s que nūo the exama proprias. Ao mesmo tempo a sua acräo tornori-se mais efficat, a sua organimasüo complicoulse.

8. Na ljecratura temos con os jestitas o auto sacro e a comcdio, jiteratura pera quem näo sabia lcr, literatura alem disso ideraficicada com a re-

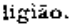

A evoluçāo consistiu na eijninagĭio do elenrectato religrioso; no apparecimento de umn fórta literaria para os que sabiam ler.

F corro estes cram poucos, a a sociedacle räo encerrava uma fonte commum de inspiractio ${ }_{i}$ uo os irmartasie, a tondencia era para ki subtileza. para o conceico, para a imitação. E o epigtamma a a rima forca e inverosimil e a copia as vezes scrví, foraus a mancira favorita.

\section{CONCLUSAO}

Frci vicente do Salvador conza a hístar:a de win bispo de Tucuman que esteve alrum tempo no Brasil.

Este biłpo viz que mandando buscar qualquer genero so riercado, roltava o eriado sem obzelo; si porkn mandava busca-lo a casas particulares, re mettiam-ro scrn naca cobrar

Verdacleiramence, disse o hispo, que nesta rcra andam as coisas trocadis, forque ella toda nāo c republica, sendo-o cada casa.

Isto, ert outros termos, ${ }^{\prime}$ a que a historia tem a dizer sobre o sejculo XVI.

Organismo de pouca matsi, de estructara ru. dimentar, em que cada orgāo represcutava mais de uma funcço, cm que naxo havia urm orgáo especial para cada funcça: faltavalithe o consensus profundo, a interdependencia fundamental, a atçâo in. corporada o que at tornara uma repoblica, na phrase đo bispo, um estado, na phrase modernat. 
No secule XIX, tсmos :

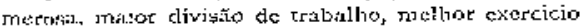
dos orgèos, funç̧⿻es mais especializadas, unia Acçín incorporadn, mais forte e mais extellsit.

O profresso a incontestavel.

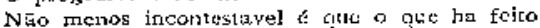
rä passa de unit jarcella do nutito gue dinda resta fazer.

\section{PROPOSIÇŌES}

Antes da occupergerio do Rio de Janciro pelos Fratsezes fouvera aqui um estabelecimento portưuez.

I'rovavelmente foi gente delle que plestou as caras de atistrear cncontraclas por pjogaffetá a Magalkies, th 1510 .

Fid no scculd XVII que: as municipalidades exprcerum tatre nós major intluencia.

An primeiras lutas entere Brasiletinos a Portufuezes tiveram um curacter numicipal pronumcite'a.

Os FIollandezes intluiram consideravelnuente para at sxploraçäo dos sertöes do Vorte.

No espirita de resistencia due ellos dispertaram está uma das crustrat das revoluçoes que houve poskeiormente en Perrambuco.

As constituicōcs ecciesiasticas formulacias por 5. Sebastišo Montciro da Vide, foram precedjdas por outras no seculo XVI

Depois de politicamente independentu de por. tugal, parte do Brasil confirtou aizda algurn rerr:po dependentc delle ecrlètiasticamente. 
Tima das causas das Iutas com os Espanhbes foram os bardeirantes.

Só no stçulo XVIII começou a haver soridaricdade entre a politica das metropoles e das suas respectivas tolonias.

O Brasil exporton escrauss antes de importa-kos.

A importaçāo de Africanos é posterior á crcação dis donatarias e antcrior á creação do governo geral.

No seculo XV11I comcçou a generalizar-se no povo brasileiro a consciencia de sua superioridade ao povo portuguez.

0 indianismo é a forma literaria desta con. sciencia.

A presença da familia real dcmorou a época da nossa indcpendencia politica.

A D. João VI deve-se a decomposiçăo quasi completa do systetna colorial.

A revoluça ria-grandense nà teve primitivamente caracter separatisti.

Estc caracter to lhe appareceu depois do com. bate de Fanfa.

\section{O DESCOBRIMENTO DO BRASIL PELOS PORTUGLEZES}



os romára ra jua origern: unxí éra nova de esperanţa c confiança alvorecia ros espiritos.

A. primcira expediçāo fizera-se em tres navios fortes. expressarrente construidos para resistir fs ondas inclementes do cabo da Boa Esperança, porém pequenos; fö:a antes viagem de reconhecintrento, tentativa de exploracăo. Agora ia una esquadra de doze navios possantes (afora um de mantimentos), preparados para a paz, levando dinheiro para fazer compras, generos diversos para instituir permuta, preparados para a guerra corth mil e dizentos a rnil e quinheztos soldados, armamentos aperfeiçoa. dos, artilharia superior a qtalgher ta cpoca. A ar. mada partia sob o signo da paz, mas levava todos os elementos para naso recuar ante a guerra.

Por capitäo-mor in Pede'alvares Cabral ou de Gouvḱ, como apparece nomeado em sua rarla de pooderes (1), filho de anigiga e illustre família, dis. tincta por servicos prestados en descobrimentos $e$ combares. Entre os capitås die navios estavam Bar. tholomeu Dias, o domador do cabo da Boa Esperança, e Nicolau Coelho, o companhciro de D. Vasco na viagem anterior; ente os passageiros: Duarte Pacheco, descobricior de terras africanas e americanas, varāo bravo e sabio; oico fcides, un

(1) A carta de poderes foi pessnda en Ligboa a 15 de Fevereiro. Por clla the eram dacos todo o intoiro poder e alcado de que podtria usar inteirstante sem dos juizos $\varepsilon$ mandados laver appella-

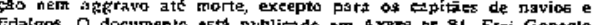
Velto, 288-785, Lisboa, IR99. delles frei Henricus ("), depois bispo de Ceuta, in quisidor que queimou en Olvença o primeito Judcu: Vaz de Caminhà, siraples escrivá de uma feitoria a eseabclecer, pcrdido anonymamente pa multidāo brilhante, Le que dipois avultou com destaque sen par. Iam pilotos da India, e os melkorcs eratâ exis terntes de Fortugal, formados na escola de Guint e do Cabo.

A 8 de Março, conclusos tocios as aprestos, houve tnissa de pontifical. Junto ao altar esteve ume bandeira da Ordem de Christo. Depois da missa prégou D. Diogo dẹ Otíz, bispo de Ceuta, exa1cando a empresa que se ia commetter, es felizes, tão nozaveis por feitos anteriores ou pelas excellencias de sua prosapia, chamados a tcalizarem a grande obra.

Durante a missa e sermão, tere El-Rei sempre a sce lado, sob a cortina, a Pedr'alvares. Consagrada a bandeira, entregoulha; confiou-lhe um barrete bento pelo Papa, e dando-lhe a ilharga acompanhou-a com toda a córte até o ponto de embarque, onde os expedicionarios the beijaram as mazos ef se despediram. Néno corria favoravel o vento: a partida

(2) Frei Henrique Lrgata toge de desembargador da casa da Supplicesajo em Lishon e edtou novico no canventa de Alemader. Foi confessor de D. Manmel, depois bispo de Ceuts e inquisidor. Sev de Ouinarāes, frei Luis de Salvador, todos quatro pregadores e ex cellenter lettados, frei Mlaftera, Sacterdose a organista, frei Pedro

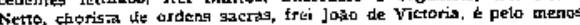
o que diz Fr. Astrokso bx Presar na Caronica do Afrabida. 
foi adjacla, o a festa popular, passitios pelo sio, toques de instrumentos, prolongaram-se o dia inteiro. A y de Março sahilu it esquadra do TRestello. ia chrmath Bclín, como aincia hoje; sinbbaklo is de oilo is nove horas, acliava.se entre as Candrizs. mais perto da Grato-Coraria, a vista della tres ou quiztr lcyuas, todo o diá em titlma; domingro 72 , avístaratn S. Nicolals, do grupo de Cabo Verde: á noite seguinte para stogurda-firn, percleu-se cla frotz a nau de Vaseo de Athayde, «sem hi haver icmoo forte ncrm contrairo pera poder ser"

O rumo föra até ahi SSW., STW. 1/4 5., 5.

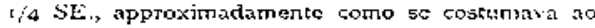
ser escripto o Esmeratdo de situ orbls Je buatr Pacheco. Do archipelago para diarte r.udou. $: D$. Valso da Gama, escreve Gaspar Corrếa, fez ton selho corr os mestres \& pilutus da navegacto que Jarian pera cncurtar o camisho, que erit rortar polo mar largo, tomando jargos os ventos do mat, sue corriam pera terra, com muito resguardo por do. brat o cabo de Boa Espcranca, e de dentro delk fossem haver vista de terra, que bern conleciarn os pilotos Mrouros de Melinde (3).

O Capitáo-mór diligenciou pela nau esgarrad a unas e outras partes, e nān a achando scguiu seu caminbo por aquelle rase de jongo (b).

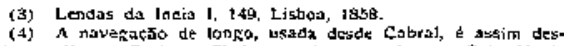
eripta por Juarte Pachoco: Todo o navio que estiver no Cabo Verde e houver de ir pera a India, si tho vento servir a seb prazer deve
A 21 de Abril, tercar.Feira de pitaras de Pas. choa, avistaram hervas compritas chamaclas botelho c rabo dasmo peios mareantes; quarta-feira, aves cismmadas furg-ibuchos ainda majs denunciaram a imminencia da terra, que apparecu neste mesmo

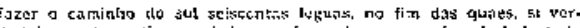

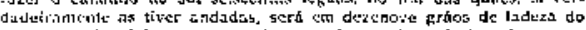

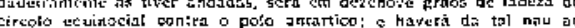

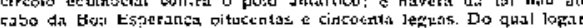

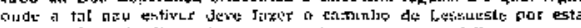

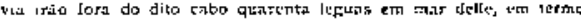

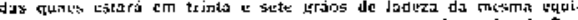

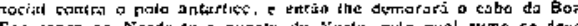
Espuranch so Nardcate a quartit de Xarte. pulo qual rumo se deve

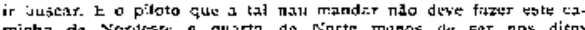
minha de Norueste a qujrta de Norte menos de Eer nos ditos

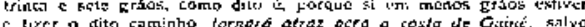

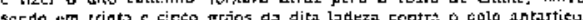

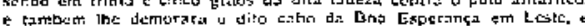
serí tanto avante como cllo Mis comb for nu logat acima dird eumpre que ticz a enminhs do Norucste da quarta de Norte e havendo vists do dito cabo correris a eosta te tomsuo, esterinho do rio do Intante [Grest Figh river, 30* 12 \$]. . E si quizarem slatgar da

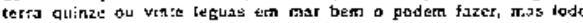

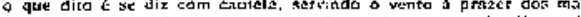

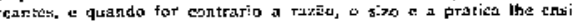
Enstá o que se deve fazer.

E na traversia desre golfom de cinboverde por diante se deve ter grande avisg e vijix de dia of Lo noitc porque nelle hat muito grasdes :roboudas que trazerth camsigo maravithasa forsa de verito c conpro que na porguc si isto nan tivesem, cousa et que pode acontecer a ratu em

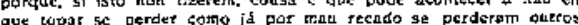
Esmeraido de sits arbis, 102/103, Listow, 1 192

As duis phrases grifadss nĩo estän assim no aripinal. Encobren

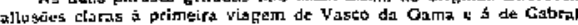


chia a horas de vesperas: primeiramente um grande monte, muito alto e redondo, depois outras rerras mais baixas ao Sul delle e terta cian com grandes arvoredos. Chariun-se Paschoal an monte, em homa das festividades correntes.

"O monte Paschoal, escreve I Iermenegildo Bar. bosa de Almeida, e un dos mais altos morros da provincia da Bahia, com bour tempo se distínguc a mais de 60 milhas distante da costa.; năo era menor de 54 milhas a distancia em que me achiva delle, demorando por $8 z \mathrm{zW}$., e represertava a con. figuraça da ilha Redonda da barra do Rio de Jancixo, solitaria no horizonte; approxinando-se mais Io mithas descobrem-se autros morros ao $5 u l$, po. rém ratis pequenos e todos separados uns dos ou. tros. $x$

A sonda accugou fundo de 25 braças. Ao 501 posto ancoraram en 19 bracas, distancia de 6 le. guas da costa. No dia seguinte approximaram-se, inclo adiante, sondando, os navios pequenos; lançaram ancora a distancia de meía legua, em dircilo á boca de um rio, hoje chamido do Frade, em lembrança de un que se afogou ao passa-lo, nos pri. meiros anmos da colonia: seriarn ro horas da ma. [1]

Dos navios lansaram os bateis e esquifes fóra e

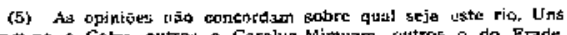

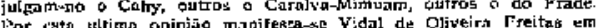
uma eredita męsmoria publicada recentemertitu ra Revisia Maritima Bressicis. vicram torlos os commandunics \& capitánea. A terra podia ser din India, e foi mondado a exartina-!a Nirolau Coclho, comprouheiro de Vasco da Gama, naturalmente com o judeu Gaspar, que sabia a Iingua arabiga $\mathrm{c}$ alguma da costa de Malabar, donde viera. Sahiram-lhe muito rijos ao encontro uns dezisito homens pardos, nus, armados de arco e flechas. A um signal de Nicolau Cocllo, depu. zeram as armas, $N$ ao poude com elles haver falas nem entendinento, yor irrebentar ruuito o mar.

Coclho dettros um barrete vermetho, uma ca rapuça de linho, que levava ma cabeça, e urr sombreiro preto, En troca, um presciteou-o con um sombreito de pennas compriclas de ive, com tumá copesinhil perpurata de pernas verriellus e pardas como de papazaio, outco som um ramal du cortinhas brancis, miudas, corno de aljaveira.

Ventoy a noite. Par bojtselto dos pilotes a nz mada levantou ancura é Fez vela ás 8 horas da ma. nhä cle sexta, 24. Tstálame juritos no rio uns sejsenta ou setenta hornens da terra: \& sabido como entre a gente inculta, onder us gencros néa circulam, a.s noticias propasam-se com incrivel rapidez. Viajou-se para o Norte, os navios pexuerros mais chegados á cerrit, os maiores seguindo de longo: tratava-se de achar alguma abrigacta f Eotxi pouso, onde jodessem tomar agua e lenha. O Capitão-mór ordinou aos navios pequenos amaisassem em achnndo pouso seguro. A dez leguas do rio deixado péla manhā cncontrou-se um artecife, com porto dentro mutito bom e muito seguro. Entraram por 
elie os mavios peruenos. Amainaram as naus no :iol posto, onra de umà Iesura do recife.

Affonsu Lopes, piloto do Caniromór, foi $\mathrm{cr}$ un sequife sondar o porto. Dali levou, já noite, Lois natecobos de bous compos que andavam poscancio en cunôta. Um trazia arco e seis ou sece fleclas. A bordo poderam os naverantes examina-los de perto: pardos, cluasi avermelhaclos, bem feitos, de bons rostos $c$ bons narizes, nús, beiços furados, trazendo inseridos ossos, cabellos corridos, tosquea Los mais alto que escovinha, rapados até acirna da orclhas. Um delles trazia atrax da fontainlra, de fonce a fonte para detraz, uma maneira de cabcllejra de pornas de ave muito bastrit a redonda, pegacia nos cabellos penna pos penna com urna fonEeccío branda conio cêra, de um covado de comprimento, que cobria o toutico e as orellials.

$A$ impressāo calrsada pelos indigernas foi maior que a por estes reccbila. Nāo fizeram mençăo de curtexia neur de falar a ninguerri; dis comidas apresentadas provistam apenas; nem vinho ncm agua thes souberam; intcressaram-ros objecsos de ouro $\varepsilon$ prate E conta5; recunheceran um papagaio c estrandiaräm uma gallinha; deitaram-se de costas em uma alcatifr para dotmir, e acommodaran-sc bern com os roxins e mantos que thes puserim por rina.

Salptaclo aj pela manbd, demandou-se a entrada muitc larga, alta de scis a sete braças de arcoragcm Eratide, formosa e segura, de capacirlack para mais de duzentos navios o naus.

Os commandantes dos navios se encaminharam parra bordo da capitanea. Con seus arcos e sctas,

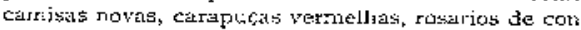
tres brancas de osso, cascaveis e campainilas, foram entr:yrics os dois indigenas a Bartholor:eu J Jias. - conluecedur la coste de Africa e Nirolau Coelho, - nuyogador da Inclie, para os levarem á terra. Apenᄀs descmbarcaratn, os dois indiescnas năo pararam nemi esperiarm un pelo outro, cacla qual corria mais; atravessaram um rio e foram a alglinas mojtas de palmas, oncic estavam outros; mais tarde vol taram, já nfis e sern carapuças.

Com Bartholomeu Dias e Nicolab Coelho desembercaratn Pero Vaz de Caminha, o perspicuo nar. raclor destes feitos, e ura degradiado. Keccberam al tocios obra de duzentos homens armados, que a um sisnal clepuzerarn as armas. Comecou-se a fazer aguaça. Do5 indigenas alguns trazjurr cheías ca. bacas, outros tomavam barris e oz enchiam. Nicolau Coetho distribuia-Ihes cascaveis e manilha.t. Permut taram-5e arcos e flechas por sombreiros, carapuças de linho e coisiss de menor valia. Ali nüo houve mais fala nem entendimento, por ninguem os en. tender nem ouvir.

Dos homens que andavam na praia quasi todos rraxiarn bicos de ossos nos bcicos t alguns tres, um no meio, duis nos cantos; outros preferiam espolhos ele pau, cono de borracha. Fistavam nis; estes metade do corpo tinham de propría côr me mtade tinto de preto, quisi azulaclu, outros pintavarn sc cm xadrez; usavam carapucas de pennas ama. rellas ou vordes. Lim, já de idade, andava toto cn- 


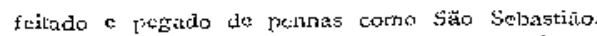

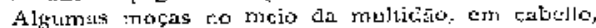
andavant igutiluejte nuas.

f tarcle sihiv o Cippitáio nor em seu batel; imitaram-no os outros capilizes; folgou-se bastantc pela bahia to longo da ptajin; desembarcaralsr em un illệa grande; brincou-sc, jescou-se; ninguem foi á tẹra, onde alís náto sa via gente.

Domingo 2巨, artrourse um csparavel na illıcta, levintou-se altar, caritou trissa frei Henrique : a missa foi de diacono e sub-diatono, informa Daminas de Gous, olficiada corr todor os frades, capellates de naus e sacerciotes que iaru ra armacta e ontras pessols que entendinu de canto. ATi assistiu o Capibăo. mór com a búncleira com que saliju de Belém, a cuial eptere sempre a parte do Evangelto. Terminada a missa, asscntol-se a gente pelid areja ofici Henrique prúcrol umar solenne o proveitosil préria. cä० cla historial to Evingelho, "c em fim della tratois da rossa virdid e lo achamerato destí terra, conformando.se com o signat da Cruz, sob cuja obsatich.

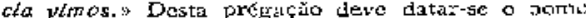
de Vera-Crux, mais tarde Santa Criz, que o Brasil teve algum tempo nos doctimeritos officiaes.

Depois da missa, passcotr-sc pela bahia, con a bandeira desfraldadis, ao lomso dis terra, por onde tstavam seus naturaes, antes de tornar para bordo. Mais tirde houve conselko do Capitấ-ruir e outros capität5; accordou.se miandar ao reino cor: a noticia o navio de mantimentos; provavelmente devia ticat a truiso caminho, corro antes ficara o cie Duarte Pa- checo na viagem de Lartholomeu Lials eo dis Bar. tholo:neu Dias na viazem ele Vraco da Gima is piloto de Cabrél newio o. conla na armada e 56 so refere a olle quando trata de sual partida para porturyal (b).

Depois do conselho foram 4 prain ver o rio, hoje jöentificsdo con o Mutäry, fibuirto usico : desaguar no mat, descle a ponka cle Santo Antonio em Santa-Crus ate o Buranhen ern Porto-Seguro. Acharam.no de muitas rtruas, debruado de palmiciras productoras de excellenus palnitos, pouco fundo, lacilmente passavel por quem năo tinha medo de molhar of jés; o Capitao-mór fez-se tomar ao colio de dois homens e passou.o. Andayam misturitios aliexigenas \& indigenas, estes scmpre esquivos, disparando a cada instante: "homem nĭo lhes oust de falar sijo por se näo esquivarerr stodo so passa crime elles querem polos bem amansar».

Contizauou o escambo de contas, arcos e flechas por sombreiros, carapuças, qualquer coisa. Diogo Dias, que os vira folganclo e dansanco uns deante dos outros sem se tomaren as nlāos, hussou um to. cador de gatin, ensinou-os a dansaren comando-se as mäos, deu depois, com grande gatudio de todos, muitas voltas saltos reaes. Um dogradado, afas" tardo.se, viu suas cașas, chouparinluas de ramos ver. des c de foto muito grandes, como as de entre Douro e Minho. Caminha notou que nâo tinham

(6) Racenifo Cotombiana, a. 3.: I, 83, Rs, Roma 1892 
senhor, rêto entendían a precninencia do Capicä́o. mob. nem disto toranvalm conhecimento.

Este dia passaclo guasì todo no convivio uncte as duas raças influiu nó inimitavel nartactro enthy siasmo pelo homem da niturezid, che cate leve aldi intuiça nitjo. Notanclo stón esquivanra, que rogava pelá ingratidio (os dois homents tío bem tra

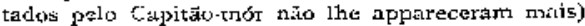
concluc: "te que tiro ser gente bestial o de pouco siber \& por isso são assi esquivos; eles, portm, cotritudo anclam muito bem curados te muila limpos,

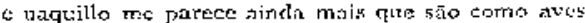
ou alimarias montezes cite lines fat o ar melloor prnna e melhox cabello que ás mansas; porquc os

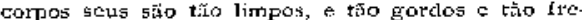
mosos que néo póde mais ser, e isto me faz prosumir que nũo tem easas nem moradas em cluc se acolham $e n$ ar a que se crian os faz taes".

Tor naram jara as naus a dormir já quasi noite. e, parcece, Fero Vaz de Caminha combcou a escrever a D. Manuel a carta que o immortatizou.

Segunda.feira z7, proseguiu o escambo, arcos flechas, carapucas de pennas, ataras vermelhas muito grandes e formosas, papazaios vercles menores, um panno de pennas de muiras chres. Viram uns ouricos de uructî semeltinr.clo castanthos, chçios de gräos pequenos de que se extrahia a tinta vermelha para pintar os corpos, ticita tanco mais vermella suunto mais se molhava. Jyiogo Dias e dois deyradados fo. ram a uma aldeia tistante lectua e rocia, e examinaram o povoado, composto de nove a daz casas palhrças iguacs em tamanio í nau capicaut:a, falhas de qualquer clivisino interna, balisacles de es reios, de esrejo a cstcio redes altas de dormír, por baiso de cada recic foge para aquecer. Em cúlia casa moravan trinta a quarenta pessioas, e tinlnotn duas portas pequeriets, utma em cacla cabo: os allitnígenas comberan das viandís dos nitujaes ta terrat carás aipin, millo, cte. Cortou-se u pau para uma cruz que se pretendia exigir.

Decidielo rnandar-Mt um emissario ao reino, desembatcaran Afforısn Lopes, piloto do capitāo-mór Fero Escolat, pilote de Sancho de Tour, mescre Jo. hasnes bacharch physico e círurgia te S. A. para tomas a altura: encontratan $17^{\circ}$ de latitude $S: l$, o que e approximadurnente exacto. Sobre longitudie não clegaram a accordo, notn ninguen se entendia cntia is tal respeito. Referisclo-se aos graus de longura, que se contam de Oeste parj. Fste c năo tóm porto fixo e firme como os pulos para os graus de ladeza, Duarte Packeco cinco ou sets annos intis carde terminava seccamene: nom curo de nisto mais falar».

Terça-feira z8, novo desembarque para lazer lenha \& lavax roupa. Cirpinteiros começaran a preparas a cruz c os indigenas tiveram pela primeira rez a visĩo da idude de ferrn, os fornteiros o da idnde de pedro. em que aquelies extavam aincla: scortam sia maecirin c palus, informa Gaminha, cotn pedras feitas como cunhos mettidas ers um pro, entre dicas talas mi bem atudas $x$.

Quarta-feira, 29, passou-se no despejo do navio 
rle martimantos a distribuipano dil cargn petos autros. Foram á terri Sancho de Toar, Diogo Dias, homent gracioso i di prezer, duis degradados. Dois cos maturaes da terma domiran a bordo do navio cie Sancho de loar, que os mardou muto bem pensar e turar; cometam toda viancla que lhes deran, dormiram em canas de Jençúes que lines nandoul faser.

Quinta-feirn, ulímo de Abril, ao desembarque do Capitso-mór estavam na praia quatrocentos a quatrocencos $c$ circoenta indigenas, raturalmente alguns cas aldeias vizinhas, até onde a noticia já alastrara com a rapidez earacteristica dos povos natu-

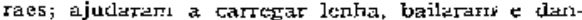
saram ao som durn taroboril; comeram e bebertam do que: Thes deram; de esquivos tornaram.se metti. diços. O Capitäo-mór \& companhoiros ajoclhados bojjaram a crus para lhes mostrar o acatanento de quo cra digna; nandararr-jles por signaes que fizessem o mesmo e obedeceram.

Caminha resurne em ponçs palavres todo o cabeđal espiritual e material desta gente, com uma

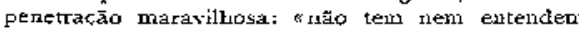
em nem uma crenç ... Elles nāo Jevram, nem criam, nem ha anui boi, nem vacca nem cabra, nem ove1ha, ncm gallinha, nem outra nem uma alinaria que costumada \$eja ao viver dos lromens; nem comen sinäo deste inhane que aqui ba milito e desta serrente e fructos, que a terra e as arvorcs de si lancam; e com isto andam taes, e tão rijos e tạo redios qile o nño 5omos nús tanto com quanto urigo e le. yumes comenos. :

Sexta-fetira, 10 de Mraio, saliu a grente com. bandeira de Christo. O Cápităo-mó indicou o loyar in cue o cruzciro दevia ser chantado. Emquanto se apromptara, foram buscar a cruz en jaixo do rip \& trouxeram-na a meneira de procissăo, com os frades e roligiosos adeante cantando: devia ser enotme, pois alguns dos indigenas metteram-so por baixo para ajudar a carreca-la. Pregadas as armas reaes, chantouste em logar bem visivel. Ao lado armou-se alrar; frei Henrique celebrou missa; houve

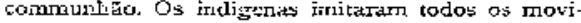
men:os Eos Porturueres.

Depois da missa, frei Hentique pregon. Era dia dos dois Apostolos Sant lago e \$t̃o Fhelippe, e todo o fermato deria volver sobre o que foram os Apostolos, a misszio a elles confiada: daceit ommes gentes, o mundo que encontraram adverso e contra eJtus nato prevaleceu, o triumphar do Jivangellho. Utn anbelo ardente de prozelytimo exhala a carta da Caminha e acalora suas ultimas phrases. $*$ Se. gundo o quc a mira e a todos parcecu, esta gerte néo lhe fallece ourra cousa pera ser toda christa que entenderenı.nos, por que assi tomavam aquilo que nos siam fazcr como nós mesmos, por oncle parêceu $a$ todos que nerr иme didolatriz лแr adoraçom tem: e bem creio que si Vossa Alteza aqui mandar qucm mais antre elles de vagar ande, que logo serāo to. dos tornados ao descjo de Vossa Alteza. E pera isso se alguem vier, nāo leixe logo de vir clerigo perr 
o5 baptisia... A intocencia detse gonce é ial que a cle Atio năo seria mais yuanka em vergonha. O:a veja vossa Altcal quen em tal junot:theia vive cosiragdo-Ihe o que pera suá salyasăo pertence, si se convertertäo ou nä́.

Depois do sermăo, frei I-Tenrique sentou-se no pé do cruzciro e começon a djsibibuir cruzes de us. teraho, resiantes das que Nicolau Cochlio levara lua primerira viagem á India. A catia indigena frei I-1er. rique Jançava a sun, atado em un fjo ao pescoso, fazendo-lha beijas e levintiar as maos. Despediclos do cruzeiro que alli ficava para attestar a passagem dos navegartes e possi da tọra tomada en noms: de el-rei de Portugal, tornararn para bordo

A ta goitc creerrancio sus epistoliz a 1). M[ñut: exprime-se assim vaz de Caminha:

* Esta terra, Senhor, me parece que da ponta que mais contra o Sul vimos ase outı pontia que contra o Norte vem, de glye rus deste ports houvemos vista, Será tamanha que luaverá nella virite ut vinte e tinco leguas per costa; traz ao longo do mar en algumas partes grantes harrciras, dellas vermcllas e drillas brancas, e a terra per cima toda cha to muiro cheia de grandes arveredos; de ponte a ponta, $t$ toda praid parma, muito chã e nujito fremosa: pelo sertăo nos parecell do mar muito grando, porque a esrender clhos nāo pudiamos ver sirio terras c arvoredoj, pue nos baresía mi longa terra. Nella act agora nāo poderios sater que ha:a ouro nem prasa, nem nem-turns collea de meral, nem de ferro, nem tho vimos; pero a terra ero si ê de nuixo bons ures, assi frios e temperndos como os de antre Douro a Mirlho, porque meste tempo de agona assi os achavamos como os de lá; aguas săo mujas, m. findas; ern tal maneira e ofraciosa que, querendo.a aproveitar, dar-sea nella tudo per bern das aguas que tem; pero o melhor fructo que nella st póde fazer the parece que será salvar esta gente, e esta deve jer a principal semente que vossa Alteza eri ella deve lancar; e gle hi nalo houvesse. mais que ler aqui esta potsada pera csta navegaçăo de Calecut abastara; giuanto nolis disposição para nella cumprir e fazer o que Vossa Alreá tanto de. sejz, a saber: acerescentamerito da nossa Santa Fe.

A 2 de Maio levantaram ancoras, a esquadra para Calecut, o mavio de mantimentos para o reino. Deseriaram dois grumetes da capitanca, talvez al gins dos outros navios. Foram deixados dois de graclidos, que ficaram chorando. 
Emquanto Pedr'alvares prosegut seu caminlyo de longo, ligeiramente vcriticrnos algumas questós conncxas a historiz do descobrimento.

Fernão Lmpes de Castankeda, Joăo de Barros - Daniăo de Góes dāo commandado por Luis Pires - navio que desgarroi 5 altura do Cabo-verde; Gas par Cotrea thatna a Pero de Firrueiro o cornmandante Nen uma das duas opiriōes serve. Caminha vinlsa na armada; em Forto-Secruro mais de uma vez foram us capitzües a bordo da capitanea onde elte ia embarcado; cotn os capitâes se achou entre outras occasioes na missa $* 26$ de Abril, celebrada no ilheo da bahia; rexr uma opinis̄o pole contrabalançar a sua affirma pãoj por conseguinte o navio desgarrado foi o de Vasco de Athayde.

Frcaminha-nos isto ś lista dos commaidantes. Os tres primeitus historiadores apresentam norncs que nâo combinan fom os to quarto. O erro inicial commum aos a uatro vicia o testemunho de todos. Até quc ponto? Impossivel decidir com os dacuknentos agora conhecidos. E nẫo se póde considerar tad 
uma estampa com trcze ravias repaoduzida na bella edicta princeps do fismeratdo de Duarte Pacheco, publicada em $\mathrm{s} 8 \mathrm{q} 2$ pelo cridito Raphael Eduardo de Azevedo Basto. fos conhecedores de historia da construç̄ōo naval golpeiarn logo os anachronismos do velame of in matreaçäb; aos conhecedores dos processos da critica historica, o nome de Luis Pires em vez de Vaseo de Athaydo revela desde logo a contaminaçāo de Castanheda, Barros e Damix̌o de Gúes. E crua rota d pag. VII1 do prologo de Ra. phael Basto confirma a conclusăo: a estampa foi irada de um livro das armadas que alcanca ate 1566; năo tem, pois, rada com Duarte Pacheco, nem com r joo: julgruemo-nos felizes si fôt exacta nà represcntarăo das naus de 1560 .

Ha anros o Inslituto Historico poz em discussão a these: si o descobrimento de nossa patrie fôra ou nāo devico a mero acaso. Lm socío concluiu pela negativa, colofou foros de extravatonte e chuverarnlhe em cima as refutaçōes. Hoje a idéa de Joaquim Norberto avassalla triumpheritemetste a maioria.

$O$ jllustre editor do Esmeraldo enountra provas da intencionalidade do acto nas seguintes palavras de Caminha escriptas a proposito do desapparecimento da nau de Vasco de Athayde: e assi seguimos nosso cominho por aste mar de longo. A estas palavras bem poderiamos oppór ourras do mesmo Ca. minha, quando adopta a idéa de Fr. Henrique de que o descobrimento foi milagre da bandeira de Belem, isto é o que se pode imaginar de mais fortuito, por ser obra, nâo da humana, mas da chi. vina vontade (1). Mas vultando ás polarras citadas pcio cracito editor: si Cabral n’’o ficon parado, si nảo inllá letre á visla, si răo eta elle so a navegar, di: ejue ourro trodo podì exprimir-se Caminha sizăo: $e$ assi seguimos nossn caminho por este mar de longor

A questāo do acaso ou nä́o acaso do descobri menco ficara mais clara formulada nos scyuintes :er. mos: si Cabral em vox das condiçōes favoravcis de veritos e correntes, comprovalas pela rapidez da viagem, cncontrasse ventos c correntes contrarios, insistiria na clerrota que o trouxe à vista do montc Paschoal? Vasco da Gama insistiur tha primeira via. gem a India; Christovam Colombo insistiu na ul tima f America. Cabral teria insistido?

A resposta nem $\&$ possivel, nem seria interes sante; e afinal do descobrimento do Brasi o acaso ou nāo acaso é apenas um lado de outra guestāo mais vasta: como entre os Portugucres de 1500 se imaginava a distribuiça das terras e dos mares? - Esmeraldo de Duarte Parheco, itlistre companheiro de Peclr'alvarcs, apresenta a este respeito indicarōes preciosas e idéas precisas, que nāo eram sós delie, mas de 'Toscanelli, de Colombo, de Ves. pucci, de todos as sabjos, antes de descoberto o oceano Facifico por Balboa, circumnacegado o globo por Magalh $\mathrm{xes}$ e seus convinuadores, e perlongada a costa occidental da Sul-Anmerica teste o est:eito de

(1) Vejam-sc as partess di carta de Cominha relativat a dom minyo 26 e duinta 30 de Abri. 
Maga:laxes até Tellimntrec por Santiatgo de Gruevara.

Sobre todos esses cspiritos exerceram extraordi. naria prossdo as setuintes palavras de Esdras, livro IV, cap. 6 :

\& No terceiro dia manclastes as aguag ajuntar na setima porte da terra, verdadeiramente as seis partes seccastes

"A augua, diz Diarte Pacheco, é posta na setima parte da terra, e as seis partcs della som descobertas pera vida da natureza humana e dos outros antmaes... O mar occano non cerca a terra cono Homero e outros aucores disserom, mas antes a terra deve cercar o mar, pois jaz dentro na sua concavidade e centro, pelo qual concudo que o mar oceand non é oukta cousa sinon uma mulico grarde alagon mettida dentro ra concavidale da terra, e a mcsma terra e o mar ambos juntamente fazem uma redoncexa cle cujo treio sahem rivicos bracos que entram pelas terras que mé̈jos terranos som chamados.

\&A terra, insisce Duarte Pacheco, tcm augua dentro ern $5 \bar{t}$, o mar non cerca a terra, como $\mathrm{H}_{0}$. mero \& outros autorcs disserom, mas antes a terra por sua grandeza tem cercactas e ineultas todalas auguas dentro na sua concavidade e centro. E além do que dito $f_{1}$ a experiencia que s madre das cousas nos desengara e de toda duvida nos tira e, portanto, bem aventurado Frincipe, (dirigia-se a $D$. Manuel) trmos sabido e visto como no tcrceiro anno do vosso reinado do anno de N, S. de 1498 , donde nos V. A. manclou clescobrir a parte or:cidental, pas. sartdo alśrt: a grandeza do mar ociaro, oncic é achada * ravegada luma tăi grande terra fime com muitas e grandes ithas adjacentes a ella jue $5 \mathrm{e}$ estencic a sarenta gráos de ladcra (?) da linha equinocial contra o pols artico e posto que seja 2ssas fora (frik?) \& grandemente povorada... *

Este trecho, do qual apparece que Duarte Prchecy acompanhou talvex os Cortcreaes, \& menos importante que o seguinte, relativo ao descobrimento da costa do Brasil, em geral da America do Sul. Faz-se aqui esta observação barlal para destaca-lo do precedente corno deve sers: unidos, tornam confusas as idéas do sabio.

«E do mesmo circulo equinocial, prosegue o auror dis Esmeratdo, torna outra vez (at torra) e vai alem em virte e oito grás o meio de lacleza contri - polo antartico e tanto se dilata sua grancleza c corre con nulita longura que de uma parte nem da outra nem foi visto nem sabido o firn \& cabo celia, pelo ‘lual, segundo a ortem que leva, é certo que vai em cercoito por toda a redondeza. a

Resuminclo: no globo terraqueo, o vceano apenas um setimo, a terra a quasi totalidade. Cabral, encontrando veatos favoraveis, podia entregar-je a elles sem receja; par todn parte enconeraria teria creastoando os mares; por toda parte estaria no caminho da India, por $5 \mathrm{~W}$ como por $\$ \mathrm{E}$. Nacla offereceria de impreyisto o slescobrimento que realizou; rada conteria de inexplicavel a insistencía, si insistencia houvesse em procurar regiōcs apparente- 
mente estranhas is regides que ia cocárresudo do buscar. Fol furlcilo ù năo d descobrimcnto? Nă E cuestīo hisiorica; dive relegar-se part is minucias ca biographía conjecturis.

Reste ingra tscudis qual o porto cxacto, o porto seguro err que pojou a armada ale Cribral.

O porto, qualquer cite seja, tem de satisfuzcr ás seguintes condiróes tiradas da carta de Caminina: Io, recite na entrada; $z^{n}$, entrada muito larga, de seis a sere brar,as de fundo; 30 , ancoragern cupaz de iuzentos navios e naus, de cinco e scis braças. $4^{\circ}$, rio de agua koca, passavel con agua pela braga, corrente ao carỉo, jito é, fronteiro e parallelo, da praia algum espaco antes de descmiocar, mas for mando depoís uma curva tāo pronunciadia que, tha quinta-feira, 30 de Abril, tendo-5e mottich pelo arvoredo o Capitāo-nibr e companheiros e encontrado um rio, não tiveram certeze si cra \& mestno da prain ( $"$ fol o capitāo com alguns de nós um pedaço por este arvoredo ate uma ribeira grande e de muita agua, qut a nos.5o parfeer exa esta mesma que ven

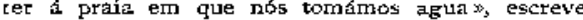
Caminha); $5^{\circ}$, ilhéo grande, cie muitz areia c cas calbo, que espraia muito a aguz e du baixa-mar fica muito vasio; $6 \sigma^{\circ}$ praia apaliada, com uma lasoa de agla docc.

Essas condiçues melhor que alhures se encontram reunidas na babia Cabralia, no ilhéo da Corôa Vernclba \& no riacho Mutary ou Itacumirim.

De estudos modernamente rcalizados por ordern do governo da Bahia póde apurat.se o seguinte:
Em 160 I $5^{\prime}$ S. abre-se lma bahia, Iirritivda . Nore pela ponta de Sarto Antorio, so Sul pela Coróa-Vermclha. Tem de comprimento $\$ 2.904$ me tros, de largura 5.556 meless. Fetcham-na a Estc cinco recifes, jormardo cinco ent-adas; excepto a mais seprentional, dăo tolis passitjeziz it navios das maiores dimensōes. Ayres din Casai, a primeiro que revelon a carte de Pero Vaz de Caminhe c poude cotcja-la com as localidades, chaniou-lisc bahia $\mathrm{Ca}$ bralia, em 1817, derominacián que term sido res. peitadil, $t \in$ a uníce a lembrar aqui o nome do descobridor: antes chamava-se encretedala de Coroar Vermelha.

Em um dos recifes da barra, sobre Lma roch calcarea de cento e tinta e cinco uncirus de com primconto, está a Corôa Vermelina, ilhota de $; 5 \times 19 \mathrm{~m}$. formada de areia grossa de côr amarella escura, sempre visivel na prea-mar.

Desde a ponta de Santo Antonio no Norte ale - rio Buranhen ao Sul, no accual Porto-šcguro, ribeira Mutary, chamado zambem Itacumirim, é o vinico a descmbocar no max. Tern largura méclia de cerca de cinco metros, corre em leito alto, no qual a agueda commodamcnte póde fazer-se, porque a accēc da mare cossa a potuca disrarcia da praia. A direçäo \& primeiramente $S W$, em suas cabecpiras, passa a Este, onde fiça o Oceano, salta depois a Sueste e corre jig metros parallelo ao mat, ao carão da praia. A foz compassa pelos quadrantes * irclinaçăo para NE ou $\$ W$. A distancia nue o separa do mar é em média de 25 metros e a ribeira con- 
stirtida de comoros de areia o cruciro chantádo pot Cabral leve ficar aurr! pequeno morro, onilo o tho Mutary bruscantate muda de direção (†).

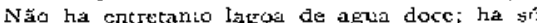
tres lagoas de agua salgada ás vezes em communi-

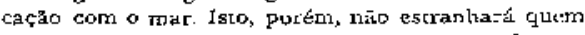
sabe rut das formas lerresteps são lagos e lagoaz as menos permanentes.

Desde que $A_{2} y=s$ do Casal a publicou cmi i $B_{7}$, a sara de Hero Vaz de Caminha tem sido considerala a base co toda a historia do descobrimen:o de P'edr'alvares, $O$ documento orifinal existe, aos que o viram nem uma suspeita acudiv quanto ai: circumstancias extinsecas: lecra e papel sậ anjlos

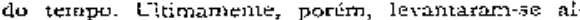
gumas duvidas a respeito de sum auterticidade. Duvidas aereas.

Si o docimento Fosse forjado, devia se-lo antes de 1508 , dada dz publicaçäo de Monrabbrére e MIa drignano, em que $\dot{e}$ natrada a viagem de Cabral por um piloto portuguees.

Si fosse forjado depois, o falsario teria pard data do descobrimento 24 e năo $2 z$ de Abril, $n$ intuito de pôr-se de accôrdo com o pilato; näڤ teria osquecído um peixe de que fala o piloto sto ta. manbo de um tonel, mas maís compricio e cotto rcdondo, a sua cabeça do feitio di de um porco, os olhos pequenos, sem dentes, com as orelhas com.

(2) Sirvajok Piazs. Eatudes sobre a bahla Cabralia a VutaCroz, Bahia, 1806 priclas, pela parte inferior do corpo inha varios butacos, e a sia raucka eria do tamanho de lim উraço; nāo cintha pón, a pelle erá da grossutúa de zrr declo, e a sua carne gorda e hrnecr comn de um porco.» $O$ unico peixe de que fala Caminia, ¿ um raodesto tubarāo.

A cartá devia ser, pois, forjada de 1 joo a $150 S$. (Lue intercsse puciia offerecer a falsificaçä́? por que attribuir a carta a vaz de Caminba, funccionario de segtrida ordem, antes ţue a um commandante de navio ou ao Canitäo-mór? 5i f por ter Caminha sido morto em Calecut, e assim nāo poder protes tar, com a mesma razāo podfam te-la subscripzo com o rome de Barholorneu Dias ou qualquer dos outros capirätes que a 24 de Maio foram trugados peio Occano inclemenue.

Um escriptor argentino, oujo nome não occorre artora, duvida da autenuicidade da carta á vista dos conhecimentos revelados a respeito dos Indios, quo năo podiam ter sido colhidos exr tha foucos dias. Näo tem razino.

A 26 de Abril resolveu-se cm conselho mandar ao reino o navio de mantimentos: só entzo Cami nha podia começar a carla, certo de ter portador. $O$ que atc ahi diz dos Indjos refere-se á nudez, ás pinturas, aos beicos perfurados, at ammas, aos acle. recos. Tudo isso exígia apenas alyumas horas de attençāo.

Segunda-feira clle falia thas casas c nas redes, potque Affonso Ribeiro e Diogo Dias foram bom uma legua \& meia a uona povoaçếo de casas, O 
riram sua förma c as rodes \& o fogo que as aquecia.

Terca-feira fala nos rechados de pedra, por intormaçào dos homens que na respera foram is cașas dos incigeras-

Quarta-feira conclue que rṹ têm animaes do. mesticos, porque lhos naxo riram; e pclo Incsino motivo concluc Fer a terra uma ilha. Attento so moto por gque se portaram, conclui:ı que näo tirthar socäo de hierarchia. nem cleviam ter qualquer culto. Note-se, porém, que os Portiguezes daquclle lemso, íaniliarizados com ins singularidades da costa d'A fizi ca já iniciados na observicăo da costa de Malabar, conhecedores dos Indios encontrados por Colorsho c Cortc-rcal, dcviam gozar de uma acuridade etir nographica rara, exactamente por que as differencas golpeavam Ingu ao primeiro ericonlro. Adnittir a falsificaçāo da carta de Caminha, $\in$ presuppór um falsario getrial, um ethnographo de primsits forç, quc descobriu os mathodos e teve a intwiçōo prophetica dos problemas que haviatr de occupar. a sciencia nos fins do seculo XIX.

A. carta de Caminha será molhor comprehendicha si inquiri-mos o motiro que a dicton. $O$ mis. sivista evidentemente conheciz el-rei de Portagal, devía até certo ponto ser admittido sntre sisus $f_{a-}$ miliares, pois de ourro modo não se occuparia de certas minuzias naturalistas e rato as extetnaria em linguagem nada castigada.

O motivo gue o levor a diritit-se a S. A. silta das ultimas linhas. Un genro seu, Jorge de Osorio, estava ¿̇gradato em 5. Thome; Caminlua escreve para pedir seu perdäo, e para dar rnais forgn ao pedido enche a carta de todas as informaçóts que, sabia, agraciariam no espirito real. «E pois que, Senhor, 6 certo que assi neste cargo quo levo, como em oura qualquer crusa que det vosso ser. viço for, Vossa Altcza ha de ser de mim muito betm servida, a ella peço que por me fazer sintsular merce mande vir da ilha de São Thomś a Jorge de Osorio meu genro, o que della rectejerci em muita merces.s

Para terminar: como se deve escrever o nome do peiz deseoberto por Cabral?

No seculo XVI nāo hntuve suridas a tal respeito: em todos os lirros impressos em Portugal, que foi posivecl examinar, escreveram invariavel. tuente Brasil. Brasil escrevia-se tambem nas outras linguas da Europa.

Em nosso seculo os amantes da cacographia, tomaram um regabofe estreverido Brazil.

Allegou-se para isto que Brasil vinta dic verzirto, norre italiano do pau-brasil, - o que é falso, porchne verzino ef gue vem te brasile ou bracir, como podera facilmente verificar quera se quizer dar a cste rabalho. Mesmo si fosse verdade, isto só fecharia a questäu para os Italianos, e os Itr. lianos : hao pouco escrapulos têm de escrever Brasile, ące Brazile t que na escrevem.

Allegou-se que Brasil vem de brasa e brasa, deve escrever-se corn $Z$. 


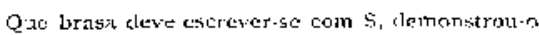

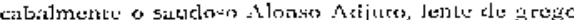
do Cymnasio Nicciunal (:); que brasa st escrevia correulemente pode ver cuem gostí the ler os li. vros nas ediçones nitrintus: "tue sú depois de ser implantiula a cacographia se comego:t a LscTuver communancute braza, 6 a gue difficilanente pacle cer:í diuvicla.

IIa quem enxerte sua carographlia no grefo brazsiza, ferver (1).

Qual a analogit entre fervura of braga? Bondo. samente responde, consultado, um illustre amigo, ctherito prolessor de physica e chimica. Alvaro Jonguim de Oliveira:

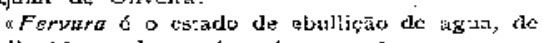
um licuido qualquer; isto $\epsilon$, o estado $\mathrm{cm}$ que 50 acha um liquido quando passa tiamultuariamente ato csiado de vapor, cotr formaço de bollhas ga. zogas na massa do liquido.

«E um phenomeno puramente physico, depen-

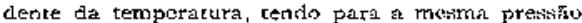
uma temperatutr constante.

"Brasa - é o carväo incandescente, isto b, rornato luminoso pelis incluecimento. Sigrilficu tambem

(9) D consciencioso Marurt șid AJi, protustor de sllemso no

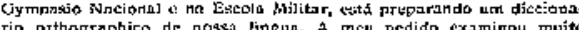

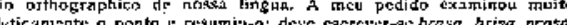
bissa.

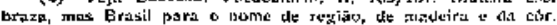

a proprio esracio cle incandescenciá \& 0.55 in que se dis - Ferro em brasa, para exprimir o estaclo do jerro acueciclo atć $5 \mathrm{c}$ tornar incunelescente.

* O phenorineno, nos casus inclícidos, É cluinice. porque o centrato a o ferro passim ao estinclo de oxydos combinando-se com o oxygenio do itr.

"Ura, que tâm de commum esses phenomenos fervura e brasu?

scienlificamente, só isto: Elles sāo manifestrposes, physica ou climica, de energia calorifica, acompanhados anbos de elevacia de temperatura, incomparavelmentr: major to segrundo do que no primeiro caso.x

Nāo $5 \overline{4} 0$ de niaior forca os argumentos his toricos.

As moedas brasileiras conservaram a graplia historica a legitima até intruduzir-5e a riçkesl, As cstanpilluas e se:los $\$ 6$ ficaram gafados $n \dot{t}$ varietur

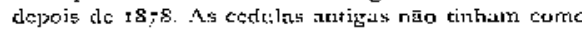
hoje cacogruphia fixa. As leis anticas geralmeste escreviam ... Rrnsil . nil ediçìo originlul, ao conrrario dis reimpresióe e das leis modernas: isto a simples arbitrio dos revisores da Imprensa $\mathrm{Na}$ rionul. Os culogratghos da Consrituicăo clc 24 de Fovereiro estāo inurnunes, graças a dois constituin its frunyanos, Leopoldo de Bulhöes e Guirnarāes Natal, cncarregados da revisāo typorraplica definixiva, c educados na escola viril de: S. Thorsé.

Nem mais fundacla é a allegaçăo de uma illa Bratl, firtirada em ruappas medicvaes.

Konrad Kretschmer encontrou-it sob in seguin- 
tes variuntes de 1 j5 I a ljos: Braxi, Bracir, Brasil, Brasill, Brazil, Brazile, Braxitle, Ererill, Briat?. Brasil, Bracili, Berith, Braxii, Braxili, Braxill, Braxyilti, Bresitge

"Já a diversidade ce numes, observa, patenter o vago do conccito cin jlha; e rinda mait o confirmás o racto de mutas das caras trezereil nāo uma só ilha dcste nome, mas ás veres tuis e á mais das rezes rres. Clrania tambem reporo nxo se icr formario um typo particliar pard esta ilha como 5 e fez para Antilia e Santanaxio: ao con trario, ora $t$ represcrada na forma de $\mathrm{tm}$ circuiv perfaitamente regular, o jue nas cartas modiewrs exprine scmipre a. aceiraça hypothetica de lura illaz; ora em forme de meia lua. Apparece taro bem como duas ilhas, separada a ilha circular por um canal no meio s djvidida em dois segrnertos semi-circulares.

* Í́ na carta de Pizigaro (1367) encontramos tree ilhas Bratir, e desce entäo podemos observar a triplice inserçino dellas tamiem na maioria das cartas maritimas. A posição das mesmas ef regrulatmente a seguinte: a miais meridional das ilhas encontramos assignaleda no grupo dos Açotes, approximadamerte ra laritude do cabo de $5 \bar{a} 0 \mathrm{Vi}$ cente; a segunda demora a $\backslash \mathrm{IV}$, do cabo de Fi. nisterra, na latitude ca Bretanha; a terceiva a br e nāo rtuito Iorge da costa da Irlanda (s):

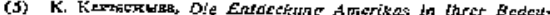
fing futer dic Oasshichte des Welfoildes, 214/221. Berlin, 1802
No bcllo liva do mesmo autor púcle scruir-so a. historis da ilha, cuja exisiencia foi primeiramente nosita em duvida no Atlas de Jeffery cm $177^{6}$ Della restam a monis do Brasil, jimto á cidadr de Angra. na Itha Terceira, e Brasil Fock, báxio pelas cartas do ìmirantado ingler figurado seis staiss a W. da ponta meridional da Irlanda. Relaçōes entre a ilha, una, dupla ot criplice et a terra do Brasil \& o que nāo je logrará provar.

Desta longa excursăo póde, pois, concluir-se que Brasil t a verdadcira srapbia para quem comsultar os doclincutos originaes e attender aos factos bistoricos e acatar o tgecio da jingrua. Oș que nada disto levam $\boldsymbol{a}$ conta contiruaráa a escrever a sel arbitrio.

E' o caso de imitar S. Raulo, dizendo:

Oportet et eacographos esse. 
DLAS CORRENTES HISTORICAS

$A=$ de Maio, Pedralvarcs Cajral levantou ancora e foi beirando a costa, espaco dc duas mil mijhas (1), isto ó, quinhentas leguas, além de porto Seguro, sem clicgar a ver-ihe firn «pelo que, segundo a ordern que a terra leva, - poderia dizer, nis phrase de Duarte Pachço, - E certo que vai em cercuita por toda a redondeza i. Do ponto extrestru alcançado, que nào existem meios de determinar, fez rumo de SE., para o cabo da Boa Esperança. Subico, illuminou o céo muivas noites urn comela admiravel de longa cauda; succedeu-lhe um butcảo (\&) que tudo enlutou, rebentou uma ternpes. rade que dispcrsen a frota, subverteu quatro navios (o de Bartholomeu Dias, entre outros), extravion um, e reduziu a seis a or 今ulbosa esquadra.

Com ellcs proseguiu Cabral no seu caminho por aquelle mar de longo. De Muçambique,

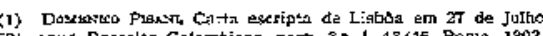
de 150l, apud Raceotta Cotombina, parte S.; I, 4S/45, Roma, 1892 (2) Vid. as. 142-: 43 , nota 4 refereneir du site bulefo. 
primeiro ponto da Africa, cm que tocon, fol por Kilwa, Melinde e Anjediras a Calccut, onde cluegru a 13 de Setermbro. Receber.o bem o Sa. morim, deu-lhe licença para estabelçer feitoria $\&$ carregar as naus. Tudo, porém, näo passau dè pa. lavras. Os mercalores e:abs: arravessavam-se a quaesquer transacçōes, no intuito de deter os occidentaes até chefarem 3.5 poderosas naus do mar Vermcino, que esmagariam no sascedouro ester ton currentes temiveis; ao nesmo tempo espalhavam mil historizs e calumnias, envenenatam o cspirito da multidāo. Resultado: o angue da feitoría, em i6 de Lezembro, com a morte de trinza e ferimento de vinte portug 10zes. Entre os feridos contava-se frei Henrique; entre os morros certamente Caminha, escrivăo da feitoria.

Cabral nào obteve ren una explicação, nerm uma satisfncta do Samorim, Tomou-as pelas proprias māos. Dez nexios arabes fundeados apprehendeu, despo:ou, queinou; dois dias a fio born bardicou Calecur. Depois em Cochirn e Cananor, a convice dos respectivos Rajahs, ebarrotou as naus de carga. A 16 de Janeiro de 5 50 1 partiu de Cananor, em viagern de volta. Proximo a Mielinde det nuns baixos a neu de Sancbo de Toar c foi incendiada; a artilharja aproveitou un regulo africano, e scriu depois contra seus antigos donos.

Dobrou o cabo di Bon Esperanga em Paschoa Florida, I9 de Abrii. Tomoli cabo Verde; ern Bezcguiche encontrou urna squadrilha de rres navios, mandada a explorar a terra descoherta por elle
Em um dos navios estave Amerigo Vespucci, flo rectino, a principio mercador, depois, inipetlido pelo enthusiasmo dos descob-imentos, nếcgảdot e cosinographo.

Viem un ponto do globo reunia tantos cunhecimentos das terras occidentaes como aquelle ob seuro porto africano reste encontro. Os Portuguezes, nos dias que as frotas fraternizaram, podiam informar Itesle $70^{\circ}$ (引) cie latitude Norte Eobre as regives frias, povoitdas, incadas de ilhas, prolongándose para o Cancer. Os Tspanhoes, represertados em Vispucci, formado $\mathrm{cm}$ sua escola, podiam corLar descle o cabo do Santa Maria de la Consolacion

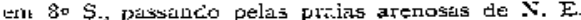
até um rio sern par, capaz de adocar as aguis aceanicas, seguindo a corrar a Equinocial por cos tas alagacas, cobertas de mangues, e defrontando ilhas, ithos, ilhas $5 \mathrm{~cm}$ tonta até o firn das rerras tropicaes. Cuba seria uma ilha? Colomio fize:a juratla continence, sob graves castiugos, mas quem. sabe' Aa Norte de Portio Seguro, infomaram rovamente os Portuguczes, iá instruidos pelo emissarin que Pedralvarcs mandara ao reino com a noticia do descuberı, extendia-se a cosea, arenosa aqui, malhada alem de barrciras vermelhas, até o cabo de Santa Niaria de la Consolacion. Ao Sul de Porto Seguro, rematava Cabral, insurgiam-se costas aitas roçagantes de verdura, recortando caprichosas, banharicio-se no mar; duas m:1 milbas nāo exgotavam a varisdade de suas formas e di riquexa de sens perfis. 


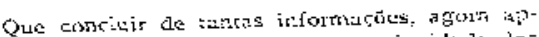

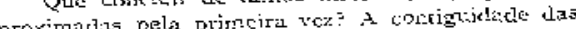
proxinathe pela puintas de terra terras Arcticas, das Antithas esponholas, da terra dos Payagaios - aseim quizartstr primeixo chamar a cue finalmente se chama Brasí. Esta idúa í́ cra vulgar ent lisbor, por Outubro, e Flumaboidt con-

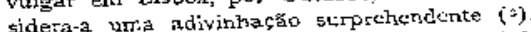

E para Oeste destas regióes que haveria? Terras, sempre icrias, a conjplemento dos scis serinos de Esclas. De que ostro mork podcria cxplicar-se a formaça de rios tăr possantej cono o ghis des a formacas di jomador, cono o rjo de sajgasa o mar Eolombo julgon vizinlue o paraiso cijas mard

Achovar.5c en frente dois homens, цाт цие dovia fur o nome a este mesmo costistencte, de po

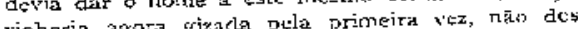
riphcria agora gizara pula primeira ve mas do cobertu por cile; outro commandare da mo po

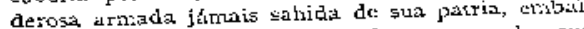
vador de um rei, sethor de $\quad$ ida c morts cle sct:s subordiris descostidor de uma terre que scculos suborcinaris, decobrido do memoria. Encarro passuli esçjecida ce acatar star meno vam anbos duas cortenies historicas diversas, clue agora tratirentos de circurnscrever a breves linhas.

Os Porturaezes, sitpples pcscalores at o scculo Portuge a constituir marinha mercante no

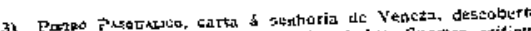
por Leopoldo van Rinrke, noticiacs pot Humboldt, Exarten criteque

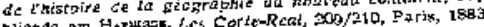

sttculo XIV, iendo por mestrcs Genavczes, o grande povo hivegridor do near Tyreheno. A marinha cres

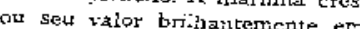
14r3, nat tomada c'e Coute sob o reinado Joāo $\llbracket$. Sel tilho, 0 infante D. intuiçäo de que futuro da patrie thestiqce, teve a e com o prestigio lue la patris eatava nos maxes, e com o prestigio que the dava a gerarthin, com os recursos abuadentes da ordern de Chisto de set mestrado, para o oceano desconhecido volvęa codas as cuidacoes.

Em 1420 foram descoberas, ou antes redesco berias as ilhas da Madcira e Purto Santo, _. ta difticil era enća un como outro

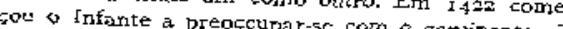
ziriha; oncle tôra tingis suas esporas de tavaliciro no sangue maldito dos creires de Islào, os inimizos leteditarios la Christanchide -itc onde alostrava scirz ralvada de Mafoma? alern da testoda lito ragen hav'eris povos nāo contayiados allind siveis contra ctles? até onde aleanga alling teras? crà habicavel aonallas enxameavam; habicavel a zona tortida? Os problemas enxameavan; o vano de 2422 marca o principio da lusit contra elies.

Boze armos passaram estereis; mas em 1434 Gil Eantes dobrola a cabo Bojador (4) e ficiloul

(4) Estc cabo do Bojador é reuito perjgoeo por carss de uma maito grapde restirfya de pedra qite delte sae $\Delta 0$ mar mais de quatto

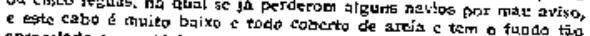

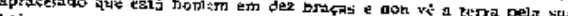
aixeza, e a costa que vert do cabo de Niam pera o Bujador cod 


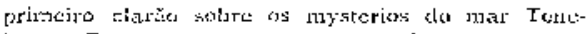

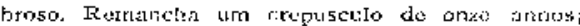

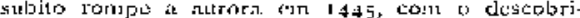

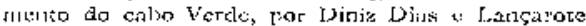

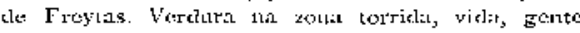

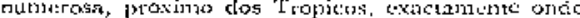

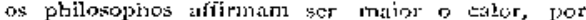
nenor o prasto entete a passagem do sol du Vorte para o lienispherio Sul? Jntäro os antigos podem terretr? ha coisnt: a elles jrnotasj o cyclo slo subcr tio ustá fechnclo at 5c1c sollos? loc'as estas sensa. cöes nowas e rejuvenesccness vil)ratm radorivelmente furrogantes nas po giras de Diogo Gones c Duarte ]'aciucco.

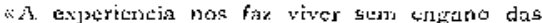
aloustose $\mathrm{c}$ findulat que alguns dos indigos cosmo

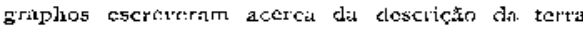
c do mar, os quass disseroth que toda a lorra que jaz debrixo clo circulo da erfuinocial tra injabitayel

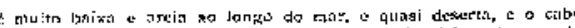

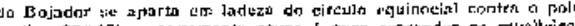

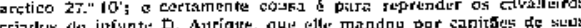

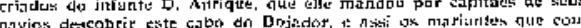
naves descabre

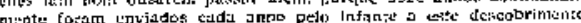

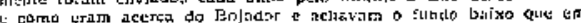

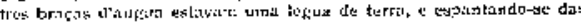

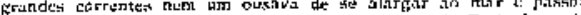

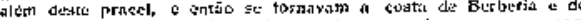

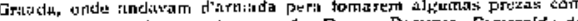

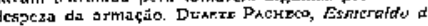
sifu arbls, $38 / 39$ pols Frande ytucntura do sol c isted arbarizes (stiso o pelo contrariu po:que aclisusts do rio co Guabons.. a ichario um protantorto baxo a delgaclo a quc cri liessir lingua o cajo kle Lopo Gorterlves chi. mamas... e este cetro de Lopa Constalves ponturi-

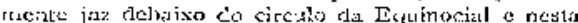

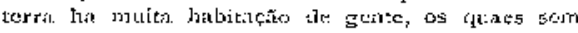

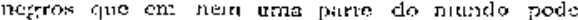
mais hraver.

z.... Eu diro que, com citamo elles (escripto.

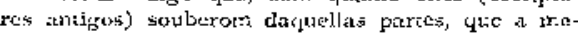

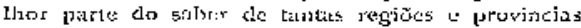
ficou pura rós a nos lho levanius a virgindactr: peorque em tnato o trajersell da Ethierpin, de Cuin:

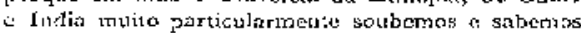

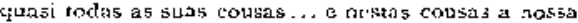

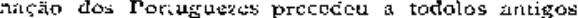
1: moclernos em canta cantidacle que sern reppresta podemos discr salue elles en nosso respeito nom souberom nitdá (")

Antes do cabo Vercle, um grando rio, o Seneg:al, evidentemerite urn bribço do Nijo (b), refira as jdsis informes do Infanle: si púds cloegar-se no

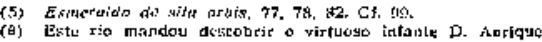

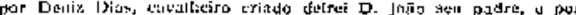
Lançarote de Freytos, sina covialheiros e capitales, 4 quando este rio

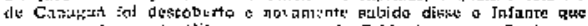

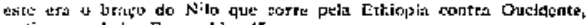
et clisset verdade. Estreraldio, 45. 
Nilo por este braço, póde chegar-se ao Egypto pcio Nilo, e podo eluegar-se á India pelo Egypro.

1 India. desde a victoria do hellenismo, exprerlia seus productos peregrinos e preciusos aos povos do Mediterraneo, pelo golfo Arabico e Nilo, pelo golfo Fersico $t$ Euphrates-Tigre. As chaves deste commercio, o mais importante da época, andaram pelas ruäos dos Seleucidas e dos Lagidas, duas dymastias hellenicas do Egypro e da Syria, ato apossarem-se dellas os Romanos que rudo absorveram e abarcaram. Com a divisa do impcrio Iotnano, passaram ao imperio grego: a appariçảo do IsIāo desencadeou entre Christāos e Samacenos luta continua e trơnenda, não acirrada menos pelo insaciarel da avidez e dos intercssea ţue pelo inconcilizuel dos dogmas e ritos.

As cruzadas simularan trítmpho passageiro di Christandade, mias o Crescerite venceu; o Egypto organizou-sc puiante, conquigton a Syria: Venezin nos, Genovezes, Gatalāes tinham de curvarise a todas as suas exigencias, c o Egypto tornou-se o po der rrais terrivel do terppo. Channar a si a commercio rla India era santarar de norte o Islāo; conduzir esta nova cruzada fundia todas as aspiraçes christäs do Infante com seus instinctos mercantis.

Pelo Senegal nāo se thegou ao Nílo, mas di expediçōes exploradoras nẩo foram sustadas. Ao monrer, em 1460 , D. Fenrigue deixou revelada a Africa até a serra Leỏa; no reinado de D. Affonso $\checkmark$ cruzou-se o Equador para o 5 ul; ao esforço de $D$. Joāo II foi depois cortado o tropico antarctico. Em
1487, Bartholomet Dias trouxe a nown de ter ai. cançado o exuremo do contírente $c$ ter visto alúm - Iiro arrumar-se para Norte e Nordeste. Lin cabo eritāo descoberto, Bartholomeu Dias baptisou Tor. meatoso, D. Joūo II chrismou da Loa Esperança.

\& V'on sem muita razão si poz nome a este promontorio cabo da Boz Esperança porque Bartholomcu Dias, que o descobrio por mandado de el-rei D. Joăo... vendo que esta costa e ribeira do mar voltava dali em diante ao Norte to Nordesce, cuja rota fazia caminho da Ethiopia sob Egypto te dali pera o sino arabico, onde sc mostrava e se esperava haver-se de descobrir a India, por esta causa the poz nome cabo de Boa Esperança (').

O descobrimento do caminho naritimo da India pediu, porém, mais tempo: só em 1497 foi man. dado Vasco da Gama a tenta-lo, e chegara en i499 decsempenhando estrondosamente a commissăo. Cabral voltava agora de reperi-la. No meiu da via. gem, seduzido pelos feitiços do céo e pelos afagos do venţo, dera ern terras por que nāo esperava. Até ali deitara a primeira corrente.

A segunda corrente historica virha tambem de lorige.

Desde a antiguidade classica consideravase uri só os mases que rodeavarn a terra habitada, a Oikumene; iulgava-se pequena a distancia maritima entre a. Europa occidental e a Astia oricntal, e esice es. paço pequeno encurava-se ainda mais inserindo

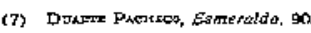




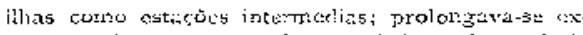

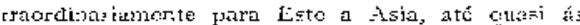
rostals da California cin nibsils cirtas atluacs.

Seres clamavara aos moradores do exitemn Oriente, productores de und esiofo procioso, a sede, que por camizlos desiairacios chegata tis gcntes

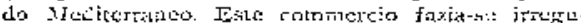
latmente por intermediarios muitiplos, atraviz co montanl:as e desertos, no theis de romacks rvido. e insabmissos. Conera os nomades dis Norre, os

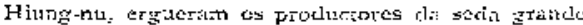
muralha, una das marilhas do mindo, remata dar ha mais de clois mil andus; contra os nomades do

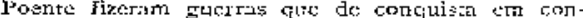
quista os leveram ás marógene lo dago Casjo. Clee. gavan ao mesmo teripo as conquistas rotanata is Mesoporamia: um instirte cncraram ens concacto os portadores da civilizacâo do cxicrno Orientc e do extremo Octjdentet, $t$ o commercio se regularizol. Ptolemen transmittiv.nos o ininerario de tin nucreador macedonio que foj á Scra mecropolis.

Os acontecimentos di Europa obrigaram os Ro. manos a recirar-se da Asia; os Seres tiveram de abrigar-se por craz de suas trinthas; conquistaramnos os Khicai, tribel dos Hiurerenu o a terra ficsu chamandose Cathayo, nome ninda hoje err.pregado na Russía para desigra-la

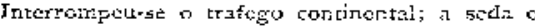
congencres só alcalsaram of Occidente por via mn. rítima, en navios grogos, axibss, clyinezes. Por via maritirna propagou.se nambem o :10me Sina ou
Thina, donce procede Chisa. $O$ primeiro a demort sirar a identidade de Chinla e Cathayo (A) foi urn jesuita forruguez, Tsonto da Góes, dit principios ths EGED:O XVIY

No secula xitI os Monzócs fusdaram un irir. perio qee conquistou Cathavo e pela Europa alastrou ate o Vistula. A tanidals do dominio em tāo vasta cxtenstu facilitou as viagens de lim a cutro extrcmo; a politica tolerance dos Kaans tartaros faroreceu-is, o ineercjic cornmercial, o descjo de ver rovas terras miugaram-rzis. Dos vinjartes o mais notavel, Marco Polo, Veneco, ditou um livro narra tivo de suas perecrivicöcs, das culturas e opulencij dagueilas gentu, de Cathayo e Cypanio, que $5 c$ cspatbor rapido e foi eradtuzido en todas as lin guas da Europa. Peşolotti escreveu um jrinerario para quicr. quizesse it do Don a Pekim. Este trito cessou bruscamente com a quédia da dynastia dos Dgentghís-Kanidas.

«Desde a antiguidade ate a śra moderna - e5creve o genial Peschel -, o commercio asiacico pro. moveu uma corente de metaes preciosos do Pocrite para o Nascente. As terras oriencaes offereciam ás do Occidente magnificos productos natriace; espe ciarias, incenso, drogas, madeiras de luxo, perolas e pcdras preciosas, scm que entre os habitantes dos tropicos st exterrasse țualçucr cobica mais viva

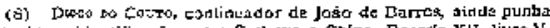

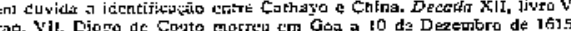


pelos artefirtons da Eurapt. Asoinz fuchado o balanço ficava sempre o Decidente un debito, obri. gaclu a remessist incessantes cle nisro e prata jara a. India, remessa linto zlais pesacla quanto os ge neros orientaes, fraças aos fretes elevadog, fo ven das $e$ revendas irtultiplas, sraças, sobrctido, aos «lircitos elevados pagos no Egypto, encareciam ex. traordinariamtnte: em Alexandrid as especiarias da India pagaram se a triplo de Calecut, 0 irictisto o quintuplo do preço corrente em Mekka. Esten percalços conmerciaes eram bem conhecidos no Decidente, e tăo pouco faltsva a comprehensāo de que em trato imriediato as boas cousas do Oriente pot pouco se grangeariani.

"A somma consideravel que nestas condiçoses passava annualmente da Europa 5 Alexandria, 56 em parte muito pectucra podia ser reparada pela תituração indigena dos seculos $X I V$ e XV, a assim, anno por anno ern hosso continente o stock monetario ja baixżndo aiśm do nivel clos stacelos ante. riores. O sugamento de metacs preciosos na Juropa annuncia-se no sectulo XV pela rapicla desvalorização de todos os generos indigenas levados as friras iu expostos no mercado, de modo que a necessiclade de Jigaçes directas com o Oriente foi nvuitandn cada anno, e a invencáo de novos ciminlos para ali tormou-se probleme mercantil, cuja soluçio nä́ admiccia inais delongas" ( $\%$ ).

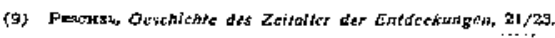

A jrimeira tentativa de achar nowos caminlos para o Orientc apparece en Genova corr Tedisio d'Oria, Guielo es fHurutino de Vivaldi, cm r 291 . Pastan-se terapps $\mathrm{sen}$ noticia de outras, até os Yor:uguezes entrartm sm campo, a partir de 1420.

No reinacto de $D$, Affonso $V$ debateu-se si, muito mais conveniente que andar tncteando pela costa africanil, acaso náo seria cortar de longo pelo goltăo a Cathay. Duarte Pacheco explica-nos o motivo de năo ser preferido este plano, de cujos fundamentos e efficacia ajias ninguem cluviduva.

Ouçamos ainda mais uma vez o actor do Esmeraldo: "muitas opiniōes houve nestes Reinos de Portugal nos tempos passados antre almuns let1rados acerca do descobrimento das Ethiopias, the Guiné e das lrdias, porqure uns diziam que nom cidrasem de descobrir ao lungo da costa do mar, e que: melhor seria irem pelo pego, altavessalido o golfaxo ate topar em alguma terra da India ou vizinhı della e por esta vìa se encurtaria o caminho; outros disstrom que melhor seria descobrit an longo clin terra, sabenclo pouco e pouco o que nelle ia, e assi unas rotas e comheccricas, e cada provingia de: Tue gente era pera verdadeiramente saberem o lugar em que estavam, pur onde podiam ser cerros da terra que iam buscar, porque de: outra guise rom podiam saber a regiaio em chle estavam.

Assi entre $A$ procura da India no longo da costa, e a procura pelo golfāo de longo, decídirann 


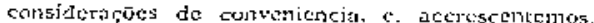

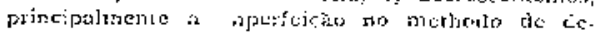

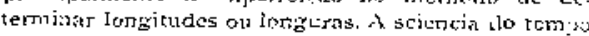
era untes it fryor da navegaca do longo, e descle a antiguidade se reputiva empresa facil csta, por urn mesron nar julgarse o glie laanlia a Earroja e a Africa a Ouste é A Asta a Eses. Ao contratio no caminto escolluido ao longo da costa, os lior. tuguezes tropcravam na idéa de piulemen: qute cx. tendia a Africa ate o polo antarcico para iferroldar bem o mar das Inclias, trojeçovian na doutrina das zonas, venerando legado da scicaria zitigid, tjus pro.

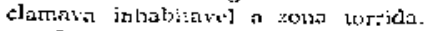

O genover. Christovam Colomba, corvereido das varztagers da travessiil vircetia \& desencanado rlo chcontrar apoio em Porligal, yasson á Esparha E soube galuhar á sua causa prorectores poderosos.

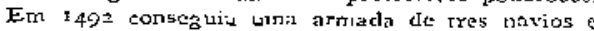
fazendo rums de Oeste chegou a ilhas, - terras de Cathay, ilhas de Cepango - acreditou ars morter. Em 1493 , tee nova viagem, ma1s as Sul qule a pri. neira, outra em 1498 ainda majs ao $S u$ o oue a segunda, e discobriu o continente \& o Orenoco, e o paraiso terrestre, e u ponto mais elevado da terra, nẵo esjłłera, como até alj se roputära, mas uma pära.

Depois da terceira vinacri de Coiombo a cotú espanhola deu lícenca a farticularis para losco. brit terras, e, caso notayel, Nino, Bastidas, I-Iojeda, Pinzon, Diego de Lepe, procuratam todos o Su': - rabo de Santo Amostinlso marcaval o ponto de parzida dos descobrirsentos meridionacs dos espa nhóes no anno de ror.

- Vas praticas de Cabral e Vespucci occorria da turalmente a interrugaça: onde tertrina o conti nente ao Sul a a Oeste? Clicgar as rerras do Sul procuravam os Portuguces por meto daquella mesma armada de tres navius cue estava pojada $\mathrm{cm}$ Beze. guiche. No anno de 1505 já sabiam que o finis terra demorava além do $2801 /$. . En 1513.1514 uma 2 . mada de D. Nurlo Manuel, que deseobriu a rio da Prata, jalgou encontra-lo nas tertas das pelles aos 40". Em 1520 crcontrou-o effectivamente Magalhāes alcm dos 50", no estreito que Ieva seu nome. Aiuda vivia Cubral, já nāo se contava cntre os vivos Ancerigo Vespuccì.

Do veo yue encobria o continente a Oeste le vanto: a ponta Vasco Nutres de Halboa, quandn on 1513 descobríl o mar do Sul, o nccano Paci. fico. Em 1526 Santiago de liuevara, companheiro de frei Garcia de Loaisa, atravessou $a$ estrcito de Magalhăes, e desde stia boca occidental foi do longa a Tchuantepec: verificouse entran que a continente năo se extandia pata o Occidente tanto quanto se tesperava.

Continente que näo era nem Furopa, nem Asia, them Africa devia sambetn ter nome differente. Obscuro geographo allemâ, estabelecido etrn recanto escondiclo do Wasgau, propoz denominarem-no Ametica on Amerifse, porque Amerigo Vespucei o des. cobrira, o que $e$ falso, c porque este nome scria 
feminino, como os de Eutopa, Asia, o que $E$ galante $(10)$.

Falsidade e galatteria favoneou a imprensa, a propagoun-as \& perpetuou-as. Por força dellas, temos o nome de Americanos.

O DESCOBRIMENTO DO BRASIL FovoAMENTO DO SOLO - EVOLUÇAO SUCIAL.

(10) Tatvez a interpretscho dada acimid hata seja de todo exalcta. Tutvey o pensarmento methor firasse. Ceclarado Asid e Africs, trey partes do mundo, têm homta de mulhtorses; vatnos

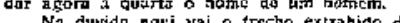

Na davida aqui vai o trcerio extratido do exemplar da Bjbliohesa Nacional:

Nene vero et hec parites sunt lasius lustrate d alia quarta pars

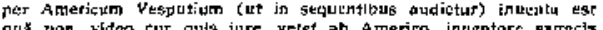
qus non video cur qujs jure vetet as Americo inuentore sagrejs

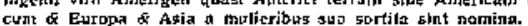




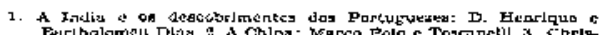

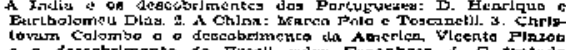

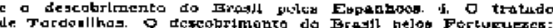

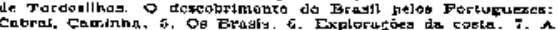
eerra descoberte.

1. Seu nome deve a nossa patria a ил pau,

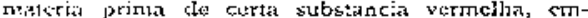
pretgata nas tinturarias meclievaes e modernas, hoje substituida peless derivados da aniitinat e prodinsica artificialmente nu laboratorios. Dave na Driente clo rellues emulo; com a satuclalo, o ebano \& restias madeiras, periumes e especiarias, marfin c pedras preciosá, entrava no trato que, desde Eras apertadas, mais ou menos ligava an rumpou a extrenio continette asiatico.

Dentre os palces tormecedores destre gencras sobresabia a Irdia. Já os livros mosaicos falan de Chavilaz, rerra da stgodảo, do lapis-laxuli c la nuro: as frotas de Saloma traziatr de Ophir macacose partosi umi rainls de Babylonja extendeu ar 0 Indo suas excursōes guxtrciras; algumas daquellas regiós cncotpotol a scis domirios Dario, rei da Pcrsi..; vencaclor da morarchia jersa, o grande Alexandre guerecou ctr Pendjab e conquistando desceu o Indo aré a foz. Por sua ordẹtr, Nearcho entre 
o delta do Ineles c: O Euphratcis ratugen to mpio To:s a rosta.

Antes de Alexanriri, algum rommercio teral feito en navios dos Hirdús, cuja remotá assistencia $\mathrm{cm}$ Socotorá e no Yemen cstá demonstradá a guasi totalidade dos generos transitava, por $k m$, por via terrestre, passindo de maso, constamindo ás vezes no percurso mezes $r$ annos. $A$ expediç⿰丿㇅口二 vicroriosa de Alexandre deu vida ás cmprosas metcantis, abriu-lhes duas portas: a do golfo Persico, Euphtates e Syria, nos territorios em que Selcuco posteríor mente fundou seu imperio; a do Golfo Arabico Nilo e Efypto, quota de Ptolemeu na partilha do mundo.

0 reino do Seleuco, primitin amente a major, pouco tempo eDnservou-se unicho; agitudo por guer ras nas fronceiras, talado ou intadioo por vizinhos main ou renos batbaros, minado intemamente por forcas centrifugas incoerciveis, nāo porde colher to dos os proveitos de sua situaçio gentraphica. Cou beram esres ao reino dos Lacidas, cuja politica previdente os jnspirou thà execuçso de um canal sntre - NiIn e o mar Vermelho, ma fundaça de cidades em sua margem occidental, lizadas por cstradax rommodas as trecho naveravel daquelle.

O commercio com o Oriente orcava por centenas de milhares de sestercios nas primciras de cadas do imperio rorrano, quando Flippalo, piloto hellenico do Egypto, descobriv as monçōes, e compassando a sahida e a chegada dos navios pelos movimentos atmosphericos, tornou mais breves porrinto mis frequemies as vingens, at unläo desespertdoramente longas. Desde logo os navegantes passaram além da costa de Malabar, de Ceylắo, 20 golfo de Ber:géla, á Inconesia. Gregos forkm por mar ate a China, denominação trazida do Oriente por via maritima, como a de Cathay, dista hoje vigente na Russia, veio por via terrestre.

As irrupcōes dos Barbaros na Europa occiden. tal e o grande retrocesso economico decorrente deIlas agiram violentamente subre esta situafbo; as drogas da India continuarata aprecixdas e consu. midas no imperio romano do Oriente, live das miscitas e flascilos companheiros das insustos; nos destrocos do imperio tomano occidental clesapp. receram da circulaçăn. O apparecimento do Isläo, sua propagardia victoriosa pelas armits, suns con quistas realifalibs le chofre en Asil, Africa e IEu ropa, ao principio agiram de mineira igualmente fatal sobre o imperio byzancino. Emquanto grassou intersa e cortiaua a gruerra entre Christāas e Sarra cenos, os pulacos fencros oricntacs levados ao $\mathrm{Me}$. dile:ranco tränportavam-łe cm caravanas que iam do Indo ao Oxo e ao Caspio, donde sogujant para o mar Negro

O commercio do Levante prosperou novatnesite quatndo o Kbalifado reuniu sob um su sceptro as terras de Ptolemen e Seleuco, o installou-se primeiro em Damasco, depois en Bagdaci. Emporio dc primeirs o:dem torrtou-so entăo Bassora; resninuaran-5e as solidoes seculares do Fuphrares e do Tigre; os portos da Syria e do mat Negro coatha- 
acirna dissernus a carreginart pesa estas faras da

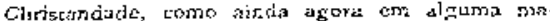
peira faxem: e per quilquer destes dous extrcisos que esta especiatio entraya nas icrias da trabis. quando vinha á buhitit era per os portos do estalio do Solrläo do Cajo, cuja potencia antes de ser meitida na crov̀a da casa ottomina dos Turcos, comecava no firm do réno de Tuncz, gr arielle cakn, o que ora od mareantes do Luvante chamam Rosuaser c... acabava exn uma cnscada chamada por tilles o goflaso de Yaraxza, na qual tistantia de custa pode haver trezentas e sossurta leguas que contcarn ext si mu:tos e mui celebres portö: (DC cadtes $1,8,1$.$) .$

Ensreganto retuscia a vida maxitima nas pla-

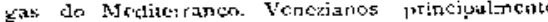

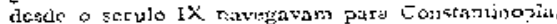
e pari1 Alekandria, donde rankerim o corpo de S. Marcos, pislroeiro e orago dia repulylicat. No mat Thyrentiv Pistnos a Gesovezes emper]:siani-se rm expulsar os Sartacenos da Corscers, da Singicishal da Sicilia, daj Faleares, ajutinndea I consituit-se a maricha catala.

Ao kerminarem as Crupatas, at tres principaes porencias maritimas cram Verczianos, Genovezes to Catalaes. Seus navios recchian os generos otientacs no mar Nefro, na Asja menor, aa Stria, no Fosplo, e tráciam-ros para os portos da Italia, da Franta - da Espanba donde 5 e distribuipm entre os po. vos da Furopa, vencendo as gargatias dos Alyos, acompanhardo o curso do Rhodano, do Damulio, do Dniciper, cvirando rs aspercas do Pyrinea, che. geuldo por terta ao extremo Occidente. Os ribeiri-

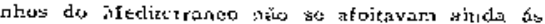
cokeras do Aclartico, nem os habitanios deste, excepto o5 Vormandus, se atínazata alem da siruples navrgacấn custeira. Ainda no secrio XV as Ingle. zes nătr passavam adejate de Eayonse (1)

At viagens repocidas no Meclicraneo formarum marinheiros peritos; a arte rautica forneceulhes embarcaçbes capazes; a irıvençio da bussola pernictiu-lhes fixarem en cartas exactis o aspocio das coltas a apartarem-se dellas sem receio de $\$ c$ perderem nos piajnos aceanicos; destle o beculo XIV Genovezes primejro el logo depois Virnzinnos esta. belecerant mivegacio resular entre o Meciterraneo c a Altantico, com as miaus da carreira de Elandizes, - gratile foco industrial cri que se fiavarn as lits itiglezas.

Coliocadt a meia diszancià, Lisbor clevou-se at cscala consideravel da carrcira, graças á excellensia do set: porro. O exempto, o continta, a cobica dis.

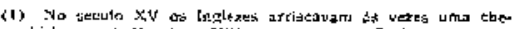

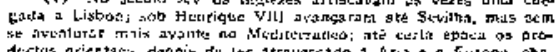
dectus orientaci, depain de lee atrovessatin a Asia e 2 Eutopa, che

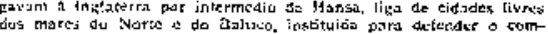

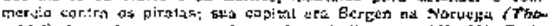

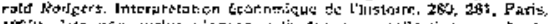

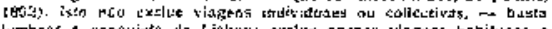

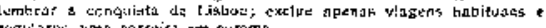


pertarian no poro portuguex o desojis de inzitar us

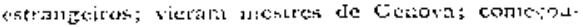

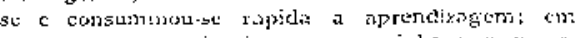
poucos unos sutgitu vigorosa a matisha portiguska. Os prinetros arnos do scetilo XV mosisar. $X \mathrm{~V}$ sL lidis e apta patáa as maniores cmpresas.

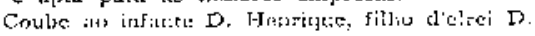
Joāo I, concebe-ias e ent parte reiblizalas. ("חis

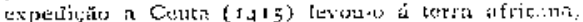

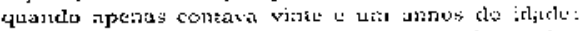
descle entẽo sua vide tere por ósjecto lesivendar

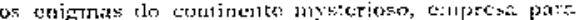

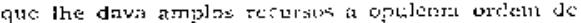
Christo de gue rya réän mesz:c

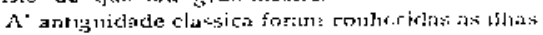
Fortanadas ol Canarias. Me Ciegon e Cartugiaces ronsiavam longas viagrons pilias rostiti africtulisi Mas tudo se apagaxa da memoria. Os Portuguczes só conheciam a costa de iHarrocos c citre cllcs corría o proverbio: a Quem fusta o crbo Non 10 . nata si ou roth:

As primeiras expedipooncs mandadas por D. Henrique revelatam ilhas clue viajantes italianos, pox cotrta propria ou do governo porticucx, tinham vi. sitado c fígurado em stus taträs mar:romias nlyui:s annos antes: Porto Santo, Madeiza, Arores, O des.

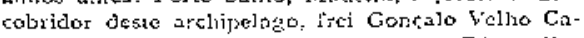
bral, điz-nos seu illt-stre coutenporanco Diggo Gomes ter passado em I fl6 térn do cabo Bojador, e Iescoberto as Ferras altes, jsto f, o Sniara. Si, porem, assim succeden, nem por isso se quebrow a encarto do cabo Bojaclor, finalmente venciclu por Cil Eanises so con I 435 : $^{\prime} 43$.

Com a montada do Bojudor as empresas marilimas ianiarim novo e decisivo alento. O litcoral deserio. inhospito, orpiziso íc portos, inçado do baixios. embuçato de bulcöes que lembravatrn to con. firmaram as tradicoes sobre o mar tencbroso, foi conquis:ado dirante dez anmos, com tenatidade tho mais adritave] quknto a sciencia kho tempo dizia inhabitaverl a zora torrida $c$ qualçucr prsso adiance apropinquaya os dominios dis desolaçāo e da morte. O premio de rancos csforcos collueu-se no descobr: menrs do cabo Verde, reslizacto por Disiz Dias em

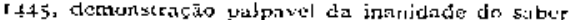
antigo, nova fril em que se rasgaram 205 dillos pasmos ceos c tertas maiores yise os ambitos de qualquar cercbro de rosmographo.

A verdura ronica!, a vida pttllilante, au contraics do quc os livros ittriunciarsm, produziram tma impressīo profurda, ainda palpitance nas pa lavras de Diogo Gomes. "Isio tudo escrevo, di. este, ram lícença do serentssirro l'tolomeu, que ex. plicou mutito boas cousas sabre a divišäo do mundo, mas em um ponto andou muiro errarlo. Elle divido o mundo, que contecia, em tres partes, que sho a media habjtzla, a arctici nño habitavel por tausa to frio, e a rropica, inliabitúrét por causa de sec ardor. Ora, achamos agora o contrario: innumerniveis po. vos negros habitat is zone equinocial e as arvores elcrian-se a alture incrivel, pois precisamente no Sul eleva.se a força a pujançı da vergetaçāo embora 
is fómas ąejas: estranhas. (Salva gratía iltustissini Ptolernei. El haes ompit invenimus in contraritm quice vidirisus... lincam aequinoctialt:m lnebitakam de nigris uji c:st tanta rrultitudo gentivgl quod inpossibile est credendum. F.r certe dico grod ridi magnam partem muxdi sed nunouam similer istius)

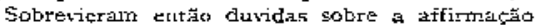
dt Ftolemeu quarto ao mar das Indias, qut tlle; prolongando a Africa até o polo austral, affirmava feclaaro ao Sul, cono o Medícerraneo. Se-lo-ía effectivamente? O littoral afriçano umas vçes corria Norte-Sul como para confimat o gcographo alexandrino: outzas de Ocste para Este desmentindo-o. Havía um problema geographico a solver: Dodcrsc-ia chegar a India depois de circlimnavegar a Africa? Já em Y 434 o infane D. Henrigue parece te-io acreditacio, pois uma bulla de Nirolinu $V$, deste anno, faz-lhe doacho chs terras existentes entre 0 cato Bojator e is Indias.

Motivos de maior monta que simples consideraçōes geographicas incitavam a procunar solver a problema. Desde o seculo XII havia noticial de monareha podcroso, rei e sacerclotc, adepto ia fé christâ, inimigo tcrnivel c rictorioso dos secterios de Yiafoma. Preste Joūo rénava algurez, além 'Ijgre, no Cathay ol: China occidertal, nos altijlanos da ibcsìisia, em todo caso nit India, que India se repurava todo o territorio das marens acejdentacs do mar Vermelhn e do oceano Irdico ao archipelaro do Jap̄as. Procura-lo, firmar com elle ali anç, conccrtar zuna accīo conmum em que Chris. tăos do Larante e Chriztàos do Occjaemec, mar. cinado do mesmo tempo contra o inirrigo heredi. cario, triturassern.ro e varressem-no para scmpte da face da :urrd, =udo isto promettia o prenunciava o bom exiro da empresa dfagada por D. Henrique depois de tomada Ceuta.

Mesmzo si nāo sé realizasstrm desde logo tantas esperaliças, am. caminho novo para as Indias sigrificava a indepencenria a respeito do Egypro e da Syria, sua provincia; a dispensa, por conseguinte, dé intermediarios sobranceiros e despoticos, cata vez mais incontentaveis, podia significar o estanco da corrente de metaes preciosos que ecsde Roma repeibicana fluiarn para o Oriente, depauperando is naçes européas, a ponto da ccouvria octiciental

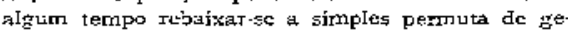
ncres de que só lentamence tccobram.

D) Henrique morseu eur i 460 , deixando o listoral africano explorado até a gerra lesa. Nos vinte arnos quc se seguiram o movimento retardou-sc, comquanto náo ficasse sustado. A' abbida de $D$. Joäo II zo throno já se cherrarn ao cabo de Santa Caharina (20 S.).

D. Affonso $V$, en cijo reinado fallecer o infante, mandou as citis grosraphicas dos Portugluezes a um gcografho veręzisno, frei Mauro, cujo mappa ainda hoje se coneprva em Veneaa; $e$ frei Iauro, cornbinancio as informasocs portuguesas sobre o littural occidentri com as dos viajantes e geocräho de Sofala (io lo parlato cum prrsona digna de fede, 
cl:c afferma aver seurso sum una rave do Sndia per rabir de fortuna de tsaversa per zormi fo fluora del maf d'India oltria el cavo de Soffala), conciviu que o mar indiano era acerno e méo pá1 (o)ecano hon stagronej. \& nem uma duvida 1havia cianto alo ser ravergavel da parte do Sul o Surlonste.

jor D. Josto II, logo qee ascindeu zo LF:rono, foi mandado Díoro Cúo a continuar of descosbrjmentos: ha jrimeira viasern descobrjte terras desde - caso de Santa Catharina ate o monte Negro; ra sergunda, em que mirsel, descobriv co mone Negro até a serra Pirtia, onde civantou pedrós: reconteneentu: descobcrtos (cabo Cross. 21048 ): do todo trezencas e cinconta leguis ise costa, como entẩ se calculou.

Im Agosto cle $\mathrm{r} 486$ fol cnviada rova expedição comoosta de dois navios e umi navern de mantimentos, commandada por Burtholomeu Dias. Co wesaram os descobrimentos cle onde Diogo Cas os deixara e os foram continuando ate taa nngra das Voltas serem atirados para o Oceinu duraste rreze dias. Quando sercrous o temporal ravegaram paxa Este, esperando encontrar a costa dirigida de forte a Sul, culal seralmetste corria mas partess atế ontăo conberidas. Como nada mats defrontasscm que mares frios, feios e mortenes, carrigaram para o siorte. onde alinal ihes surgiu a terra, na direcsin inespe. rada de Ocste para Iste.

Era sxperiencia commun entrc as Portugueres qte um cabo indicava sempre modificaço di litı ha liscoranea; dcscobrindo agora modificaçís no rumo

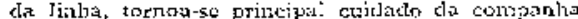

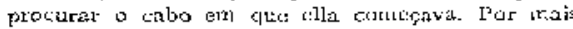
que: o chofe da expediça quícisic ir pura ciane, apenas obteve dos companlaciros perseverarem tres dìs, Neller a costa tenervou-se qunzi spripre Oeste para Este; so no ultimo jonto alcunçado; o ris cho Infante, hojz Grat joish-river ( $33^{\circ}$ jo S.), alvo receu promissotia para N. E.

Voltarara. "Chegados ao iltico da C ruy, - inform Joâ, de Barros - quando Bartholetreu Dias se apar.

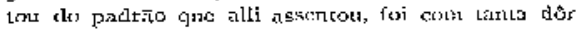
e sontimento como se leixara jm fillo desterrad? pera sempre, Iembrando.the com cuanto perigro de suá pessos o cle toda acuella zonte, de teio lonse vixam sómente aquelie offeito, pois lie Jous nino concedera o principals.

Tomando do oecano Indico pata o Atlantico, Bartholomel Días descobriu o calon, o malfadado cabo as $5 u l$ do continente, e chamou-thie Tormentoso, em mernoria das tormentas dos homens e dos cle mentos qui por suil cassa padecera. Melhor inspirado, 1). Joăn II thitgoldtie Bon-Esperança. De facto, o novo camirho das Indias estava achado: era 56 ligar as trezentas e cincosnta leguas de costa. em que fol calculado o descobrimento de Bartho. lompy Vins, a Sufale ( mais, de latitude, a distancia do Rio a Macteib, confiar-se tos ventos de fíppelo, deixnt-5e levar e trazer por elles, como se praticara desde tantos sectulos. Depois de Sofala e daki para o Norte ent. 
contrar.se-iam pilotos que tinham feito una c mui. tä́ vezes á travcssía pera a Intia.

Si, porem, o vento, que desde a angra das voltas ou buhia tle Santa Helena, obrigou Bartholomeu Dias a arnarar.\$c no quadrante do Sudoeste, hovvera durado mais ajguns diat, elle teria descoberto teras brasileiras! Ajudou a descobri-las treze annos mais tarde, as ultimas por secs olhos vistas autes die encontrar a morte nas aguas revôltas do cibo que - immorralizou, -- cabo da Boa.Esperanga paxa us outros, para elle sempre das Tomentac.

2. A' influencia das especiariati solure as viagens e exploraçōes do oceano Indico e peripheria meridional da Asia corresponde a da seda no devassarnenso do interior do contínente, de sua peripliería oriental e do oceano Pacifico.

Desde terrpos remoros cliegavit aos ribeirinhas do Mediterraneo esse estofo peregrino, tmonopolio e scgredo de um povo nysterioso, vaganente de sigratclo pelo rome de Seras; pror ext тnāo, a intervallos espactedos, levanto annos no transito, e sì os consumidoress ignoravam sua ver. dadeira procedencia, tão pouco os productores curaעatn do seu destino ulterior.

Mais de clois seculos ante:s. da tra christā os Seres rematiram a celebre muralha, que os poz a coberto dos Nimaties do Norte e enviou os No. mades para a Occidente; á sta sombra poderam concentrar-se, mificar-se, finaimante expandir.te alom dos limites a si proprios tracalos. Em I 23 antes cle Chri.sto urd scu gencral visitou a tcrra dos Xüelh-chih, Ephtal:taś ou Indo-uxytas, que das abus septentrionaes do Nan.chan, sua primitiva hasitacrän, se transferiran á Bactria e 2 conquistaram. Quasi do mestro tempo suss tropas guerrearara em Fergharia. Um seculo depois ie Christo o generai Pan-Ischao exterdeu o donirio de sua naç冖̃ ate - mar Caspio e fronteira do reino dos Parthas. Seres e Romanos entram pela prirncira vez en contacto.

Já entäo os Seres conheciatn os desyairados caminhos por onde corria seu pripcipal producco. Do extremo Oriente sahia por uma das duaz c5iralas pritcipaes: Pelu, estracla do Nortes, du Norte do Ticn-sclian, pela Dzungaria; Nan-I's, estrada do Sul ao Sul do Tien.ecian, pela Cashgaria. Depois de chesar á Asir central pelo Pe-lu ou pelo Nan-lu, a seda seguia para Antiochin Marginal (Micrv), Felatorpylos, Ecbatana, e por Kitesiphon e Babylonia descia até a barra do Elphrates. Do golfo Persico circumnavezava a Arabia, subia o mat Vermelho aré o golfo dre Aknbá, donde ia pur terrá á Syria. Na Syria era novamcnte tecida ou desfiada ou tinta, ot bordada, ou cntretecida com outras marcrias, aclaptada a costo occidental : fare e damasco ainca recordam as modificacoses por que passava o o. logares onde 5 e faziam.

$O$ commercio terrestrc foi se antimando. Dez at Hexe coratwas annuans, compostas ás vezes de mais de cen parceiros, mal bastavam aos peclidos. Stbitamente estancou, em 165 depoìs de Christo, qaando 
Aridio Cassis, seneral romano, tonto aos Parthin c destruiu os grardes tinporios de Sclectia e Vtesi.

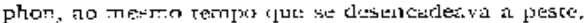
consequencia cia guerra. Sob or retinatio do inperador Justitec, no siecuio $Y$, os lurcos, aincin nāo fanaizados pelo Islāo, of́fercectam-se por aliralos do Imper1o romano do Oriente q quiziran reabrir - caninho antigo; mas slias propostas nāo foram corrprclicndidas ou foram desclenhacias, to com. macrcio por essa via $5 \mathrm{c}$ conscrion rastado ninda anizos e antios.

Conteriporanco da interzlipçato clo traco torres. tre $\mathrm{com}$ as Sczes, Ptolemelu nos dá o irinerazio de urs Nacedovio para Scril metropolc, sobretuco no. tarel pela demasiada exionsāo que noljo fundiclo se acribuiu para Este to continente asia:ico, extensĩo que influiv posteriomente sobre o modo de representar o riobo terrestrc e sobre a dirteçăo dadis aos descobrimentos geographicos. No fundo o que Plolemes e seus contemporaneos sabian drquellas tersas alongradids recluzia-se a mujto pouco. "A regiāo dos Jeres, condensa Yule, era visto c populaso paiz, tocando a Este a Oceano o os limives do nundo lıabitavel, extendendo-se a Oeste parn Imaus, isto c, o Pumir. Os povos sùo civilizados. marisos, justos \& frugacs, evitatido collisúes cotn os vizirhos, csquivos á conversaçāo estrcita, não avessos, porćni, a negociar seus prodliclos, de que al seda biula é a principal drogra; têm tarrubern estofos de sed:a. proll's finzs e ferro de notavel quislidictex. Cerradas por kerra, as communicaçoes abriram- se mazitimaz, erinando no systema commercial do

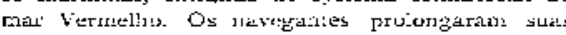

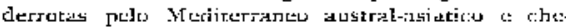

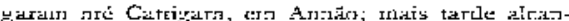
çarur Cantāj; aos poros entâa visitados chamararn Sinaí ou Trinai. A seda era o principal gentro exportado pelos Chins; coraes, perolas, ambar, objectos de vidro, estofos preparados ao gosto occidental, nos guaes tambem enriva a seda de torna viagem, represontasam o.5 principaes artigos de im portaç̄ōo.

Este commercio, feito por navios occidentas, aviltou e prosperou muitos anjos; pelo seculo If começo a definhar ate por fim extinguir.se; os na

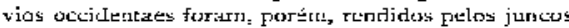

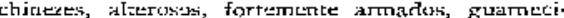
Iess de quatrocentess a wisrentos horess midos de projecteis de raphta contra os piratas. Na sua marcha para o Occidcose chegaram atú Ader c uma vez por outra enfiaras o mat Vermelhz; o golfo Persico algum tempo chamou-se mar dos Chi nezes. Mais carde o cato maritimo passou para is minos dos nrabes.

Lambem as commtricaçōes terrestres se reabriram e, graçaz a ellas, prcpagou-se o christiamismo, sob a forrma que the imprimira o patriarcha Nes. torio. Nestoriano fez-se o pava dos Kheraitas, primitivatentto babilaciores das cabereiras to Amur,

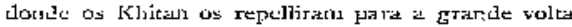
do Hoangrho: seu chefe, etra:uado Wang-Kan, $f$ dos muitos elementos que entram no vulto myste- 


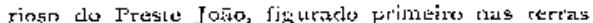
centracs da Asia, antes de finalmente identïicar-se com o dynasta de Abessinia. For via terrestre elac. toll igualmente aot povos do Mediterranco o conhecimscito dos khisan, ou Khitzi, posos de oritstrm turco-nongolica, como os Kheraitas, qtu no ptincipio do seculo $X$ comccaram suas incursops ha China, conquistaramelhe o Norte, e fundaram o rcino conhecido no Occidente pelo nome de Cachay ( 979 a I133). A identidite da China c Cathay oid Scrita só se apurou to scculo XVII, graças no jesuite portuguez Benedicto Goes.

Commcrcio maritimo com a Chína, commercio terrestre com o Cathay passaram por pbascs diversas ao influxo des constellasoute nacionaes $c$ internacionues: ora os Chins avançavam e recuiva a. Eents occidellat, ori dava-st o contrario; lamas vezes o Culute imperio apresentava-se unido, hos pitaleiro, tolerantis, uutras fragmtatiado, segrcogdo, rompia etr manifestaçoes foraticas a huitis; is hordes entre os doij Turkestans e o Azof affluian fiara Oeste ou refluiarn para Este; e fermentacio igual decompunha e recompuntín a Arabia, a Persia, a Syria, Egypto, a Europa, wo calor dos odios religiosos, dos antagonismos ethnicos, das preten şōes clynasticas, dal cobiças territoriass tivali dades mercantis.

Noo seculo XIII surgiram do centro da Asia os Mongoses, a sob Dgenghis-IFluan, sol) stus successores immediatos furdarant ern poucas e decisivas campanhas um cmporio enterreirado do Vistula ao

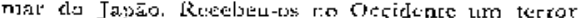
sagrado, - 'Trateri, nor Tatari cliamavan-lhes, insirevando suas affinidades diabolicas. Logo, port́r, reconheceu-se haver lavrado muto de exagrèro erri taca terrorest, e o paluice transformou-se em enje rartça quando se soube da existencia de rusmerosos Christaos entre elles, uns arrancalos dos logares por oncle passaram ás hordis conquistadoras, f ijvenda corn ellag na melhor harmonia, necociando suas mercadorias, excrcitando seus officios, vindos outros do Oriente, clentre os povos convertidos á confissăo nestoriana. Na maioria não christä, longe de dominar o finatismo caracteristico dos Sarra. cenos, sentia-se a indiffertuça completta, si nĕo a enterancía larga e a ausencia de quasequer precon. ceitos secturivis.

$S i$ os soubeserm dirizir bum, os Mongâes pocreriam tornar-se auxiliarcs prestinosos e alliatlos da Cluristindade nas lutas contra o Islazo. A ver gi cooseguinn quillpuer coisti neste scnrido, Inrocencio IV mardou-lhes cluas embaixatas de mis sioniarios a mais tarde Luiz IX da Frarca outias duas. Das enbuixadus mantialin pelo papn, consti tuica uma de Franciscanos, outra de Dominicanos, chegaram a karakorum, nas aguas do lago Baikal e capital do Grāo Khasn, no Pe-lu, André de Longjumel e Piano di Carprini; alo mesmo vlestino che. gou Rubruquis, tmissario de rei de Franca. 0 re sultado affital foi rem um para o fito irnmedicto da missēo; mas a Rubruquis e Piano di Carpini devem.se as relaçós de stas viagens, que pela pri- 


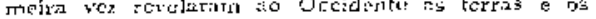

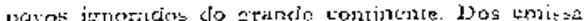
earios, uls forain ou vieram pela Syrue c Mesopro

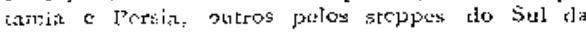
Rusia.

Maior ziterçín qute esses envindos pontificios c reaes peclem os Poís, nobects lenceianos, yue

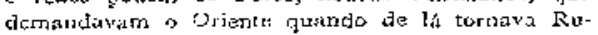
braçuis.

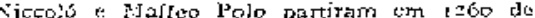
Constartinosta para a Crimen, com jojsts byzantiness c pedras preiciosis para verter entre os Nhans do Volgri. Dejrois Le fazer bons negocios, uãu pode-

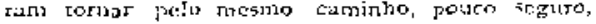

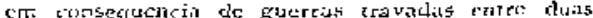
forrlas, e forans se internando além do volga, do Iral, do Catspio at'́ Tiakhara. Nesta cichade demojaram rete anos commerciando e aprendendo a lingera ratarsi convidudos para acompitrdaralos pelos membros de uma errbiliciclal expeclada da fersia no grâto khaan, aceitaratn o convire, schdo os primeiros europeus is artavessar a grande muxallaz, as prixrtiros, pelo minos, cujo nome se conselva.

Era grāo Khann nacluclle tempo Kubilati, neto de Drengnis-kbaan. Acolheu-os berignamente. Na vola dou-lles por companheiro um cisviado, que devia padir ao papia homens douto3, aptos a bosinarem o rrivis e o quadrivio a $5 \mathrm{cus}$ polos. O emis. sarin adoeccu na fornada. Maffes is Niccoló chis. gatam $s \delta_{s}$ ao Mediterrateo, ao porto de Lajax, no anno do 1260 .
Tentaram satisfizes os debejos do gräo bhatiss, mas nắ poderam. A secie pomilicia vitgara; a clé câe demoroll-se rnulto; dois frades, daclos por Gre grorio $X$ depois de eleito, duscororonarm logo no principio dia jornátala. Finainjente partiram os doj Venezialuos, levgnelo conajgo líareo Polo, nascicio em tast, illho de Niceolo.

Em Novembro de $5 z y_{1}$ Săhiran ce Lajacko, gtra. vessaram a Arrmenia, virnts o snonte ncrato onde quedou inaccessivel a srca de Nos, passaram as montanhats dos Kirdas, comaram o Tigre c por Mrosul (couz its diaps it or et it soic quj sc font en at pass, s'appellent mosolins, diz Marcosj. Liazdac', Bassorit, ondce emharcaram, chezaram a Orrivi. De Ormiz atravessaram a Perbla por Ker. marl e pelo cieserto de Lid; em Barlikelinn, proximo das caloucciras io Oxo. lotuaram o caminho

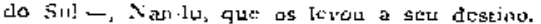

Kubilai recebeu os da melhor maneira e prin. cipalmente i Mareos votou nuita sympatbia, deu provas ctoquesites de confiança, incumbinda-lhe commissōes importantes, entre outrás a de govemador de unlá das provineizs do \$ul da China, durante tres anros. So depois de uma assistencia de dezesetc annos poderant voltar os viajantes en conpanhiz de uma princeza, que ja a Persia cassar com Aroun Wlyath, sobrirtio de Kubilai.

A viagern foi por terra de kiambalú ( $\mathrm{I}^{3} \mathrm{ckin}$ ) a Zaitun, no estreito de Fulien conce conrinuou por thar, cm treze navios providos por lois annos, crr principios de 1292 . Entre Cambodje of Tonkin 
ayistaran costa; felo estreito de Halacca, Nicobares e Andamanes passaram a costa de Coromandel, pelo pair dos Comari ao Malabar a finalmence a Ormuz. Depois de levar a prínceza a córte, onde casou com outro, por sel noivo ter morido, os illustres Venezianos tomaram o crminko de Basgdad para o Norte, atravessaram o planalto amenio e sahiram en Trebisondi, no mar Nickso. Tocando em Negroponto (Eubea) \& Constantinopla, chefaram á Veneza en t295, dep̧wis dL um quarto de seculo de ausencja.

Em urлa guersa cntre Venezianos e Genowczes, Marco Polo armou á sua cutsta uma galera no combate de Curzola aprisionada ( 6 de Serembro de (298). Levado para Genova, ditol a Rusticiano de Pisa sobre as suas averituras $c$ peregrinacoes um live que 5e divulgou tä́ clepresia quanto possivel ers tempo e paizes dinda na a compecedores da imprensa, e traduzido err todas as liriguas dei. xou signaes irdeleveis de sia passegera na histo-ja - cartographia do extremo Oriente.

Em 1474, Yaolo Pozzo de Toscanelli, sabio florentine, escrevia cma epistola, inspirsda toda ainda exu dixeres do narrador veneziano. Zaatun, onde este embarcou para tornar á parria, \& "porto no. bilissimv, onde earregam e descarregam thas cem taus grandes de pirnentas, alcm. de muiras ourras naus que carregam as oltras especiarias. Quinsav, onde Marcos asteve antes de embarcair, 6 "nobilissima c gande citale, que tem de circuiro cerm millhas, que sāo vinte $t$ tinco logras, na qual exisrem dez pontes dc pedra marmore, e seu noms en nosso romance quer dizer cidade do Ceos. Cy. pantro, que cile nür clregou a pisar, E ritha fer. tilissima de ouro e perviar e pedras preciosas; os templos a casas reates să coburtos de ouro puron. Desde $136 j$, os Mandjus expulsaram os Mong6es da China; para Toscanelli courinuava nido, po:kn, no estadir on que Murco Polo deixiara: "esta partia e poderosissima, e ha nella muicas provincias e muitos reinus a cidades $5 \mathrm{~cm}$ conta dcbaixo do se. rborio de um principe, que se chama grảo Khran, - qual nome quer diver em nosso romarce rei jos reis, o assentr do qual \& o mais do tempo na provincia de Catayo".

A. epistola de Toscanelli, dirigida to conego Fernāo Mantins, seu amigo e valida do rei de Portugal D. Affonso $V$, dandi dt Florencs a 25 de Junho de 1474, trata de assumpto mais int:res. sante do que o fariam suppür as vetustas informaçōes tretridas em Marco Iolo. Forra consiltuta pur ordern do rei de Portugal si haveria para a India va caminho por mar nolis curto quc o de Guine feitn ate cntäo pelos rortuguezes, al1ás sem lograrem ainda chesar em thra tăo desejada; re5ponde $c$ acompanha a resposta de uma carta seme. lhante ás usachlas para naverar, debuxada por sua propria mäo. Nella, compenta, «está pintado todo o fim do pocnte, tomando descle Irlanda do Austro até - fim de Guine con todas as ilñas, em frente das quaes direiro por Poente está pintado o comcr,o drs Indias com ae ilhas e os logares aonde podeis desuiar para a linha equinoxial, e por quanto espaço 


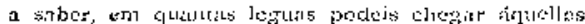

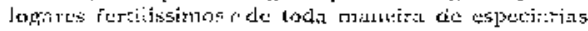

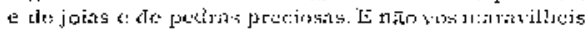

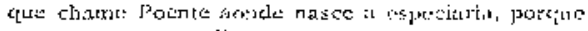

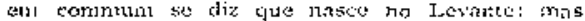

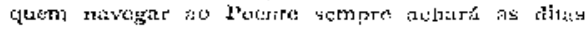

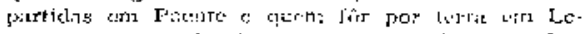

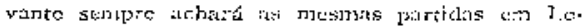
vis:ten.

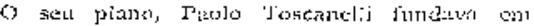

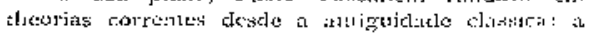

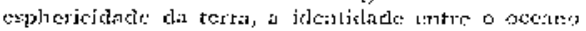

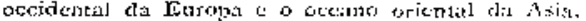

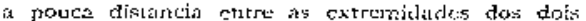

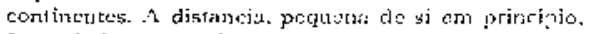
fura ainda cucurtada con as numerosil's jinass espat-

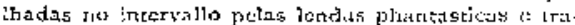

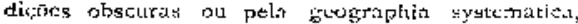

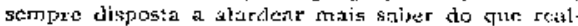
mence possuia. Dentre as illati nvoluwom a te $C y$ pango, revelada por Mirco Pols, a de Antilin, que um nosgo illustre: compatriota ( -$)$, por culsideri-

(2) A myzterioy:1 Antria, dix Jonquim Enctalle da bilvn, Jonge

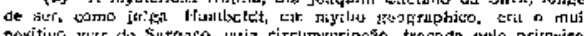
de Surgaço, utja tircumpertipcsio, tragndn pelo pritreziro

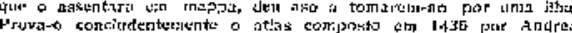

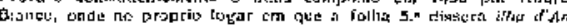

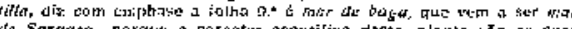

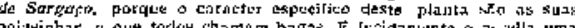

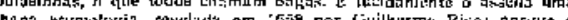

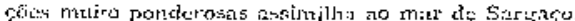

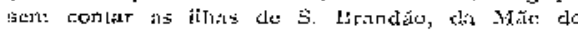
Salidjins, a as siete mit e tartas altestadas por Marco foles.

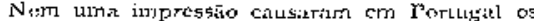
prlanos do illustre Florertino, a menos ‘ue a ellos

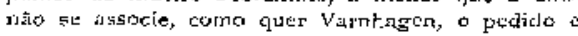

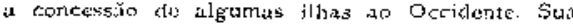
influencia foi enorsmo sobre um Cicnovez pira atimelo palos : wires d sort: Christovarn Colombo. Tamathí o tio profurda tile se pode dividjo siut vidi em dois periodos ben caracierixuldns: antes a slepois dat epis:ola of dit cartia geographich clo Tosconelli (3).

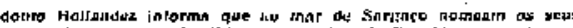

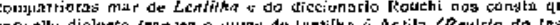

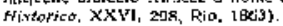

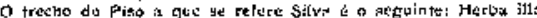

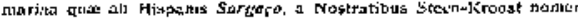

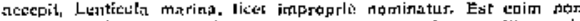

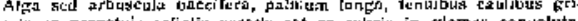

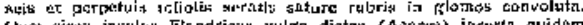

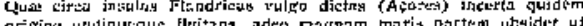

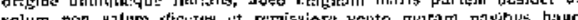

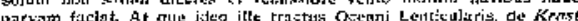

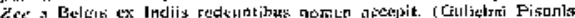

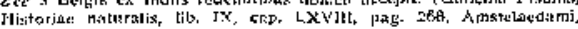
1658

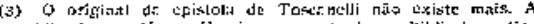

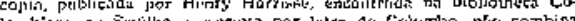

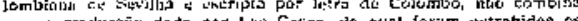

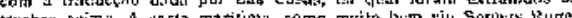


3. CIristovan Colembo nasceca te: familia ple-

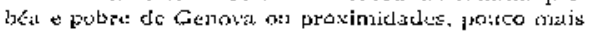
ou menes ao tempo etr qLe Djniz Dias revciava ao mundo a exjicencia to cabo Verds. Nolids regis. tzicis nos carlorios de cobeiliāes mostiatn-no en. rregue it profisste de cardador ou tecelíto do lă,

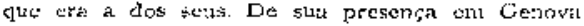
ou Savona ha vestigrios ate Agosto de 1473 .

Si exercin concinua e sffectivamente officio; si - interrompia eni excursöes mäis en menos rilpialas peto mar Ligrurio e allneris; si cu una dellas visitou Clijos e Tunis; si foi mariulleiro morigerado ou corsaljo sur cscrtpulos, igmora.se inicitumente: "puanto sc refere aos primeiress anmos da lixistencia ters: o cuicládo cle calar, mutilar, confuntir os al teras de mancira a tornas ierpossivel distingkijr-se qualeuer nucles de verdiacte no enredo.

Enu fir.g de $1+73.3$ ou começo de 1474 transferia-se para Portugral a comecor stats viangens no Atiantieo. Para o Vorte asserarara ter passado da Inglaterra e das iltas Feroe (Thute); para o Sul fori até a costa de Guine. Farece 1 ter residido uma temporadx end Madtira ou Porto-Santw. Diz-șe ter consciltato as cartás geographicas de Bastholomeu

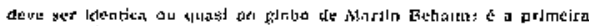

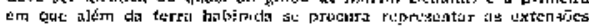
वcernicisa

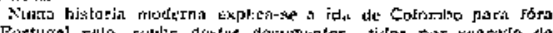

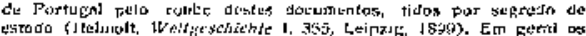

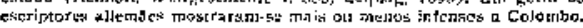

Percstrello, se' affim, romtconporarwo de $D$. Iiten. riclue; rer colhido roticias de Affonso Sinchez. piloso indalu\%, que teio morrer $\mathrm{cm}$ sua easia, depois de kiescobertas territs desconfecidas; mas nesr umas rem: outras poderitm actuar subro seu espirito si eram verdadeiras, pois en tal caso deram nuticias de gentes e paizes iskacs aos posteriomente $\in$ contrados no costlinente occidencal, estes ren Colombo tentou descobrir netr os zeconduceeu depois de descabcrtos.

Etr Purtugal casol con Fêlippa Muriz, iтtrâ de Pero Corrèil, donatarjo de Po:ro-Santo. Ali concubeu o pĩario etja execuçāo, irnmortalizando sev nome, abriu nova era para a intelligencia humama.

Por qualcuer moin chegou-line noticía cla epistolá de Pau'o Toscanelli aconjanhada de uma earta muritima cxplicntiva. Obteve cbjin de ambas, do proprio autor, ainda vivo, si sä́ autenxicos os documentos addusidos na biograplia attribuida a scy fillo D. Ferriando. A cpistola näo podja offerecer arandes novidales a um teitor de Pedro Alíica e do mindar Sir Join THaundevilic; 56 conlinha ele notitvel n. cencisāo e elatexá no propôr e solver do problexin. A calrex niuticen, pelo contratio, tom as costas europlas a alricunas oppostas is da A.sia, com as distancias demurcadas, as illas figuraclas em 5 ea verdideira posicăo, os poncos apropriatos ao refugio contria as tempestacles previmentc escrolhidos, foi umia verdadrira -revelaçäo. Tal ronfinnca the jncutiu que nerr: as quatro vingens por elle proptio feitas, nem todas as expedicyes, 


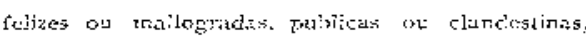

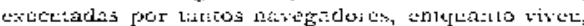
divergen:es todits en seces resuitados to rufracenjias

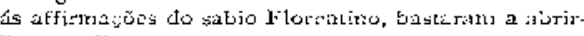
Ihe os olhos.

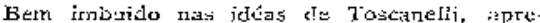
scmiou it inja junta comocada por D. Jō̌o I1, rei de Portugal, o trasado de rovo camisho raritimo e majs breve para a India do que o procurado e tho rchacho ajndie no lircor] africalo.

Estribava-se em factes ubservados por lijoros: iiflas vistas andito alem dis icores, pinlatiros exoticos fluctiantes no racio du mar, twyturas peregriпаз сол gonos de capacidale descomn:ura!, паdeirus con incisoses feiras por nato de finmere, bo. mens de côr e raça cifferentes dn Europa, achados mo:tos cm crnbarcacōes acscarradis, diversos de quaesquer da Europa e di Africa, pormanco asiaticos. islo 6 , Indios. A estes factos inxicativos de terras proxiras a Oesie, juntava consideraçoses sobre : esphericidade do nosso plancta e sooje sua exigiridide. Marino Tyrio calculara a distajucia de Espariha a India om quinze horas de tempe ot du zcritos e virte c cinco sraus err irco: a distancia descunnecida a percorrc: Ínitivin-se, pols, no ma xino, a $135^{\circ} \mathrm{cm}$ arcu ou nove horas om tempo.

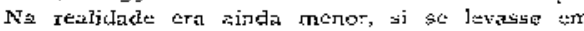
conta o archipelago do cabo Verdit omitudo por Marino, as terras orientacs, cuje fim ningesem vira ainda, o Cypango tio famou desdo if arco Poio, as scre mil quatroccntas a cincoenta o nove ilhas

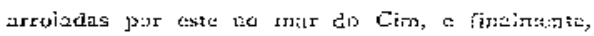

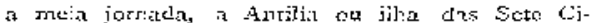
carles. Tudo isto rematusa erre troveis reijgiosos : impulsos mysticos, que com a idade cala vez mais sc corroburar:m, fodigrava-o o dominio do stíno sohre o Santo Sepulchro depois de tunto s t to gentoso sangle christäo iertido nas Cruzarias; pelo rovo canilino virian os recursos necessarios pria o esmatramento do irisigo perpetuo din Christan.

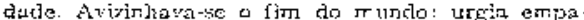
rethar os drominitas ta religiào de Claristo rom os

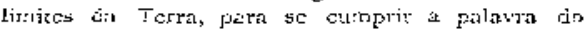
Evangelino. Seu rome rnesno, Chrisum fereis,

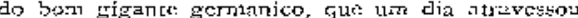
o ris cum o monino Jesus asos hombros, proclünava a missa ouc the corava destinata $a b$ elcrno (s)

Que pensaram D. Diogo, bispo dc Cruta, e os cosmorraphos mestre Rodrimo \& mestre Josepc incumbidos de exáminar as plarios coloribinos, deste mixto de factos scguros, sciencia indigesta e mys ricismo militante, deixaran $\mathrm{cm}$ silencio os contern

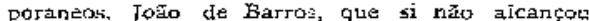
alstm deiles, poude ainda cлсолtrar is tradiçōes vivas, chama ao grande navegador "homem faila dor, glorioso err mostrar suas habilidades e miais fantastico de inaginacōes corn sur itha typargo que ctro no que diz $\pi$.

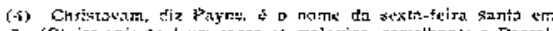

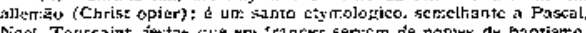

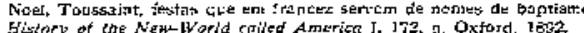


Estc juizo, «xacto a respeito de alguns dos as pectos exteriores, encobre o gue havia de inrimamerate gerial en tăo extraordinária inclividualidade. Silas propostas foram rejcitadas; elle, gue para leva las a effeito, reclamatial as malores hon ris c prerogatives, teve de salifir is pressas de Portugal, dẹt xando malher e filhos, como affirma, levando aponas um filho. Diogo, de cinco if seis annos te iclade presumiveis. Talvez se visse embaraçado por dividas, como se pode conchujr de algumas verbas pooco cxplicitas de seu testamento. Alguma coisa hourc pois en I438 obteve un salvo-conducto de D. Yoũo II para poder voltar livremente (s)

Entre 1484 e 1485 , derr-se o sev exodo pata as rersas da Fspanha, oncle reinnvam Fernando de Arasăo \& Isatrel de Castella crppenhados itm extinguir os nllimus restos dos Mouros ajnda exis tentés na peninsula. A elles Colonbo, cada ver mais convencido de suds idtas e cretic em su missâc, apresentou-se offerecendo um mundo. Fo ram oito ammos de luta constanite, afina] coroados pela victoria. A 17 the Abrif de 1492 assintoli-se entre a coréa e Colombo que das terras a lies cobrir, allu reria o cargo vitalicio e hercditario de

(5) E por que por ventuga tergels algum receio de nossas juse

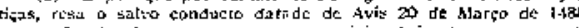

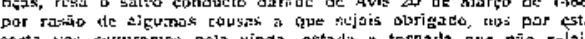
corta

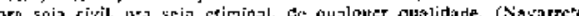

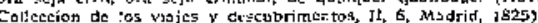

almirat:ce com privilegios ighaces aos do aimirantemór de Casiolla; que dellas soria vicc-rei on go vernador seral; que do ouro, prari, perolas, pedris preciosas e espccizrius pliaesquer outras coisis e mercedorias perceberia o dizimo, tiradas as des. pesas; que em rodos os negocios de commercio tas ditas terras exerceria jurisdiçăo por si ou por um renente; quc, si entrasse com ula vitavo para as despesas de gureschue: futuras expediçōes, tocarlhe-ia um oitavo dos lucros.

Quatro vezes vio Colombo ás terras encorporadas 1 humanidade por sua açílo maravilhosa.

$\mathrm{Na}$ primeira (1492/14933) sahiu com tres caravellas de Palos a 3 co Agosto e cirigil se a Go mera, nas Салатiss, ultimo ponto entia alcaneado pela cjujlizaçio curopsa. A 6 de Sotembro ungol fou se ro Oceano deseontecido; it 12 de Outubro descobriu uma ilha, chamade Gianaluetri pelos In. digenas, S. Salvador pele Almirante, loje Watling, no arupo das Bahamas, percencente a Inglaterra. Nivecando purat so., foi dar a Cuba, cujo jirtoral seprentrional perlonsoa algum tcrspo; passon 6 idha a que deu o nome de Espanhola, hoje chamata Haiti, donde partiu para a Esparing.

Na segunda, ( $1443 i^{\prime} 496$ ) buscou ajrda as $\mathrm{Ca}_{2}$. narias; depois da ilha de Ferro, fcz ruajo mais to Sul; descobriu as ithas Dominica, Maria Galante, Guadelupe, \& outras pequetias Antillias, Portorico - a mais oriental das grancies. De Espantola navesou para Cuba, percurrendo o litrorai meridjonal ate a ponto ern que se julgou na peninsula de Ma- 
larcu, - jurteo 4 ilha de Pitiog, onde a cosia corre

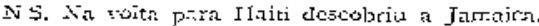

$X_{i i}$ ier

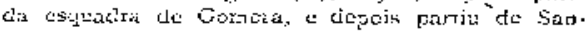
lispo de Cabo-lercle, no irtento de allavesser a

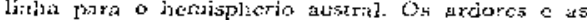
cainaias da Equador obligaram-1na a ater.sn no Torte, onde descobriu uma jlhi, a da Trinidad, a nutis nerjicional das artiihns; o poderoso Orenoco, c) afinai, o contincnte. Perturbous o actrado de ura rij, cuja possança indicava terras roniores que

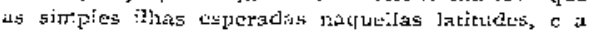
wica oxplicasāo plausivel co jacto con gue atirou foi clizer qia a terri liāo oral uma esplera, porim urna pitra; na pira havin uri perto mais saliento onde dersarala o paraiso rerreal, a culalleiro das aguas do dilivio. A esies logares inaccessiveís clis gazal agors.

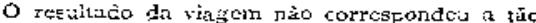
b-itbante começo. Na Tispanlola encontrou a unais

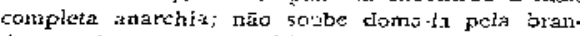
ftra, acjroi-a com arbitrariedades e riolencias, por urn de seus aclriniadores consicieratias proviz. de yue excreca na mocidatle a profissto de cor. sario. Os clamores chegaran ats a côrte, resultando voltar preso e acorrentado para a Isspenha.

$A$ ultime viagen f th de 15 is a 1501 . De E $5 \mathrm{pa}$ panhola foi ś costa de Honduras e por ella descen aré o isthmo do Pinams, sen ver, porír.7, uru es. treito que ptocurata e cija nccessidade senria para chegar is regioes, sempre annuncjadas o scmpre plarnisticamente longintruas. Em Jandica perder

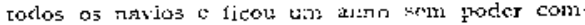
mrunicar com o resto do murado, a prircipio nen mesnio cisı a Téspaninolá, it tâo poticos lías de distan-jin. Tornou en 504 . A so de Naio de 1506 folkeces sm tuthadolicl.

Todas as viarons etescobridorats de Coiombo riferam por theatro as agnus do már dos Cara. hibas. Yer un 50 instante duvjdlou ter cincgado as terras annunciadas por Toscaneli. Culd, sempro Icputou corrinente:; uma parte do littoral cubano, perinsula de Mralacca: err agucu cubaras rominou a pena de doz mil maraverlis de multa e lingua cor tada, sh lingua cortada c cern acoícs, a quem dlividasse estar ali a terra de siangi; utr celipse linaz obsecrado de 14 a 15 de Serembro de 1494 derthe uma lontizude $\pi 0$. de Cadiz de 5 hora. $23 \mathrm{~m}$.

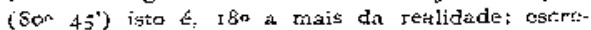
vendo ao papa $\mathrm{em} 1502$, diz que C>pazro \& a Espanhola; ouvindo em sua vitima viagcrn falar vagamente de um mar do outro lado da terra no istlimo do Funamá, confinmou-se mais na sua teimosile: andava no golfo de Ber:sala, do outro :ado dcrnorava a lndia enterior, so restarat achar o essreito, isto ś, o ceminho pitra Í.

Emquanco Vasco Nures de Bábon nāo des. cobriu en Setembro de isis o mar alo Sul corro the chirion, on oreano Pacifico, some por que o chrismou Ferrando de Magralhises, todo o mundo gyrava pouco mais ou menos dentro do cyclo das ideas de Toscaneili assimiladas por Colombo. Ainda 
etr 1500 connusugava siellas vicence Ance finzon, compandeire do Almirante ra memoratel expedi. 5. qual o descobridor cornou, depois de perdida a Santa Maria na costa do Ilaiti o Martim Alonso fínzon, irmào de vicente, separado, a descobrj por conta perpria.

Vicente A.̄̌ez Pinzon, obtida licença para armar utna expetticrio, at is de Novembro de 1499 saliu de Palos corn duatro caravellas, para Santiaro de Cabo-Verde. Nas licenças parta descobrir excluiratrse us terras ju anteriormente visizadas; por joso Vicelute Afrey, primeiro entre os Espanhoes, atoitouste alcm da linha equirocial, êm paragens näo jhlu. minadás pela estrelia polar.

A 25 rle Janciro de 1500 a agua clo retar isplareces turva. a solydu rerigto:d fundo do clexsistis bracas, c is costh abomol pieximo. fatä ellat velejaram, nejla cleseuburearan e torraram contá da regiắ etr nore da coróa de Lisparian, proclismando o feito en vores altas, cortanclo gallios e eniolhando rones nos troncos clas arvorts, fusendo mouxises de rerta, bebendo agur, chinatirdo cruzes. De gente risam simples pegadas: a este primeiro ponto chamaram Santa Naria te la Consolacion, hoie cabo de Santo Arostinho, er Pernambuco.

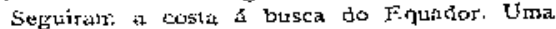
noilc avistatam fogus e no outro dja pela manhä desembarciram cuturenta lomens apparellados e disposto' á peleja. Sahiram-1hes a encontro trints e dois indlizenas armalos do arcos e flechas, de

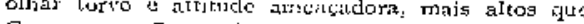

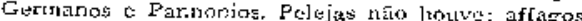
acm un resiltaclo deratr, e us Espanlaces torrat ram pira borda: acharam estes cite on rastros do naturiats da torra eram o duplo dos dos pós de um dos sels.

Proseguindo, chetaran a um rio incapac do caravellas. Fomens armados foram a rcra, ond virart alguns indigenas splare $4 \mathrm{~mm}$ alto. As tonta. tivas pira trato pacifico nato deram resultado. Um espatihol abaixou-so para apashiar glálquer ob. jecto dourado atiraclo pelos incligenas; junnecliacr. mente cstes o rodearam a mataram coms mais viro vindos ers seid soccorro, e apoticrarata.sc de am dos hotes.

Perlongaricto a costa paras NiO, deram enin yio, antes max de agura due, desctido rapicio de altias

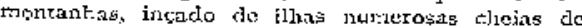
gente. Chamiva-se Maranon, e hroje o Amaxonas: as terras ao Este delle, Cannariori; as terros 20 Occílente, Paricora, hoje Guayalia, "E hallaron dentro del rio un macaseo, dix Anforio Hernandez Colmersero, es estanto 5:y tos los navios, alzaba de golpe de la mar $\theta$ el ruido clute trais is alzó curtro brazas el navio. Era a pororoca.

Do Arazonas seguiratn perlongando a costa: - mume de Vicente IPinzon, dado a un ric, gue foi disputádo no Brasil pela França, artesta aincla d

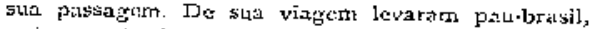
a impressăo de arvores ia collossaes a due dezeseis horrens hajo bastarin a abarei.olis $c$ um saruc que 


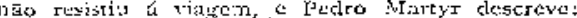

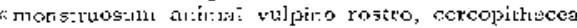
cruda, vesperijlimeis auribus, ruarjlys: humanis, pe

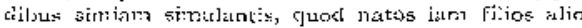
gestat eum:inl:chuc proliciscatur utero exteriore in modum magne enumcinie».

E depois de täo longr viagem Pinzon con

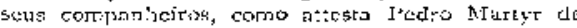

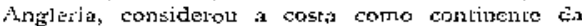
idu de Ganges; depois di naverger pela costa de Paria maisi de seiscontas leguai, juigaram-sc alem

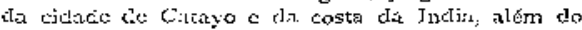
Ganeres, cm outros termos, labutavan ainda no colo tis idsas do Colombo e Toscatielti.

Chegada as tesmpo al vilgen de Vicente Pinzon e contigha nos logares percorriclos, a a de Dioro

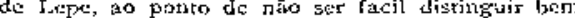
75 duas. Na opinifio mais fundarla ${ }^{\circ}$ idenzica serrindit dit Ameriro. Vospucio.

Porto de partida no urchiptlago de Cabo-Verd. toi a illa clo Foro; runo SO, duracāa cla tra vessiz quarenta \& quatro djas; lorgares vistivisos: castas do Fio Grance do Niorte a I'cmambuco, alem um pouco do cabo de Sanzo Agostinho, oride se ohscrvou a inflexato do littoral para Oesce. De Diogr de L.cpe antce que tle r'inzon parece proceder nome de Rostro Hermoso clado talvez ao cabo de S. Roque

4. Dorrinava os plams de D. Joäo il o pro posito de chogar dés terras do Preste Jnäo, locali- zades agors nos jinites moritionals do Irgypto, frontcirs qulasi clus descobrimentos de Dityre Cão Partholomen Dizi levilra romsigo net nxmada a'gu.

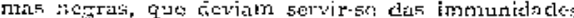
do sevo (podinm lienr sesuras, diz Joảo do batros, rorque somo erart mulheres coct juem os horne:sis

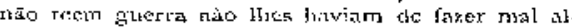
s.um) Virri a acancar, si possiyel, o reino sempro cubirado, scmpte r.squivo.

Aincla clle arcaví contra us lomsens a a ratu. rex. a Jorusatem fre: Anton io cle Lisboa e Pero de Monthroyo. Jem J trusalem, - cliscorria, - jaz o centro ela Christanclarle; si t'restc Joüo sitgue a doutrima de

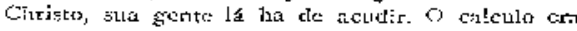
rirroroso, e saliu certo; mas os dojs canissarios ignoravam al fir:ruil arabc, hẻ se atreveram a acom parhar os religiosos abexins, que de ficto enron. iraram ni Ciclate Sarita.

Novos enviados expediu D. Joäo II de Santarém a 7 de Majo de T187: Pero da Cuvithä a Affonso dc Paiva, ambos provavelmente senlore da ]i:zguta, o primciro con certeza. Foram por Napoles a Khodes, a Alexindría, no Cairer, a Toro. Fm Toro separaran-se: Affonso de Fajta partiu para a Abessinia e de sua viăgrem rấn ceu conta precisa, por morrer no Cairo a volta; Fero da Co. vilha foi por max a Côlerut, a Cananor, a Gôa, de Gổ a Sofala, ponto cxtrema da carreira de Malabar; de Sofala, por Aden, no Cairo. Näo achou, como esperava, seu velho colleza, mas doja 
outros ritensayeiros regios: Abrathāo, rabbi natiral de Beja, e Josept, sipatciry de Lameso, vindo poucs antes de Bagdad, com frescas noticias do largo trato fieito por via de Ormuz. Josepe devia Jevar para o reino as cartas e informacopes de Paiva o Covilhä; Abrahěo fazer a jornada de Ormuz a Aleppo; Covilha desencantar o Preste, si qualquer ntcurrencia houvessc estomado Affonso de Paiva.

Mais uma vcz Pero da Covilhā cortou as aguas do mar Vernelho e atravessou as portas das la grimas para Ormuz. Dal: Abrahăo seguiu sula rota para a Syria, Fero da Covilhã retrocedeu para Oeste c del ra Abessiniz. Burn recebido foi mas năo teve mais licençz de sahir. Lá o encontrou mais tarçe, cm IjIj, ume cmbaixada portugecza, velho, honrado, cheio refithos. Tầ pouco como a Bartholomen Lias $c$ a D. JoIo IT the conbc entrar no dicscobrimento da India, que secs eslorços tinham tornado possivel c atć lacil, á altura de qualquer personagom somenos, capaz de levar treze graus ki latitude do cabotagem, antes de encortray pilotos praticos do oceano Indico.

Com tolos ester stibsidios $\rightarrow$ a naveração franca do oceano Indico no Sul de Sofala attestada minitos annos antes por frei Mauro de Vineza; - extremo do continente aíricano attingido pela costr occidental, e a costa pricntal inclimada pronissoria. mente para NE, coms entrevíu Eartho!omeu Dias; Solala, a aurifera, escela animada en carreira do golfo Arabico, do solfo Fersico, de MaIabar; a costa de Malabar, ccatro de irradiação de movimerzto commercial incomparavel, corno encontrata flagrante Pero da Corilha (c), - com sodus estes subsidios podía D. Joāo il ansadurecer caimo e dssenfadado n renate da obra iniciada por D. Henrique.

Sua quietude foi perturbada por um acontecimento imprevisto. Em Março de 1493 entrou pela barra do Tejo acossaca peios temporaes lima caravelia esparthola, a kiña, trazento a bordo Christovam Colombo, o mesmo dos planos de viagen de Levarte pelo. Poente rejeftados pela junta no meata para examina-los; o emigrado de Portugal, "insalutato hospiten, deixarido mulher c fillos; o do salvo-conducto de $r_{488} 8$. Descabrira as terras prometriclas, blasonava; e provava-o ate certo ponto, aprescntardo niso especiarias, perfumes e escofos, alardicando homens evidenterncnte diversos dos brancos da Euxopa e dos negros da Africa.

D. Joāo II mostrou desejos de ve-lo. A entre vista dreu-se a $g$ de Mírço ern Valparaiso, proximo dc Santari'm, el-rci correcto e fidalgo, o navegante orgulhoso de seus feitos, lransiordante de sua superioridade, a côrte humilhada, indignada, azk̂da to bom exito da empresa tanto como dos ares de triumpho e de victoria ldo teceláo e filho de teceläo assumpto a almirante de Castella. Alguns dos mais zelosos offereceram-se para mata-lo. Tudo passatia lisarente, jegrundo as leis do brio e do borr gosto:

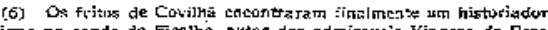
condigto no chide de feolio, altor das admiravcia Vingens de Pero da Covithen, Lisboa, 1898. 


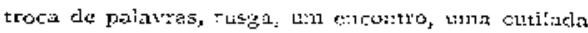
certcira.

Nia conversa lisse D. Joño Ii que Conmbo entrara por terras a illi: pertencentes, por forç:1 de ratados assertes cone a Corín de Espranlis, por força de blallas anteriorcs Ia Curin Remant. A isto

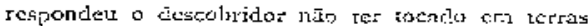

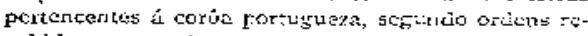
cr:bidas ao parzir.

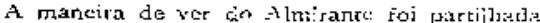
poios rejo da Espanha e pila Sarta 5i. Ém duas

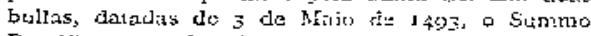
Pontifice conecier ti Espanira lockas as rerras por Coloribo descobertas to par cesccibrir a Ceste : porque de todas as obras a ruij agradewel á Tivina Magestade \& que a relitiào christis soja cxaltada e divulgada por toda parte; que a salvaçăo da almia hurlana seja assepracia ern torlos os paircs, e as naçōes barbaras 5 ejarn sulgiugadas a coivcr. tidas a Fis Catholica:.

Na segunda bulla Eximide devotionis, df mesinil daxa, Alexandre VI réfere-se a Portloal, mas para dizcr gue as concessōcs feitas à Espatha importam favores, privilcyos, isencoes, Jiver. dades, pocleres, immunidades islenticas aos toncedicios áquelle réño. Só na torctitat bulla, datacia de 4 do Maio, attendu iur pruco ás pretersōes de D. Joźo, limirando as possessezes dos dois no. narchas por ursa linha traciita cem leguss a Desic dis qualquer ilha dos Açores $A$ do Fabovicrde $i F$ a. bricando et constitutedo tratam linearn fl loolo are- lico, scixicet usptemlrione, ad foium antarctioum,

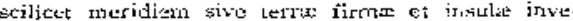

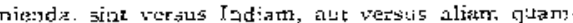
cunquam parcon; qua jinca distet a qualibet in sularum quie :ulgaricer nuricurantut de los Azores et Cabo Verde ceatum loucis versus accidchtchin of mexidiens).

IIsta concessāo mesmo foi implicitancrite revo. gadu em bulla de 25 de Secernb:o ainda do 1493 , conhecica por tralucräo espantola es for uma co jía nīo autenticada de Solorzano, pois o original latino desappareceu, na quai se anpiiou a dractes?

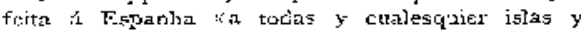
tierras firmes hailadas e por halla-, descubiertas y por destubrir, que anvegar, do o caminando hacis

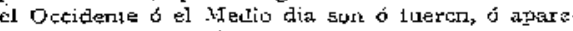
cieren ora eșter cr. las partes occidenealcs'b meri. dioneles $y$ orientales $y$ de Ia Indià

D. Joāo II quiz mandar uma esquadra áa re giōes novamutete descobettas; propoz a divisāo por um parallelo, em vez de LM meridiano; expediu e reccbeu embaixadas. A atritude de Alexandre VI

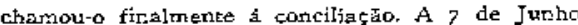
de 1494 as duas carôas assignaram en Tordesi thas um trataclo fixindo a linha divisoria a tre zentás e sessenta leguas do archipciazo de CaboVordc, infelizmente sem irelicar a illa de yue devia partir a contasem, nem fixar a medila das leguas, pois a um grau no Equador correspondiam seglindo ak opiniốes pouro seçuras do terupo $14: \%, 15,16 \%$

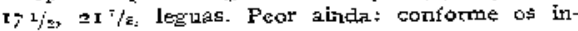


teressos de morsenlo ä durs efortes varialfant com o decenleso de rempo no ponto de partricla e na mediela itincraris.

Exn segujda ao tratado de Tordesit]las faltecel D. Jos̄o II e succedeu-lhe D. Manuel, primo cunfardo, cort razino singularizado pela antethornasia de Venturoso. Un' dos seus primciros cuidacles foi continuar a obra de Birtholomeu Dias e Pero da Covilha, incumbencia cle rue deu boa conta Vasco da Gama ( $497 / 1499)$. Thandou tambem clanclestina merte ás terras crcontradas por Colombo? IJi-lo Duarte Paclicco: "tamos sabido c visto, escreveu em I jofi a D. Mantel, coino no terceiro anno do vos50 reinizla clo ango de Nosiso Schhor de 1498 clonde ros Vossa Alcera mandol descobrir a parte occiclental passando slem a pratidewit slo mac Occano

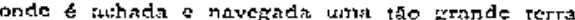
firme conn muiras e grandes ilhas adjacontcs a talla que se escatcli: a seteinta grates te Jacleza da lisha equinocial contra o polo artich... \& do mesino circulo equinocist sorna outra vez $\mathrm{r}$ vaj alón an $261 / 4$ de lidexa concrá o polo intirytico (i)\%. E até certo ponto confirma-se este dizer jula opinião corrente em Lishiciz crn Outubro de bjot, Ie quc eram cotre si conibuas as terras gelickits desco.

(7) Exmeraldo of Situ Orbis. 7. Publicado pela primeira var em

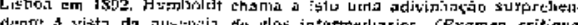

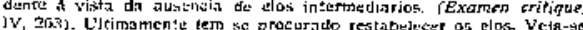

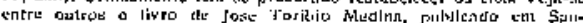
tisure de Chile, scbre juйo Dias de Solis. bertas polos Jortiguczes ao Norte' com as Antilhius descobertals peilos Espanluejes e a terra dos I'apaguios descoberta mais a sul por Pedr'alvares Cabral, cono vereiros. Em todo caso, de taes vinusens

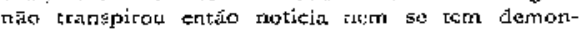
stracho qualquer influencial palpavel sobre as posteriormente foitas.

A volta de Vasco da Ganna rzuson o major enthusiasmo entre isus compatriptas. Colombo demonstrarti stu descolorimento da lridia, upresentando home:hs differentes dos Europeus e Africanos, intis. tindo 5obre certias simelhanças nos nonses das lociljdades, cotno Cibăo e Cypargo; Vasco da Gama rrazia tambem homens differentes dos da Europa, da Africa 6 até Iosi apresentados por Colonbo; trazia o cravo, a cancellas, o zingibre, todas ats $95^{\circ}$ pectarias caracteriscicas cla lndia recebidas até wiü por meio de navios itolianos; etitivera cm Cinlesili, c si nảo vira todos os legares e emporios famosos. sólbial onde cstrvam c onde procuraloss.

Lirgit randar outra e mais furte armada a visitibr novamente a Indian. Em Masco de 1500 astava prompla is desforit a vela para o Orience mua cscuadra de treze tavios, levando mil e duzentos homens d'atmas, sob o commando de redr'alvates Cabral, de tamiliu nobre e já assignalada nos des. cobrimentos de D. Henricyue: frei Gonsalo Velho Cabral, D descobridior dos Acorcs e da Terra alt $x_{\text {, }}$ era seu parente.

A $S$ do Margo, domiuge, houve missa sojerno, a qute assistiu el-rei, tendo sempre alo láto o chefe 


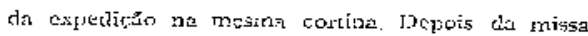

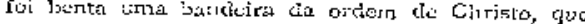
estivera sobre: a altar, e ci-ret entregon-a a Cabral jurramente coill un harrece consasraclo pelo pape D. Diogo de Orix, bisjo de Ceuta, présou exal-

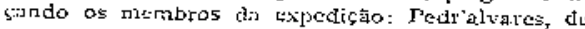
ascendentes tăo jllustres, Nincolau Coeiko, o conz parheiro de Gama, Jevado outra vez ao scenario de seus triarphos, Bartholomeu Dias, o Conatox do cabo Tormentoso.

Depois da missil, zegilin el-rei para o Rastulo onde acu a miñ a beijex o despediu-se la rodos. Foi ur dia de fustus e alegrias. Joúlu de Barros icscrevto assim:

«-4 qual especitia geralmenze a toclos foi de grande contemplaçăn: porduc a maior parte to povo de Lisbor, por stet dia de resta e rais tam. bem celcbrada pot el-rej, cobria acuelias praias e campos de Belén; e muitos em baceis, que rodea. vam as nalus, levando uns, trazendo outros, assi fervian todas con suas librés e bandeiras de cores diversas, que nato pirecia mar, mas um campo do flores, ran a frol dagueila mancobia jevenil que emparcaia $E$ o que maje levorata o espitiso destas cousas eram es trombetas, atabagues, sestros, 1al bores, frautas, paydciros; 4 até gaitas, cujat ventura foi andar em os campos no apascentar clos gudps,

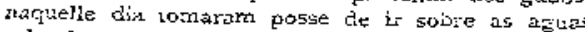
Eadgatdas do mar, nesta e oulras anradas gue Ic pois a scyuiam, porquic petiz viacrem de ranto tcmpo tudo os homer.s buscavati para tirat a tristera jo mar.

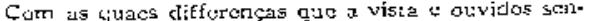
rjam o corapio de todos entre frazer c lastimat, por esta jer a mais Lormosa c pocierosát cstavi amada que te aquelc compo pera täo longc deste reino partira (s). $\%$

No dia securinte, sçunda-trtire 9 de Narço,

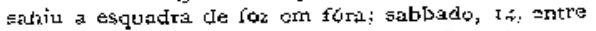
otio e nove foras, achou-se rntre as Canarias, crr calma, obra de tres a quatro leguns a rista da Gran-Canaria; domínero, $\mathbf{2} \mathbf{2}$, foi vistán a iline de $\mathbf{S}$. Nicolau do Cabo-I'erde; segunda keira, 23. deszar, rov-se e nár mais appareren a nau de vasco do Athaide, 3 cm ahi faver tempo forte nen: contrario

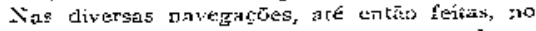
rarath-sa ventos muito nukis constantes e galcrnos arraranti-sc, do que chegrando.5e pata o continente, гujas massas exercian aç̧⿸丆⿰丨丶㇀ engolfou-se pelo mat, de longo, e encontrou a crr rente equatorial, que descle a Africa clespede suas aguas para as regióes fronteiras.

Terça-feira, 2I de Abril, encontratam varias hervas, sirnaes de terra quc, no dia sesurinte atanurciada por aves chamedas furabuchos assomor, a hora de wesperas, grande montc, mtito a'to e redonco, serzas mis baixas a sul, terra chi com graitles arvorecos. Estava-se no oitavario da Pas chian: monte Paschoal cliamou-se ao primeiro porno avjstado. Fundeou-5e a poire em dezenove braça, á cissancix de seis legruas da costa.

(8) Drcadas I, 5. I. 
Quinta-feira, 23, a arnatio $f(t z$ vela, com os rarios pequinos sondardo aliante, até as io horas lançurema ancora em direjto du boca de um rio. Lançados bateis c esquifes fGra, form todos os cupitions ár rau do capitāo-mbr. Quc terris erä aquelia? Ividentercente a India, nem podia ser outxe, pois enxre a Europa e a Asia orjental haria un só max. Nada mais simples do que verificalo: ahi estava Iricolad Coslho, que já estivera ne India: elle proprin iria tíra-Jo a limpo.

Iijcolau Coelho tornou com resposta bem äiversa da esperada; e no dia 5eguinte a ammada velejou para o Norte, ao longo da costa, por umas cles leguas, ats encontrar uma abrizada convcniente.

Sabbado, 25, penecrou-se na bahia, ctrjas vastas aguas podiam recolner mais de duzentos navios. Os capitāes reuliram-țe a bordo da capitanea; foram mandacos a terra Nicolan Coelko, e, o que nàn \& menos caracteristico, Bartholomecu Dias. Si nāo exam Indios aquelles homens tue ancavam nus pela praiz, cotmo nấ se podia ma:s pretender depois do laudo de visolau Coelbo, berr podiatr ser qualquear casta de Negros: ringucm mais cothpctente. para decidj-lo do que Bartholoncu Dias. E nāo se tave de absurda a confusăo entre os inditernas ali prescntes e os negros: antes do se encontrar un appellido gerall pará denomina.los eran chamados negros, - prova-o chtere outras uma carta do padre Maruel da Nobrega, escripta em I549e chamados com igual raztio ou $5 \mathrm{em}$ razāo $\dot{2} \mathrm{com}$ que depois ficrtam e continuaram chamailos indios.
$O$ dia 20 do Abril exa domingo de Paschocla. $O$ eapităo resolvisu ouvir nissa; numa ilha da vasta erzeada, arthou-se um esparavel; levantou-se um aliar nutito butr corrifido; nelle a parte do Evan. gelho esreve sempre alta a bandeira de Christo corp que o capitzo-nór saliu đe Bclém; cantou a missa em vot entoads frei Henrique, depesis bispo de Centa, inquisidor de Portugal, em cujo tempo sc queimou o primeiro judeu; con voz igual officiaram os padres e sacerdotes, quic ali todos erann.

Depois da missa frei Henrigue poz-se numa cadeira alta, a gente assentou-se na areia, á espera

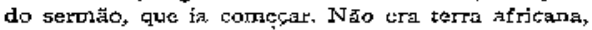
nă era terra indiana, a terra agora felizmence achada; era terra nova. Seu achamento conformara-se com o signal da Cruz, sob cuja obediencir vicra se armada, a mesma Cruz rcceb: Aa solenremente em Bclém das māos de un Iế, fluchando a'i mosmo aos ventos de largo ao sol do Sul: seu nome estava de antemäo dado, ncri havia outto a escolher, - ilha da Vera Cxtiz: - tal podemos

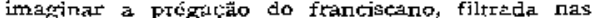
palavras fugazes de Pero Vaz de Caminha, escriväo nomeaclo para a feitotia de Calecut, ahi presente.

Depois da festa hotive conselho a borko da capitanea, e venceuse que se mandaria um emissario ao rejno, tevando a noticia do novo achamento, para Sua Alteza melhor mandar destobrir e 5abcr de tudo molbor to que se podia fazer de passagem. Foi destacado para este fir o navio de mantimentos : a baldeacia pelos outros navios e distribuicáo 
cios ganeros melle conticlos occuparint os dias se givintes.

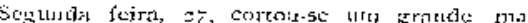

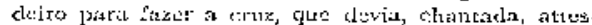

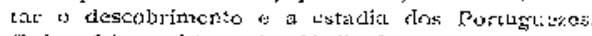
Quirta-foira, t:ltima de Akril, ionm a cru, q que csiave encostada a cima irvore junto a tula pe queno rio que fenecia na prain; sjoplinirasm ante e:jis, beijarsm-na, piara os Ineigs percebere:n c clianto at açitivam.

Scxta-fcirz, primeiro de Mrio, desembarcou a geaterla armacia corn a barjeleira de Clisisto, foi busca a Cruz onde a deizera te trouxe-it tom os ieligiosos

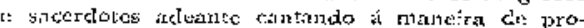
cissāo e plantou-r no logar çte mais conveniente

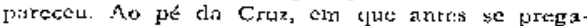

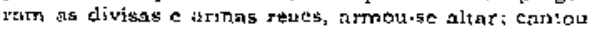
a missa frej Henriqué; comnengaram o capilảo. mor, alisuns dos seus companliciras o os rutígiosos. Acabala a missa précou outra ves frei Herrique: era dia de Stro Felippe e Sartiate, aposto:os.

A z do Maio a armada sirgrou para S. E. í proctri do cabo da Boa Esperancá; o commanLance to ravio de ulantimenlos, encurrerasto de levar a moticia do reino, fez-se a seu rumo; clois degreciarlos, deixúdos na rersa, lícararn na prain chorando. Uה2 delles servin de lingud maquelia parte e. depois lomou ao rino: at cruz aindia durow alguno tempo.

Da cetrts de Pero Vay de Cuminta, resctipla a I de Vaio, cliplorta natelicio lavrado a beira do

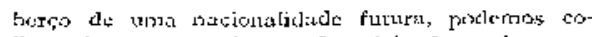

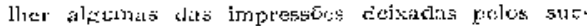

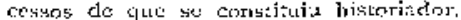

A terra fui consideracla uma jho, por muilas rayores. O rio abordicio as 23 de $A$ brit, a rio que descmbocava cm Porto Scguro, ambor cle pouca

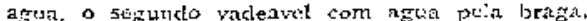
c nìo majs latrog que um jogo de mangit, mos. travaza pelo seu peçueno cibledat nấo pertencer al continemte. O mesmo insininva a zusencin de jua]. gleer fluadrupede entre os zaturaes. $\mathrm{Nom}$ diziem coise difterellet duas pontas de rerrit avistichas no Norte e no Sul, distantes entre sí vinte e einco le

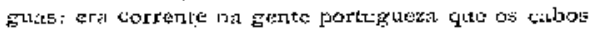

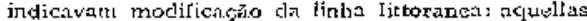
duas portits, jantas á pobrer das aguats pluvises

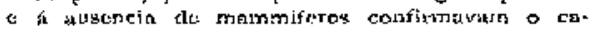
racter insular da cerra $(\%)$.

Deta Pero Vaz de Caminha admira sobretido a vegetaciato: Os nrvoredos 5 ăo muilos o rrantes * de infindas maneira... O arvaredo é tanto e tarmánho e tijo hasto e de tartos prumagens, cque nâu póde homen clar contá.

Istualmente sympathica a sta attitude a respeito dos indigcrias: "De boos rostros c boos na. rizes, bem feiros... Ali verieis guinntes, pincades

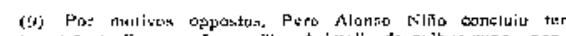
tocado em Terri firme $e$ nźo em ilha. Animalia de quibus supra menFiorem Oecanetle decadis pristite liber oetayas). 
te pruto e vermetho e quartejutlos assi pelos corfos como jelas pernas que certo pricéfinn assi bens; tambenz andivam antrelics cjuacro os cinco mullieres mogas assi mas que nato paretia mal. Lhes nosso Serhor dau boos corpos t boos rostros comlo a boos homens... Non comen sinar deste inharne que aqui ha muito, e dessa semente $E$ fruitos que a terra e as arrorts de si lancim, e com isto axdan tacs e täo rijos e tăo nedios que a non somos nos tarto coma cluanto trigo e lezumes comemos». INa explicacho que nos tit do facto vibra trma ligeráa nota de poesia. Depois de dizer cpue $5 \bar{\mu}$ esquivos comp anjmaes montezes, esciuivos como pardiats de cevadouro, accrescenta: "ulles porem, contuclo andan uluito ben entados, e muito limz.

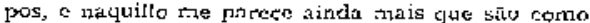
aves ol alimarias monteres que lhe faz o ar incluor pena e rethor cabcllo clue is mansas, por que os corpos seus são tă jimpos, a thjo gordos te tảo formosos clue 12 jo pnde majs ser, e jato nje fez presimir que not torn casäs, nem moradas ern glie se colham, co ar a que se criam os far tacs $2 .$.

F. As terras descolbertas estavan habitadas de tribus diversis clas até entāo con!ecillas pelos Partuguexts. Năo cram ellas menos diversas entre bi, mas no meio de differencres golpeantes apresenta. vam monaveis porntos de profuncla semelhancia. Nem uma designafio geral os comprehenclia: os estran geiros chamaram-thas Negros, Brasis. Brasilienses, e pur fim Indios, ulaimo reaiduo de uma illusăo millenar, reverdecida por Golombo. Nos logarus ondc ainda loje existutn indepondentes o 12 wherrosus confrecemiros por Bugres, cotrio an S. Paulo, e en gríal no Sul.

De seu passndo fallecem monumentos. Sanbaquis, scrnambis, ou ostreiras do littoral \& do Anvizonas; inscripçōes traçadas a tinta vermelha em rochas; pedras dispostas umas sobre as outras por modo que soan quando percutidas, nem um posso facilitam ao conhecimentes dos indigenas no tempo anterior éo descobrimento.

O estudo das linguas pouco resulkado apura. A maior parte perclerani-se; de outras restam escassos glossarios; rextos nio possuimos de msis do duas ou ures (tupi, cariri, kiriri, bacaeri). Dellas póte dizer-se mais on menos o scguinte:

Apesar das divergencias de vocabulario, a rrakmmatica 6 a x.esma, tauto para a lingua geral, essim cluarada por apparccer cm quasi todos os poritos do littoral primeiramente estudlados, tomo para 13 linguas rravadas, de que se servian muitas das populaçes do interior, chamadas Tapuists peios que falavam a Jirsgua seral.

Atsion o rome appartece debaixo de duas for. mas: absoluta, a menos usado e para algutmas palavras näo conbecidas em certas linguas; relativa, a mais commum, em que o nome vom precedido do possessivo, - bem enterulido ý quinto o nome dusjeris objecto susceptivel de ser rosurido. Assirn, ern tupi uu lingua geral, $t u b$, pac, \& a fórma absoluta; x\&rab, meu pac, nderub tex pae, orab, seu 
jes: om barneri. liл

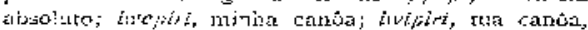

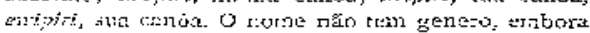
colias palauras designativas de pareicis:5co rouden cort a sexr do possuidor. O nome só adnui te numero

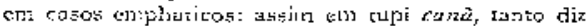
mulker como mutheres; mus, zi quizermos insistir sobr: a piuralidade pude emprt:gar-ze curde rots; nom bucaeri peliodo \& milher ou milhercs, nas existern os piur'ses pekodomodo, perodomo, c pekodo; ama cliz tanlo tu curno vís; mus si se quizer insisir sobre a multidso, ha a palava ama-re-mo.

0 ronc un presente, yassado e futuro; exern p.o: $\mathrm{con}$ tupi taba, aldcia; topero, aldeis que ja foi; em becaeri ofa, rasa; otabüri, casa que já foi. Em tupi a baceeri os prefixo's do pissuclo poclery rambern desigmar piurn]; dir-se-ja que para elies - numa desigra um individuo exclusivanente, e dœ्sdc que se extende a mais já passou. Alguns fos nomes passados da linguit geral ficaram en nosso falar conmusu: capocra, ramipuera, tambuera.

- verbo tern polco desenvolvijos os tempos: pódem tomar-se precisas as itlias de passado, pré sente ef futuro, mas existe uma forma quc a todos synchretiza. Os verbos intransitivos sāo verdadeiros nomes c declinarn-5e ajuntando lies o posscssivo; os varbos transitivos encorporam seinpre dois proromes, un: sujeilo, outro objecto. o que ir.porta vores nuio vatiantes chamadas transicōco pstor graminariros do periodo colonial. De supino e re runclios nẫo ha falta, e com elles os missionarios cunseguiram traduzir mais ou menos os conceitos

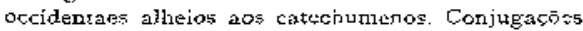
fit duas: Lira affirmativs, outra neyativa.

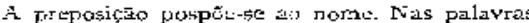
compostás, o adjectivo ora verm antesi, como no cariri e ses linguds maiperes, ora vem depois, cotous no tipi e ner bacaeri; mas o none traz sempre o

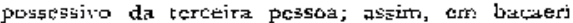

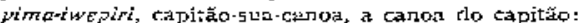
penfi-wimari, canûa-seu-capitāo, o capitāo du cantia. A construcçắo de phrāe nầo excedia gerajmente a paitlaxe. Geraimente apparece stijeito em pri. meiro logar. o objecto por eItirro, Niāo tinbam rerbo substartivo: para a predicajāo basta pospor c zdjectivo zo rome: xecats, cm tupi, sitrnitica ell sou bom: malex inaknra, aquelie $t$ bom, em ba. cateri.

Si da estructura grammatical passarmos ao vocabulario, veremos as semelbancas csriaecerem, e avultarem divergeлcias que obrigam i scpiração dos indigenas em grupos bem defínidos.

O princiro gruiso tratado pejos Portuguezes, que por isso desde logo estudaram a lingus e pro pagaran-sa além de sux frca primitive, \& o dess Tupis.

Encontraram-nos em quasi todo o littoral desde - Rio Grande do Nonte até o Rin Granue do Stil, n. médio Cruguay, no Paranà, no Paragray e por Deste ate quasi os Andes (Chirigoanos), no bairo \& no mediv S. Francisco, na manetrir meridional do Amazonas; mais tarde appareceram en outros lo. 
gares, Suas derominaç̃es locaes entre outrus st̄o as seguintes: Tapes, Carijbs, Iupiniquina, Tamoios, Temiminos, Tupinaens, Tabajaras, Ráliguaras, Catrés, Petiguares, Jurunas, Maús, Mundurucis, Apiacas. $A s$ vezcs una $5 \dot{j}$ tribu tem mais de un nome: assim, os Indios do Rio a si proprio chamavam Tupinambás e cram chantados Tamoios palos di S. Paulo.

Entre o Rio Grande do Norte e o Rio Grande do Sul este grapo subdivide-se em tres seç̋̄es menores: Carijós, Tupiniouins e Tupinambás. Seu centrc de irradiaçāo parcce o Paraná, entre S. Paurlo, Minas e Goyaz. Uns desceram o rio, outzos foram para o NO., outros para Este. Os Tupis do Anna zonas, Mundurucús, Maús, Jurunas, provavelmense esgalharan do ironco commum antes do descobrimento da America; os Tupinambaranas do Madeira, os Tupinambás do Maranlatao e terras acljacentes emirtaram depois de comecada a colonizaça do Brasil. Diziarn os do Miranhão que sua pairia pri. miriva ficava no ropico do Capriconnio (10).

O segundo grapo, com o dual os Portuguezes só amiudaram contzcto no seculo XVII, $t$ a dos Curiris ou Kiziris, (voz tupi, os tristontoos). Anpa-

(10) En pretuícr thu il convient sçavojr gute les lndiens de Maragnan tieapent que ters le tropique de Ciapricome is $y$ a vn beol

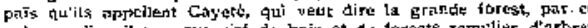
qu'en ce lieu it y a quantire de bois et de toreats remplites d'arbres

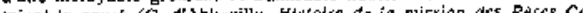
pucits en riste de Maragnata cap. 43, Paris, 1614). recerr pelo intecior dcsde o Pararuach e riv $S$ Frrancisco até o Pamaliba; serras do Cenrá e Pàrabiba guardam-lhẹs o nonc. Variam os appelli. dos locaes: Tremerubss, Jucśs, Jijicó, Ico, Curcrna, Sucurí, etc. Pelo que conlavam alguns, saas mi. graçóes partiran do Norte, de um lago encanzado, que bem podis 54 i o Amazonas (11). As tradiçes dos Tupinambás, quaes foram colnidas na Bahia $c$ em Pernambuce, apresentatn estes Tapuias como os primeiros moradores do lítcomal. Por Farahiba e Ceará deixaram os vestigios exr nomes de rios do sertäo ou da costa (Sirido, Sibiró, Siará, Choró (Siarós), Sitía. A sua internacă $f$ ali contempo ranea do descobrimenco do BrasiJ. Que err algurs

(II) O erro en qua estivestes ayé agora de trer que yassos antecessores, de guem procedeis, sthirnth fortrados de und, gratd

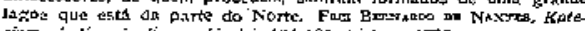

Os Follandezes procdrayant catechisar estes lndiog, mas nade us atormentasam. Entre clles vizjou Roylox Bsio, om demonios que

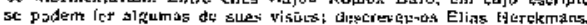
Alguas dos cobtalacs a day trengas yos Karixis enamrra o seguinte trechio do rarissimo livro do padie kiamianis

Curar es dotentes com assopgro; suras de palavra ou com canti-

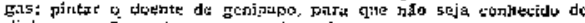

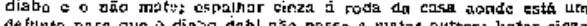

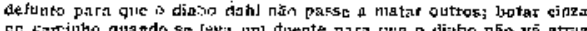

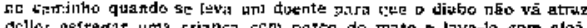

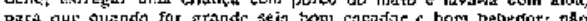

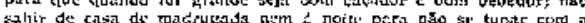
bexi

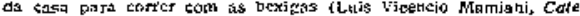

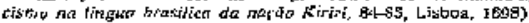


Acuwoyos, Waxá: to Amazonns e Glayads. Seu certro de clispersiso. seizutudo Carlos von den Steinen,

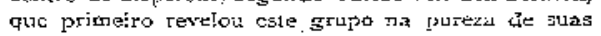
linhas fundamentaes, localiza-ie entrc o Madeira c - Tapajux, donce emigrararr priscipalmente para - Norte. Na Glayena travaram lutas crcarniçadas contra os Majpures. Em aligumas dis Ancilhas mataram todos as homens $\&$ apossaram-se das mllheres; por jisso existem ahi dois idiomas, o dosi homens puro carailiba, o das mulheres puro maipure.

Quinto grupo ż⿺辶⿻ o5 Maipures de Gilii, Nu Aruak de Steinen, Aruäs e Nheengabibas (deriominaçāo tupi --- os que falam mal) da foz do Ama zonas, Wapixnns e Manaus da Guayana, Para maris do Purús, Custenaús do Xinerú, Griantśs do Parazlay. De todos os grupos possue a área geoorapiica mais dilatada, pois vae das Givianies to Paraguay, e ainda trasborca para os Estados vizinhos. Parteren ter partico do Torte: avultam hoje ers maior numero 130 rio Pulis.

Áćn destes cinco grulous mais consideravetis, outros se sicontranin menores, salteados fimas ve zes. cotrio os de Cunzracá de Campos, constituindo rucleos mais vigorosos, como Cuaycurís, Charrias

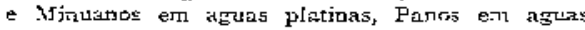
amazonicas. Vinliars elit!s se ercaminiando para terras biasilciras: Forkm antes dellas rechacacos? O proserte năo sate ainda responder, e a resposta póde esperar-se tem impacicreia, pois os cinco gru- pos adcuziclos abarcam a quasi totzlitade do zentio [rectibralio.

Asjim, temsis era simmras quc os Tupis, do Sul. Jo rio Parani provizuelmente, pelo littoral a palo interior chextistrm até o Atlantico, os Andso c O Amazonas; os Carirís do Norte furam clescendo a litorai, até que os Tupiniquins primeito e depois us Tupinarnbés os foram tangendo pard - serrāo, rumo Este-Qeate, za mesmo cerr.po que de Oeste para Este vinham os GEs afocinhar-5e no Ocenno entre Espirizo Santo e Bahia; finalmente, os Curahibas cornprimidns á esquerda pelos Maiputcs, que atravessaram o Amazonas, á dirctim pelos Cós, talver acossados a seu turno pelos Tupis ou Cariris, Airigiram-se para o Norte, Ievando as devastacöes até o rlar que guarda seu nome.

Notavam-se differenças de inculnura entre estes cinco grupos, e aié entre as tiibus do mesmo grupo: os Botocudos do rio Doce, por exemplo, cstavam muiso más atrazados que os Suyáa do Xingú, pertencurates, como aque!les, an grapo Ge

Fntreta:1eo, alemmus feiçōes positivas un nega. tivas etin communs a todos elles.

Văo tinham mctacs; năo havia acjui boì, nem vacca, nem elbra, nem ovelhil, nem gallinha, nera outra neuhuma alimaria que costumada seja ao river cos homens, na phrase de Canirithas nào 5e aprovitiavim de ovos e leite; alghins, que se poderiats chamar apanhadores(13), viviam do que encon-

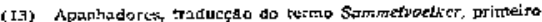


trîum, iructas, raiyes, caracbes, cafantrotos, tomi-

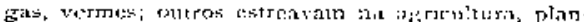

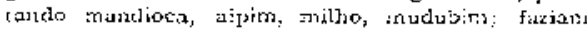
logo por fricrá. o preparavala a alimentacío rio-

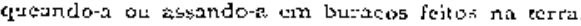
Mutras iribus nūo conheciam o cal; o uñ da pimetiti era geril. A prosira do conducto $v$ sgetal cabia a mulher; o homen encarregava-plo do conducto a sisnal,

Predorinilavat tha slimentaçĩo o peixe, negicto ems pequenos appaicilios como o puch, cir tajurues como o pari, en anzocs foitos du cspin) monhangalaz, o anzo'ciro), flechado ou smbarlsas. cado por meio rlc cetas hemvas. Xil cara, menos imporante pasa a ecromia seral. I ponto de Vespucci dizer que os indigcras da costa häo eram caçadores, serviam.se do arco o fiecha, da palbeta chamada bybyte pelos Cariris, da cogratalana de fleclias peçonhentas despledidas pelo supro, ce irrma. dilhas ou mundéos para animaes mais icforcados. $O$ abastecimento, obtiäo só por esforcos incividtac.s, era o mais irregular possivel, um oscillar continuso entre o desperdicio e a inaniçāo. Certo comito de trabalho collectivo iemporario revcla-se no porirum ou motitüo, siada hoje priticacto no jnerior bataihāo na Bahia, jurta ou adjunto no Coarś.

As atmas apparcitavam semclhanç, cm zeral

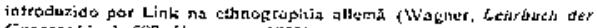

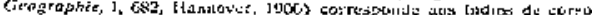
ders nossos chronistas. arco \& flect:a; mas no macerial do arch, Má secç̄o trausversalmerte tomacli, no tamanho, no entirlla dis extrenitiades, no modo de amarar a corda, nо empenamento dus flechas, na inserçĩo da punta, cada grupo, si naีo cado tribu, divergia da outra, c urr. arco ou flechil encolitracha acaso clizia loro a Indio si cotava entre: amigos ou inirizos (2.1). Possuian geralmente canóas, cle arvores exavadas ou de cascas de arvore, ou balsas de talo de bc. ritis, por exerijio ou de juneos e virkas reunidis. Havia lmectros, de que os mais aproveítalos perteneiarm no grupo Maipure (25).

Andivam niss, pintavas ou tatilavare o coipo turavar os iobulos dis arelhas ou o $5 \mathrm{cpto}$ :hatsal, mas tudo seguncln pretcitos muito tigorosos, conforme is pusíça, a idadc. a sexo, os fins reliriosos: era scu nodo de andarem fardacles ou propiciar o5 maus espiritos. Jf de longe dois Indios, 1 sim. ples inspecę̃o, sern trocar pàlavra, lism a historia um do outro no batoque, na penna enfiado a orchina, nas eisuras do corpo.

Os sentidos possuiarn extraordinzriamente sfínados, vista que na espursarada dos rins leletrcava

(14) O citudo do arso e tlecbar dog indiaceras do Srusil foj jni-

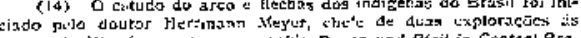

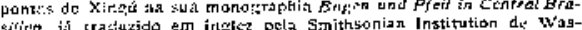
binetur.

(15) O estudo an ceramice indigenz, iniciaco pelo insxquecivel Charles Freder:c Hart, foi sysencialmente adcanando pelos brilhyntes e protuncos livros de Carios van den Steinin, primaito axplotador scientifico do alte Xingu. 
a esteirat dis canotas passaldes dias antes, ouvidos Tus percebiam e incerpretavăm os nuinisstos rumo res mimerosos cla floresta, olfato que subodorava os elfluvios mais scbtí. Suá intelligencin cra inteiramente concreta; a memoria de grancle tenacidade, guardando tradiçỏes antiquissimas, nartadäs nos mesmos termes, como que estercotypadas; existiam no estado mythopeico, e tinham muiros mythos $\mathrm{em}$ que tentavam explicat os plemometios naturaes. Para os Bacaeris o anno cetm dias mais longos que ou. tros, porque em certa estaçáo o sol do occaso \& carregado subterrancimente por um animal ligeiro, em outros por um animal tarclo e lerdo.

En sell systema religioso adritriam dois prin. cipios: Tupan intre os Tupis, Nakueri entre os Bacacris, nume Iuminoso, bom, indifferente, cujos favore nūo cra mister conciliar; Anhang dog Tupis, Yamuira dos Bateactis, numos renebrosos, ciosos, vigilnntes, sempre a cspreita de offersas para castigar incxoravelmente, legiño dos espiritos dos antepassados. Por elles furavain-se at orclinas dos moninos, pintavam-se os corpos on untivars.se de azeire, sujeitavarn-sc as mulheres a dieta rigorosa durature a Eravidez, penitenciaram-se os homess. choco si alguro filho rascia, ruspotiavase a vida de certos animaes, deixavan-se no malo dadivas propiciatorias. A este cyclo de ideas ge prendicm suas conccpsöes totomiçђ

Representante visivel dos espiritos tenebrosos era o paje ou piati, que rea podia mais morrer, por ja ter morrislo, assumia todas as fórmas, appa recia cm todos os logares, sabia a lingua de todos os entes, vencia todos os estorvos, curava os-clocn tes, dava ou tirava a saucle, roubava e escondia a alma de quem o offendia, quando compade. cito ainda the permittia viver mais algum tempo. O piahi encamaya o poder espiritual, os mortos go vernando os vivos, a espontaneidade fepelida como crime, a tradiçăo imperando ferrea, o homem es cravo sem libertaç⿸丆𠃋 possivel.

Ao lado deste, nada significava o pouco do po der temporal que rcstava. Algumas tribus, v. $\mathfrak{g}$. a dos Xavantes (Akuens), nǎo tirh ham terma quire significasse capităo ou regredor. Nos outros elle sú valía emquanto sc sujeitava \& opiniēo dos companheiros. Si näo, era facil elinira-lo ol eliminar-se; ainda majs facil deixa.lo e fazer bando á parte. riada prenditi no solo: as casas eram cle palmas olr ramas q'ue havia ero toda parte; as rogas eram de plantas antulas, cujo proparo nằ demanduva utensilios colnplicados; naquella socicdade elamentar a somma cra exactamente isual ás parcellas c nảo maior, como entre povos cultos; por assim dizer dominava um estado gazoso em dilatacja espontanen t permatnente.

A pressăo da gucrra sớ e unicamente poderia susci-la, pois o provimento indiviclual da alimentaçĩo, segundo o cermo introduzida de Karl Buccher, neีo dava de fi mats que o motirzo; an इuexra, porem, fazin-se corno ell caçada, sem plano, sem persistenciá, conforme os caprichos, para toubar malheres umas vezcs, outras por molivos mais futeis. 
E, unid vez cornchadr, tornava-se hereditiria. Exa. ctanente porque urn individuo resurria a tibu, focm - offerdia, offendia a contutividade.

Dos prisinutiros feitos, lins ficavin escravos, outros eram devo-idos, No gosto pela carne humana dceracavam-se os Tupis, que faziam o sacrj. fício com toda solentidade. Parecc, porér, que - Sucrificio jál adquitira serto caracter aymbolico; en logarcs occupados por inimigos, nāo tendo a queri malar e conves, desenterravam os mortos $t$ quebruvani-hes o craneo. Não scria este $2 \mathrm{~m}$ mcio dا mazar a alma do inimígo, de libertar-se de suas perseguiçöcs?

6. A a de Maio partiram a armáa para a India, o navio de mantimentos para Portugui.

Peciralvares desdc Porto Seguro proservilu beiranto a costa, acompanhou-z nzais de guinhentas. ieguas: nao the achando fim, convcnceu-se de ter dado ert rerra fírme e for rumo para o cabo da Boa Esperanca ("o). A 12 illuminou-se o céo com urr cometa de Jonfos cauda, que se conșervou visivel oito a dcz noites; extendeu-sc depois um bulcáo que rudo obumbrou (2i). A 24 desabou uma

(:B) De snpte du capo de Bsoa Spersarza, verko garbin, harno

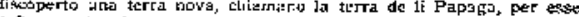
it Papsaga Jongi und brazo c piü, de vori colori, de li gual ai hanno $v$ sto dyy indichaso questa terrs esser ferm, nerché corseno per consth duo mita hila e piú, at mali trovorno tine Carta escripin do

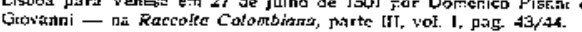

to:menta tāo lu-iosa que submergiu quatro navios entre outros, o de Bartholone Dias; um desgarrou,

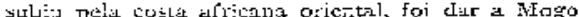
doxo, - o de Proro Dias, imāo de Bartholomes. Redurido agora a seis vasos, contincou Cabra a joirada e a $\mathbf{1} 3$ de Setembro chegow a Calecut. Os mercadores arabes, sicarinesitalos com o pro cedimento de Vasco da Gama. indispuzeram os es piritos contra os Oeciduntacs.

Nada podiam estes permutar; tudo eram de longas e promessas; queriam prende-los att the garem os mavios to mat Vormello para dar-lhes corabati. A imprudercia ou complacencia do capi:äo-mór a proposito de uл eleptante de Ccilâo qte mandor lomar por Duarte Pachceo, aunda mais excitou a populaci. A í de Dezembro foi saqueadar a feitoria, mortos trinta portuguezes, feridos rinte knue cunseguiram escapar; cntre os fe ridos contavarse frei Henrique, entre os mortos quicá Pero Vaz de Caminha.

Cabral desaffrontou-sc bombardeando dojs dias - porto com mais violencia ģде trficacia. En Co chim e Сапалor obtcre a carga desejada fom a qual 54 fez de volta a 16 de Janeiro de $150 \%$. Do-

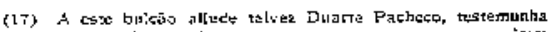

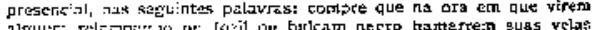

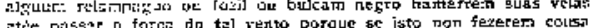
atse passer q for de he a

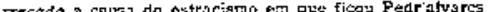


Mirgo de Ramos (4 de Abril) coboou a cabo da Ban Espcrancis; un: 26 de J:ibu Hegou a Por:ugal. Tranicl apenas cinco dirs primitivos navios, porqu a volta por imprestavel foi queimado o de Sintho de Toar.

O navio de mantinentos seguiu de Forto Seguro para o siorte, naturalmente reconhccendo a casta de passacem. Taivez se excontroc com vlgurn dos viajantes tes. Santo Agostinho e immediarōes. Já chegara a seu destino err Serembro, pois na carta de Jual de la Cosa, a mais antiga que se conhece do Nivvo Tindo, conciuida em Setcmbro de 1500 , se encontra figurada a terra descoberca por Cabral.

D. Manucl tratou da explarasa cio paiz. Preparouse una arnada de tres navios, comnantados, segundo Gaspar Cortêa, por André Goncalves, o mesmo emissario mandialo de Porto Seguro a levar roticia do descob-imento. A partida deu-sc em Maio de 501 (18) A bordo sinba Ameriso Vcs-

(16) A existencia desta expediząa de 1501 cemorstret-gc pelos uintes divarmetitors

1) Scrive esso orator aver itoto tetere di Z,istana. तi Zua fratcesso Ascaitrto, cremonese, di 10 scptembrio stise... E te cartivele

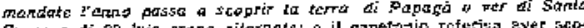

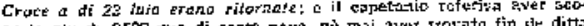
pete piu di 2500 ma di costa nova, ne mal ave towata fin de dits specis bet dite cat

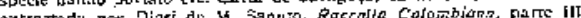
vol, 1 , pas. 91 .

3) Amerigho Vespucci ariom qui tra gochi di, cl aualc a dursto asi istiche e 4 'uto pocine porritto, the purc meritava altro eth puect, il]-ist:e florentiae, suie deria dar o inome

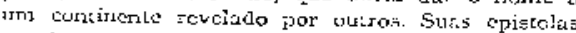
conterm as pouras roticias conservedas do foico

Fizeram rumo as Conarift5, al cula vista raml sem demorar, perlongaram is costä afticana des Bezeguiche on I3czcnegue, hoje Gorúc, pertoncento á França Ah: enconcraran-se ror Pedralvarcs, de volra da Yrdia; ahi nas praticas naturacs depois de taztos successos tragicos, combinaces as infor maçốcs de Vespuecti, conhecolor das viagens es panholas, com as de Cabral, ja cortheccolor de quinhentas leguas da costá de Porto Segt:ro pelin pri.

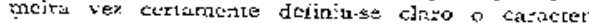
contincntal tas novas terras deste os grclos polares deparados to norte por Cortercal a Duatte Pachiso

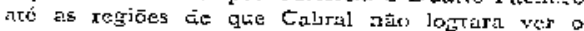
fím.

De Bezeguiche partiram as emploradores $S \mathrm{r}^{r}: / \mathrm{s}$ $\$ ., c$ navegaram mais de dois mexes sob um cio ireicrierte. \& Quanto solfremos, escreve Vespucti a

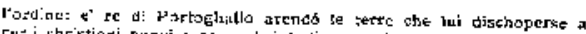

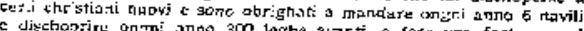
discliocerto

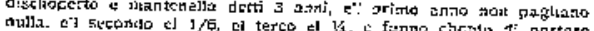

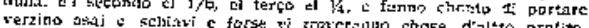

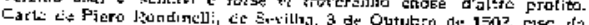

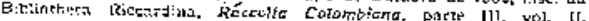
Pas lis:

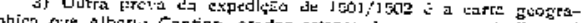
phica gire Alberlw cantino, orador estense, levol para a brofiz e li

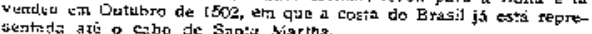


Lorenzo di Pier Franctsco dei Mredici, que perigo d: naufrigio a de torpo atuentamos, em que an sicdacle de animo nos simos, deixo di considerraçíso dos qule têt pxăcto combecimento das cojoss, e de que seja buscas o incerto \& investigar a igno rado; s para dizer tado em poucas palavras. accres centarei que dos sessenter e sete dias que de continuo ravegarros, quarenta e quatro tivenos de chuvas, trovōes e raios: e täㅇ escura que nem viamos dc dia o sol, nem de noirc o sersno cto. O facto 6 que tanto atgmenlara em 11 ís o media, que haviamos perdido quasi roda espezanca de vida.

sio mejo destis teriveis tormentas aprouwe no céo altisimino mostrar-jos terra contincnial e no vas regiōes e ouiro mundo descorhecido, carn o que rarito nos alerríros quanto podem imaginar os que renham experimertado variaz calanicades

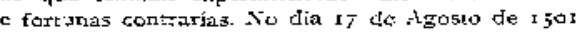
surgirncy na costa daquelia terra agradccendo a Deus com soleuncs preces, ceicbrando uma missa *intada. *

O primeiro fonto cncontrado recebeu do santo cuja tesra ze comtremorava o nome, ainca vifentc

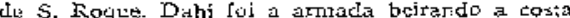
primeiro etr rumo de SW, aré o cabo de Sinto Merstitiho, alahi por deante rerso de SE. O ponto mais meridional alcançado ap:ura-sc Inal das epistolas de Vespucio: umz carta Le A?fnitadi, escripta de Lisbo: a 10 de Setembro de 1503 , faia erT 2500 milhas, a cuㅏ significaria 600 !eguas al/sm do crbo de $\mathrm{S}$. Ruque. Bástá suber-se que como ponto extremo figura no mappa de: Cantino o cabo die Sania Martha; nos que immediarmerite succedem desile Cananca ou Canarnt romeca o anonyrsato do lougars; atr I go5 Duarte Pucheco limitava a zona conhecida pelo parailelo de $28^{\circ} 30^{\circ} \mathrm{S}$, Dos nonues tusados a esce rerapo dú a sogllinte lista: muitos de:les, curno se verá, ainda subsizreri; c segutem-se ra ordem do calendario.

Angra de $\mathbf{S}$. Ruque em trez grálas e trinta rinutos $\ldots \ldots \ldots \ldots \ldots \ldots \ldots \ldots \ldots$ o. of 30

Santa Marid d'Arrabida $\mathrm{cm}$ cinco gráos og

O cabo de Sanw Agostinho em cito grétos \& quinze minutos $\ldots \ldots \ldots \ldots \ldots \ldots \ldots$ os 15 O rio de 5. Fiancisco m dcz gríos. ... to to oo Agunda de S. Miguei. em dcx gráos ..... Io do

Porto Real cm quatorze gráos. .......... It

Angra de Todos los Sitrtos cni quinze Exáns e quarenta minutos $\ldots \ldots \ldots \ldots$ 15 40

Parto Seguro en dezoixo stáos ........ Is oo

O rio de Santa Luzia em dezenove oríos e vinze ninutos $\ldots \ldots \ldots \ldots \ldots \ldots \ldots$. 9 so

A illa de Sarta Berbora on vinte grás e vinte mintutos $\ldots \ldots \ldots \ldots \ldots \ldots \ldots$. 20 to

6 rio dos Arrefens em vinte e guarro grios : cuarentá minzitos...$\ldots \ldots$ 24 40 A itha dc Santa Crara en vinte e qualro orráos e cuaicnta minutos ...........

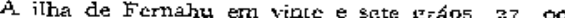

A ilha de Sarto Amaro era vinte e oito gráos e rrinta mirutos $\ldots \ldots \ldots \ldots \ldots$. 28 


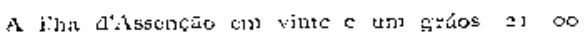
Angra fiermosis em gluibet grácos ..... is on $A$ il? $1 x$ de $S$. Lourenro (10) .......... of 0 As injpressues communicadas pela tertis foram as mais vivas: *A terra daqucllas regiües 6 fertil e anelin, sscreve Amerigo Vespucci, de mulios krontes e morros é infiritos villes, e regrada de grandes riow e fontes, cobertia de extensus bosques, donsos e apenits penetraveis, e poronda copiasartucrite de feras te todas as castas. Nella nascem scrin culttrest grandes arvorcs, of quies produzem fructos dcloi. tosos, e de proveito so corpo e rada nocivos, nerr uns fructos são parccidos com os nossos. $1^{2}$ :o duzcm-se innumeraveis seneros de arvores e rajes, de que fabricam pasas êptimos mingzios, além the mlsitos grāos ou sementes núo semclliantes itos nossos... Seria demasiado prolixo e descommadieis si quizesse dax conta tmo por uina de toding as coisas dignas de nolifin of das numenosts especies e mulijelăo de atimuletes. E verdadeiramente creio que o rusiso Pljno rito conschuju cratar da nillesima paxte dos minees, aem dos jacpagaios a outros pitssistos, os quaes naquelles paizes sío de for mas e cores tho varisdas que o artigta Polieleto năo conseruturia pinta-los. Todas as arvores sāo odoriferas, e produzem zon?mas ou olcos ou algum

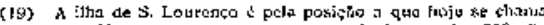

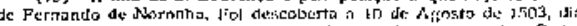

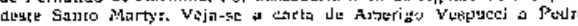
Soderini. outro jicor, cujus prorpricditcles todas, ji tosstm conhecidas, nâts dıviclo qu< anclariames todos săos. It froi certo que si o paraiso terrest \&xistc un al guman parte dia tarra, creío que nāo deve set longe destes paizes. ...x

Dor Brasis dános o ceiebre vinjante informa.

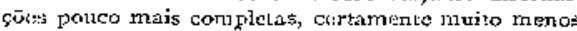
penctrantes que ‘s di Caminhn; a maior novidade reftere se á anthropoplagia, de que foram vicrimas alguns marituheiros. Descobcrto jf o caio de $S$. Roque, tomada posse tha terra cm nome del-rei de Portugal, preparavi-se a companha para fazer agruz c lenha, quanclo appurecelt algurлq geлte em cima dc un monte. Niso holuve sigmaes bustantes a faze los clescer: e os marinlicios tornaram para bordo, derixazulo nat fraia cascaveis, espell:os, avelorios. No outru diat os indigenas continuarion esepuvos; Jois Furopes com livenra do capitüo ordern de tor ras dentro de cinco clias, aprompietam-se com muita

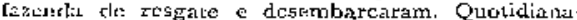
usctite viniza gente a pria, sem gluarer erteritr t:m tráto, arć que, passach uma semana, vieram ho 1'usts trazendo mulheres... * Vento que nũo acis latis de comar confianca, continúa o mes:yo misrador, deíbçrámos enviar-1hes uni dos mossesis, man ccho meito esforcado, e, frarn t) segurarnos mais, ficírses nos bareis, e este foi cer com as mulheresi, c rlocrando jurto a ellas, metteram-1u ro ritio de ur grande circulo, e ajal|ranclo-o atentamente se maravilhavam sobreinutricita.

«Eslanclo visto virnos descer do monte $11 \pi n a$ 
mulher que rraxia ura pau hạ mấo, e chegands onde cstava hosso christa loo saliu por detraz e icrunrande of pau the deu um täo gratadt golpe que o extendeu morto; as octras iomaram-no logo pelos pus e o arrastaram para o monte; os lomena co:reran para a praila c começaram a atirar com as sctas, pordo a mossa gerté ria tal conjtsāo que es. tando surtos com os bateis sobre fareisas, non uris se atrevel a tomar as arras, por causa das muitá t̂lechas, con que cran accommcrielos. Nós disparámos quatro tíros die borribarda, que nẻo accrtararr; porem, ouvinclo o cstrondo, fugiran todos para o moris, onde íl cstavam as mulheres sa. zcndo o christio $\mathrm{cm}$ pedaços e assundo-0 tem um grantic fogre, que tidisam accenclicto a nossia vista, mostrando-nos muitas porçōes delle co comenco-as; tos homens, fazendo-nos signaes, como dando-nos a entender que tirham tambern morto e comidn os outros dois christāos.?

No meio da multidāo de gentes e coisus novas, Vespucci rāo perdeu a cabect, educado na irieza da mercarura... « Si el me propuresse a contar as cojsas que vi nesta naveģa nāo tería papel bastantc; màs pódc-sc dizer ça nella nân encontramos nada de proveito, excepto infinitas arvores de pait brasil, de caniafistuls, as de que se lira a myrriat o outras misis mafovilisas da natureza, que scriam longas de reterix.... il mesma opiniăo formul-ze nos circulos dirtecrores is Fortugal e D. Mar:scl livrou-ge de cuidados arrerdando a terta por tres annos.
Os arrendatarios, christāos novos entre os cuecs figurava Fernāo de Nororılza, compronettiam-se a manclax annta] mente seis navios, a uescobrir arnuijmente trezentas leguas de terra, a maneira de que fizera Fernäo Gomes cm tempo de D. Affonso $V$. a fundar a manter lima fortaleza cirante um ri ennio. No primeiro anoo nadia paseriam, no scgundo pagariam un sexto, no terceico usn quarto. Contavan indemniáar-se por meio de pau basile espravos: Fomse vi trovararizo cose d'attro profitto. escreve piero Rondinelli, com quem esteve de passagem em Sevilha Amerigo Vespucci ( $\left.{ }^{\circ}\right)$.

Que proveito poderia scr?

Pero Var de Caminha insinuara gue is itha de Vera Cruz scriat boa polisadia para as viagens de Calecur, e como tal encontra-se desde lago rccotn. merdada e Joào da Nora (21) expedico para a India ainda antes de Cabral tomado. Por quí só polisada e não camiuho? por que nāo procuras pas. sagem pelo sul do continente, chegar em jornada mais rapida a Malacca, de que se ia percebendo cada

(30) O trceho de Rondinelt! jö atraz citads é tro importante que ralc a ptat riptiti-le: Amerigho Vespucel jresm quti fra pochi

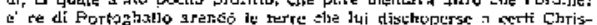

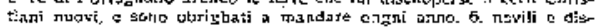

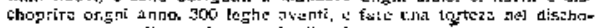

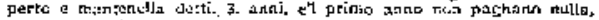

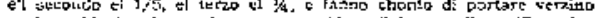

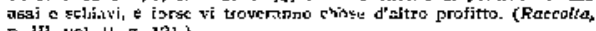
P. 1 in:

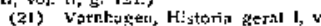




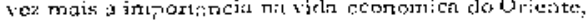

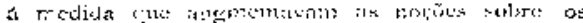

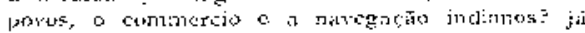

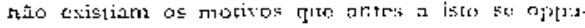
תilits : (

Isto ponderatia Amerigo vespucci abs christitos

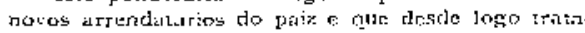
ram de cumprir o ajuste. De facto em iluio de I 503 sàitan on seis navios (-s). Nella virha com mandaido, seyundo parece, um navio, Amerigo vespucci. Desde o principio esturnecerath e azedaram suats relacóes com o capitüomór. A to cle Agosto, por $3^{\circ} 5$, avistutatzl uma ilta alta e deserta no

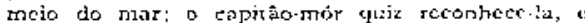
perdete contra urn cachopo, distante slclla cluatro leguas, a catpilaned, ribu de trozerias foneladas, de que 56 a gente s? silvau

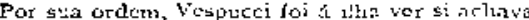
algum surgidouro em que pojassem :odos. Achou - - - - -

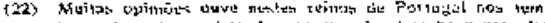

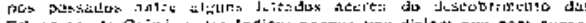

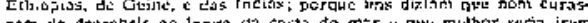

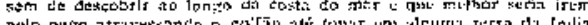

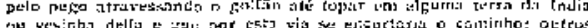

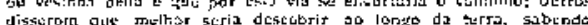

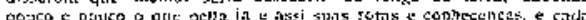

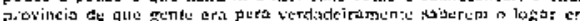

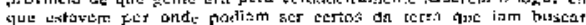

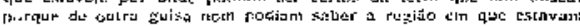

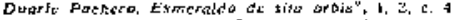

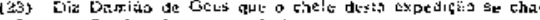
mave Gonçalo Corlho. 2 oum ponsivel.
Lellissimn porto \& deisou-se ficar a expera sesn elatr sianases tle si. Passados oito clins, vits raveganclo coja rat: com a quat se jurtes e foi f́. bahta do Jodos os Sisıtos, ponte mureaclo parn al reunioin de toudus os natios, caso si dúbue por cuálquer mo. (iver dispersio. Alt: esterc algum tempo. Dopois fundou nais pitra o Syl ruma fortaleza em que dejou vinte e cuniro christāos com muntimitnto para seis niezes, sloese bombardas e mutas outras ismas; acompanback ts trinta lomers penetrou

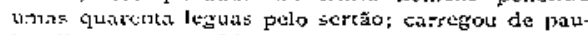
brasil e clicgou a Lisbial erti iz de Junho de I504.

Que ie? o capităo-mor reduzido a tres navios? Até onde chlgot, gue demora teve, si fundou ou riio a fortalcza do contrato, iznora-se. Parece certo gin tin mavio estuva de volta en firs de 1504 ou principios de Ijo5, \& por elle se solule de sedo quinco passitra e do procedinento do florcusito lor estas iniortusūe: stria Amerigo vespucei desjuecliclo co scrviço portugite\%, com o 4 tial jí im Setertibra de I 502 =E declarawa descontente a piero

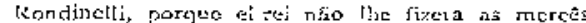

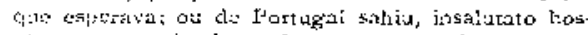
pitce, con receio de clitilcjustr cattigo: alguma coisa

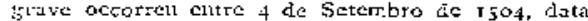
de sua calta triumplat a Soderini, escripta de Lis. boa, $c$ s de Fevereiro do unur srcusiute, clata fla carti: fic Sertlia etr que Christovan Colombo o f preserta \& recanmendia a seu fitho Diogo.

Foi renoudo ao expirar o contrato de Ferräo dè Noranthas? 
Pode concluir se jato do sebstrnctioso Jëator:o de Lconardo da Chin nIasser, inclimbicio pela se.

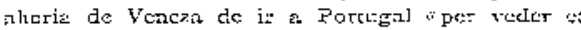
inrondere quille naverazioni di quailo Screnissimo RA ne!l India novanente ravezata. Cha do IILsser, tue dois arnos consuniu em sul mistän inforrava cm I job estar o lrato da rova terra tincu. lado a Fersāo de Noronha, christāo noro, por clex znnos. Exirahia vinte mil quintacs de pas.brasil anzuzimente, por ellos pagara quatro ril ducidos á Coróna e a Coróa comprometia.se a não deixar ir cia India a preciosa radcira. $\lambda^{\prime}$ terra nova man. dava lodos os amnos lromeris e nasios, acio nuico

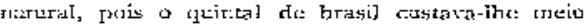
ducaclo o cra vendido em Flandres cois e moio a tres $(2 t)$.

(26) Item de tre ansi in qun, efte ju discoperto Terra Nova,

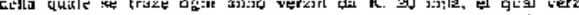

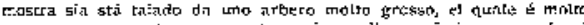
peisso e grave: tamen non terze in quella periczion come fa cl nostro da Lessante: nisnte de mance se ne spaza molto in Fioudra, e do qui in Castilis et in lialia per molt: lochi; el quill valje ducat

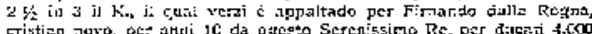

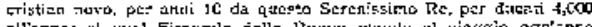
allisno;

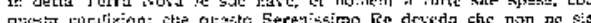

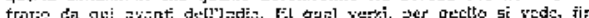

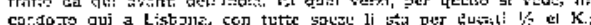

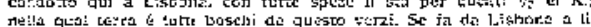

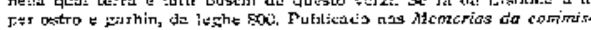
süe portugucza de centerario da descobrimento da Asterito por $\mathbf{P}$. Peragalo. cra appendice a Cara de 11. Manue: ao rei Cathotico, for $83 / \mathrm{s}$
Em 8 de Noycratro de I 5 to Fellegrino Venjer escrevia dc Falemo, noticiando a chegada de 니 mercador pisano, vinito de Lisbua com a nolicia que el-rei de Portugal pernsava lim tier liberdide

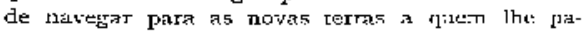
gasse o quinio ( $\left.{ }^{*}\right)$. Si a resoluçāo foi dssde lorgo Icriada a effeiro, năo se pode affirmas: iudo quanto

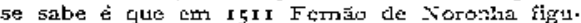
rava erte of crmadores da nau Bretor, mandada a tera nova para buscar brasil \{erys que en Ijis Jorge Lopes Bivorda (t) tinlua \& trato do vau bras!] que trazen desta tera de Santa Craz

Mais intercssante que estas expedicōes de Chiis. tāos novos e mercadores, a chumala armada dc

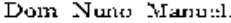

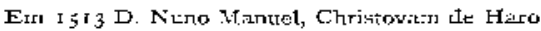
- ousros obriveram del ré licenga para dois ravios percorrerem as terras ainda desconhecidas. Prra - Sul rutio se adiantaram; descobriram im cabo, - de Santa Maria, á entrada do rio da Patria; ravesaram por eate acima ats ver as duas margens se approximarer; descendo depois pela costa chegaram aos $40^{\circ} \mathrm{S}$. ou isto entendeu o colono de ilha Macleira a quem devemos a nocicia. Ttouxerain pciIns ded Patagosid; houveram noticias de moritanlas

(25) Faccolts Cajortsians, gatte III, vol. II. pag. 23:.

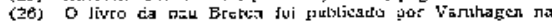

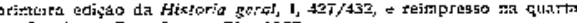
do Diario dit Fero Lopes. Ric, 1857.

(27) Dagiand de Gocs, Chronica do folicissimo tey D. Manuct, p. 1.9 c. 56 . 
permancenteriente cobertas de gelo, de um powo adjintado que moraya nas serras, encontuaram principaliziste: prata, rnctates vitudes deste powo por un rio gue nuo viram, mas souberan ser affluente do Prata; sobretudo noticiaran o uchamento de um estreito ao Sil do contirente, a proxinichale de Malacca, dislante apenas seiscelatas leguas, a existencia de Clinczes commorciantcs o nesociantcs por aquelias latitudes.

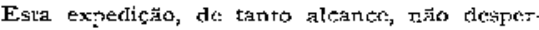
tou artcnç̄o exn Portigal. Della só lemus infor. maçōes por un colono da Madcira, ondc dc volra chegou um dos navios a Iz de Outubro de I5I4, escriptas a urn amige dt: A הtutupia, O etscripto confuso e pouco íntelligivel, foi logo impresso tha A.lemanha e passou por tres elicócs. $O$ cosmographo Johannes Schoener leu.o, rradarín-o em parte,

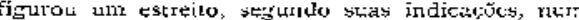
globo que plblicou cm 151;. Dojz annos anses, $\checkmark a s c o$ Nunes de Balboa descoistra o mar do SuI, - Occano Parifico. As duas descoberas completa ram-se e fructificararn na circunnavecracăo do glodo, iniciada por Fernāo de Magalhāes en 1519 , con tíntada por Jod̆o Lopes to Carvalho, o piloto da nat Bretor, que comsigo levou un fithinho tido em India do Rio de Janciro, virimada can 1522 por Sebastiāo del Cano. Assim, quando gareciam triumphantess as idéas classicas, inconcussa a identidade entre o aceano occidtintal ta Fiurapa 0 o oceano oricncal da dsia, o elemento solido occu. pando muito maior parte do globo que o elemento licluicin, o Oçano cono unia srande lagóa, na phrase de Duarte Pacheco, nundando pelas terras dentro bracos quic sāo mediterraneos, os mares encadeados no meio dis terras, quando em Ijis 0 descobrimerto de ern estreito ao Sul tudo contir. nava e documentava, veio o ardimento do Balboa descobrir um oceano tor contiatente, $P$ ara os quaes năo haviz foga: nem no saber antigo nem no sabber corterporaneo.

As exploraçö́s to littoral $\mathbf{x}$. I. alem do cabo ac $\$$. Roque perrianecen obscuras.

Em 13 de Tulho de I $_{503}$ os reis catholicos ter citjiam noticia de que quatro navios portugutzes haviam tocado no paiz descoberto por Bastidas o levado muitos escravos e paus de tinta ( ${ }^{2} 3$ ).

Existe um alvará de lembranga, passadon a I6

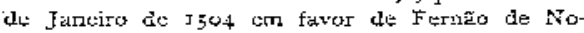
ronha, cavalieiro da casa real, doando concicional mente "a nosta ima de $S$. Joào que de ora novamence achou e descobriu cincocnta Icgtias a lix mar da nossa terra da Santa Cruzs. De ora nāo cs. tava en logar de se ortí Fernáo de Lioronha, fi. dalco da casa real, será o mesmo que Femano de Nuronha christäo xiovo? e este deixaria seu telonio de argentario para expor-se aos perigos do mar, abeberar-se de poesia tropical, embevecer-se nas magnificencias dn céo do Sul

$O$ nome de 5 . Joāo àado á jlha pódc indicar

(28) Matina, Juala Dias de Solis, Estrdo hisforice, CXV, Santiago do Ehile, 1597 . 
a pasperterr de aIruem pela itha em 24 de Junho e com esra data combinatn alguns romes da costa fronteira transnítidos por Oviedo: Süo Miguel, Sc ter.bro; Todos os Santos, Novinuid; r:o ta Netividade, Dezembro. Seria Ferneo de Noronha altiscopriclor de loda a costa uté a Pará on Nativi clade? A canto najo chera o nosso saber, que se recluz todo a norres rís: Joāo Coelho, da porta da Craz em Lisbon, Tiogo Ribeizo, artuto dit-rei motio pelos Indios, (Affonso Ribeiro, deixaclo en Porto Segura por Cabrals e neste caso aruto räo serát synorymo de lingua?), Franciseo Corso, pern Corso.

Estevam Froc:s cut: tilid Estes nomes, a acom panhava of dois ultimos; astegura terem chegado suas ripiaracöes so a cento e cincoentn leruas ao sul do Equador. Corth a caravella comesta de lsu sano c broma, fazendo nuita agua, com o leme Fucbraclo, acolheram-se a Porcorico e leviados a S. Dormingos foratn subrettidos a processo (\$9)

A terra Aescoberta por Cabral chamou-se pri neiro ilha de Vara Cruz ou da Cruz ( ${ }^{0}$ ) e como

(20) Ciatir excripts do S. Domingos 30 de Junto de I514. e primrciramente pubteqzala no Descobrimento do Brasil, do que esereve esta jinha. Por crro de copis snh:u Fernando em vez de Estevatr -

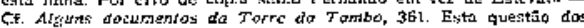
Porteguczes presas tem S. Dotuilgcos, basallada por Varnhagen, gdce sur agora cabalmente tesolvida, eotil os hovos dacunentos pujlicadas ta 1 llveo da Tarre do Tonibo a o de Medina sobre Solis.

(30) Rusimento dado a D. Francisico de Alineidia ena 5 d

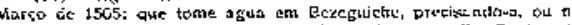
itha da Cruz, si no caminho que sernuir se chegar a clla. Tegim:ento ponvo que podia ser procuratio ou devia ser evi. rado tia derrota da Indir apparece em diversos documentos officites: cluannay-5e terra da Sanili Cruz já cnl $150 j$ em scguida ás exploracồes que cvidenciaram sua contincotalidade. Pouco tempo apenas; o atmt de terra do Brasil já apparecc com

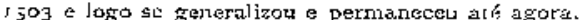

Alguns autores propuzeram extender a designaç̄̄o a todo continente; mais feliz foi a sutggestāo de EITylacomilus ou Waldrecmüiller feita en Ijo?, de chamar-lhe America ou Anerite, en honra de Amerigo Vespuceci (31). Acolhida ciesde logo n.a Lorena, ande surgiu, propagolsts fetos paizcs vizi-

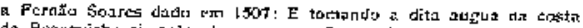

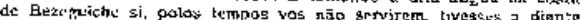

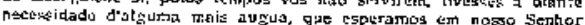
ques nam scja, purúm acontecendo fur assi losa si vos achasees

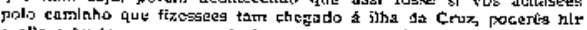

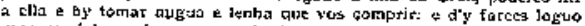

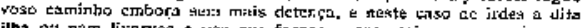
itha n's nam lixarvos a was que façaes 0 que misis nosso serviço vos

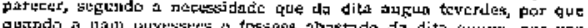

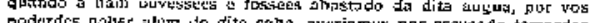

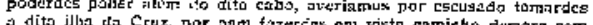

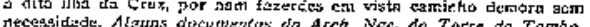
140, tE.3, Lishon, 1893

(31) No excmiglar de Cosmogrephice lntrodtetto de Hylasomilue

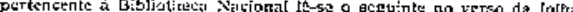
r.ü numersds qire se se'țue a aiij

Nune v'erc et hacef portea gunt lat:Li: lasteatae \& s.jia quafta pars Fer AntLrieum Vespotiual (ut in: seluentibes aud.ctur) indenta est

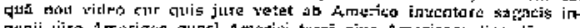

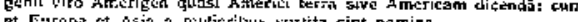
et Europa et hsia a naticribus surtita sint noming. 
cire o catarser cosencial da laura e cha flola da

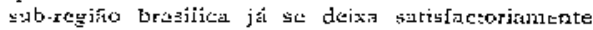
dejizear, focto monos nos actis comornos gerals c exteriozs. A sciencia procierí ra maioria dos cosos irlormar si taca planin ou aurelle arimis. é andino, ytayanense, argentino, ou si pertence á nossis sù. rogiāo. Was não podemoz dizer a mesma coisa quuzrto an estado dos conlıecimtutos relativos á exacta distribuição iritcrior. Ainda tato passe da phase emlaronaria todo o nosso saber hodicrno acerca do problema: Como sulmalividir a nossa sub regiatór Eis a tarefa do nova seculo.

Tres roodalidaces disinctas offerect: o aspecio physionomico do textensissino littora: do Brasil, an visitante cht: tiver oczasiäo de percorre-lu pelo lado do mar, desde o extremo Sul atś o Jonginquo Norte.

Déple o Rio Grarde do SuI até a Bahia mais ou menós nocará gue a terra fime se descortina ern animado quadro de rrontankas e morros, d differente altura \& variadas fornas, cmbora a do cône mais ou menos estirado seja o fejtio pecti. lecto. Acla a sua expressia typica sobretudo no trecho chtre Rio de Janciro e Espirito Santo. Uevido á sua côr roxeadin, rirta neutra, estes mám millos graniticos á distancia de alymmes milhas as sumerin certo ar sombrio, grave, quasí oppressor por assior dizer; o navegante, ao pasjar, por excrn plo, pọlo cabo Frio, nä́ conscguirá facilltente libertar-se desta jmpressāo. Neste sentico ha um que de pa-ecido com a physionomia de certos g:hpos de ilhas, solteiras no vasto oceamo (Cinarias,
Cabo-Verda). Mas, do patsso que nestaz ultirns, alo approximatern-sc, cort o seu culurjde de scipia rotintia, tho carar.-eristico dos fuins vulcan $\cos \&$ yluto nicos, o sentimento tende a nurrecentar, - recol:cilis e anima o aspecto Uas scrranias do lictorai do Brasil me. ridio:al vistas dle perto. Viçosa L exuberante vegctaçio arborea enrolve com sympathico tapetc de um verie sadio e benefico o cimo, ben como aquel.es lados do manto, que näo \$e precipicam corn falc por cernais escrrpada e ingrerne is profundezas submeliras. Denure as arvores dicotyledontus são hiversas Cinellas que err. certa predilectäo escollom tacs culminancias, \& diverșas e'çantes i’almciras

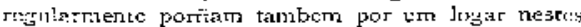
elevedos miractauros. Mias mesumo nos parcalones guasi verricals o oihar jifficilmerte percebe ainda fenda,

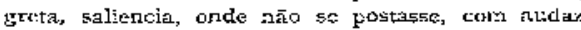
gall:ardia, pelo menos algum ramilhece de Bromelias ou die Orchideas. Nisto vai un palpavel con. traste com o cararter physionomico das sypra. mencionadus ilhas vulcanicas, que com ㄱ' gumas parcas Gramineas, Cactos, Tamariecos arbustivos, etc. сл v'а̀ lutam para crtremear com alrtm sulpico vcrde a monotonia $\mathrm{c}$ a rudez de sua roupagen corrida.

Da Bahiz para o Norce muda o espocto do litcora.. Primeiramente alternando ainda, a vequenos trechos, corn paredōes pouco elevaclos de barro ver. melho, mais a mais chegam a absoluto a incondjcional predorninio as alvas praias arenusas, que en interrinavel orla cingem a costa dos estados de 
Sergipe, Alitroas, I’ernambuco, Tio Grande clo

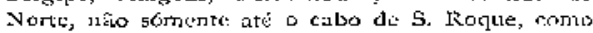

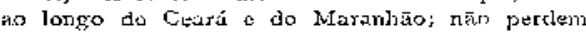
este prcdominio, sinâo, por assim diztor, no proprio porto da capital do iltino estado. E o feudo sectular da areia movediça, assumindo aqui a forma de praìs extersas, plarias e raskíls, acolá a de dunss, com ora mais ora menos elevadas collinas, Monotona, melancolica of a impressác causada por esta paizagcm, campo de batalba, oncle contra a despotico regimen colico trava uma pobre o opprimida vegetaçáco herbatca e atbustiva bem desigua.: com. bate de existencia. Săo principalmente alsunas Convolvulaceas rastciras nas praias e algunis Muricys (Byrsonima) irbustivos no tope dis dinsti, clue com particulat tenacidade sustentarm a acerba contenda, de succegso variavit] conforme as tocaliclacles e as estagaes do armo. Ao lado drista vegrecarcyto espon. tanca notarse, por incervallos, effjeaz intervents̄o humana, que coull pitinares, ora mais, ora menos extensos, de coqueiros din India veio dar a esta parte da costa um uspecto que ella nwo póde ter adcjuirido sinäo desde tempos historicos foo restricto sentido do termo relativo 4 historia do Brasilj.

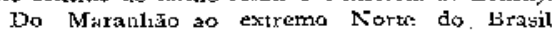
occorre a terceira rodalidade physionomica, a matta littoranea adapticla á influcnctà das mirés. O navegaclor parece estar presenceando o spectacilo do uma Fata Margara, quarido desta costa va crier. finclo mo horizonte umis copas despegadas priluciramiente, fanijando succosstvamente e aos poucos

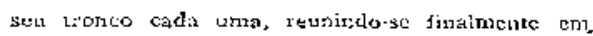
conipserto o injntarrupto debrum floreslill, que $\mathrm{dj}$. recciajucete do mar surge e porioclicamente ex jaun. ditio stincla resias ordas salsas. Nat compositsa destat vergetacia Wangral (formado pelo Rfilzophora) a o Siriubil (formalo polia Avicennia) - arvores, gue, sens serern duladas de excepcionaci encantos paizagistas (fiaira-ihes para isto copla sufjicientemente compat e den5a), incomparavelunente agrétam mais do que a screra monolonia des duniss arernosas, cuja alvura nivea acaba por matcyrizat os olhos, quandos ba nhadas profusamente pela intensir luz do sol tro pica?. Tista matta clo littoral baixo, que tianto con. trasta com o carbeter physiononico dasi cuas ou iras categorias descriptas e sicas mais para o Sul, previlutece typica sien da for to Mmazonas, por lada a Guayana, aŕ́ o Oyapok.

Corn enscenaçũo murto diversa surprehendt:-nos a naturcza, si a viagem de exploracio fơr dínifida cm dutro situtido, no to littoral para o interior, ramn $\mathrm{E}-\mathrm{O}$. Find semelhante commettimento subruttemo. nos primciramente so effeito de urrá mudança as\$az consicleravel e abrupta de elevaçäo verticill; rom as linlias ferreas tondertas temos accasing de tro car, em rajica successäro de horas gomente, a bul. rada queate, o torriclo reconcavo, pela arager fresca de alrutas sulmalpizas, tenclo vercido uma differinga de rivel de r,oon metros a mais. Claro ć que o azpccio da raturexa náo sorá de todo mesmo, si effectuarmos a viagetr na alteura do fio 
do Jareiro, oю ла cla Bahin, ou 7 il do Ceara, reu-

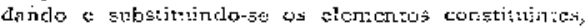
conforme á latitide; mas no deive de sez noinrel

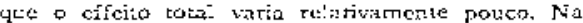
baixada quente, nu resinga, 1 át onde clin fôr cnxutr,

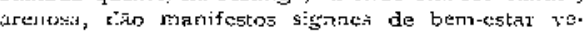
yetace como o Cajuciro, a Geiabeira, a Pitaisucirs, diversos Cactus de exquisila forma; hos brejes tominers as Coceolobas, o Piri (Papyras), ns Flchico. rias, de aromaticas flotes avinitentes. as láto to

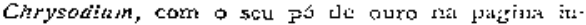
ferior das frondes.

Luxlosa devérás é a vogetacăn em ambas as

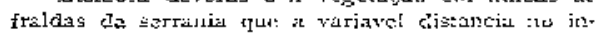
terior corre patilelanente ao contongo matimo. Persence ao matis bello que a nanurcza produz no Territorio do Brasil.

Garrídas Embaúbas, de fo'ras jratendas, mui-

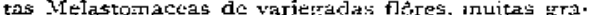
ciosas Palmeiras, grandes imma, anis ourras, esbeitos Fetos arboreos destacan-se pot sua frequereia, formas c bellexa tho complifedo conjunto regctial, estrante aqui dc um viço e vigor inclomarel, o ciun]

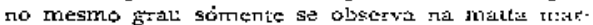
ginal tos grandes rios, attingindo o scir jino de incensidace ria Hylaca ftondose do valle artikn-

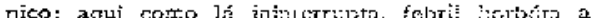
Eaina de procilucçäo, sulire: tucle da follas, perenis

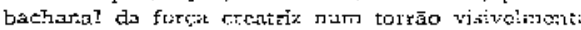
[?rivi]egiado.

Wenos rico de pittorescos contrastes, de agre diveis surprozts a artulientes pontos de descans:

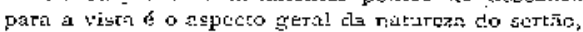
do vasto planalco do Brasil contrat : extenas áreas, com a pouea ou nenlinma movimentaçto dis nive!, cobertas de Gramintas rijas e pithentas: squi bai xás e parcancrie revesidincln o crosta ierrestre, la eleverirdo.se á altura de enbarnçar a oricntação no viajarite a carallo, aiternando com thas de $12 m$ mate ralo, baixo, de vegetaes arbustivos ou de mō̌o tamanho. Estranha impressāo causam nos cerrados os gallos tortos, os troncos obíquas e curros, as folhas, por viz de regre, tandes 40 riaccas, alsm da roupagen espinhenta ou lanjgirosa das associaçōes das caracteristicas formás vege:aes. Sem difficuldaci recor.hecertisus aqui u=n apparelho protecto: contra as excintricidiales do clima continental, iscolá medida de procauçăo conera as investidas das animacs herbivoros, que á proczra de abrigo e sombra nāo podem drixar de frequentar assiduamentc taes capóes de mato.

Esbojados assim, em traço corrido, contornos gcracs $c$ côr de fundo danouilo que $h a$ de fixo immutavel na orandiosa tela da naturean brasilera, e alinhavada a moldura veyzctril, resta-nos estudar a correlatão com as manifeszaçōes da vida anirru:

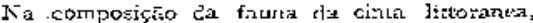
conjrel:cedida entre beira-riat e o pí des serras comes:ras, chtram diversos contiarentes. Tudo qus

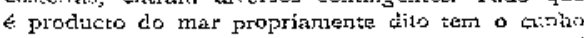

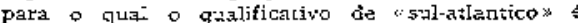
talues o que mclhor corrvem, por caracrericar corn 


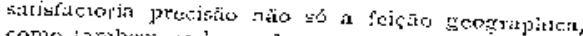

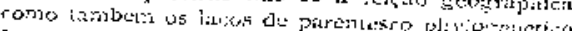

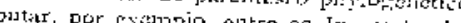

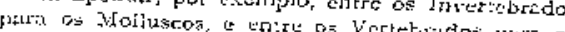

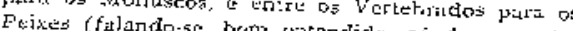
nab-se, beme eatendido, so dis r5pecie marititras)

Dutro contingrente, assiz nitidamente circtum scripto, \& fornecido peln- Omjs littoral, opde antro as Aves acilaticas civisto pronumciado panderncricanisno. $D_{3}$ faltidia dos pernaltos, por rexemplo, he

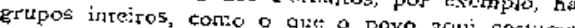

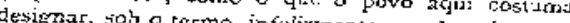

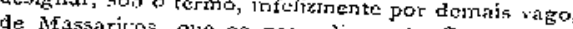

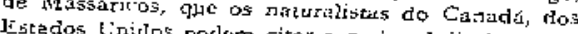
Estedos linilos poclem bitar com igual dircito somo pertententes á fauna dos respectivos país. Diversis

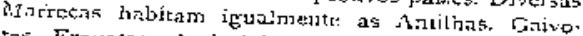

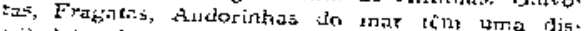
tribuiçăo di vezes incrivclmęull vasta. Nio rundo alado dīose ainda foje periodicas migraçócs cutre pericas miguacoes ctrtre to Pacifiro do comincrite dmorican, ques do lado tenciarico, thter do At]ariticn, mistucóts clija cxis. rencix, ra vidacla, só será jantectida pelo naturalista profissional e cuja origem nysteriosis jax no prossado renoto dis ptriodos geologicos anteriores. Este instirttu migralorio existe tanto no peculeno jejro lo riti!ante ficija-flor, como no do reforchto Gáriào.

Leduzictos csies dois contingenses, iinda Tt:3to da fauna do jittoral תão comstitu coriunto de todo homogenco. Oliando de mais perto, nio tardaremos a reconluece hospedes dis serras cos- teiras cra vijlexictura, por un lado visitantes do sertiue crintral, e da zoná dos cammos, por oultio.

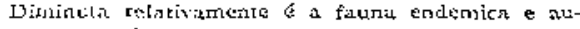

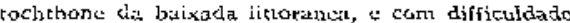
achariamoi uma urica forma animal rais vistosa

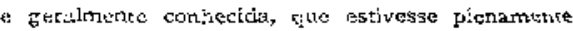
neste caso.

Quaddo muito poderiamos citar etro numero de Aves a alguns Repteis, sem exrepçio abaixo de meio tamanila.

Un Eacto digno de nota $t$ que, tanto entre os Veriebrados como entre as Invertebrados, a ratu. rezá prodizin formas paxticularmente adaptadis ao arbience: ha Ares, Crustaceos, Insectos e Arachnides, euja coloriclo concorda de tal tondo con a arciā, yuc ent posiçāo de repouso niño scrá faci descubrillos.

Sendo compostr de selvicolas, mais ou menos sereros c observantes, a maioria dos Mammiteros, Nves \& Repreis cartcteristicos do Brasil, tompteherede-se cue ra zona das mactas, tatico das serzas conteiras como das margens fluviacs, $t$ onde atharenog conclensala a parte thais expressiva do cont junen faunistico do paiz. Coipacide, portanto, numa e mesma zora visivilinente o optimo de condiços exteriores de existentia no feino vegetil con o optine antmal. Entre as Mammiferos sago os Ma. cacos, as Carriveros, os Rocdores e os Didelphos (Surues) aqueles aos quacs a vida no mato apraz

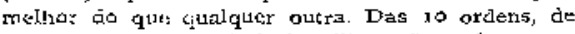

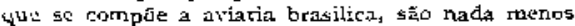




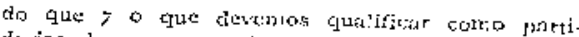

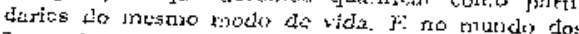
invertebraclos ventes gue nắo 5 e colmportajl de ou. tra mancira os grupos moraclares de terra firmo. Na solinara verecia da flocesta lerisuos a major pro orbilidhde de encontriar as fthomias, deijcados

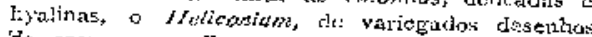
de preto, emirrello e entarindo, os esplendidos Morpho e Cigoat, gigintescas Burboleras clinuras fluc em gravibundo rythmo ostejtetno o brijhes se doso das silas atas celostes.

Interminavel a serie de trpos oue offurece a passarada moritor da ratze. Si no Brasil abe incontestruclmente a palma no riquiza oruthologica, alojando por si 50 pertu de $1 / 6$ de toclaz as especiss de Avos do globo - nen unza mistra parte

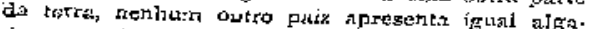
rismo - \& a zona da matra, sobretulo. que contstituc o zenuino viveiro de semelhantit thesouro. Com. "ido destis incomparisel avifaum sto calvez suffi eientes tres typos pista determimar o caracieristico essencial: a schboril Ardea, o groresco Tucotio - mimaso e petwlatate: Bejia-fior.

Nada menos do que 20 familins de Aves bra

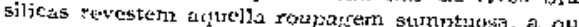

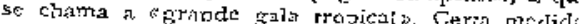

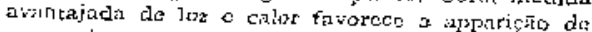
cores vivas, $n$ assima vemos reservalo sialiente po fel á avjaria indigona na arena, encle toilas as re-

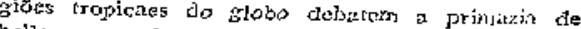
bellexa e opulescia para as suas produccóos. Cí

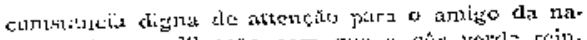
tureza o a predilenta com dilli: it cû́r verda réin. cide aurniname em certas fanilias de: Aves: bustí aponiar, pot excmplo, para a clos d’apagios.

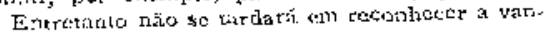

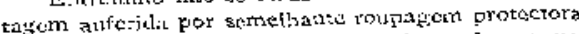

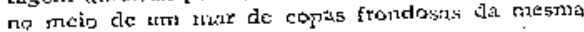
cist.

F tis-noy outra vez rat pista do nisterioso nexts aus.s encre o reizo veretial e o xcino animail $A$

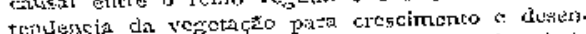

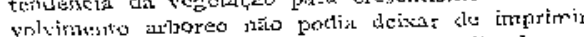
tasulem cuntio pertalior fa fauna a ella ligada por i.s. prisma podemas comprebicnter o costume de tre-

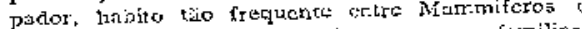
Aves do Brasil, observado ate on errapos of familists, cujos antegasjallos evidentemence eram foitos para a vida complos consticuetn a vida no chao. Siguticativos exe Prezuiças os dois entle os princiros rertanente as Preguicas os dois Tamanduss menotes, os Soluet e Chicas. Nenhtin dos Simios neotroyicos se decide a s.bandonar \$tha arbores vivenda, sinfis por momentos, par nesessiarbercen vivendis clach o ainda a

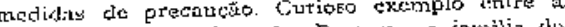

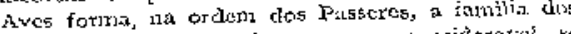
Fomnicariftes, da qual am ramo considteratef desenvolyc rin sometico paralledo coma a fariilia do Picapouz legitimos.

Niais rallid ern coioriclo e fracil em forca nu. Niajs pallidą etri coloriclo e frncil em forca nu 


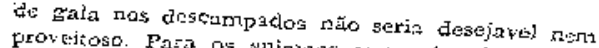
proveitoso. Paza os winizes scranejos 6 de mais

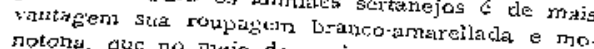
notors, quc no krejo do capin he corlserva e no

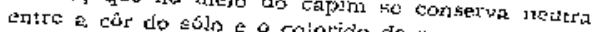
pelo sol

Si for wn lido, no lidtoral, e apparelho urit a and comprida, aproprizda ao wo pcristente e por outro lado o pe trepaciar para o morador de mact --torna-se precioso dote par o morador del mactä, vivern cotrendo palo para formas animas que capar de correspondor a for uma perna comprida para atcesta gimantesca

$O$ proprio Avestruz sul-antericasa.

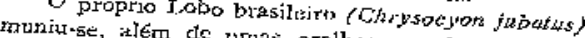
de de Chacal do deserto, de lonerts perras a feitio de algo.

Irra Mlaturiferos terrestres o Brasil actual poilcos pode apresentar: a Gaç pintade entre os $C_{a r}$ nivoros, a Arrs ertion pintade entre os Car-

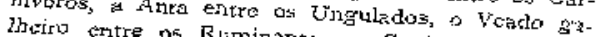
Ruerlares os Rliminantes, a Capivare entre os entre os Desientacios Produdeira e o Tarú-canastro sul-anericano pareos. Prodicto aucochehone do solo deriace unicimexte o ijpo dos Dus ainda dos roedores) que ar

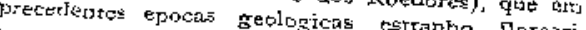

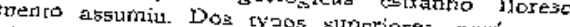
nhum tomou aqui a sua origerores, porim, ne

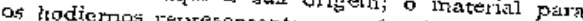
fijtraçes, via Anmetico do Norto de diversas in

nentaes hoje sobreagudas. Os mais viliosos ani. maes fomesticos, como o Boi to Cavallo, embora acliassem condiches notoramente favoraveis en

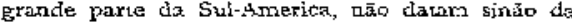
invasto europea. A sil-Amerjca ditrante os quatro ssculos decorridos contribuil com uta unico pro ducto seu jara o inventario internacional tos aniducto seu jara o inventario internacional dos ani-
qazes domesticos: o Pato (Cairina moschata) que ga sula indole semi-bravia dinda deixa perceber uma đom

Concluindo, diremos de passagem que pata a sciencia nüo paira hoje mais a monor tuvida de que $D$ berço do geriero himano rầ deve ter procurado em teritorjo americans".

FONTES DA HISTORLA

DO DESCOBRIVENTO DO BRASIL

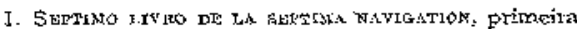
narrativa da viagern de Vicente Anez Pinzon es. criptar por Pietro Martire: a' Anghiera, transmittida para Veneza a Domenico jalopiero orr carta ts cripta da Espanlia, em 150 , por Angelo Eor mardin de Trevisan reproduzida da Raccolta d documenti e studi pubticati dalla R. Commissione Colombiatio pet quarto centertario dalla scoperta delta America, parte 11I, voluune T, pagtinas $80 / 8 \mathrm{z}$ -II Custrota re Sycovoo nayrativa da víngem 
de Pinzon ou Dicgo de Lepci, escripta por Ame rigo Vespireci em carca de Lisboa a de Setembro

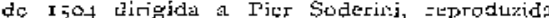
ato raccolia, parte III, vol. II, paginas I ja/160. $\rightarrow$ III. Canis escripra a S. $A$. Dom Mianuel, re de Portugal, da Porto Sceuro da ilha de Ver Craiz por Pero Vasz de Ciminha, escriväo da feitoria que 5e it estabelccer err Calecut, reproduzida regotudo copia extrahida do original cen I87G para a Biblíotheca Nacional e Publica do Ris de Janeiro por Jọ̆o Pedro dis Costi Baston, afficia? mior ta Real Torre do Tornbo.-IV. Cirin de mortre Johannes artium er medicine bachalarius, escripia de Vtra Cau\% a D. Máruel en I de Maio de $1500_{\text {r }}$ reproduzida serando o fac sirnile đado por A. C. Tcixsira tet Aragāo no Cenienario do descobrimento da America. Memorias ua Commissāo Portugucer, I.iston I8gn. - V. Nankats ${ }_{A}$ da siagers de Pedralvares Cabral, enviada depois da sua volta da India por Giovarrai isatteo Cretico, reproduzida et Raccolta Colambiana, parte III, vol. I, pag. $83 / 96$.

VAZ DE CAMINHA E SUA CARTA 


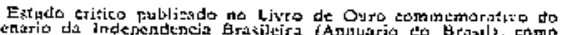
政 do Instifuto H:xtorjeo e Ocograpicite Brasileiro, tomo 7 , parte
Muiros seculos jouve desdenhad a ou esquecida a carta de Caminha, e a este acaso feliz be pódc. sem temeridade, attribuir sug conservaçäo.

Cerca de itgo descolyriu-a en suas pesquisis o erudito historiador castelhano J. B. Muñon, affirma Navarrete. Som sather disto, alyuem ainda descontue. cido fornecen uma copia ao :cal atrchivo da Marinha do Rio de Yaneiro. Delia serviu-se Manoel Ayres do Casal para puhlica-la inregralmente em isiz, no primciro volume da Carogrcphina, sahido dos pralos da impressāo desta cidade. Ninguem mais digno de publica.la do quc o verdadeiro creator da geograptia nacional.

Nove annos depois desta ediçâs princeps, apparecell outra em Lisboa, mais compteta, cotejada pelo original, ao que se crê, no quarto volume das Noticies uttramarinas. Por julga-la demasiado accessivel, ou por autro motivo sernelharte, o Instituto His. torico excluiu da - Reyista Trimensal - a carta de Caminha, so por instancia de Varnhagen estampada no romo 40 , parte segunda, quasi 40 annos depois Ac sua fundacto.

Antes e depois desta, houve nutkerosas reim. prcssoes, arroladas ate cerra época nos Annoes da Bibliotheca Nacionat. Dertre ellas cumpre destacar duas feitas em Lisboa para commermorar o cente. 
nario solombino, inza pela Torre do Tombo, outza pulia Acadernia das Sciencias.

A todas se avantajaria a do Instituco H́storico Bahiano, err 1900, com a reproducrēo fac-similar do cocice, uma transcripłäo em linguagem da spoca e uma versāo modernizada, st do livo constasse como foì obrido o jac-simile, comn $=7$ paginas della correspondem ás sete folhas do original, quem se cncarregrou da palcographia, a qucm st commetteu a versāo moderíl. Taes informaçes substituiriam com vintayem as estampas sem valor historico servidas em seu logar.

Noì Anrzas lamben existe o rol das diversas radıcçঠes. Entre ellas figtra umz em vernaculo, devida a João $F_{\text {rancisco Lisboa }}$

Entendeu, com muita razāo, o Timon maranhensc, que nem rodo mundo poieria orientar-se na prosa emeranhadi do correspondente dic D. Maruel c arvorou-st em sertanista. Seus conhecimentos de erammatica historica näo davam, porkcr, para tanto, מcm Ayres do Casal lhe forrecia um texto escorreito. As passagens cruciaes continuaram e rontinuam obscuras. Urn commentario philologico feito por um entendido, ainda hoje $t$ imprescindivel, hoje mais do que rumca fuáo Ribelro deu o primcito passo no $F$ a Bardão.

Quem era Pero Vaz de Caniriha?

Nos livros de Castanheda e Damiāo de Góes lè-se que sahiu de Lisboa nomeado escrivāo da féitoria a fundar en Calccat.
Da carta do escrivāo resuita que embarcára na capiralea, Tinhato em grande conta Pelrialvares, a ponto de acimitti-lo a um conselho de capitäs da fróta, convocado para tratar de aşurnptos graves. Doria conhecer o monarcha de longos annos; de outro modo r:ẗo se explica o tom familiar d cpistola.

Conforme Hocumentos divulgedos por Sousa Viterbo, orcaria por 50 annos guaxido se dex - acbamento de nossa terra, pois já era maior em 8. de Marco de 1476 , quando $D$. Afforso $V$, de cuia casa era cavalheiro, o nomeou mestre de baJança da moécla da cidade do Porto, por morte do pai, ou quando o pai the quizesse ceder o lo gar. Este, Vasco de Caminka, protegido do Duque de Guimarates, occupou rarios carmos fiscaes, entre outros o de recebedor-mór dos dínleiros de Tengcr.

Nāo é impossivel que o filho mettesse alguma lanca em Africa; é mesno verosimil que suas raras aptidöcs de observator $j$ i se tivessem excrcitado em outras partes e em outros povos antes de attinzir a mestria revelada a proposito dos Brasis: o teparo de que estes năo eram circumcisos (fanados) pode bem resultar do concacto com populaçðes musulmanas.

Caminha começou a escrever em 26 de Abril, depois de ficar decjdido mandar um portador ao reino, con a noticia da terra novamente achada.

Foucas linflas bastam-lhe para a viagem de Lisbora ad Cabo Vende; aisda menos consiagra ao resto do caminho, por este mar de Iongo, 660 ou 
670 !efras, na estimativa dos pilotos, percorridas ngtre a ilha de 5. Nicolau e a costa avistada na tarde de 22. Da Farinhagem \& das singraduras deixot a conta aos entendidos. A 21 nota signaes de proximicade c's tirra, marifestados em lutras compridas cono botelhos e rabos de asno, accrescidos na cutra manhà pcla passagem de aves chamadaz fura-buchos, e afinal confirmatos pcla visán veepertina de serras e arvoredos longinquos. it 23 lrata sobrciudo de manobras, marche, sondagens á cata de bom ancolizdouro, afinal enconurado a 2 :

Dosde entāo a narrativa se expande, afflucm os pormenores, anima-se o scenario e o obstrvador apparece, pesspicaz e sincero.

« Bem certo creia que por aformosear nem afeiar haja de pôr mais que aquillo que ri c me parcceun, essegura ao real amo, c cumpriu a promessa.

Affonso Lopes, incumbido de sondar a bahin dezejala, apanliou dọis indigenas en uma almadia, e levollos com escuro á capitaned, onte Caminha o5 viu e desce logo os desenhau em tracos tivos.

"A feiça delles b́ scrern pardos, mapeira ds avermelhados, de boos rostos e boos narizes, Lem feitos; andam nús sem mesmo lima cobernira, nem cstimian nern uma cousa cobrir nem mojtrar 5uas vergonhas, e estāo a cerca err tanta innocencia como tê toi mostrar o rostro; traziam ambolos beiços de baixo furados e metidos por clles senhos ossos de osso branco... os cabellos seus sấ corredius e ar davam tosquiados de toscuia ala mais que se sobre. pentem, de boa grandtura e rapados te por baixo da sulapa, de fonte al fonte para detriz, uma ma. neira de cabcllcira de: pennas d'ave amarella, que scria dir compricaso de um cojto muj basta e mui carada que the cobria o rolituco e as orellyas, a qual andaya pegada nos cabellos perina e penna, com una confeccão branda como a cra e nāo no era, de mancira jue andava mui redonda e mui basta $f$ mui iglal que nảo tasia mingua mais la vagen para a levantar, $:$

Neste primeiro encontro, em que os gestos fizeram de unica linguagern, succederatese os qui. proquós. Os indigenas purtaran-se en geral indiffe rentes, repugnaram-lhes as romidas e rinho e.com maior rasao, a agua de bordo. "Wostrasam.lies um paprgaio pardo que açui a capităn tràz; tomarameno logo na māo e acenaram para terra como que os hevia hi. Wostraram.thts um carneiro; nâo fireram dclle mencäo\%. Mostraram-lhes uma gallinha: "quasi haviam mexin della a nāo the qucriam jồr a mấ - lepois a tomaran como espantados." Maior in teresse sentiratri por contas de rosatio e objectos metallicos, mat o tétio por fim superou, se entrio atiraraml-se assi de costas na alcatifa a dormir, scrr ter nern uma maneira de cobrirem suás vergonhas... O capitāo thes randou pör a cabeça $5 c$ hhos coxins e o da cabelleira procuraya astä pola nāo que brar, lançaram-lhes Lm mano erm cima e elles congentiram e jouveram e dormiramy.

Sabbado, $\geq 5$, depois de furdeadi a [roca, Ca. minha foi a terra em compantía de Nicolau Coelho. $O s$ naturaes continuan a prender-lihe a curiosidade: 
*Andaram alli muitos delles on quasi a maior parte, 미나 todos trazian aquelles bicos de oszo nos bei. cos;... c andavam ali outros quartejados de cores, saber delies a metade cle sur propría còt, e a metade de tintura negra maneira de zulada, c putros esquartijatios d'escaques. Alli andavam cntre elles tres ou qualro moças, bem moças e bem sentis, com cabelos tuito pretos compridos, pelas espaduas.. Lin era já de dias e andava todo por Iouçainha cheio de pcnnas pegadas pelo corpo que parecia asstetedo como Sajo Sebastiăo; outros trazianl cera. puças de pennas amarellas, e outros te vertmelhas * vutros dic verdes, c uma daguellas moças era toda cínta de fundo acima daquella tintura...?

Domingo, 26, a missa da Paschoela, primeira diza no Brasjl, num ilbeo dà vașta bahia, nầo absorve a ponto de fazer-lhe esquecer os naturaes da terra, sujos movimentos na praia frontcira nota durante o sacrificio incruentes a a pregaç⿸厃㔾 de Fr. Elenrique.

"Andava hi um que fallaya muico aos outros give se afastasscm;... cste que os assi andatra afastanclo trazia seu arco e setas, e andava tinto de tintura vermclba polos peitos e espacluas e polos quadris, coxas e pernas até abaixo, e os vasios com a barriga e estomago eram de sus propria cht, a a tintura era assi vermelha que a agua nzo tha comia nem deqsfazia, antes quando sahia d'agua ora mais vermelha

Depois da missia « vieram logo todo los capitäes a esta sau por mandado do capitäo-mor, com os quaes se elle apartou e eu na compantia, e pergunto asjír a todos se nos parecia sin bern mandar a nora do acjumento destn terra a vossa Alteza pelo havio dos mantimentos pera at ritelhor mandar descobrir e saber della ruis to que nos agora podiamos saber, pur irmos de nossa viagem; e satre muiras fallas que no caso $5 \mathrm{f}$ fizcràn, foi poz todos os a maior parte dito que seria muito bem $f$ nisto concruditan.:

Desta conclusia procedeu a carta de Caminha, e procederiam a de Cabral e as de seus companheiros si o sempo as poupasse como a do modesto escriväo dc fétaria rue escreveu por propro fosto scm responsabilidade official, e por isso tanto nos deleita hoje, e afiria pelas rossas predilecços e curiosidades. De passagern note-se que o nome de Pascholl dado ao primeiro mionte enlrevisto e de terra de Vera Ciné parecern datar des:a do mírga e nào de quarta-feira, 22. O facto de figurarem desde 4 primeiza linha da missiva mostratria apenas como o baptismo era recente. A dcnominaģāo de Fasclual explica-se peì descobrimento no gitavario da Faschoa, a da terra pela bandeira de Christo, entregue por D. Marruel ao capitāo-mór antes da dcspodida em Belérn. Sente-se em tudo isto a influencia de $F_{x}$. Hentique, guardifío dos franciscanos. *Alli era com o capitzo a bandeira de Christo com que sahio de Belém, a qual esteve sempre alta a parte do Ewangello. Acabada a missa desvestio-se o padre e poz-se em uma cadcira alta, e nós todos lançados por essa areia e prégou umat 
solemne e proveitosa pretgräa da bistoria do Evanscilno, e em firs delia trator de nosso vinda c do achamento destä terra, conformando-se corr $\circ$ signal da cruz sob cuji obeciencia rimos, a qual reio

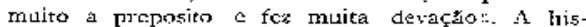
torio das duviclas de Thomé, lidis raquella solennidacic, prestaviase a muicos desenvolvimericos oppor tunos.

$O$ describarque a tarde, depois do conselho de capitates, forneceu ensejo a novas observarpes: "Ait verieis galuntLs pintados todos de preto e vemncho e quartejados assi pelos corpos como pelas pernas que rexto pareciam assi bem; ramben andavam tintre elles quatro ou cinco mulheres noças assi nua que rāo parecian $\mathrm{mal}_{\text {, }}$ antre as quacs uma com uma coxa do giolho atí o quadril e p nadega roda tinza daquella tinnur.a preta e o al todo da sua propria cor; outra rrazia ambolos giolhos com as curvas nssj tintas c tambern on collos dos pc3 . .. tarrbem andäva hi otita mulher moça com um menino ou merina no collo aído coin um pano nāo sei de guc aos peitos, que ihc nāo parçiam se năo as perminhas, mas as pernas da măj e o ె? nāo traziam nem um panos.

Outzo desembarque á 5 counda-feira, 27 , serve a precisar mais as primciras impres 5005 : $k$ Neste dia os vimos de mais perto e mais a nossa vontarle, por andarmos todos quadi misturados, e ali delles andavam daqueilas tintijras quartejados, outros dc motades, outros de tanta feição como em panos cle amar, e todos corr os beiços furados, e rruitos corr
Os o:50s nelles, e dellez sem ossos. Traziam alsur rkiles uns ouriços verdcs darores gue ra cốr queriam pareç castanheiros, serão quanto cram mais e mais pequenos, c aquelles cram cheios de uns srälos vermelhos pequenos quc esmagando-os encre un rycolos facia tinitira mito vermetha da que ciles andavan tistus, e quanto se mais molhavam mai vermelhos ficavam. Todos andám rupados até acima das orelhas e asti as sobrancelhas c pestanas; tra7.ת iocios as testas de fonte a fonte tintas ia tin rira preta que parece uma fja preta ancha do dots dedos $x$.

A attericäe prestuklis is gente conserva a mesma intensidade applicada nos artefactos, e para comple tar-se ro:ta mais de uma $\vee \uparrow 2$ ao assumpto. Assim 2 24 meruciona $\alpha$ assos de ossn branco da compridäo de uma mão tíavessa e trossura de un fuso de algndāo \& agudo na ponta como furulor; ruetem nos pola pare de dentro to beico, $\&$ o que llie fica artre o beico e os dentes $\&$ feito como roque de encadraz, e em tal maneira o razem nlli trcai. xado quar lhes nào dł́ p̧aixấ, nem lỉe tor va a falla vern comer, nuth beber $\$$. A 25 recorda: 2 todos traziam aquelles bicos do osso nos beiços ealghtin que andavam sem elles traxiam os beiros furatos a nos briacas traziam uni espelhos de pál que pareciam espelhos de borrachi, e alguns delles traziam tres daquelles bicos, saber, un na metade e os lous nos cabos's. $A$ 26: esrazin cstc: velho o beiço tä口 furado que lise cabria pelo furacto um gräo dedo poicgar, e rrazia metíclo no furado uma dedra yerde ruim yle 
carava por fora aqlelle buraco, e o capicato (Pedr' ahares) lha fes tirar, e eldt nito $5 t$, que digo falatvad e iáa corra tllá pura a boca do capitäo para lita meter; cstivemos sobrr isso un pouco rindo o

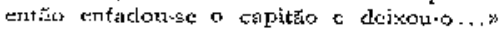

A almadia tomucia por Alftriso Lopes a 34 volta-llac at memoria no dia 76 , 2 vista de uma jangrada: "c alguns delles se meriam en almedius, duas ou tres yul: ahí tigham, as quaes näo sāo feitas coma as que eu jaj vi; sómente jân tres traves atadils jurtass. Ao lado das carapucas variegadas menciona кum pano de peminas re mi:itns côtes, maricira de tecido assoz formosop. Qunto aos arcos * š̉̆ pretos e compridos, e as scttes cormpridus e os ferros dellas dit cannas aparadag $》$

Preso il praia proxima, incerrogava es cue po. deram pentrar nas aldeiay. A 27 : "foram ben

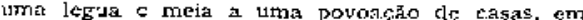
que havelia nove ur dez case, as quies diziam que

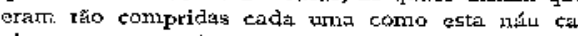
piranea e eran de mackixir e das ithargas de ra. boas e colbertils de palla, de rasoada altura, to todos em ursa so casa, sem nem um xoprartiniesto; tinli:ın de dentro muitos estcios, $c$ de esteio a esteio uma rede atada polos cabos em cada esteio, altas em que dormian; c dc baixo pera se aquentarem fa. ziam scus fogos; e tinha cada casa duas portas pecucnas, uma em um catro e oltra no outro; e diziam que tm cada casa se colhiam trinta ou tcluarenti pessoas e que atsit os achavam, e que lhegs davam te comer daquella vianda que elles tinham, saber, muito inhami: e outrats sementes que na terka ha...) A $2 S$; « Muitos delles (indigeras) vinham al.i estax com os carpinteiros, e creio que o faziam mais por verer a ferranenta de ferro com que a fiziam quo por verem a cruz, porque elles nato tom cousa que de ferro seja e cortam sua madeira e páos com pearas feitas como curhas metidas em uri páo antre

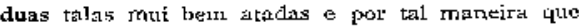
andam (ficarn) fortes, segundo os loomens que bonLen as suas casa (toram) diziarn, por que llas viram la". Fste hontem mpregado aqui mostra qianto escrevel Canjinha no domingo a na segunda, :Ljesax da missa, do sermito, dos pasaejos por max, to desembarcjuc. Exăctamente estit concentraçāo mais avivou-lhe a memoria das coisas vistas.

$O$ talento do observador refinaya pela compa

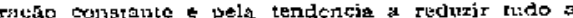
algarisino. F $\mathrm{H}_{\mathrm{i}} \mathrm{b}$ tos adquiritos no emprego de mescre de balaina de móda, obrigado a pirifonos nume. ros e responsivel por fraçöes minjmas?

Compara tudo: $\triangle$ corpo o os membros da gellte desta ede sun terra a abmacera a a cêra, o urucí a as casranhas, as contas indigemas e as sementes de aljaveira, os rostos de wns e outros individuos, (chegando por duas vezes a concluir que eram irmioj), as aves que pasisarn voaludo. \&Imquanto an. davamos nesia mata a cortar a lentua, atravessavám alguns papagaios por essus arvoses, delles verdcs c. outros pardos, trandes e pequenos, cle mineira que me parecc que haverí nesta terra muitos, pero eu năo vería mais cue nove ou dez; outras aveg 
Eltâto näo vimos, somente algumas pomibas slixas c parererdil maioris em bon equantidade ca as de Portugal; alguns dizizm que virim rodas, mas ex non as vis. A 29 : "crouveran papagrias e Dutras aves pretas quasi como pègas si nho guart" tinlaum o bico brance es os rabos curtos\%.

Un trecho já aprovejtado acima póde ser to. perido conno exemplo du nodo por que apurava os conherimemos a boa fo curr que reconhecia sua

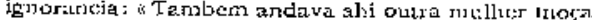
corn um menisto on menita to collo, atado com um pano nāo sei the que, ç̣c nato the parecian senăo à̃ pertinhas:

A conta, o peso, a mellictis sāo-lhe, por assing dizer, improstindiveís: conta as aves que pelsisan, estima è cincoentă a cincoenta e cinco anros a idade de um vello que croconera, orak a largura e o fundo de um rio, aporita as sondigens, calruliz quintos vasos cajoriam na bahia, da as djotancias guarclaclas pelos esquifes num passejo ao longo da praia, avalia pela costa o comprimento da terra nova

Năo pára nas exterioridades $c$, segundo sto pronessu, entat o que the pureceu. Converce-se de falta de senhorl, isto é, de pessoz acatada to te mida, regosija-se com a atisencia dc idolos, tă favoravel ao futtro da caltehose; inclica at an sencin de circuncisäo; nota a indifferenç, a in gratidăo apparente dos naturaes, a esquivança instinctiva seguida logo de confianca indiscreta. "' mavam logo uma esquiveza como monteses... Logn de urne măo para outra se: enquivavatt como pardaes de revrelouro, c homem nä́o llyes ousa de fallar rịo por sq mais nấo esquivarcm, o tuclo se pisser como elles querem pelos bern armitsisar... Os outros dous que o cipitinis teve nas dúos, a que deu o que já ditu t́, nunça aqui mais pareceram. de Que tíru ser berte bestial e de pouco saber e jor isto sia assim csouivos; elles, porern, comtudo, andann muito bern curados e mujto limpos e naquitlo $m$ e parece ainda màs que são como aves ou alinarias montezas, que lines faz o ar melhor penna melhor cabello que als mansas; porche os corpos setus săo impos e thio grordos e tăb termosos que năo póde maís ser, e isto me faz presumir que non tom casias nera moraclas enr clue sc oolham eo ar * yue tet criam os fä tacs. Nerr nús ate agora, ha vitnos nera-urnas casas neri matreira dellas". Isto pensava a 26; a existencia de casas for conht: cida so a 28 de Abri?.

A convivencia despertou cada vTy axtis a sycmpathia pelos filhos da terra a tellues favoravel a scu juizo final, «Cerco ests gente of boa $e$ ac boa simplicidade, e imprim:r-se-a ligeitamente nelles qualquer cunho que lhe quizeren dar, e Iugo Nosso Senhor delr boos coipos a boels rostos tomo at book brimens a elle clue aqui nos trouxe, creio que năh foi sem calusa. E, portarto Vossa Alteza, pois tialito descja accrescentar riz Santa fé catholjca, deve in. terider em sua salvaçăo, prizerá a Deus que com puuco trabalho será assim. Elles năo lavram nem criam, nem ha aqui boi nem vacca, them cabra nem 
ovelha, nem gallinha, nem outra nenturna alimatia que costunada seja ao viver dos homens; nen corucm sericho dosse jnhame, que aqui ha muiro, dczsa sernente (abaty) on rлilbo of frutos que as areores de si lançam; e com tuclo isso andam taeg e tüo rijuз e tăo nedios que o năo somos nós tanto com quante trigo e legumes comemos".

Caminha nTo seria do seu tempo si consagrass largas paginas á lescripcīo da natureza mas es creveu o bastante para mostrar que timber vi brava a estas emucóes.

"Eska terra, senhor, me parece que da ponta que mais contra o Sul vimos ate a outra que contril o Norte vem, de que nós deste porto houvemos vista, será tamanha que haverá nella bem vinte ou vinte e circo leguas por costa. Trai ao longo do mar em algumas partes grandes barreiras, dellas vernelhas e dellas btançs; e a turra por cilina tode chà e muito cheia de grandes arvoredos. De ponta a ponta é toda praia parma e muito cha $\varepsilon$ muitu fremosa; pelo sarria nos parecen do mar muito grande, porque a extender olhos thà po. diamos ver senăo terras e arvoredos que ros pa. recia mui longa terra. Nella atá agora näo podemos saber que baja ouro nenl prata nem uma cousa de metal, nem de ferro, netn lho vimos; pexo a terra em si 6 de muitos bons ares, assi frios e tempe. rados como of de antre Douro e Minho, porque neste tempo de agora assi os achavamos cotho os de la; aguas são maitas infindas; em tal ruaneira é graciosa que çuexendo a aproveitar dar-se-a nelia tudo per bem das agoas que tern».

Uma lacuna o bem nocavel sente-se na epistola de Vaz de Carrinta: o sol ardente, o luar, as con stellaçōes novas, tẽo diversas das do kemisyhurio septentrional, nato lhe artancan und. referencia si quer. A sua ignorancia de sir.graduras e marinha. tias se extenderia aos plyenomenos astroncmicos? En tretanto estus questoes interessaram pelo menos os pilotos da frota, e mescre Joào, bacharel de arte e medicina, ransmituit o eco enfraquecido dos de. bates.

A carta de mestre Joäo, tambem fatada cle t de Maio e descoluerta por Varnhasecty des azo Joanuim Narberto para lovantar o problema da camolidach ou proposito no descobrimento do Brasil. Explicon-o mais tardo com sua bonomia resignada e sur inonia ligeiramente melancolica a quem isto escrevi: apenas quiz semear duvidas. Fstas duvidas

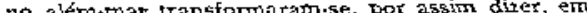
certezas, \& hoje \& quasi clogma alt que o descobri. mento do Brasil thấ foi fortuito, em outros terros foi fingido; pensam alé alguns que o verdadelro descobridor so chamava Duante Pucheco, A Achílles insistatio.

Corninha de nen urm trodo suffraga esta thess: a de Fr. Flenrique contenceu-o e mais de uma vez em tudo ve a mão divina. Os partidarios di desco. brimento proposital deviam pesar bern as occutreycias do conselho dos capitâes reunidos a 26 de abril. Pedralvares eperguntou assim a todos se 
hos parecia ser bem mandar a flova Lo achanento destat terra a Vossa Altera pelo navio dus muntirnentos pera a melliox mandar dcscobrir e saber della mais do que nós arora podiamos saber, por irmos de rossa viagern o antre muitas fallas qué ue cisso se rizeram foi por todos ou a maior prarte dito cue seria multo bext e nisto concrudirams. "Гăo pouco fundamento assiste ass pancryristels de Duarte Pacheco: só a leiluráa desatienta do Esmeratdo permitc transferir para augem da equinocial viagens c descobrîmentos realizados nas altas latitudes do hernispherio do Norte. A dichotomia satta aos othos.

Outra applicasço ño menos curiosa den um illustre historiador argentino â lenga-lenga confusa de sriestre Joüo. Luis $L$. Dotningucz serviu-se délia parn declarar apocryphis a cista ce Caminlin, em um artigo publieado pot La Bitjitoteca, luwenos Aites, 1507

«Los Portugleses (diria nuelhor os Brasileiros, a guen tocă thais de perto), miran con respto 5 a cramental la carta detallada y prolija de Peciro Vaz de Carinha, secretario de Cabral, en clue da al rey minuciosos pormenores de la tierra y cle los indios recojidos en Ios cinco dins qute illi se demotarar.

E'l desermbarco tuyo Iugar el $z 6$ de abril; la carta es del tis de mayo de 1500 . Probablemento fué escripta muchos años después de esta hecha; y este juicio $\$ c$ confirma leyendo la descripción :utóntica te este viaje, escrita por un piloto portugué y publicada por la Academia de Ciencias de Lisboa en la cotección de Noticias Uttra-marinas, worte 2, y la caria del cirujano español de la cxpedición de Cabral, Johanness Fontẹtulans, pul,jicueliz por Varr. hagen.

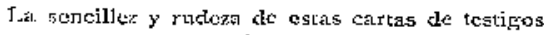
y actores contrasta con el estilo limacio y la narzación llena de jormetnures yue sulo podian conociste desputs de una residencía en a.cluel pais derconocidos.

Nem Caminhat era secretario de Cabral, nem desembarcou s6 a 26 de abrit, nem demotou apenas cinco dias, mas isco pouco inporta. Si o piloto porturuez passou ligeiro pelos dias de Porto Seguro, explica-se isto pelo facro de ocelparse da viagrem inteira de Pedralvares. A importancia dos stuccestos da India, as perdas de navios, o saque da feitoria, o bormbardeio de Calecul, etc., ojscureceram $\circ$ jelyllio brasibeiro. Todo o essencial da carta de caminhe apparece na relaçăo anonyoxa, ás verets em termos quasi iclenticos, e sua chronologia tern tanto de rimorosa como a do piloto de isexacta, o que, atilis, nēo merere $x$ cparo especial, pois um escrevia aco compasso do successo, o outro narroulo mais de urs anno depois. $O$ pituto, scm colorido enbora, thas com precisăo incontestavel, abunda em "pormenores que solo podian conocerse despiús de una residencia en aquel pass desconocido\% Mrestrc Joäo nào poclia da-los, todo embebjd em sstroiabios e mapón-mundi, e, alem disso, tiante do zuna pyerna gue tengo mui mala duc de una cosadura se me ha fecho una chaga nayor que la palma de la macos. 
De resto, o original tri piapel e caracter do terngo, conserva-ge ainda ris To:re do Jombo, sers jamiais ter despertades a minima duvicla cr: quantess on maruseauram. Emfim, slua]quer diploma fabricado visa sernpre uma cletronstraçico ou um interesse. Que the monstraçāo se pods: encontrar na carta do visjante e que incertshe della deduzir?

A 2 de Main partirarn os onze navios, logo raduzjdos n quati netade por umá tempestade ua passhgem de Boa Esperança, donde aproarana a Calecut. A I 3 b: Dezembro foi ali assaltaca a feitoria e morros quasi todos os portuguezes retlit encontrados.

Peru Var de Cominlaz foi un delles quiçá en tuclo casc, moreu na India, cm sterviço del-Rei, segunde uma carta, $x$ egria de 3 de Dextmbro de $\mathrm{j}$ jol.

Isco forcinos a retrocedis.

Quando Caminha comon a pernat na balia cle Porto Segraro, sabia approximalemente o que ia dizer \& com toda a precisản o que ia pedir. $\mathrm{E}$ pois que, Senhor, \& certo cue assi jeste cargo que levo como em outro quilquer outra cojthe que de vosio serviço for, Vossa Altezt ha de ser de mim mui bern gervido, a ella pero que por me farer singutar merce mande vir da ilhal de $S$. "rhome Jorge. d'Osouro. mols crunro, a que della recebcrei en muita metcey — taes sutas vltimas lintias.

A cxplicaçåo é pátente: Jorge d'Osojo forra degradado parz a itha de $\$$. Thoms, c o sogro pedia para clic indurto real. Os documertos publicacless pirr Sousa Viterbo tornatr muito provavel a conclusaro, Cerea de 1491, Jorge dosouxo foi junta-

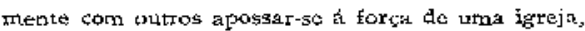
erratamente considerada vasa, e accusam-no de te:r roubado pāo, vinho $\leftarrow$ gallinhas e outras coisas que podistinn valer mil e trezentos reats. Pelo rnesmo terpo dẹu feridas em um clerigo "scilicet, unia pela cabeça, e outra por um braço e outra pelo pescoço e tres feridas pequenas pelas costas\%. Por estes crimes anitou homisiado cinco ou seis annos até que, desistindo as partes, D. Manuel a perdoou a $\mathrm{Y}^{6} \mathrm{E} \mathrm{y}$ de Janciro de 1496 . Talvez o casamento $c 0 m$ a filhi de Pero $V_{a z}$ seruisse a estes perdöes.

Si D. Manuel o fez cornar de S. Thome on si Iá sucrumbiu do clima pestilento, igrara-se. Apenas sabemos que em 3 de Dezenbro de 1501 El-Rei fez mercé do carzo de mestre de balanç a Rodrigo f'Osouro, «neto de Pero Vals de Caminia, que ora falleceu na India onde: a elrviansos, confiasto delle que tanfo que for de idode pcra isso o faré bem - como a ros3o servico e bem das partes pertence. e querendo lhe fueer graça $c$ merch, visto como o ditc sev avio morreu em nosso servico. $)$ Tanto que for de idade... veria entho cinco annos, si Jorge d'Osouro casol loge depois de Jareiro de 1496 .

Fallecendo Radrigo, succedeu-lhe em I $53^{\circ}$ Pero Vaz, seu irmão, que $r o$ arnos mais tarde renlinciou - logar eñ Francisco Pereira.

A existencia destes Osouros seria mais uma prova da autenticídade da carta de Caminha, si realmente podesse ser posta em duvide. Segumelo informaço verbal de Vieira Fazerıda, houve Osouros no Rio, alguns com a pecha de christäos novos. 
HISTORIA PA'TIA 
Nas fromeicas de Parahiba 6 Perambuco continente attinge sı maior expansāo oriental, e a costa do Brasil reparte.se em duas secçocs bern defin:dass de aspecto a dircç̧ão: a costa de Sudoeste:

a costa muico tempo chamada de Leste.Ocste. A dífierencas raturacs entre os dois dechos influirom tambern sobre o curso dos acontecinentos historitos.

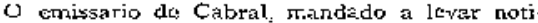
cia da terra novmente achadih chegou á Europa anles de Outubro, pois ao descobrimento dos Por. tuguezes jâ se refere o mappa de Juen de la Cosa. D. Minecl trasou de orgunizar una armada, incumbida ac explore-ia por menor. Constoly de tres navios, coromandados por André Gonçalves, si este foi realmente o portador da nova do descobrimento (1); a bordo servia de cosmographo o florentino Amerigo Vuspleci. Partiu de Lishoa em Maio de 50x; junto a Bezeguiche encontrou Pedrialvares que tornava do Oriente; amarando-se depois para Oeste, avistou o novo hemispherio en Agosto.

(1) Estia noticia deve-5e a Gayjar Corrës, caja autoridase ficola (1) Esta noticia deve-5e a Gasjar Corters, fija autorida de tico de Gama. 
O primciro ponco descoberto chanjola-be cabo de $\$$. Roulue, do rome do 5anto cujo srat o dia. I'inno de Sudoeste descolsticam-se e nomearantse

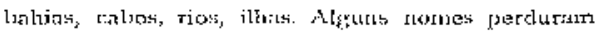
uinda: cabo de Santo Agostinho (2S de Agosto), rio de $S$. Francisco (4 de Ouubro), bahia de Todos os Suritos ( 1 de Novembro), cabo de S. Thomé (a) de Dezenbro), rio de Janeiro ( 1 de Janciro dte 1502 ), aners ras Reis ( 6 de Tameiro), ilha de 5. Sebastiāo ( $z o$ de Janeiro), Sào Vicente ( $2 z$ de Janciro); perderants-5c outros; outros passaram a designar localiclades diversas dacjuellas a que a principio foram applicados. Atte onde rcompanbarane a costa de SW? Ignora se, $c_{\mathrm{i}} u$ : at affirmetivas de Vespucio se prestam a mais de und interpretação. Em todo caso nāo perderam de vista a serra clo Iar.

A armatia cxploradora largou degradados e

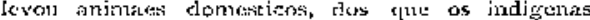
cluartavaris mimbabo na lingua geral. Suas informaçбos serviran de base ao contrato fimmdo por tres annos entre a corôa, Ferriēo de Noroulia c alkubs christî̀us novos, estabelccendo ; obrigaçắ de explorarcm a costa, concedendo-Ihes o monopolio do commercio, défininelo os dircitos a pagar á fazencla tral.

Cans corsequencia do urrenclanicrio partu nova armada em 1503 , composta de seis navios: deviát, cntrec outrans coisas, ver si encontrava rovvo camstho para as Indits

Já sabiam os Portughezss que chegaram a vor- dasteira Inctia, donde trazietra as especiarias e ou. tass drogas preciosals, por cujo jiskr se atiratum

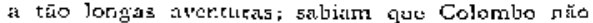
alcancara us reinos de seus sorahos, e isto estayam cridenciando as genter atrazadis deste laclo do Atlantico, tăn divcrsas los povos do Gräo Kihar. e de Zaitun e Cypanco, c de suas riquezas apregoadas par Mateo Polo.

I glioravam, portem, a existencia do oceano Eacifico; criam no predominin no esnaco tas partes soliclas sobre a mitssa 1:civida do pluneta; achavam D plano de Toscanelli (:) plausjuel e exequivel; tormisaln ns terris de Colombo e Pelralvares por guardas avançatas do continente oriental queriam o espernvar, um estrejto, que os levaria adiante, seul palssar pe'o cabo dis Tormentas. Resurge agora e preciss-se a idea de clregar at Indiă rumn $\mathbf{S W}$, mais tarde rerlizada por Fernatruo de Magatháes. circummavegando o globo.

A armadir commantada por Grontyalo Cocho percleti dois navios proximo dn ilha ulteriormente claamarlá de Farnāo de Nortonla. Scińdia-se tritão en dua Modill:as: uma, sob o commando de V V cspucio, demosou ne ilha trifasta, passou depois a bshia de 'luclos os Suttos te do cabo Frio, onde carregon de pau brasil e dali tomou para o reizo, $5 \mathrm{~cm}$ milis inquirir dal sorte clos companticiros; outra soguiu para o Sul, onde Goncralo Coetho este-

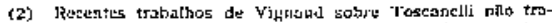

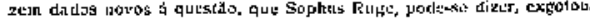


cionou bistapte tempo, sem aljás dilatar os confins de contecicto, segundo parece, Fla clucul ligue a este branco o nome de carioca.

Outros ntrios continuarim a procurar o Basil na viggencia do arrenclamento. Uma amach rnertice particular mençāo: a de D. Nino Mantre], valjclo c collaço del rei, socio de Cristobal cic Ilaro. Mandacti en I sris, periongou a costa de $\$ W$ até un inunenso estuario tido peto estreito suspiraclo, avan cou pela Patagoniz a lovou para Furopa noticias de scrras nevadas e paircs aburdances te rurro. 0 zit da Prata deve seu nome a un macliado desic metal pela armada de D. Nuno Martuel encon. trado cm suas ribciras.

Eecassciari muito as noticias das exploraconos fa costa de Leste -Oeste. Joāo Cuello, (Joìo de Lisboa dos primejros mappas?), Pero Corso, Es. tevant Froes estiveram por aquellas bandas. Onde? quando? I gnora-sc mesno si its exploraçocs partiram de $S$. Roplue para o Amazonas ou do Ana zonas para S. Roque, como a que se attribue a Vicente Anex Pixzon a Joño bolis em 508 .

Durarte todo o seculo XVI as duas seccóes do littoral ficaram segregadns, e a.ssin continum. ram de facto enquanto năo houve navegaçăo a rapor.

Istas exploracōes todas provaram cue o Brasil era improprio para ser logo trafegrdo. A populaç⿸ indigena, rala e rucle, não aprescitava centros de

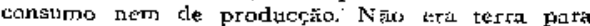

commercio, mas para agriculcura; at collueita exigia prévia sementcira.

Ferna de Nurunla e sels socios colmeçaram a cortar pau brasil, e co:tarart en tan chantidade clue, com posco, a tarritorio trocou o nwme de Vera Cruz ou Santa Crue pelo que ainda conscrva. Dess. cobriu-se que os Brasís como os Africatos bem podian scrvir de estravns. Anjmacs vivos, como saguis, ruacicos, araras (algurn tempo chamoli-se to Brasil tersa dos Pajagaios), pekles, algodio, pimenta completaram os carrogamentos. Providelmotite Eorart aqui deixados algurs animaes coma gallinlizs, porcus a cabritos, c valvez tentadas algunus plantacios. Si tiverent tazano os que combatem - incligeratio da baninctra, esca platita deve ter vindo desde as primciras expediçost, tào vasta a area era que gevographicamente ge distribue. Tal. ves se refira a estas erss prirtitivas um vago boato sobce a prohibicä́a da cultura do gengibre. Tamberm a çna de assucar foi introcluzicla desde o conneso.

Navios destinados an Oriente aqti passarana a fazer aguadu e lenha, a refífescar on a aguardar melbot tempo para dobrax o cabo da Boa Espe. fancin, serppre tormentoso. Soldados desertaram indizitos pelas seduccóns de vida livrc, clegrachados remetteram-sc do reino e até da Incliz. Nizrifragos, freçuentes na costa pouco conliocida, forneceram outo convingente. Para facilitar as carán do havios, de uma a outra viagem ficaram feitorcs, que, con espelbos, avelorios e sobretudo ubjectos mie tallicos, obtiveram dos retarclatarios lomeris it 
idade de pedía penetrassem ro screāo á proctra ic pall vernelho, transportando.o a hombros para - littoral. Estanpas quisi contemporaness represen. taram este espectaculo.

Fundaram-se feitorias. I'odemos imarina-las galpōes mais ou menos espaçosos, assentes no mejo de wra estacada para cvirar surpresas, tendo por mobilia alsumas arcas e caixotes contendo on generos de resgute. A installaçāo summıria perrititia mobilizal-as como simples barracas, apenas havia notjcia de outro ponto mais vantajoso, ou surdia qualquer receio ou desconfianca. Mais tarde estes estabelecimentus chesaram a tor artilharia.

As relasōes entre indigenas 5 alienigcrias variavans $\operatorname{com}$ as latitudcs. Nia costa do Rio Grande do Norte a primeira expediça de 501 entrou logo em conflicts con a gente da terra, provarclmente Petiguares. En outros pontos a cordialidade durou mais tempo. Na Gazeta allemã portadora do noticias da armala de D. Nuro, lése que, zinda em I3-14, honens e mulhores embarcaram alvorocados para alem-mar, onde pensavan depiras a tecta da. promiszão, A historia desses primitivos tempos em. buch-5e en lugendas obscuxas, conservaclas em roteiros c mappas coevos, que picam a curiosidade e soiram a phantasia: rio dos Kefens, bahia dos Innocentes, ingra dos Negros, terra dos Funos, basia da Traição, etc. Que innocentes? Que ncgros? Que traiçżo? Que fumos?

A anarcin sobreyeio naturalmente, pela volatilizacaxo dos instinctos sociaes dos inmigrados, e pela a:tract,ăo da massa de selvajarie alestrarido por tadas as regiōes accéssireis. As rejacyucs com as cunhās, de que jogo nasceram filhos, chamados ma. malucos; a presenca e ajucla em suerras de unk tribus contra outras; a assistencia aos fesins anrhropophagos marcam o processo rerressivo dos colonos. Houve alguns que mataram gente no terreno, ataviados á modia dos Indios, $5 \mathrm{cg}$ dondo seus ritos, informarn os Jesuitas; houve-os cue trincaram carne humana, confima Itery; um no Rio Grande do Notte furou os beiços e as orelhas, affirma Gabriel Soares. Alguns raros, arremedos de sobrehomens, dominaram as vizinhances: Joäd Rumalho, 0 ba charel de Cananka, e, com muito menos força. Caramurú (s).

A unarclia fermentou com mais violencia quando appareceram os Francezes. A primpira via. gem aucritica, a de Binot le Paulmier, de Gonnsville, em 50j, juntararn-se outras e outras, tancas

(3) En esta vay'a hallamos on portugues que svia yeynte ci circo (3) Eue costabn alli entre 108 indios y con él otros asis o siete por-

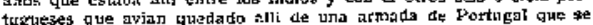
avla perdido en aquella costa y este porlugues me dio de in que teria

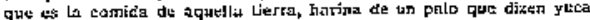
y algunas batatas y raizes dy apio $y$ harto poco y alli cierta gente

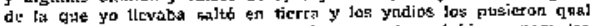
gu madre los partio y aun segun desputs sube estubicron paro jos correr simo ftera pot un otro hidalso portugues que estava alli que

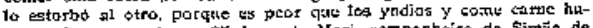
manti. lsto ascrevia en 35 Juan do Hori, companheíro de Sintăo de

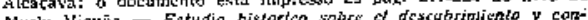

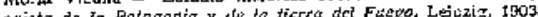


quet nāt cediata em numero ís dos Porlugutzes; c corno näo tinhan de parar dircilos á coring, rem precisariam de licenca dos idrendarisios, \& seus na. vios jarl diectamere as costas nortrandas ou flarrengiss, proximas dos celtiros populosus onde as crogas do Brasil uncontravan mais accitacha, as viagcrs dos Franceres saldím maís provcitosas c prejudicivam serialatente aos mareantes e mercato Tes de: Portugal.

Rcbentaram conflictos entre os representances dos dois povos estratiguiron, cos Indios formaram ao bado cie cida un. A favor dos Mfeirs, sto e. dos Francezes, rombita an os Tupinambás (Poti

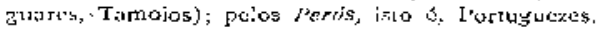
declara-am-5o os lupiniojias (Tibajaras, Piertes vortes dos Yrancescs). Agurlles acmatuaram do preferencia " littorst peraatributano, como prova a denominacio de bois de fernambotze, dacio zo parl brasil. Si Peruhipe, rio bahiano, quizesst dizer ilfua dos Pserbs, poder-se-ia concluir que es:es referiam ns plagtas descoburtas pot Cabral. A hostilidadi cotre us Tupinambas e os Perós persistiu durante o correr de tocio o seculo $\mathrm{XVI}$, e so terminou com as den vastaçöes terriveis de Btrito Macicl nas brentas do Maranhāo \& Fars, nos primciros lustros do siculo seguinte.

A irinizacle $e$ os conflicros witre Francezes $c$ Portuguezc proseguirum con vario successo. Já err 15 I4 D. Yíanuel majdivio á liranç qurixar-se. contra as invasōes clos entrelopos em sris dom:nios uhramarinos. Quando D. Io 10 ill subiu ao throno en $z$ t verifican tic o Brisil, a pritscipio Ente de

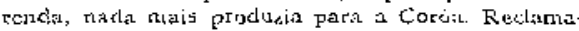
cücs reperidas, neyocincoss secretas, peilas de altos funcrionarios resultaraliz cm promessas näo cum pridis. Impunlua se stitude mais encergica. Fan 27 resolveu si rablodar tura armadia da guarda-costa orclens de Christovar Jaques.

Casteliłano 2o serviço kle Portugal, Christovam Jaques já ustivera no Brasil os ultimos tempos, aiada por mandado de D. Mrnuel. Encairegado de pes quizal ricties, cheerara ate a rio cla Prata, onds alguns companheiros de Solis confirmaram is no.

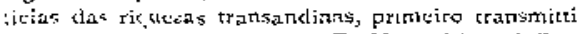
dis a Eiropi na asmada de D. Nuno Hiduel. Fro.

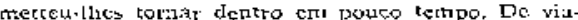

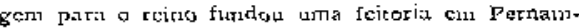
buco (ग), que rtrirou algums annos, ravivez de 27 a 30.

Sob a novo reinadu, Christovam Jaques reclatrous os premios promestidos por D. Miantaes, si sua expedirano disse resultado; abortecto das delongas, offerecelusc io embaixador de Carlos V em Evors, part tomar novanente o serviço de Es-

(4) O que se ilfirmas gquj sobsc C. Jaquts resulto de uma carts

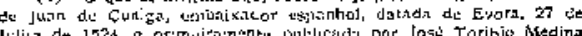

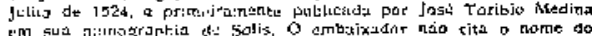

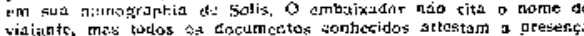

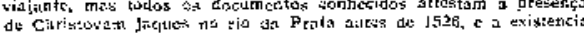

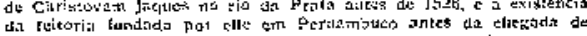

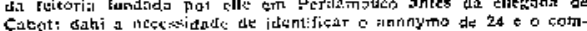
Crandants da armadia de 27 
panha, st the compersassem os cincoenta mil meravedis de cortos regiengos que deistructava en Portugal.

Afinal poudt vir sovamente ao tirasil, mas corn objecco muito differente do que pretendia, - nāo a devassar minas, mas a guerrear Francczes.

De uma rau e cinco carayellas conscava a arrada de seu commando que ern meiados de 27 : aportou a Eernambuco. Ueria caravella tornou logo dali carregadia de pau brasil. Com as outras vinjou para o Sul, travando combates scmpre victorioso contra os Francezes, urn delles na bahia de Todos os Santos, sezundo trádiç⿰彳 conservada por Cabriel Soares. Grandes crueldadcs anclam associadas á sua memoria: entcriava prisioneiros ate o pescoco para alvo de pontaria; entrefinaros a voracidade dos anthropozhatros, perjuro de prometsas feitas sobre a hostia consagrada. Nistas historias deve entrar muito exagesco, si effecivamente aíncla con duzju para o reiro trezentos prisiontiros, como parece. 'Tambern poife ser jut o nuriero dos Erancezes fosse muito maior do que imatrinamos. Em 28 Antonio Ribeiro aşumiu o commando da as mada ple guarda-costa.

Christovan Jaques, que en 24 affirmava ao embaixador espanhol nan existir coisa de proveito no Brasil, tiradas as minas do Frata, expoz no reino em 529 un plano de colonizaço dá lerra. Do facto conhecido e attescado par Disgo de Gouvèa ignoram-se as circumstancias. Talvez as queixas, furdadas ou nảo dos Francezes, se onpazessem a acciraçăo da proposita cle seu ferretllo perseguido: Em todo cast a idea de colonizar as terras des. cobertas por Perdravares ardava por essirn cizer no ar. Aprescritou-a ao mesmo tcmpo alourem que nunca viera ao Brasil: o irmăo do capiräo-mor dit 5. Míguel, Jozo de Mello da Camara ("), descendente de unsa familia de illustres navegadores, como icmorava cm carta a D. Joăo 11I: a porque a ilha da Madeira meu bizavoo a povoou, e men avoo a de Săo Migel, e misu cyo a de șāo Tomé e com muito trabalho e todas de geitu que ve, e cu espero parectr-l1je nisso, pois no mais as earonyrus dos rejs pasados dour em prova, e sc mā corlhecera de

(5) Uma carta de Diogo de Gousvìa, velgarizada nor Varnha-

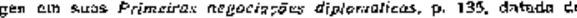
29 je Fuvertiro (sic) de 15.32, diz que tres alinos anfus se ojicteecram a povaer o Brasil o irtito do capitäo da ifter des. S. Mizuet com dois mis tritratorus e Christcyars yagues com mil. 1sto fixa

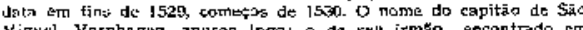
Yigz:el, Varshagen apuron logo: o de seu irmato, encontrado em liveos de historic acoriana, sppatece agora pela srificisa vez i carta ac Joso de Metlos prols 1898 . náo ter data nem indicar o logar inde tol eacripta, o que faz com que nos parç̧a ainda mus prolixa e obłeura. Irdubitavelnulertes

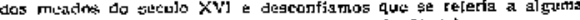

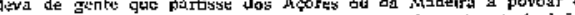

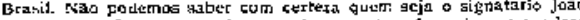
de Mello da Camara, que faz ums importante referencia aos swrviço de stus antcpassado*. Un delles, seu bisand, povogu a Madeira; sel

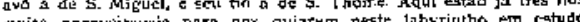


mi a que digo rï connettera tal emprean né menos estes omcs me escolheră pera issu, ne' qizerāo gutstar suas fazendas o aventurar suas pissoas comygo\%.

Qual o plano de Mello da Camara? "Por em duas riages rail moradores \& pessoats tiles e ourigarmis a iso a minha propia custa e desplosa claqy a myl e tresentas lletoas, a ganhar ihe hume tert de cue rā :om nenbum provito e pode ter muivo e pronarhit e conqyslarlha de muitas gentes que tern e mui gerciras».

E contína: «cu a qero servir sem gastar de sua fazenda nentuma cousa, e porque os onens que comygo hāo de ir șo de muita sustancya e pessoas muy abastadas, \& que podem röniyo llevar muitas croas, carallos e gadoz e todallas cousas no cusarias para frulyfiesmento da terra, e săo taes que pera a conquistarem e sujigarem em nenhuma

mais demorado, Em todo Caso, a carta merete năo ficar so esquzecitnersto dos afchivos e wob mais rigoreso cenme cive ser interesean-

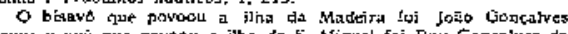

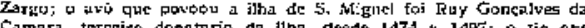

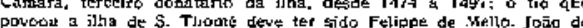

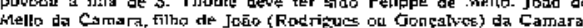
quarto donatario de S. Misuet, e de D. IEner da Silveirs, mettellare tracte Ie Aleobaç, mate depois obteve bullas e provisōes apostolicas, park passar i ordem de Santiago. Nas demandas a que allude carta publicada por Sousa Viterto, obteve sentenca fasoravel, tes-

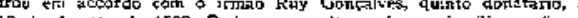

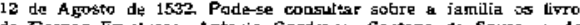
de Gaspar Fructuoso, Antorio Cordeyro, Caetano de Soursa o Ar chlyo dos Acores, parte saberia buscar outros que mais para iso foṣem c nā sä omens que estimerr. tāo poucuo o servico de vosa allteza c suas honras que se contentem com cerem quar:o indias por mancebas e comerem dos mantimentos da terra como faziam os que della agora vieram; que eses s̄o ô quc lla queren tornar por thoradores e outros taes $\%$.

A allusāo é clara a Christovam Jaques, a quen Joāo de Mello da Camara em outos pontos se refere com actimonia, insistindo beri cor que elle Camara é nncional. o que nāo teria scntido si Christovam Jaques tambea o fosse.

A proposta de Camara nāo $5 \mathrm{de}$ del andamento: n Brasil contiruuu entregue a homens que se chr tentavam : com terem quatro indjas por mancebas e comerem cos mantimentos da terras.

Esta expressão lapidar resume mais de trinta annos de nossn historis. 
Que tra is vida sigura c conversavel:, jnsti. tiida por Marim Affonso nas praias de $S_{a}{ }^{\circ} V_{i}$ cente e nos campos de Piratininga?

Ao comecar o seculo XVI, Forrugal labutava na transiçāo da idade média pára a éra moderna. Coexistiam em sctio seio cluas sociedades completo.5, corn sua hierarchia, sua lecrislaçăo e seus iri bunacs; mas a sociedade civil nāo professava mais a superioridacle transcendente nem se sujeirava : dependencia absoluta da isreja, despida agrora de muilas de suas historicas prerogarivas, obrictula a reduzir țuas pretençōect.

O estado reconhecia e açatava as leis da igreja executava as sentencas de seus tribunacs, ieclarava. se incompetente em quaesquer litigios debatidos só entre clerigos, só punia um ccclesiatstico si, dippis de degradado, lhe sra entregue por seus superiores ordinarios, respeitava o direito de as\}lo nos ternplos e mosteiros para os criminosos cujas penas cram de sangue, abstinha-se cle cobrar impostos do clero.

A igreja dominava soberana a familia pelo baptismo, tăo necessario 2 rida civil como á sal vaçao da alma, pelo casamento que podia permittir. 
sustar ou annullar com impedimentos clirimentes, pelos sacramentos distribuidos atravez da existencji inteira, pola excommunhão qui incapacitava para rodos eltes, pelo interdicto que separava comrinjidades inteiras da communicaçấo dos santos, pela morte, permittindo ou negando suffragios, dejuando que o cadaver descansasse em logar sagrado juxto aos irmāos ou apodrecesse nos monturos ern com panhia. dos bichos; dominava pelo ersino, limi tando e defirindo as crencas, extremando o que se podia do quo nāo exa licito aprender ou ensinar

Contra ella, ra esphera estreila ainda em que firmara sua competencia, Hepois de luas com o japado e com o clero indigena, o estado empre rava o plact para os documentos emanados do solio pontificio, os juizes da corùa para resguardar certos otgăos essencjatss no exercicio norma! da soberania plena, as leis de amortizas, āo para iimi-ar.lhe as accuisicões prediaes, as temperáliclades para abater ccrtas resistencias. Im compinsa-

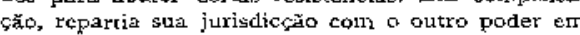
casos por isto tha mados mixti forl, prestava o braço secular pura execucar, até por morte víolenta, ot condernnados pelo juizo ecclcsiastico, duramerte castignva certos actos só porque a igreja os corlside hava pecrarsinosos, etr bumtral o mesmo que hoje

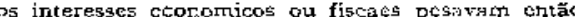
inspiraçōes: religóosas e consideraçōes ecclesiasticas

Apesar de: tudo occorrian frequentes aterito entre a igreja e o estado, aqueila disposta a abri o menos possivel mão de stas attribuiçốes antigas, estc conquístando ou assuminde sempre novas attribuicítes, para arcar com os problemas croscentes, iegados oncrosos do regimen medieval, exigencias inadiayeis de uma situaçăo transformadi pelo com mercio fortalecido, pelas communicaçōes amilúadas pela industria renascente, pela renovaça intellectual, pela circulaçäo motallica cm luta contra a teonomia naturista, Jasgando horizontes mundiaes.

Como, o papa, cabeca da socieclade retigiosa o tei torraura-se o sujeito juriclico da sociedade cit vil; na qualidade de senhor absoluto, seus proderes nāo admittiam fronteiras definiveis, in rocados como um prillcipio de equidade superior, como rernedio a casos excepcionars. graves e imprevistos. De ou tros poderes sutceptiveis de clefíniço, podia fazer uso mais ou menos completo e aliena-los $\mathrm{cm}$ partc

Ixa direito real bater rnocoia, crear tajitües na terra e no mar, fazer offjcines de justiça, do infimo ao pino da carreira, rravar guerra, chamando - povo us armas com os mantimentos necessarins. Papra seu servico tomava careos, bestas o havios dos subditos; pertenciam-lhe as estradas of as vias publicas, os rios navegaveis, os dircitos de passagens de rios, os portos de mar com as portagen. relles pagas, as ilhas adjacentes ao reino, as ren da* das pescarias, das rtarinhits, do sal, as minas de ouro, prata e quaesquer outros metaes, os bens scm dono, os dos malfeitores de certos crimcs. Elrei concentrava toda faculdade legislativa, os votos las Côrtes $\$ \sigma$ valiam con o seu assenso e emquanto the apraziam, pois as disposiçōes mais precisas podia 
dispe:ısas, especificando-as; tuizes e tribunaes oram deturgentes do throno.

Abaiso do rej estava a nobreza, ntirmerosa em: familias como nas distinçöes que separavam umas de outras, comprehondendo descle os senhores to. natarios, com hontas, coutos é juriscicçă̄, 巳 os gráos-mestrés das ordens milinares, cuio nestrado o rej houve por bem afinal assurrir, ate sineples cavalheirss e cscudoiros. Scu poderio lôta grande; ayora conientava.se con o monopol:o dos cargos publicos, соп o papel salienee nos tempos de guerra ou ros conselhos da corôa, çom a situaçäo orivilegiada nas questrits prenacs, em que o rituto de nobre deferdia dos torntertos ou acarretava dininuição de pena. Al nobreza nāo era uma casta exchoiva; davan para ella varias portas, entre as प나명s as das letras.

Aluixo da nobreza acampara "s povo, a grande massa da nação, sem direitos pestodes, apeias defendidos scus filhos por pessoas morats a que 3e acostavam, lavradorck, r:icalicos, mercelolores; os de nor qualidade clrantavatre se homens bons, $c$

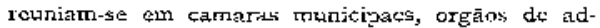
ministraça loçl, cuja importaricia, entāo e sempre somenos, nunca pesou decisivanente em lances mo menzosos, tien no reino, nem aqui, apesaz dos es. forcos de escriptores nossos contempuraneos, illudiclos pelas apparencias fugazes. on cegados por idéas preconccbidas.

Abundaram pessoas moraet a que o poro se podia filiar, - corporaçōes limitadas como is de mocdeiros a hombarcleitros, coilceritidades maiores como os cidadáos do Poto. Os privilegios inleterentes a estes foram outoryados a varias cidarlcs du Brasil, Mrazanhāo, Bahia, Rio e S. Paulo pelo menos: pelo que encertarn dāo bern a idéa de di. rei:0si regateados a quem tinha para sotcorrer-se at mera quálidade de ter humano.

A estes felize: cjelaciāos do Porto corcedcu D. João Iิธ

que elles näo fossem metidos a tormentns por ncribuns maleficios que tivessem feito, commetído e cormutressen e fizessem clahi por diante, shivo nos fivios \& daquellas qualiciades e nos modos em quc o devem ser e são os fidalgos dio reino eso ninores:

que nấo podessẹn ser prezos por nenthim crime sómente sobre suas monagens e asssim corno o. são e devem ser os ditus fidalgos:

que podosscrn irayer to trolixestem Trot tocos os seus reinos e senhorios quaes e quantas armas the; aprouvessem de noite e de dia, assim offensivas corno defcnsivas:

que: nào pousassern cum elles nem lbes to. massem suas casas de morates, adrgas, nem cavalıariças, nem suas bestas de sella, nom outre nenhuma cousa dt: seu contra stas vomtates e thes catusjem \& tuardessem muito inteiramente suas casas, e houvessen com ellas e fura dellas todas as liberdades que antigamente javiarn os infançdes e incos homars; 
que os servicates agricolas só fossem á guerra com os patrös.

Abaixo do rerceiro estado havia ainda os ser vos, escravos, etc., cujo dircito unico se cifrava cri poderer, dadas cizcunstancias favoraveis, passar classe immediacamente superior, pois, compuanio rentes as separacóes, as classes nunca se transformaram cm castas.

Os rros braços do clero, da nobreza e do povo. convocados ext otcasiōes solcnncs \& a interviallo arbitratios constituiam as Cortes. Merancite cor: sulirias on por igual deliberatixas? Iiçujdern entro ij este ponto os craditos de alér-már; fọra de dyvida \& que s6 valeram emquanto os reis consice rarata reinar como urn officio e precisanm clts recursos pecuutiarios

A prosperidade c o porommento do Brasil pro-

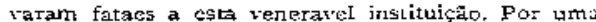
coincidencia rada fortuita, reuníram-sc as ulimas Corres em 169\%, quando o ouro das Geraes comecava a In:lumbrar o mundo, e $s \delta$ reviveram con a revolucão franceza, as guerras napolconicas $c$ a independencia de facto do Brasil, trasladada para aqu: a sede da monarchia portuguezá.

Em I 527 a somma total dos fogos em todo reino andava por duzentos e oiterta mil quirhen. tos e vinte e oito; dando a cada um destes o nt mero de quatro indíviciuss, a populaçāo do reino seria naquelle arno de un milbāo cento s vinte dois mil cen:o e doze almas. Com esce possoal exiguo, que nāo bastava para enche-lo, ia Portuga poroar um mundo. Como conscguj-Io, sem romar "mulheres da serra por mancebas'?

A ayricultura ostava atrazada. Damiäo de Cbes. que conlecia os trabalhadores agricolas de Portu-

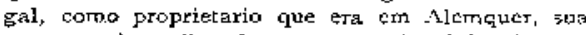
lerra natal, explicando, em r54r, á opiniāo leirad da Europa a razảo dos atrazos da africultura cm Portuga: e Espanina, faz-lhe saber que * a jertili. dade espontanea do solo \& manka que a maior parte do алло os escravas it os homens pobres se rodem sustencar lauramente de fructos silvestice mel c crvas, o quc os faz pouco propensos á agri culeura». Não estava esra gente lisposta a arirar-se Iogo á mandloci e contentar.se com os mantimentos da terra? conn the reproxava indignado Joāo do Mello da Camara.

De todos estes clementos da vida terorra e conversavel, já nos disse Fero Loves quaes Martim A.ffonso implantou nas virgens planas paulistas; deu terras em 5tsmarias, criou camaras, nomeon alcai des, rabelliăes $\mathrm{c}$ juizes, com que cada rm ficou se. nhar de seu, vestiu as injurias particulares, ctc.

Fundadas as duas villas, Martiru Affonso to inou o parteer das pessoas que para isso eran sobro - proceder mais ajustado $\boldsymbol{A}$ situaçắo, e concordou. se toriarem os navios para o reiro á vista do scu lastimoso estado, levando a girte do mar, para nāo ficarem perceberido soldo sem prestar servicos, e comendo os poucos mantimentos. O capitāo.mor aguarderia a volta de Pero Lobo e Francisco dre 
thaves, com os quidrocsintos escravos carregados the wiso.

Quar:a-fcira s:2 It Miaiu, umi kora antes da wol se raor, sahiu Pero Lopes do porto de Săo Vicente; a 24 polo meio día tertirou ma bohia de Ge. nabara A espera da Santa Maria das Cusicléas,o preparacivo de mantimentes jara tres mezes toma rarr wodo o mez de Jutnho. So a 2 et Julho partiu a armada, reduzicln agora a dois navios: o tuleâto S. Vicente $c$ a lual tonada nos Francezes, prara a qual Pero t.opes lnfo se palisou. A 18 entravan na bahia de Todos os Santos. Durante duze clias dc clemora, caitataram-se os altos dos mavios, tomarnm-se mantimentos, fizeram.5e outras coists ne cessărias; passácla revista f́ gerute propria para lu ar em combittes apurou-se gue eram cincosita ires.

Proseguiram a 30 de Julho. As aguas corrians para o Norte; a 4 de Agosto tstuvam na ilha the S. Aleixo. "Dumorava-me ao Notre, c comlo ma cheguci a ella vi hóa náu yue escava surta entro clla e a serra: parceia ser mui grande: Iog'o me. cieci da cavea, o mandei fazer prestes a artelharia (: rnandei laxer sinal ao galcāo eue vinha jur mitha popa, e en chegando-se a diyrt loe disse que puscssc a artelharia em orcem e sc lizessis a gente prestes por que si a nílo que estava nat illa surti fosse de Frarsca, avia de pelejar com ellan.

Era effectiyamente franceza a nau? Houve peIeja? O diario interrompe-se açui para só continua tres meres mais tarde: $\alpha$ Segundi-foira 4 dias do mes de Novembro da era de 1532 parti do porto de

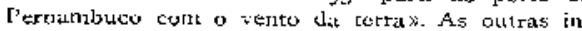
formaryes que se extendem ate sabbado 23 , com aț quaes termina i narrativa, nerm uma referencia farem aos successos. Fundado ern docurrentos des. conhecidos uinda, asstgura Vambisen que Pero Lo pes tomou uma fortalesa ali estabelecida pelos Fran: ceres e dejxanto-a guornecida de rente sua ás or deny de um Paullos Nuncs, fez-se do vela part portugal, levando consigo duas naus franceyas quo comata, alguns indias $c$ trinta e tnntog prisionciros.

Dois documentos. um dos quats conternporaneo,

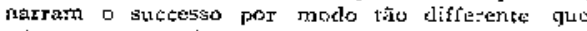
pode haver duvida si em I'ernambuco praticou unl ou duas pmexos o irmīo cle Martim Aifonso.

Segurdo o primciro, Bertrand d'Ornesin, ba. rao e sentor de Saint-BIancard, armou entr MarseIt 1 a uma nau chatadia La Péterine com muitas pe fas, cento es vinte homers de armas, es maindou. a resgatar en Pernambuco. Depois de tres mazes do viagem, approximadamente om firs de Fevereiro on Março de $3 \mathrm{r}$, chegaram os nututas a set testino, venccram en terra sti.; purtuguezes que lies re sistirara ajudados pelos indios, fundinam una for taleza, que thes custou quatro mil ducadas, $c$ entabolaram proveitoso commercio com o gentio. A wau, bem carregada de mercadorias, estimadas pelo dono em sesserita o doit mil e trezentos ducadns, - cinco mil quintass de pau brasil, trezentos quintaes de alsodäo, trinta de pitmenta, scigcentos papitzixios jí falando um pouco de francez, tres mil pelles de 
leopardos e outros anjmaes, trezentos roacricos, oleos mudicisacs e atu minerio de ouro (et de mina auri qux purificaca ut decebat ter mille ducatos reddidisset) - fez-se de vola, e a viagcm corret placiJamente até Malara, onde arribou por falta de martiritentos. Estava ali urra armada portuguexa que recebeu muito ben os Francezos, deu-lhes os alirnentos de que procitsirvirrl, saluiu em sua comparhia do porto, sempre com as maiores demonstraçỏes cle carinho e amizacle. Tuto aleivel A is de Asosto, ns Portuguezes assaltaram La Péferine, tomaram-llec a carga, aprisionatandhe a gente, mandaram a todos para Portugal, onde ficarim jresos. Ėl-rej, ao sabcr da noticiă, armon tres laus para irem tomar em I'ernambuco a fortalcar afi drixada, o que Proro Lopes conscguiu, (cirrin menssen decembris dicti anni millessimi quingentesstmi prinij), chepois de bombardeada dezoico diats.

O outro documento, incorporado na listoria de frei Vicente do Snlvador, concluida em Ibž, \& evidentemente contemporareo, ou yuasi contemporanco, tantas as particularidades nolle contidas.

Tamben segundo frei Vicente, Pero Lopes de Soura partiu directmente da Europa, e comchunto - chronista nao declare o aumero de navios, vese que deviam ser tres.

A chegada, da ilha de Itaniracá partia umat raut franceza carregada para a França, contra a qual mandou uma caravella muito veleira (a caravella exa um pensamento, asscgura frei Vicente). Como a nau franceza estava sobrecarregarla, "posto clue alojou muita parte dä carça de pau brasil, err firm foi alcançada e querendo sc por con defesa, the

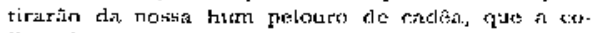
thro de proa a popa e a descrarceou de huma bankla e the inatou alguns hornerts, com o que se renclerâ us rлajis, que cră grinta e cirço ontre frandes e jequenos, e a hau com oito pecas de artillaria.... Outrus duas caravellas, commandadas por Alvaro Nures de Andrada e Sebostiăo Concalves de Arvellos, comerúm usnat duau que vithla dle Frauç̧ com municótes is tengates its Francerzes.

Rendia a fortaleza, brande parte da guamicào loi mortax por motivos en clue o barāo de Suint Blancard e a fonte de frei vicente variam.

Eni ver de combinur os iocuntentos visess por Varnhagen e ainda desconhecidos, o protesto de Bertrancl d"Onnegan $E$ o informante de f:ei Vicente, deixemo-los com todas as discordancias aos inves. tigatoriss futuros.

Em summa, interessa-ros sómente saber que a feitoria 4 pritcipio fundada por Christovam Jakques aincla destil vey restrogiu das cinzas.

Is sbaticios pela distancia e deformados pela re. tentiva, tecentrias mais torde 05 successos nartados e os que vāo sobrevir assim se espelhavam na alma de um indio pernamburano:

«Vi o estabelecimento dos Terós em Perram. buco e Potyú. ... No principio os Perbs nảo faziam sinzo resgatar, sem querer se habituar de ou. tro modo. E neste tempo dormiam livremente com 
as fillzas de nossas semelhazres de Pernambuco e Potyú, que o tinham por grande honra.

i: Depois disseram que cumpria que se habi. u uassem com clies, e precisaram fazé fortaleza para guarda-los e coristruir cidades para morarem todos jontos, fazendo pareccr que năo desejavam ser si nāo uma nacio. Depois fizeram-lhes entendex due no podiam tomar suas fijhas des:a sortc, que Detrs Thes prohibia servir-se dellas a rắo ser por casa ukento, e que năo deviam com cùias usat si nāo fossem baptisaclas e para faxe-lo era neccsintio ter Pays (Padres)

* Fizeran, pois, vir Pays, d5 qua 5 plantaram crazes, começaram a instrui-los e depois a baplisa. los. Persuadiram-lhes mais ylue năo pocijam passar "em escravos nem us Pays tăo poucus para o scrvico caseiro e trabalharem para elles, o que se foi obrigado a dar-lhes. E nāo cortcntes de cscravo somados na guerra, quizeram ainda ter seus filbos e atinal catjveram a nacia com tananha tyania crueldade continuamente exercicias sobre nossos se. melhantes, gue a maior parte dos syue restavam foram como nós obrixyedos a largar a serra,
Assim desafogavi junto aos Francezes do Ma-

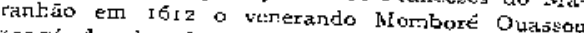
"aagé de pluz de neuf vingos ans (G)"

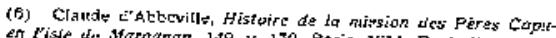
de Haraznar, 149, va 150. Paris, 16ilt. Deste livro raco

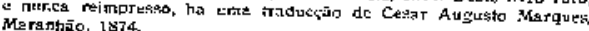
Por e, 1874.

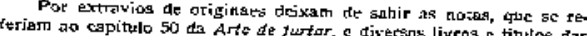

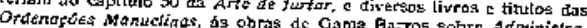
gho pubrica em Portugat, it dc S. S. Costa Labro subre a Aistorita Sotiedade ent Portugal no seetsto XV. Procesto criminat or. porta to

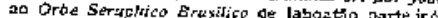
dics. J 34 T 780 , Rio, 1802 , ete 


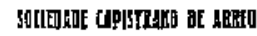

Rus Capletrans blo Abrou. 48

RIO DE JANEIRO

Fuadade ent 21 as setembion de 183

\section{ESTATUTOS DA SDIEOADE EAPISTRALO DE MBPEU}

DE RË́RE - Sob a denominacá de SOCIEDADE CAPISTRANO

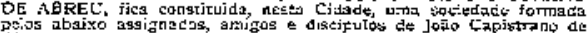

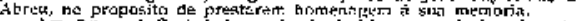

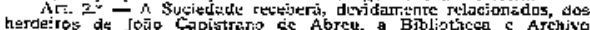

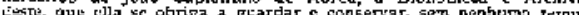

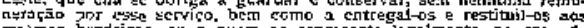
mesmos herderes, ou a quem os represente jegalmente. no casp of Art 3. - A Sociedade promovert.

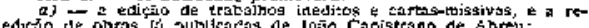

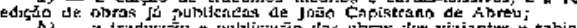
estrongeiross que percinteram o Brs:il.

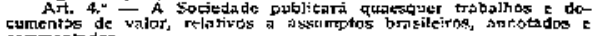
A Socicdade criari premiog par as investitactes. Art 5." - A Socicdade criari premios po contribiricues e abrak ogrtideradab de merito, rekcrentes a Historia, incentive os resfectivas estudas

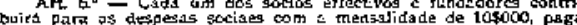
adiantadar.

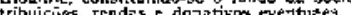

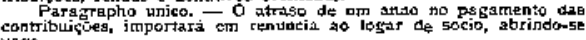
iaga 
Ast. $7 \hat{\sigma}^{\circ}-\mathrm{O}$ O remero de

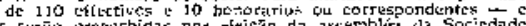

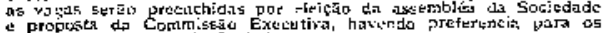
sresniados pula propria sociedide.

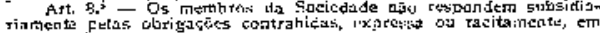

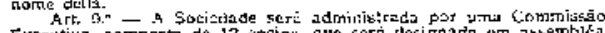
Executiva, composta de 12 socios. che seri desifnada am assembilea

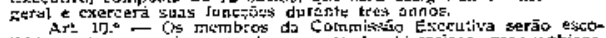

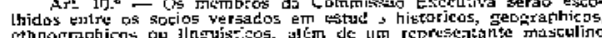
da familia dc Cepistrano de Abreu, que tavera scr um dos mert-

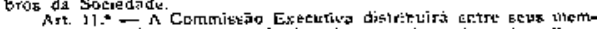

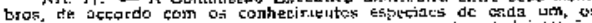
respcctives trabalhos, cumo tarr:Jern as encarpus de admitistrticio

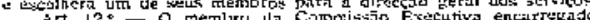

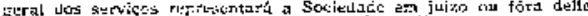

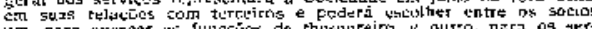
um. pzта sixiscer

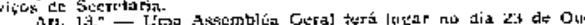
tubro de eada slito, annjeersario do rascimento de Capisirano de A desta, com excepero da bibliotheca $r$ arebivo an qute se relere o $7 \mathrm{~T}$ A

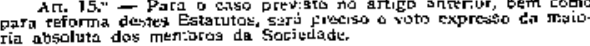

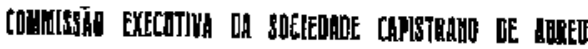

$1927-1930$

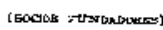

91, Avenian Fystenopolst (8. Patia)

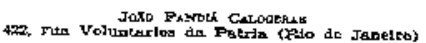

42. rus Cugtosto Serrǟo (Fila de Jasedro)

428. proln de Brotnrogo CPlo de Janeiro)

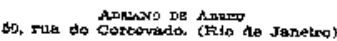

IIV, eatrada da Savidade. (Pint Aut

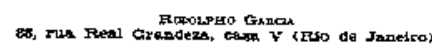

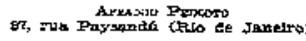

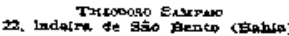

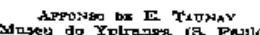

Mrubath Thretangl (Fila de Yaneiro)

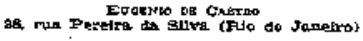

Henelime Doymato

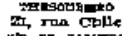




\section{SOCIEDABE CAPISTRANO DE ABREU}

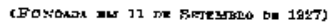

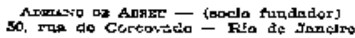
Arrosso de E. Taviax - (noclo Funcador)

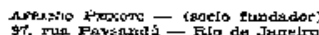

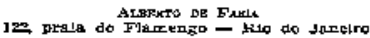

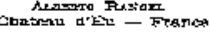

249, rua A. Marlsons - Fila de Jageiro

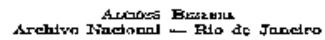

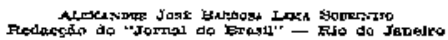

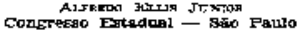
SA TUB S. Bento - S, Fawo

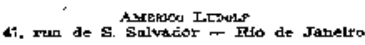

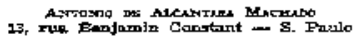




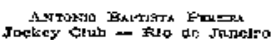

90, rua Feralra da slivs - Kuio de Janclro

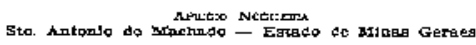

srolo - Raprubllon del Yruguay

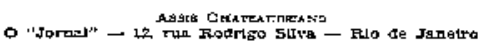

45a, ris Marques de $\mathrm{S}$. Vicente - Rio de Jacelra

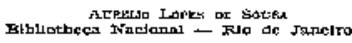

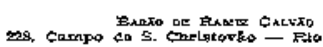

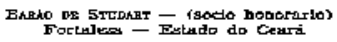

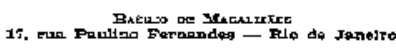

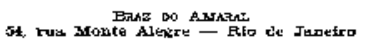

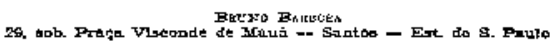

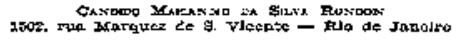

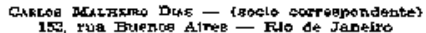

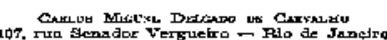

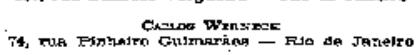

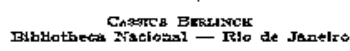

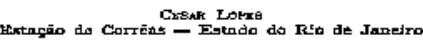

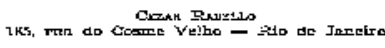

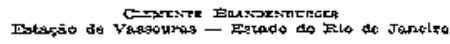

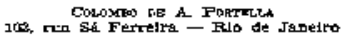

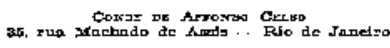

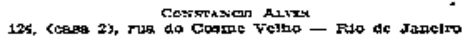

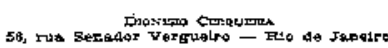

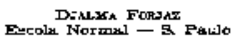

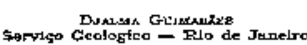

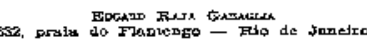

E. Fosterta Forro - caocio turdadars

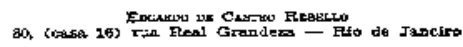

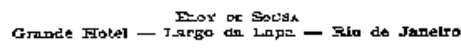

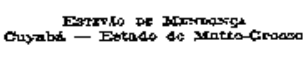

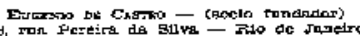

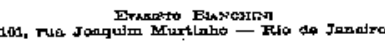

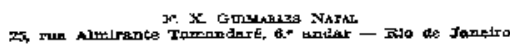

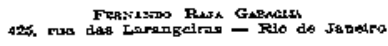

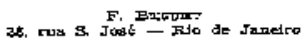




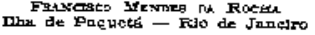

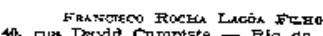

Fruvesea si

Tamandere - Rid to Jabetro

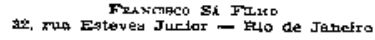

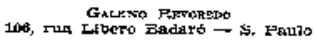

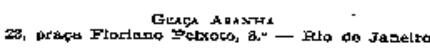

63, yua Si Grstato Eamposo

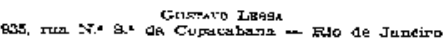

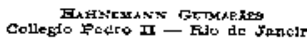

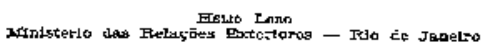

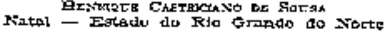

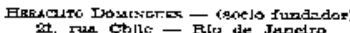

Toszosgo A.sensi

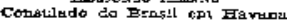

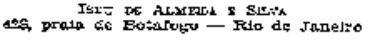

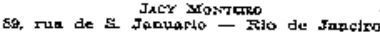

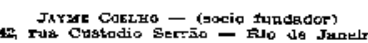

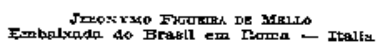

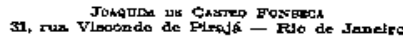

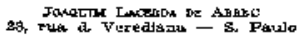

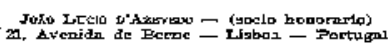

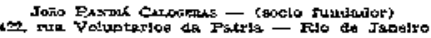

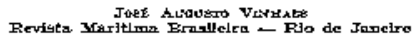

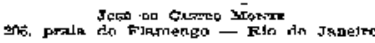

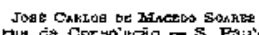

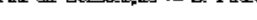

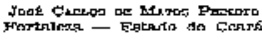

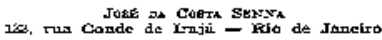

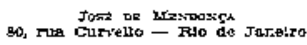

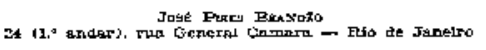

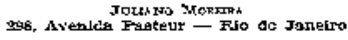

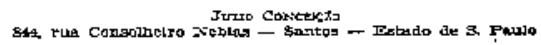

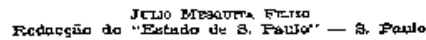

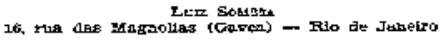

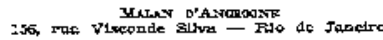

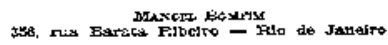

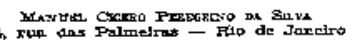
54, xun ar Falmelrat - Fíp de Jaxdro

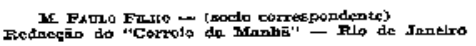


PREMIO "CAPSSTRANO DE ABREL" DE 1028

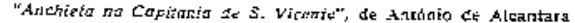
Mituchato

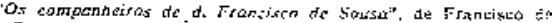
Assis Cearvalho Franct.

\section{HOMENAGES}

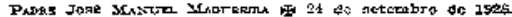

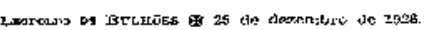

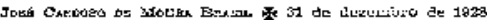

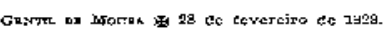

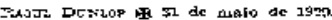

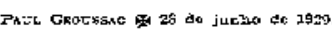


EDICAO DA

SOCIEDADE CAPISTRANO DE ABREU MANDADA IMPRIMIR POR

F. BRIGUIET \& Cia.

NA TYP. DO ANNUARIO DO BRASLL EM OUTURRO DE MIIS?

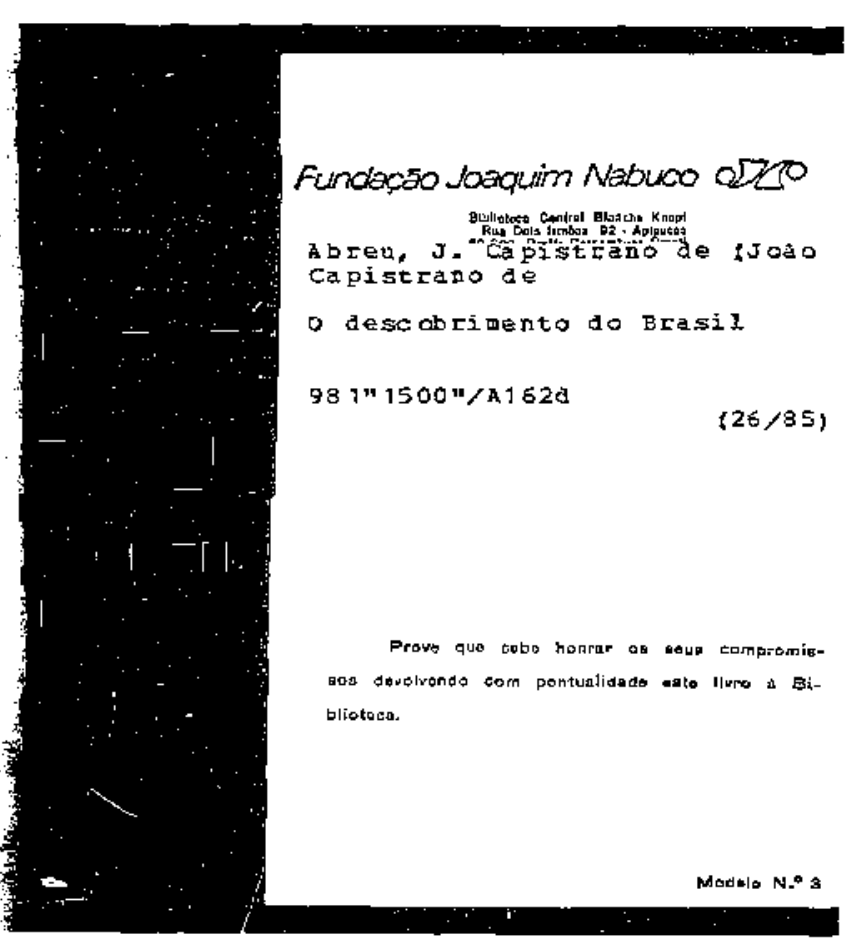

